\title{
Sajjad Hussain
}

\section{Comparação entre diferentes processos de degradação do antibiótico sulfametoxazol}

Tese apresentada ao Instituto de Química de São Carlos da Universidade de São Paulo como parte dos requisitos para a obtenção do título de Doutor em Ciências.

Área de concentração: Físico-Química

Orientador: Prof. Dr. Artur de Jesus Motheo

\section{Exemplar revisado}

O exemplar original encontre-se em acervo reservado na Bilblioteca do IQSC-USP

São Carlos, SP 
Autorizo a reprodução e divulgação total ou parcial deste trabalho, por qualquer meio convencional ou eletrônico para fins de estudo e pesquisa, desde que citada a fonte.

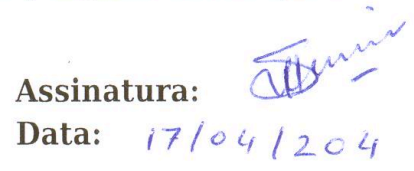

Ficha Catalográfica elaborada pela Seção de Referência e Atendimento ao Usuário do SBI/IQSC

Hussain, Sajjad

Comparação entre diferentes processos de degradação do antibiótico sulfametoxazol / Sajjad Hussain. - São Carlos, 2014.

$159 \mathrm{f}$.

Tese (Doutorado em Físico-Química) - Instituto de Química de São Carlos / Universidade de São Carlos, 2014.

Edição revisada

Orientador: Prof. Dr. Artur De Jesus Motheo

1. Sulfametoxazol. 2. Degradação eletroquímico. 3. Contaminante emergente. I. Título. 
Dedico este trabalho com todo meu respeito, admiração e imenso carinho à minha família, especialmente minha esposa Saima pelas palavras de incentivo e apoio durante o trabalho experimental e na redação desta tese e minha filha Mahrosh pelos momentos de alegria! 


\section{AGRADECIMENTOS}

Em primeiro lugar, agradeço à Allah por me abençoar incontavelmente;

Ao meu orientador Prof. Dr. Artur de Jesus Motheo pela oportunidade, orientação, paciência, confiança que me proporcionou durante esses anos de convivência e por viabilizar a realização deste trabalho;

Agradeço a todos os meus amigos de grupo: Douglas, Luciano, Juliana, José Mario, Eli, Miriam, Leandro, Josias, Hebert, Castelo Branco e Carlos, pelas sugestões, atenção, amizade e pela agradável convivência durante esses anos;

Aos amigos paquistaneses com que compartilhei minha vida durante todos esses anos, pelo companheirismo, amizade e festas;

Aos professores Maria Olímpia de Oliveira Rezende, Marcos Roberto de Vasconcelos Lanza e Eny Maria Vieira, agradeço pela colaboração e uso ocasional de seus laboratórios. Também agradeço ao Dr. Guilherme Miola Titato da cromatografia IQSC pela colaboração com as análises de LC/MS e ao meu amigo Gabriel pela ajuda na redação de minha tese.

À todos os professores, funcionários e colegas do IQSC/USP, especialmente do departamento de Físico-Química, do Programa de Pós-Graduação, do setor de convênios, e da Biblioteca que de alguma forma colaboraram para elaboração deste trabalho.

À Sra. Eledy Grisel Helena Ferrari do IQSC/USP pela solicitude e apoio quando de minha chegada ao Brasil;

A The World Academy of Sciences (TWAS) e Conselho Nacional de Desenvolvimento Científico e Tecnológico (CNPq) pela bolsa concedida.

À todos que não foram citados, mas fizeram parte desta história e deste trabalho, muito obrigado! 


\section{Sumário}

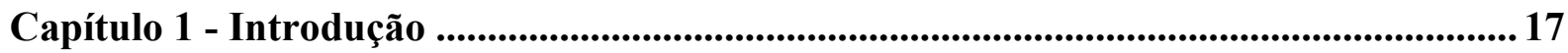

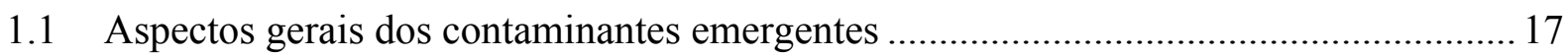

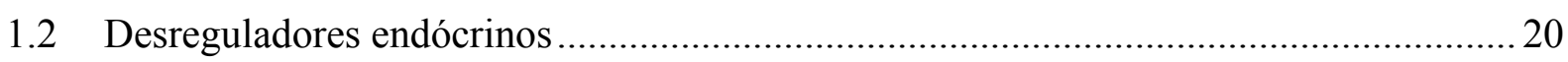

1.3 Produtos farmacêuticos e de cuidados pessoais....................................................... 21

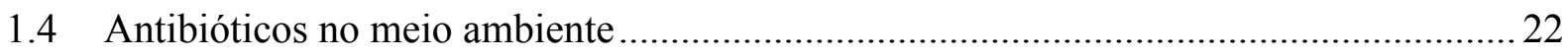

1.4.1 Presença de Sulfametoxazol no meio ambiente e seu efeito toxicológico ...............23

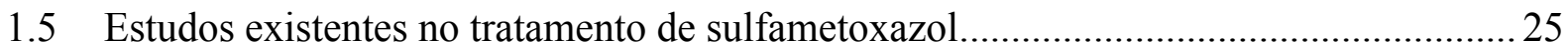

1.6 Métodos para os tratamentos de águas residuais ...................................................... 28

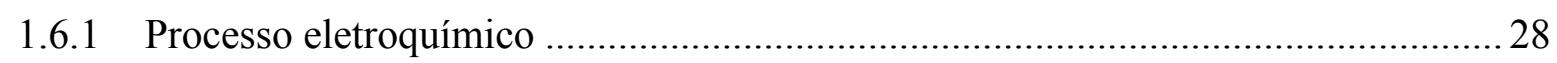

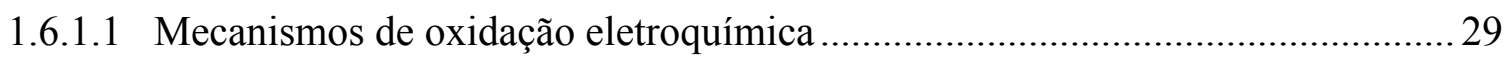

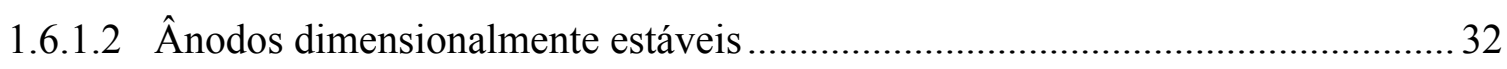

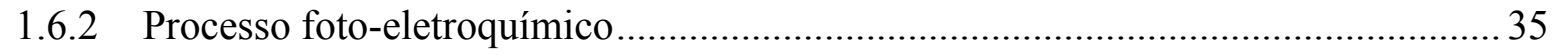

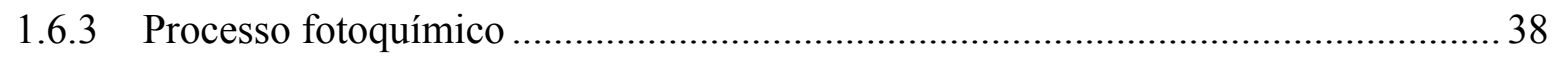

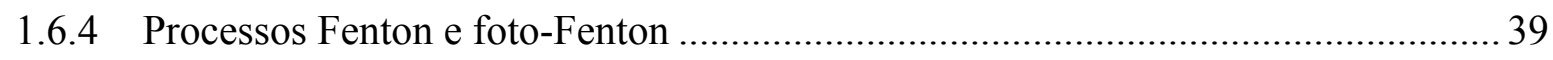

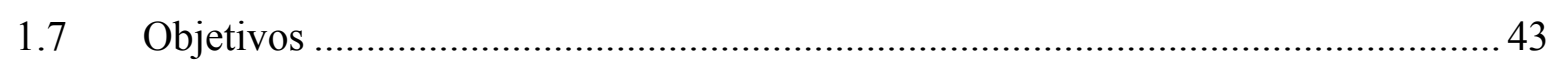

Capítulo 2 - Experimental ........................................................................................... 44

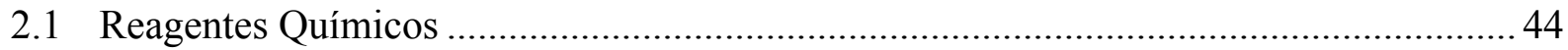

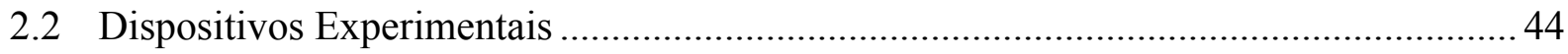

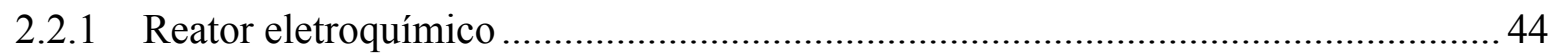

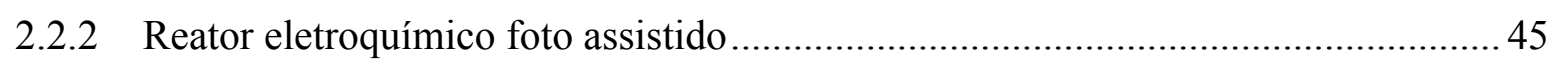

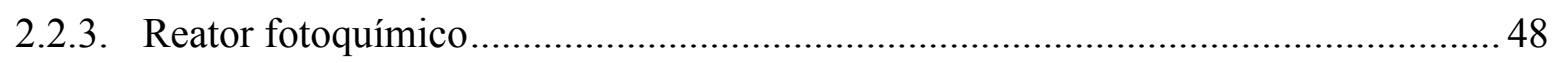

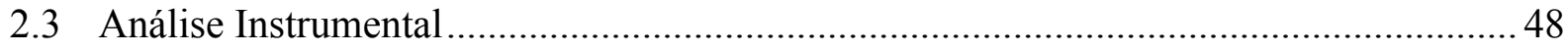

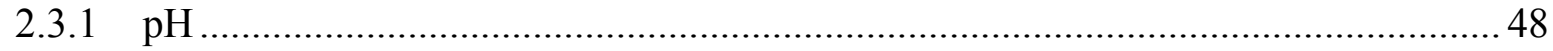

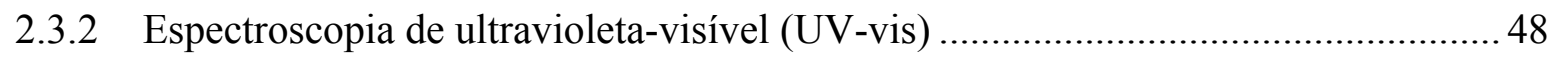

2.3.3 Carbono Orgânico Total (COT) ........................................................................... 49

2.3.4 Cromatografia líquida de alta eficiência (CLAE) ............................................. 49

2.3.5 Cromatografia líquida de alta eficiência e espectrometria de massa (CLAE/EM) .. 50

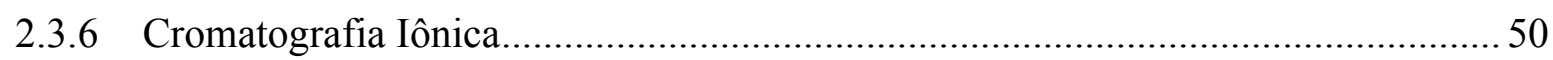

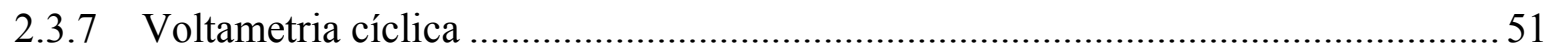

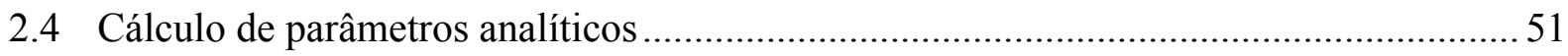

2.4.1 Determinação de consumo energético.............................................................. 51

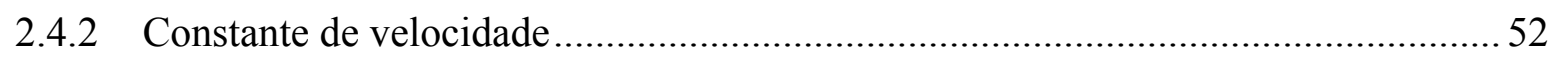


Capítulo 3 - Degradação eletroquímica do sulfametoxazol ............................................53

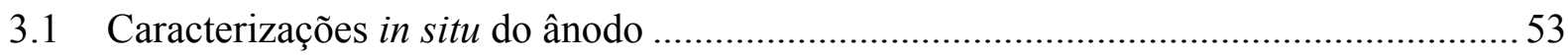

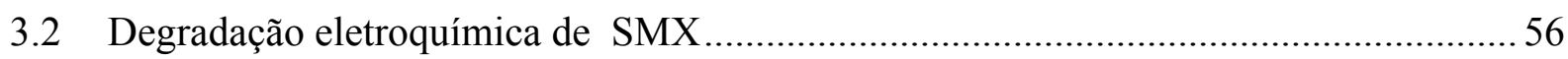

3.2.1 Efeito da natureza do eletrólito na degradação do SMX .......................................56

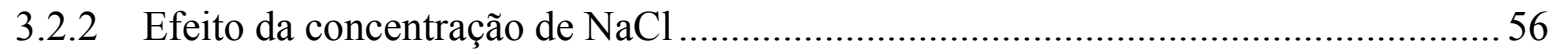

3.2.3 Efeito da densidade de corrente aplicada ............................................................59

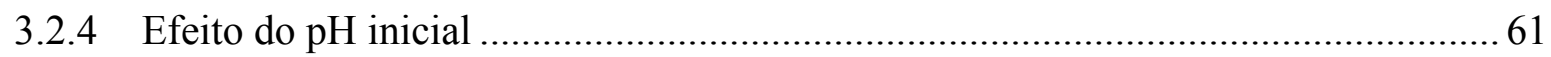

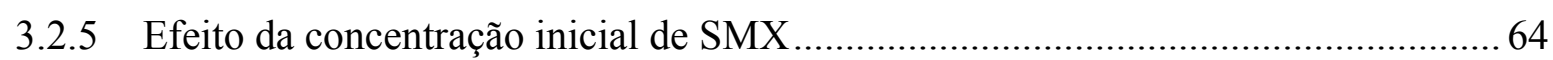

3.2.6 Efeito da temperatura na degradação eletroquímica ............................................ 65

3.2.7 Monitoramento da degradação eletroquímica de SMX por UV-Vis e CLAE ......... 66

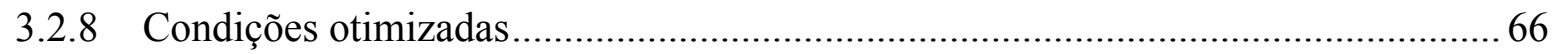

3.3 Identificação dos intermediários formados durante a degradação eletroquímica de SMX

68

3.3.2 Detecção dos intermediários inorgânicos de SMX .............................................. 80

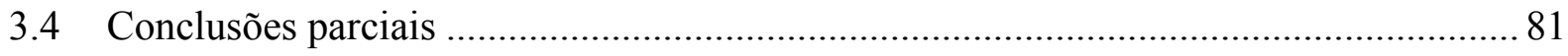

Capítulo 4 - Degradação eletroquímica foto assistida de SMX........................................83

4.1 Caracterizações in situ do ADE na presença e na ausência de radiação UV ................... 83

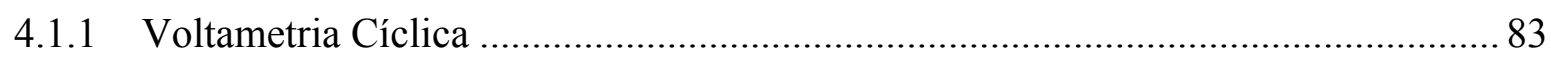

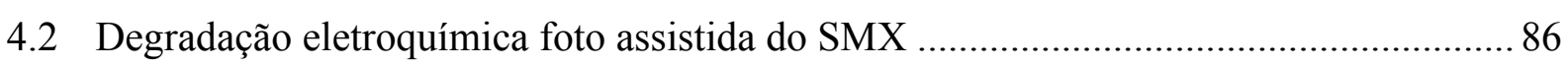

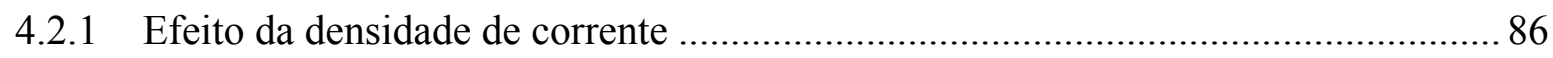

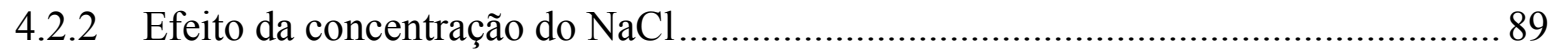

4.2.3 Efeito da concentração inicial do SMX.................................................................... 90

4.2.4 Consumo energético de degradação eletroquímica foto assistido............................ 92

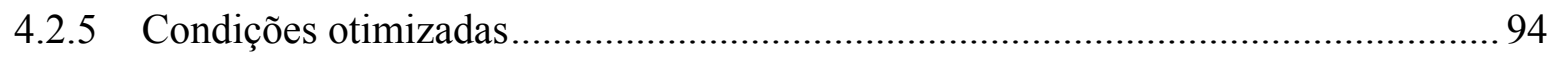

4.3 Detecção dos intermediários e proposição de rota de degradação ................................ 95

4.3.1 Intermediários inorgânicos do SMX no processo eletroquímico foto assistido .......... 99

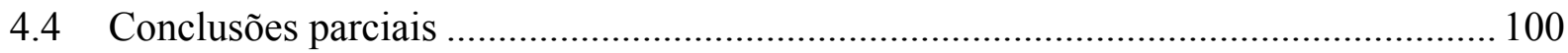

Capítulo 5 - Degradação de sulfametoxazol por processo fotoquímico.............................. 101

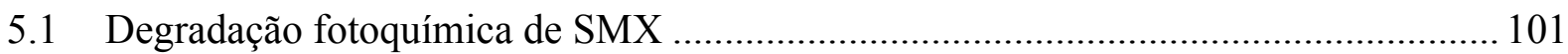

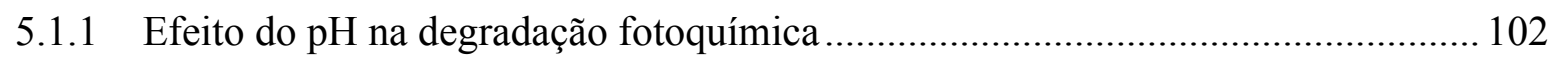

5.1.2 Efeito da concentração inicial SMX na degradação fotoquímica ........................... 104

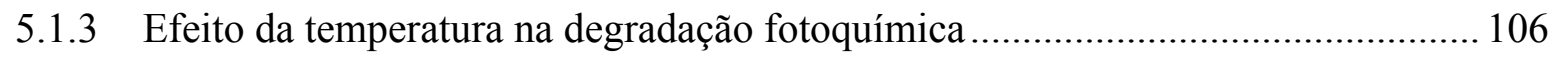

5.1.4 Consumo energético na degradação fotoquímica de SMX ..................................... 108

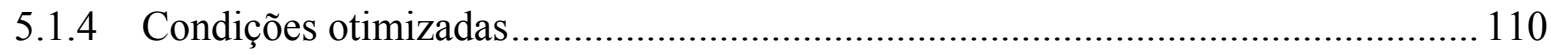


5.2 Detecção dos intermediários de degradação fotoquímica e proposição da possível rota de degradação para o SMX

5.2.1 Detecção dos intermediários inorgânicos de SMX durante o processo fotoquímico... .116

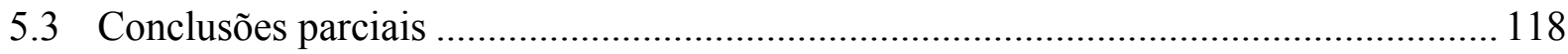

Capítulo 6 - Degradação do SMX por processo Fenton ..................................................... 119

6.1 Avaliação da degradação de SMX.........................................................................119

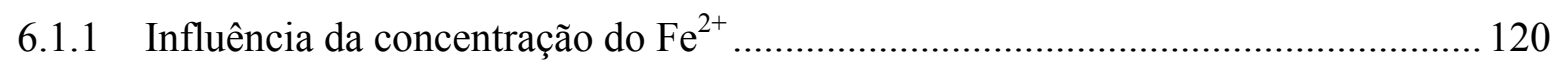

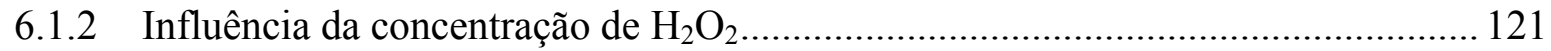

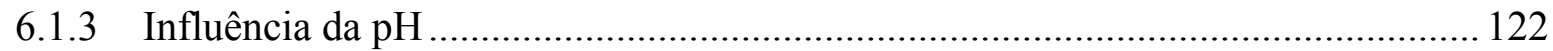

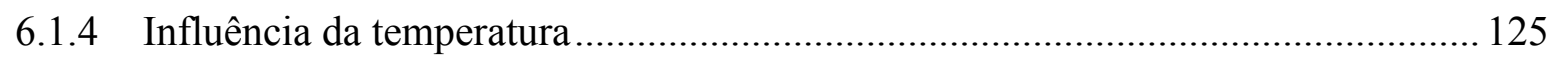

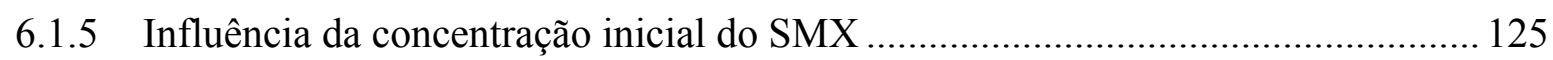

6.2 Identificação dos intermediários e possível rota de degradação................................... 126

6.2.1 Identificação dos intermediários inorgânicos do SMX ......................................... 129

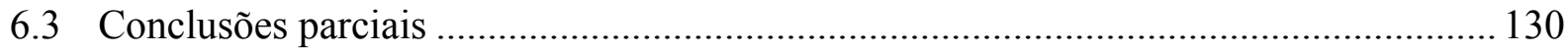

Capítulo 7 - Degradação de sulfametoxazol por processo foto-Fenton ............................. 132

7.1 Estudo de parâmetros importantes para o processo foto-Fenton ................................... 132

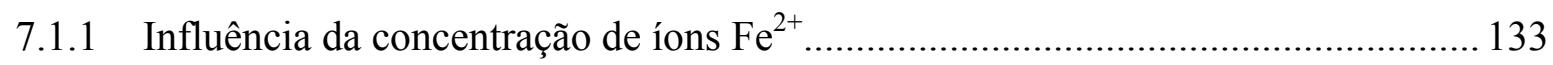

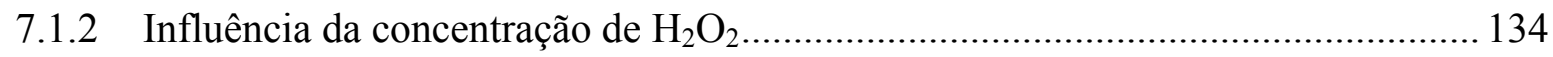

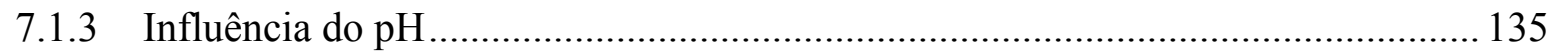

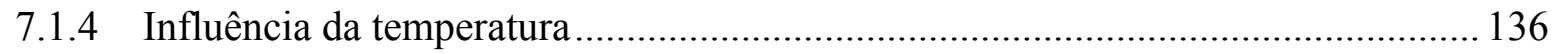

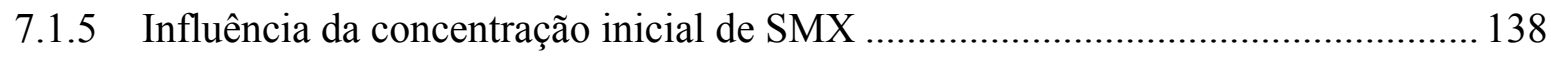

7.2 Identificação dos intermediários na degradação de SMX pelo processo de foto-Fenton...

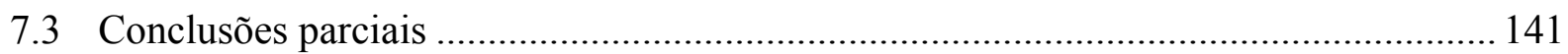

Capítulo 8 - Comparação de eficiência e conclusões..................................................... 142

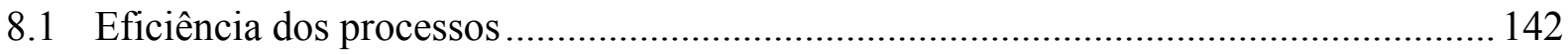

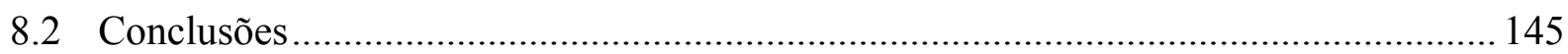

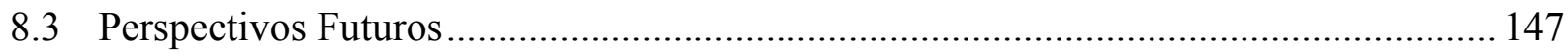

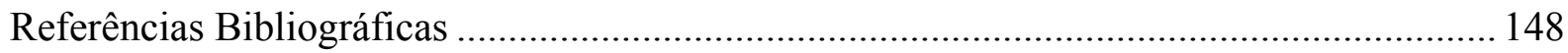




\section{Resumo}

A ocorrência de produtos farmacêuticos e de cuidados pessoais no meio ambiente tem levado a preocupações sobre seu impacto ambiental e à saúde pública. O sulfametoxazol (SMX) é um fármaco que tem sido encontrado amplamente no ambiente. Neste estudo foi verificada a eficácia de vários processos, a saber eletroquímico, eletroquímico foto assistido, fotoquímico, Fenton e foto-Fenton, para a degradação de SMX em solução aquosa. A degradação eletroquímica e eletroquímica foto assistida foram realizadas em uma célula de fluxo do tipo filtro-prensa, usando um ânodo dimensionalmente estável comercial com composição nominal Ti/ $\mathrm{Ru}_{0,3} \mathrm{Ti}_{0,7} \mathrm{O}_{2}$. Durante ambos os processos, efeitos de diferentes parâmetros foram analisados, como a natureza do eletrólito, a concentração de eletrólito suporte $(\mathrm{NaCl})$ e a densidade de corrente aplicada. Os experimentos fotoquímicos, Fenton e foto-Fenton foram realizados em um reator de vidro cilíndrico de compartimento único. $\mathrm{O}$ efeito das concentrações inicias de $\mathrm{Fe}^{2+}$ e de $\mathrm{H}_{2} \mathrm{O}_{2}$ foram estudados para os processos Fenton e fotoFenton. Similarmente, o efeito do pH inicial, a concentração inicial do SMX e a temperatura foram investigados para todos os processos. A variação da concentração de SMX foi determinada por cromatografia líquida de alta eficiência (CLAE) e a quantidade de matéria orgânica foi monitorada por análise de carbono orgânico total (COT). Os resultados obtidos indicaram que o SMX foi completamente degradado, porém, o COT foi apenas parcialmente removido em todos os processos. No período de tempo de ensaio estabelecido o aumento da densidade de corrente e da concentração de $\mathrm{NaCl}$ mais eficiente para a degradação e remoção de COT nos processos eletroquímicos. A quantidade de $\mathrm{Fe}^{2+}$ e $\mathrm{H}_{2} \mathrm{O}_{2}$ aumenta a eficiência do processo Fenton e foto-Fenton, e meio ácido foi favorável para todos os processos. $\mathrm{O}$ consumo de energia elétrica, baseado no parâmetro $\mathrm{E}_{\mathrm{EO}}$ (energia por ordem) mostrou que os processos eletroquímicos são energeticamente mais eficientes do que os fotoquímicos. As degradações acompanhadas por CLAE acoplado à espectrometria de massas, permitiu que vários intermediários fossem identificados, sendo então proposta uma sequência reacional para a degradação do SMX. O radical hidroxila e o cloro ativo atacam os anéis benzílico e isoxazólico, tendo sido demonstrado que os compostos iniciais formados foram os compostos hidrolisados e clorados. Os íons inorgânicos, tais como: $\mathrm{NO}_{3}{ }^{-}, \mathrm{NH}_{4}{ }^{+}$e $\mathrm{SO}_{4}{ }^{2-}$, também foram identificados durante os processos de degradação.

Palavras-chave: sulfametoxazol, degradação eletroquímico, contaminante emergente 


\begin{abstract}
The occurrence of pharmaceuticals and personal care products in the environment has raised concerns about their impact upon environmental and public health. Sulfamethoxazole (SMX) is a pharmaceutical that has been found widely in the environment. This study investigated the effectiveness of various processes such as electrochemical, photo assisted electrochemical, photochemical, Fenton photo-Fenton to SMX degradation in aqueous solution. The electrochemical and photo-assisted electrochemical degradations were performed in a filter press type flow cell using a dimensionally stable anode with nominal composition of $\mathrm{Ti} / \mathrm{Ru}_{0.3} \mathrm{Ti}_{0.7} \mathrm{O}_{2}$. During both these processes the effects of different parameters were analyzed, such as, nature of the electrolyte concentration of the supporting electrolyte $(\mathrm{NaCl})$ and the applied current density. The photochemical, Fenton and photo - Fenton experiments were carried out in a single compartment cylindrical glass reactor. The effects initial iron concentrations and $\mathrm{H}_{2} \mathrm{O}_{2}$ were studied for Fenton and photo-Fenton processes. Similarly the effect of initial $\mathrm{pH}$, initial concentration of SMX and temperature were investigated for all processes. The variation of SMX concentration was determined by high performance liquid chromatography (HPLC) and the amount of organic matter was monitored by analysis of total organic carbon (TOC). The results indicated that SMX was completely degraded, but TOC was partially removed in all processes studied, during experimental period the increase of the current density and $\mathrm{NaCl}$ concentration enhanced the degradation and TOC removal in the electrochemical processes. The amount of iron and $\mathrm{H}_{2} \mathrm{O}_{2}$ increases the efficiency of Fenton and photo-Fenton processes and acidic media was favorable for all processes. The electrical energy consumption parameter based on $\mathrm{E}_{\mathrm{EO}}$ (energy per order) was also evaluated and it was observed that the electrochemical processes are more energetically efficient than the photochemical. The degradations followed by HPLC coupled with mass spectrometry, in which several intermediates were identified and proposed a reaction sequence for the degradation of SMX. The hydroxyl radical and active chlorine attack benzene and isoxazólico rings, and has been demonstrated that the initial compounds formed were hydrolyzed and chlorinated compounds. Inorganic ions such $\mathrm{NO}_{3}{ }^{-}, \mathrm{NH}_{4}{ }^{+}$and $\mathrm{SO}_{4}{ }^{2-}$ were also identified during degradation processes.
\end{abstract}

Keywords: sulfamethoxazole, electrochemical degradation, emerging contaminants 


\section{Lista de Figuras}

Figura 1.1 - Dispersão de poluentes no ambiente aquático.

Figura 1.2 - Rotas de entrada e de dispersão de fármacos no meio ambiente

Figura 1.3 - Estrutura química de sulfametoxazol.

Figura 1.4 - Esquema dos processos eletroquímicos que permitem a remoção de compostos orgânicos.

Figura 1.5 - Esquema do mecanismo de oxidação de orgânico na ADE no meio cloreto....34

Figura 2.1. Conjunto de reator e componentes. 46

Figura 2.2. Registro fotográfico do sistema eletroquímico em operação com indicação do reator eletroquímico. 46

Figura 2.3. Esquema do reator eletroquímico foto assistido. .47

Figura 2.4. Registro fotográfico do sistema eletroquímica foto assistida. 47

Figura 2.5 - Diagrama esquemático do reator fotoquímico (fotólise, foto-Fenton e Fenton)...

Figura 3.1 - Curvas voltamétricas $\left(10^{\circ}\right.$ Ciclo $)$ do eletrodo de $\mathrm{ADE}$ a $0,1 \mathrm{~mol} \mathrm{~L}^{-1}$ de $\mathrm{NaCl}$, $(-)$ na presença e (-) na ausência de SMX. $v=50 \mathrm{mV} \mathrm{s}^{-1}, \mu=0,1 \mathrm{~mol} \mathrm{~L}^{-1}$......

Figura 3.2 - Curvas voltamétricas $\left(10^{\circ}\right.$ Ciclo $)$ do eletrodo de ADE a $0,033 \mathrm{~mol} \mathrm{~L}^{-1}$ de $\mathrm{Na}_{2} \mathrm{SO}_{4},(-)$ na presença e (-) na ausência de SMX. $v=50 \mathrm{mV} \mathrm{s}^{-1}, \mu=0,1 \mathrm{~mol} \mathrm{~L}^{-1}$ .55

Figura 3.3 - Curvas voltamétricas $\left(10^{\circ}\right.$ Ciclo) do eletrodo de $\mathrm{ADE}$ a $0,033 \mathrm{~mol} \mathrm{~L}^{-1}$ de $\mathrm{H}_{2} \mathrm{SO}_{4}$, $(-)$ na presença e $(-)$ na ausência de SMX, $v=50 \mathrm{mV} \mathrm{s}^{-1}, \mu=0,1 \mathrm{~mol} \mathrm{~L}^{-1}$

Figura 3.4 - Efeito da natureza do eletrólito suporte: $0,033 \mathrm{~mol} \mathrm{~L}^{-1} \mathrm{H}_{2} \mathrm{SO}_{4}(\mathbf{O}), 0,033 \mathrm{~mol} \mathrm{~L}^{-1}$ $\mathrm{Na}_{2} \mathrm{SO}_{4}(\boldsymbol{\Delta}), 0,1$ mol L${ }^{-1} \mathrm{NaCl}(\boldsymbol{\square})$ na (a) degradação e (b) remoção de COT (condições: $\mathrm{pH}_{\mathrm{i}}$ $=3, \mathrm{~T}=25^{\circ} \mathrm{C}, \mathrm{C}_{\mathrm{smx}}=200 \mathrm{mg} \mathrm{L}^{-1}$, e $i=40 \mathrm{~mA} \mathrm{~cm}^{-2}$ ).

Figura 3.5 - Efeito da concentração de $\mathrm{NaCl}$ : (⿴) $0,02 \mathrm{~mol} \mathrm{~L}^{-1},(\mathbf{O}) 0,04 \mathrm{~mol} \mathrm{~L}^{-1},(\mathbf{A})$ 0,08 mol L ${ }^{-1},(\nabla)$ 0,1 mol L ${ }^{-1}$ (a) na degradação e (b) remoção do COT (Condições: $\mathrm{pH}_{\mathrm{i}}=3, \mathrm{~T}=$ $\left.25^{\circ} \mathrm{C}, \mathrm{C}_{\mathrm{smx}}=200 \mathrm{mg} \mathrm{L}^{-1} \mathrm{e} i=40 \mathrm{~mA} \mathrm{~cm}^{-2}\right)$.

Figura 3.6 - Variação do $\ln \left(\mathrm{C}_{\mathrm{o}} / \mathrm{C}\right)$ em função do tempo de eletrólise em diferentes concentrações de NaCl: (⿴) $0,02 \mathrm{~mol} \mathrm{~L}^{-1},(\boldsymbol{O}) 0,04 \mathrm{~mol} \mathrm{~L}^{-1},(\boldsymbol{\Delta}) 0,08 \mathrm{~mol} \mathrm{~L}^{-1},(\boldsymbol{\nabla}) 0,1 \mathrm{~mol}$ $\mathrm{L}^{-1}$ (Condições: $\mathrm{pH}_{\mathrm{i}}=3, \mathrm{~T}=25^{\circ} \mathrm{C}, \mathrm{C}_{\mathrm{smx}}=200 \mathrm{mg} \mathrm{L}^{-1} \mathrm{e} i=40 \mathrm{~mA} \mathrm{~cm}^{-2}$ ).

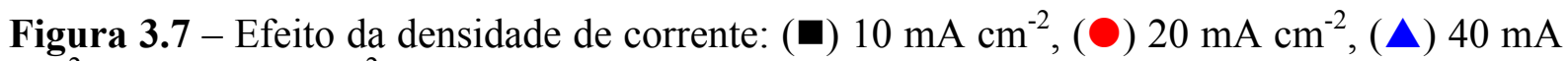
$\mathrm{cm}^{-2},(\nabla) 60 \mathrm{~mA} \mathrm{~cm}^{-2}$ na (a) degradação e (b) remoção do COT (Condições: $\mathrm{pH}_{\mathrm{i}}=3, \mathrm{~T}=25$ ${ }^{\circ} \mathrm{C}, \mathrm{C}_{\mathrm{smx}}=200 \mathrm{mg} \mathrm{L}^{-1}$ e $\left.\mathrm{C}_{\mathrm{NaCl}}=0,1 \mathrm{~mol} \mathrm{~L}^{-1}\right)$. 
Figura 3.8 - Variação de $\ln \left(\mathrm{C}_{\mathrm{o}} / \mathrm{C}\right)$ em função do tempo de eletrólise para valores diferentes

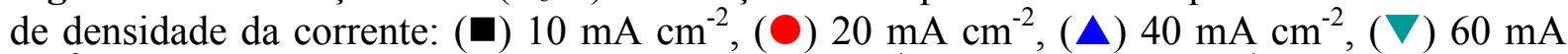
$\mathrm{cm}^{-2}$, (Condições: $\left.\mathrm{pH}_{\mathrm{i}}=3, \mathrm{~T} 25^{\circ} \mathrm{C}, \mathrm{C}_{\mathrm{smx}}=200 \mathrm{mg} \mathrm{L}^{-1} \mathrm{e} \mathrm{C}_{\mathrm{NaCl}}=0,1 \mathrm{~mol} \mathrm{~L}^{-1}\right)$.

Figura 3.9 -Efeito do pH: (ם) 2,5 (O) 5, ( $\boldsymbol{\nabla}) 7,(\boldsymbol{\Delta}) 9$ na (a) degradação e (b) remoção do COT (Condições: $\mathrm{T}=25^{\circ} \mathrm{C}, \mathrm{C}_{\mathrm{smx}}=200 \mathrm{mg} \mathrm{L}^{-1}, \mathrm{C}_{\mathrm{NaCl}}=0,1 \mathrm{~mol} \mathrm{~L}^{-1} \mathrm{e} i=40 \mathrm{~mA} \mathrm{~cm}^{-2}$ )....63

Figura 3.10 - Variação do $\ln \left(\mathrm{C}_{\mathrm{o}} / \mathrm{C}\right)$ em função do tempo de eletrólise para diferentes valores

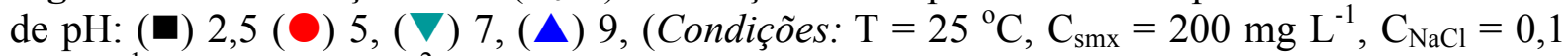
$\mathrm{mol} \mathrm{L}-1$ e $\left.i=40 \mathrm{~mA} \mathrm{~cm}^{-2}\right)$.

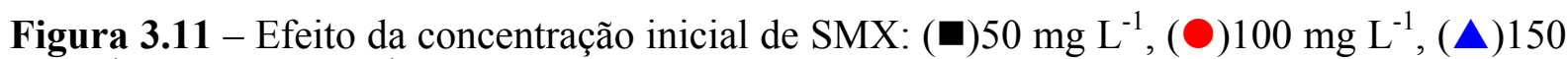
$\mathrm{mg} \mathrm{L}^{-1},(\nabla) 200 \mathrm{mg} \mathrm{L}^{-1}$ na (a) degradação e (b) remoção do COT (condições: $\mathrm{T}=25^{\circ} \mathrm{C}, \mathrm{pH}_{\mathrm{i}}$ $\left.=3, \mathrm{C}_{\mathrm{NaCl}}=0,1 \mathrm{~mol} \mathrm{~L}^{-1} \mathrm{e} i=40 \mathrm{~mA} \mathrm{~cm}^{-2}\right)$.

Figura 3.12 - Efeito da temperatura: $(\mathbf{\square}) 25^{\circ} \mathrm{C},(\mathbf{O}) 35{ }^{\circ} \mathrm{C},(\mathbf{\Delta}) 45^{\circ} \mathrm{C}$ na (a) degradação e (b) remoção do COT (Condições: $\mathrm{C}_{\mathrm{smx}}=200 \mathrm{mg} \mathrm{L}^{-1}, \mathrm{pH}_{\mathrm{i}}=3, \mathrm{C}_{\mathrm{NaCl}}=0,1 \mathrm{~mol} \mathrm{~L}^{-1}$ e $i=40 \mathrm{~mA}$ $\left.\mathrm{cm}^{-2}\right)$

Figura 3.13 - (a) Espectros de UV-Vis das soluções (SMX 4 diluições em volume) para a degradação (b) cromatograma de CLAE (Condições: $\mathrm{C}_{\mathrm{smx}}=200 \mathrm{mg} \mathrm{L}^{-1}, \mathrm{~T}=25{ }^{\circ} \mathrm{C}, \mathrm{pH}_{\mathrm{i}}=3$, $\mathrm{C}_{\mathrm{NaCl}}=0,1 \mathrm{~mol} \mathrm{~L}^{-1} \mathrm{e} i=40 \mathrm{~mA} \mathrm{~cm}{ }^{-2}$ ).

Figure 3.14 - Decréscimo relativo de COT $(-)$ e concentração de $\operatorname{SMX}(-)$ em função do tempo de eletrólise (Condições: $i=40 \mathrm{~mA} \mathrm{~cm}^{-2}, \mathrm{pH}_{\mathrm{i}}=3, \mathrm{C}_{\mathrm{NaCl}}=0,1 \mathrm{~mol} \mathrm{~L}^{-1}$ e $\mathrm{C}_{\mathrm{smx}}=200 \mathrm{mg}$ $\left.\mathrm{L}^{-1}\right)$. A força iônica foi mantida a $0,1 \mathrm{~mol} \mathrm{~L}^{-1}$ sob adição de $\mathrm{Na}_{2} \mathrm{SO}_{4}$

Figura 3.15 - (a) LC-UV cromatograma de padrão de SMX; (b) espectro de massa de SMX $\mathrm{m} / \mathrm{z}=254\left(\mathrm{C}_{10} \mathrm{H}_{11} \mathrm{~N}_{3} \mathrm{SO}_{3}\right)$.

Figura 3.16 - Cromatograma de LC-MS da amostra retirada após 15 min de eletrólise de SMX. (Condições: $i=40 \mathrm{~mA} \mathrm{~cm}{ }^{-2}, \mathrm{pH}_{\mathrm{i}} 3, \mathrm{C}_{\mathrm{NaCl}}=0,1 \mathrm{~mol} \mathrm{~L}^{-1}$ e $\mathrm{C}_{\mathrm{smx}}=200 \mathrm{mg} \mathrm{L}^{-1}$ ).............54

Figura 3.17 - Espectros de massas referentes aos intermediários, condizente à $\mathrm{m} / \mathrm{z}=179 \ldots . .72$

Figura 3.18 - Espectros de massas referentes aos intermediários, condizente à $\mathrm{m} / \mathrm{z}=141 \ldots . .72$

Figura 3.19 - Espectros de massas referentes aos intermediários, condizente à $\mathrm{m} / \mathrm{z}=274 \ldots . .72$

Figura 3.20 - Espectros de massas referentes aos intermediários, condizente à $\mathrm{m} / \mathrm{z}=303 \ldots .73$

Figura 3.21 - Espectros de massas referentes aos intermediários, condizente à $\mathrm{m} / \mathrm{z}=341 \ldots .73$

Figura 3.22 - Espectros de massas referentes aos intermediários, condizente à $\mathrm{m} / \mathrm{z}=189 \ldots .73$

Figura 3.23 - Espectros de massas referentes aos intermediários, condizente à $\mathrm{m} / \mathrm{z}=321 \ldots .74$

Figura 3.24 - Espectros de massas referentes aos intermediários, condizente à $\mathrm{m} / \mathrm{z}=110 \ldots .74$

Figura 3.25 - Espectros de massas referentes aos intermediários, condizente à $\mathrm{m} / \mathrm{z}=222 \ldots . .74$ 
Figura 3.26 - Rota de degradação e conversão de SMX por processo eletroquímico para os compostos de baixo peso molecular e referentes a $\mathrm{m} / \mathrm{z}=110,149$

Figura 3.27 - Sequencia reacional de degradação e conversão de SMX por processo eletroquímico.

Figura 3.28 - Variação de concentração de intermediários inorgânicos como $(\bigcirc) \mathrm{NO}_{3}{ }^{-} \mathrm{e}(\boldsymbol{\square})$ $\mathrm{SO}_{4}{ }^{2-}$ em função do tempo de eletrólise (Condições: $i=40 \mathrm{~mA} \mathrm{~cm}{ }^{-2}, \mathrm{pH}_{\mathrm{i}}=3, \mathrm{~T}=25^{\circ} \mathrm{C}, \mathrm{C}_{\mathrm{NaCl}}$ $=0,1 \mathrm{~mol} \mathrm{~L}^{-1} \mathrm{e} \mathrm{C}_{\mathrm{smx}} 200 \mathrm{mg} \mathrm{L}^{-1}$ )

Figura 4.1 - Curvas voltametricas $\left(5^{\circ}\right.$ ciclo) do eletrodo de ADE, utilizando-se solução de $\mathrm{Na}_{2} \mathrm{SO}_{4}$ com concentração igual a $0,033 \mathrm{~mol} \mathrm{~L}^{-1}$, na presença (-) e na ausência (-) de SMX: (a) sem aplicação de radiação UV e (b) com radiação UV, empregando-se uma lâmpada de mercúrio de $250 \mathrm{~W}$. Condições: $v=50 \mathrm{mV} \mathrm{s}^{-1}$ a $25^{\circ} \mathrm{C}$

Figura 4.2 - Curvas voltamétricas $\left(5^{\circ}\right.$ ciclo) do eletrodo de ADE utilizando $0.1 \mathrm{~mol} \mathrm{~L}^{-1}$ de $\mathrm{NaCl}$, na presença (-) e na ausência (-) de SMX: (a) sem aplicação de radiação UV e (b) com radiação UV usando uma lâmpada de mercúrio de $250 \mathrm{~W}$. Condições: $v=50 \mathrm{mV} \mathrm{s}^{-1}$ a $25^{\circ} \mathrm{C}$

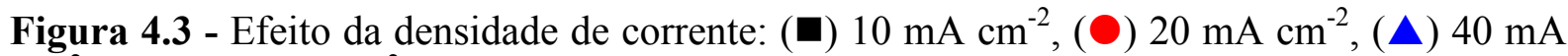
$\mathrm{cm}^{-2},(\boldsymbol{\nabla}) 60 \mathrm{~mA} \mathrm{~cm}{ }^{-2}$ na (a) degradação e (b) remoção de COT (Condições: $\mathrm{pH}_{\mathrm{i}}=3, \mathrm{~T}=$ $25^{\circ} \mathrm{C}, \mathrm{C}_{\mathrm{smx}}=200 \mathrm{mg} \mathrm{L}^{-1}$ e $\left.\mathrm{C}_{\mathrm{NaCl}}=0,1 \mathrm{~mol} \mathrm{~L}^{-1}\right)$.

Figura 4.4 - Variação do $\ln \left(\mathrm{C}_{\mathrm{o}} / \mathrm{C}\right)$ em função do tempo de degradação para valores diferentes

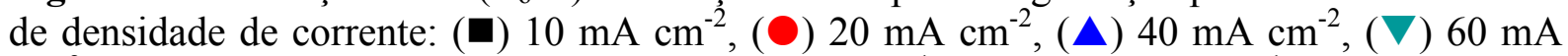
$\mathrm{cm}^{-2}$ (Condições: $\mathrm{pH}_{\mathrm{i}}=3, \mathrm{~T}=25^{\circ} \mathrm{C}, \mathrm{C}_{\mathrm{smx}}=200 \mathrm{mg} \mathrm{L}^{-1}$ e $_{\mathrm{NaCl}}=0,1 \mathrm{~mol} \mathrm{~L}^{-1}$ )......

Figura 4.5 - Efeito da concentração do $\mathrm{NaCl}$ na $(\boldsymbol{\square}) 0,1 \mathrm{~mol} \mathrm{~L}^{-1},(\mathbf{O}) 0,08 \mathrm{~mol} \mathrm{~L}^{-1},(\mathbf{A}) 0,04$ mol L ${ }^{-1},(\boldsymbol{\nabla})$ 0,02 $\mathrm{mol} \mathrm{L}^{-1}$ na (a) degradação e (b) remoção de COT (Condições: $\mathrm{pH}_{\mathrm{i}}=3, \mathrm{~T}=$ $25^{\circ} \mathrm{C}, \mathrm{C}_{\mathrm{smx}}=200 \mathrm{mg} \mathrm{L}^{-1}$ e $i=40 \mathrm{~mA} \mathrm{~cm}^{-2}$ ).

Figura 4.6 - Variação do $\ln \left(\mathrm{C}_{\mathrm{o}} / \mathrm{C}\right)$ em função do tempo para valores diferentes de concentração do NaCl: (ם) $0,1 \mathrm{~mol} \mathrm{~L}^{-1},(\mathbf{O}) 0,08 \mathrm{~mol} \mathrm{~L}^{-1},(\mathbf{\Delta}) 0,04 \mathrm{~mol} \mathrm{~L}^{-1}$, ( $)$ ) $0,02 \mathrm{~mol} \mathrm{~L}$ ${ }^{1}$ (Condições: $\mathrm{pH}_{\mathrm{i}}=3, \mathrm{~T}=25^{\circ} \mathrm{C}, \mathrm{C}_{\mathrm{smx}}=200 \mathrm{mg} \mathrm{L}^{-1} \mathrm{e} i=40 \mathrm{~mA} \mathrm{~cm}^{-2}$ ).

Figura 4.7 - Efeito da concentração inicial do SMX : (ם)50 $\mathrm{mg} \mathrm{L}^{-1},(\mathbf{O}) 100 \mathrm{mg} \mathrm{L}^{-1},(\mathbf{\Delta}) 150$ $\mathrm{mg} \mathrm{L}^{-1},(\nabla) 200 \mathrm{mg} \mathrm{L}^{-1}$ na (a) degradação e (b) remoção de COT (Condições: $\mathrm{T}=25^{\circ} \mathrm{C}, \mathrm{pH}_{\mathrm{i}}$ $=3, \mathrm{C}_{\mathrm{NaCl}}=0,1 \mathrm{~mol} \mathrm{~L}^{-1} \mathrm{e} i=40 \mathrm{~mA} \mathrm{~cm}^{-2}$ ).

Figura 4.8 - Variação de energia por ordem em função (a) densidade de corrente (Condições: $\mathrm{pH}_{\mathrm{i}}=3, \mathrm{~T}=25^{\circ} \mathrm{C}, \mathrm{C}_{\mathrm{smx}}=200 \mathrm{mg} \mathrm{L}^{-1}$ e $\mathrm{C}_{\mathrm{NaCl}}=0,1 \mathrm{~mol} \mathrm{~L}^{-1}$ ), (b) concentração de $\mathrm{NaCl}$ (Condições: $\mathrm{pH}_{\mathrm{i}}=3, \mathrm{~T}=25^{\circ} \mathrm{C}, \mathrm{C}_{\mathrm{smx}}=200 \mathrm{mg} \mathrm{L}^{-1} \mathrm{e} i=40 \mathrm{~mA} \mathrm{~cm}^{-2}$ ).

Figura 4.9 - (a) Curva do decréscimo relativo da concentração do COT (O) e da concentração do $\operatorname{SMX}(\boldsymbol{\square})$ em função do tempo de fotoeletrólise (Condições: $i=40 \mathrm{~mA} \mathrm{~cm}{ }^{-2}$, $\mathrm{pH}=3$, concentração da solução de $\mathrm{NaCl}=0,1 \mathrm{~mol} \mathrm{~L}^{-1}$ e $\mathrm{C}_{\mathrm{smx}}=200 \mathrm{mg} \mathrm{L}^{-1}$ ); (b) Variação do $\phi$ em função de densidade de corrente (Condições: $\mathrm{pH}_{\mathrm{i}}=3, \mathrm{~T}=25^{\circ} \mathrm{C}, \mathrm{C}_{\mathrm{smx}}=200 \mathrm{mg} \mathrm{L}^{-1} \mathrm{e}$ $\mathrm{C}_{\mathrm{NaCl}}=0,1 \mathrm{~mol} \mathrm{~L}^{-1}$ ) 
Figura 4.10 - Espectros de massas dos intermediários, referente à $\mathrm{m} / \mathrm{z}=288$.

Figura 4.11 - Espectros de massas referentes aos intermediários, condizente à $\mathrm{m} / \mathrm{z}=272 \ldots .96$

Figura 4.12 - Espectros de massas dos intermediários, referente à $\mathrm{m} / \mathrm{z}=321$.

Figura 4.13 - Espectros de massas referentes aos intermediários, correspondente à $\mathrm{m} / \mathrm{z}$ (110, 193).......

Figura 4.14 - Possível rota de degradação de SMX por processo eletroquímico foto assistido.

Figura 4.15 - Espectros de massas referentes aos intermediários, relacionado à $\mathrm{m} / \mathrm{z}=377 \ldots 98$

Figura 4.16 - Rota de degradação e conversão de SMX para os compostos referentes à $\mathrm{m} / \mathrm{z}=$ 377,324 .

Figura 4.17 - Variação da concentração de intermediários inorgânicos como as espécies $(0)$ $\mathrm{NO}_{3}{ }^{-} \mathrm{e}(\boldsymbol{\square}) \mathrm{SO}_{4}{ }^{2-}$, em função do tempo de eletrólise (Condições: $i=40 \mathrm{~mA} \mathrm{~cm}{ }^{-2}, \mathrm{pH}_{\mathrm{i}}=3, \mathrm{~T}=$

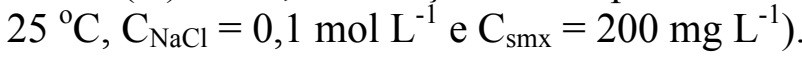

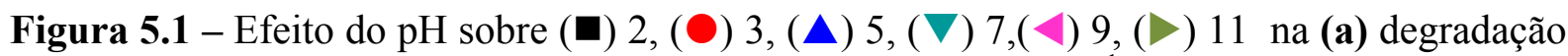
e (b) remoção de COT (Condições: $\mathrm{T}=25^{\circ} \mathrm{C}$ e $\mathrm{C}_{\mathrm{smx}}=200 \mathrm{mg} \mathrm{L}^{-1}$ )..... 103

Figura 5.2 - Variação do $\ln \left(\mathrm{C}_{\mathrm{o}} / \mathrm{C}\right)$ em função do tempo de fotólise em diferentes pHs (ש) 2,

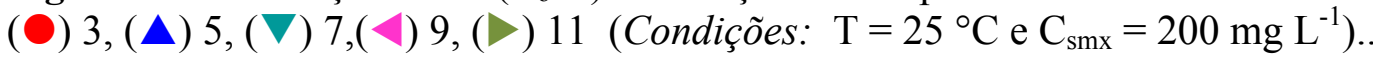
103

Figura 5.3 -Efeito de concentração inicial do $\operatorname{SMX~(\nabla )~} 50 \mathrm{mg} \mathrm{L}^{-1}$ (A) $100 \mathrm{mg} \mathrm{L}^{-1}$ (O) 150 $\mathrm{mg} \mathrm{L}^{-1}(\boldsymbol{\square}) 200 \mathrm{mg} \mathrm{L}^{-1}$ sobre (a) degradação e (b) remoção de COT (Condições: $\mathrm{T}=25^{\circ} \mathrm{C}$ e $\left.\mathrm{pH}_{\mathrm{i}}=3\right)$. 105

Figura 5.4 - Variação do $\ln \left(\mathrm{C}_{\mathrm{o}} / \mathrm{C}\right)$ em função do tempo de fotólise de SMX em diferentes

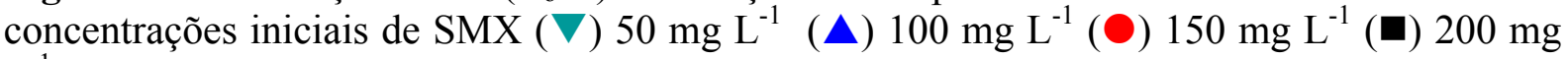
$\mathrm{L}^{-1}$ (Condições: $\mathrm{T}=25^{\circ} \mathrm{C}$ e $\mathrm{pH}_{\mathrm{i}}=3$ ). 105

Figura 5.5 - Efeito de temperatura (অ) $15{ }^{\circ} \mathrm{C},(\mathbf{O}) 25{ }^{\circ} \mathrm{C},(\boldsymbol{\Delta}) 35{ }^{\circ} \mathrm{C},(\boldsymbol{\nabla}) 45{ }^{\circ} \mathrm{C}$ sobre (a) degradação e (b) remoção de COT (Condições: $\mathrm{C}_{\mathrm{smx}}=200 \mathrm{mg} \mathrm{L}^{-1} \mathrm{e} \mathrm{pH}_{\mathrm{i}}=3$ ).......

Figura 5.6 - Variação do $\ln \left(\mathrm{C}_{\mathrm{o}} / \mathrm{C}\right)$ em função do tempo de fotólise de SMX em diferentes temperaturas (⿻) $15{ }^{\circ} \mathrm{C},(\boldsymbol{O}) 25^{\circ} \mathrm{C},(\boldsymbol{\Delta}) 35^{\circ} \mathrm{C},(\boldsymbol{\nabla}) 45^{\circ} \mathrm{C}$ (Condições: $\mathrm{C}_{\mathrm{smx}}=200 \mathrm{mg} \mathrm{L}-1 \mathrm{e}$ $\left.\mathrm{pH}_{\mathrm{i}}=3\right)$.

Figura 5.7 - Constante de velocidade (k) em função de (a) $\mathrm{pH}\left(\right.$ Condições: $\mathrm{T}=25^{\circ} \mathrm{C}$ e $\mathrm{C}_{\mathrm{smx}}$ $=200 \mathrm{mg} \mathrm{L}^{-1}$ ), (b) concentração inicial de SMX (Condições: $\mathrm{T}=25^{\circ} \mathrm{C} \mathrm{e} \mathrm{pH}_{\mathrm{i}}=3$ ), (c) temperatura (Condições: $\mathrm{C}_{\mathrm{smx}}=200 \mathrm{mg} \mathrm{L}^{-1} 1$ e $\mathrm{pH}_{\mathrm{i}}=3$ )... 108

Figura 5.8 - $\mathrm{E}_{\mathrm{EO}}$ energia por ordem $\left(\mathrm{kWh} \mathrm{m}^{-3}\right.$ ordem $\left.^{-1}\right)$ para degradação fotoquímica de SMX em função de (a) $\mathrm{pH}$ (Condições: $\mathrm{T}=25^{\circ} \mathrm{C}$ e $\mathrm{C}_{\mathrm{smx}}=200 \mathrm{mg} \mathrm{L}^{-1}$ ), (b) concentração inicial de SMX (Condições: $\mathrm{T}=25^{\circ} \mathrm{Ce} \mathrm{pH}_{\mathrm{i}}=3$ ), (c) Temperatura (Condições: $\mathrm{C}_{\mathrm{smx}}=200 \mathrm{mg} \mathrm{L}^{-1} \mathrm{e}$ $\left.\mathrm{pH}_{\mathrm{i}}=3\right)$ 
Figure 5.9 - Decréscimo relativo de COT $(\mathcal{O})$ e concentração de $\operatorname{SMX}(\boldsymbol{\square})$ em função do tempo de fotólise (Condições: $\mathrm{pH}=3, \mathrm{~T}=25^{\circ} \mathrm{C} \mathrm{e} \mathrm{C}_{\mathrm{smx}}=200 \mathrm{mg} \mathrm{L}^{-1}$ ).

Figura 5.10 - (a) LC-UV cromatograma de padrão de SMX; (b) espectro de massa de SMX $\mathrm{m} / \mathrm{z}=254\left(\mathrm{C}_{10} \mathrm{H}_{11} \mathrm{~N}_{3} \mathrm{SO}_{3}\right)$

Figura 5.11 - Cromatograma total de LC-MS da amostra retirada após 30 min de fotólise de

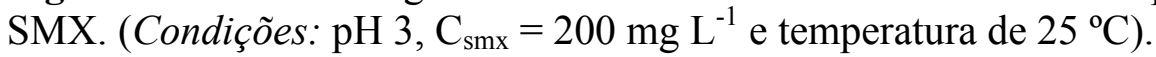
113

Figura 5.12 - Espectros de massas relacionados aos intermediários, referente à m/z $(99,156$, 272).

Figura 5.13 - Espectros de massas relativos aos intermediários, referente à $\mathrm{m} / \mathrm{z} \quad 174 \ldots \ldots \ldots .115$

Figura 5.14 - Espectros de massas referentes aos intermediários, condizente à m/z 188.....116

Figura 5.15 - Rota de degradação e conversão de SMX por radiação UV para os compostos referentes a $\mathrm{m} / \mathrm{z}=301,338$ e 322 .

Figura 5.16 - Variação de concentração dos intermediários inorgânicos como $(\boldsymbol{\square}) \mathrm{SO}_{4}{ }^{2-}(\mathbf{O})$ $\mathrm{NH}_{4}{ }^{+}$e $(\boldsymbol{\Delta}) \mathrm{NO}_{3}{ }^{-}$em função do tempo de fotólise (Condições: $\mathrm{pH}=3, \mathrm{~T}=25^{\circ} \mathrm{Ce} \mathrm{C}_{\mathrm{smx}}=$ $\left.200 \mathrm{mg} \mathrm{L}^{-1}\right)$.

Figura 6.1 - Influência da concentração de $\mathrm{Fe}^{2+}(\boldsymbol{\square}) 2,5 \mathrm{mg} \mathrm{L}^{-1},(\mathbf{O}) 5 \mathrm{mg} \mathrm{L}^{-1},(\mathbf{\Delta}) 10 \mathrm{mg} \mathrm{L}^{-1}$, ( v) $15 \mathrm{mg} \mathrm{L}^{-1}$ na (a) degradação e (b) remoção do COT (Condições: $\mathrm{C}_{\mathrm{SMX}}=200 \mathrm{mg} \mathrm{L}^{-1}$, $\mathrm{C}_{\mathrm{H} 2 \mathrm{O} 2}=150 \mathrm{mg} \mathrm{L}^{-1}, \mathrm{pH}_{\mathrm{i}} 3 \mathrm{e} \mathrm{T}=25^{\circ} \mathrm{C}$ ).

Figura 6.2 - Influência da concentração do $\mathrm{H}_{2} \mathrm{O}_{2}$ (口) $25 \mathrm{mg} \mathrm{L}^{-1}$, (○) $50 \mathrm{mg} \mathrm{L}^{-1}$, (A) $100 \mathrm{mg}$ $\mathrm{L}^{-1},(\boldsymbol{\nabla}) 150 \mathrm{mg} \mathrm{L}^{-1}$ na (a) degradação e (b) na remoção do COT (Condições: $\mathrm{C}_{\mathrm{smx}}=200 \mathrm{mg}$ $\left.\mathrm{L}^{-1}, \mathrm{C}_{\mathrm{Fe} 2+}=10 \mathrm{mg} \mathrm{L}^{-1}, \mathrm{pH}_{\mathrm{i}}=3 \mathrm{e} \mathrm{T}=25^{\circ} \mathrm{C}\right)$.

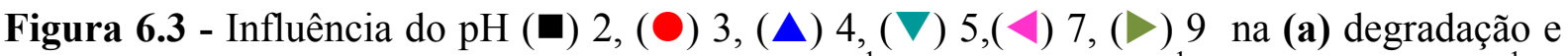
(b) remoção de COT (Condições: $\mathrm{C}_{\mathrm{SMX}}=200 \mathrm{mg} \mathrm{L}^{-1}, \mathrm{C}_{\mathrm{Fe} 2+}=10 \mathrm{mg} \mathrm{L}^{-1}, \mathrm{C}_{\mathrm{H} 2 \mathrm{O} 2}=150 \mathrm{mg} \mathrm{L}^{-1}$, e $\left.\mathrm{T}=25^{\circ} \mathrm{C}\right)$.

Figura 6.4 - Influência da temperatura (ם) $15{ }^{\circ} \mathrm{C},(\boldsymbol{O}) 25{ }^{\circ} \mathrm{C},(\boldsymbol{\Delta}) 35^{\circ} \mathrm{C},(\boldsymbol{\nabla}) 45{ }^{\circ} \mathrm{C}$ na (a) degradação e (b) remoção do COT (Condições: $\mathrm{C}_{\mathrm{SMX}}=200 \mathrm{mg} \mathrm{L}^{-1}, \mathrm{C}_{\mathrm{Fe} 2+}=10 \mathrm{mg} \mathrm{L}^{-1}, \mathrm{C}_{\mathrm{H} 2 \mathrm{O} 2}$ $=150 \mathrm{mg} \mathrm{L}^{-1}$ e $\mathrm{pH}_{\mathrm{i}}=3$ ).

Figura 6.5 - Influência da concentração inicial do SMX (ם) $100 \mathrm{mg} \mathrm{L}^{-1}$, (O) $150 \mathrm{mg} \mathrm{L}^{-1}$, (A) $200 \mathrm{mg} \mathrm{L}^{-1}$, na (a) degradação e (b) remoção do COT (Condições: $\mathrm{C}_{\mathrm{Fe} 2+}=10 \mathrm{mg} \mathrm{L}^{-1}, \mathrm{C}_{\mathrm{H} 2 \mathrm{O} 2}=$ $150 \mathrm{mg} \mathrm{L}^{-1}$, e $\mathrm{pH}_{\mathrm{i}}=3$ e $\mathrm{T}=25^{\circ} \mathrm{C}$ )......

Figura 6.6 - Possível rota de degradação do SMX por meio do processo Fenton.

Figura 6.7 - Espectro de massa referente aos intermediários, para valores de $\mathrm{m} / \mathrm{z}=108,156$, 173.

Figura 6.8 - Espectro de massa referente aos intermediários para $\mathrm{m} / \mathrm{z}=288$ 
Figura 6.9 - Espectro de massa referente aos intermediários para $\mathrm{m} / \mathrm{z}=270$.

Figura 6.10 - Variações nas concentrações dos íons inorgânicos $(\boldsymbol{\square}) \mathrm{NO}_{3}{ }^{-}$e $(\mathbf{O}) \mathrm{NH}_{4}^{+}$em função do tempo do tratamento (Condições: $\mathrm{C}_{\mathrm{SMX}}=200 \mathrm{mg} \mathrm{L}^{-1}, \mathrm{C}_{\mathrm{Fe}}{ }^{2+}=10 \mathrm{mg} \mathrm{L}^{-1}, \mathrm{C}_{\mathrm{H} 2 \mathrm{O} 2}=$ $150 \mathrm{mg} \mathrm{L}^{-1}, \mathrm{pH}_{\mathrm{i}}=3$ e $\left.\mathrm{T}=25^{\circ} \mathrm{C}\right)$.....

Figura 7.1 - Influência da concentração de $\mathrm{Fe}^{2+}$ (ם) $2,5 \mathrm{mg} \mathrm{L}^{-1},(\mathbf{O}) 5 \mathrm{mg} \mathrm{L}^{-1},(\mathbf{\Delta}) 10 \mathrm{mg} \mathrm{L}^{-1}$, (v) $15 \mathrm{mg} \mathrm{L}^{-1}$ na (a) degradação e (b) remoção do COT, (Condições: $\mathrm{C}_{\mathrm{SMX}}=200 \mathrm{mg} \mathrm{L}^{-1}$, $\mathrm{C}_{\mathrm{H} 2 \mathrm{O} 2}=150 \mathrm{mg} \mathrm{L}^{-1}, \mathrm{pH}_{\mathrm{i}}=3$ e $\left.\mathrm{T}=25^{\circ} \mathrm{C}\right)$

Figura 7.2 - Influência da concentração do $\mathrm{H}_{2} \mathrm{O}_{2}$ (ם) $25 \mathrm{mg} \mathrm{L}^{-1}$, (○) $50 \mathrm{mg} \mathrm{L}^{-1}$, ( $\left.\mathbf{\Delta}\right) 100 \mathrm{mg}$ $\mathrm{L}^{-1},(\nabla) 150 \mathrm{mg} \mathrm{L}^{-1}$ na (a) degradação e (b) remoção do COT (Condições: $\mathrm{C}_{\mathrm{smx}}=200 \mathrm{mg} \mathrm{L}^{-}$ ${ }^{1}, \mathrm{C}_{\mathrm{Fe} 2+}=10 \mathrm{mg} \mathrm{L}^{-1}, \mathrm{pH}_{\mathrm{i}}=3$ e $\mathrm{T}=25^{\circ} \mathrm{C}$ )

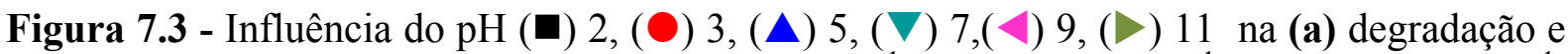
(b) remoção de COT. (Condições: $\mathrm{C}_{\mathrm{SMX}}=200 \mathrm{mg} \mathrm{L}^{-1}, \mathrm{C}_{\mathrm{Fe} 2+}=10 \mathrm{mg} \mathrm{L}^{-1}, \mathrm{C}_{\mathrm{H} 2 \mathrm{O} 2}=150 \mathrm{mg} \mathrm{L}^{-1}$, e $\left.\mathrm{T}=25^{\circ} \mathrm{C}\right)$.

Figura 7.4 - Influência da temperatura $(\boldsymbol{\square}) 15^{\circ} \mathrm{C},(\mathbf{O}) 25^{\circ} \mathrm{C},(\boldsymbol{\Delta}) 35^{\circ} \mathrm{C}$, na (a) degradação e (b) remoção do COT, (Condições: $\mathrm{C}_{\mathrm{SMX}}=200 \mathrm{mg} \mathrm{L}^{-1}, \mathrm{C}_{\mathrm{Fe} 2+}=10 \mathrm{mg} \mathrm{L}^{-1}, \mathrm{C}_{\mathrm{H} 2 \mathrm{O} 2}=150 \mathrm{mg} \mathrm{L}^{-1}$ e $\mathrm{pH}_{\mathrm{i}}=3$ )

Figura 7.5 - Influência da concentração inicial do SMX (ロ) $50 \mathrm{mg} \mathrm{L}^{-1},(\mathbf{O}) 100 \mathrm{mg} \mathrm{L}^{-1},(\boldsymbol{\Delta})$ $150 \mathrm{mg} \mathrm{L}^{-1}(\boldsymbol{\nabla}) 200 \mathrm{mg} \mathrm{L}^{-1}$ na (a) degradação e (b) remoção do COT (Condições: $\mathrm{C}_{\mathrm{Fe} 2+}=10$ $\mathrm{mg} \mathrm{L}^{-1}, \mathrm{C}_{\mathrm{H} 2 \mathrm{O} 2}=150 \mathrm{mg} \mathrm{L}^{-1}$, e $\mathrm{pH}_{\mathrm{i}}=3, \mathrm{~T}=25^{\circ} \mathrm{C}$ )

Figura 7.6 - Espectro de massa referente aos intermediários para $\mathrm{m} / \mathrm{z}=174,156$. 140

Figura 7.7 - Espectro de massa referente aos intermediários para $\mathrm{m} / \mathrm{z}=110$. 140

Figura 7.8 - Espectro de massa referente aos intermediários para $\mathrm{m} / \mathrm{z}=288$ 140

Figura 7.9 - Espectro de massa referente aos intermediários para $\mathrm{m} / \mathrm{z}=270$. 140

Figura 8.1 - Eficiência de degradação após 30 min e remoção de COT de SMX por vários processos, após 120 min de tratamento.

Figura 8.2 - Avaliação de energia por ordem para a degradação de SMX por meio de vários processos 


\section{Lista de Tabelas}

Tabela 3.1 - Parâmetros cinéticos e de consumo de energia para o processo degradação eletroquímico de SMX

Tabela 3.2 - Principais intermediários formados durante degradação de SMX através do processo eletroquímico

Tabela 4.1 - Parâmetros cinéticos relacionado à degradação foto eletroquímica do SMX

Tabela 5.1 - Parâmetros de consumo de energia e cinéticos de degradação fotoquímica.....106

Tabela 5.2 - Principais intermediários formados durante a degradação de SMX através do processo fotoquímico. 


\section{Lista de abreviaturas e siglas}

ADE - Ânodos dimensionalmente estáveis

AMP - Ampicilina

AMX - Amoxicilina

AO - Anodic oxidaditon (Oxidação anódica)

BOD - Biological oxygen demand (Demanda Biológica de Oxigênio )

CE - Contra-eletrodo

CG-MS - cromatografia gasosa e espectrometria de massa

CI - Carbono inorgânico

CL-ES - Cromatografia liquida e espectrometria de massas

CLX - Cloxacilina

COT - Carbono Orgânico Total

DDB - diamante dopado com boro

DIF -Difloxacina

DoD - Departamento de Defesa dos Estados Unidos

DQO - Demanda Química de Oxigênio

$\mathbf{E}_{\mathbf{E O}}$ - energia elétrica por ordem

EF - Eletro-Fenton

ERH - Eletrodo reversível de hidrogênio

ETE - Estações de tratamento de esgoto

IC - Ion Chromatography (cromatografia iônica)

IUPAC - International Union of Pure and Applied Chemistry

LC-MS/ESI - liquid Chromatography and mass spectrometry elétron spray ionization

LC/MS-TOF - liquid Chromatography and mass spectrometry time of flight (cromatografia liquida e espectrometria de massa tempo de voo)

$\mathbf{m} / \mathbf{z}$ - mass/charge (massa/carga)

PEF - Photo-electro-Fenton (Foto-eletro-Fenton)

POA - Processos oxidativos avançados

PVC - polivinil cloreto

SARA - Sarafloxacina

SMX - Sulfametoxazol 
SPE - Solid phase extraction (extração em fase sólida)

USEPA - (U.S Environmental Protection Agency), Agencia proteção de ambiental de Estados Unidos

UV-Vis - Ultravioleta-visível

UVA - Ultravioleta A

VC - Voltametria cíclica

u- Velocidade de varredura

$\mu$ - Força iônica 


\section{Capítulo 1}

\section{Introdução}

\subsection{Aspectos gerais dos contaminantes emergentes}

A superfície da Terra é coberta pela substância mais abundante que existe, a água. Cerca de $97 \%$ da superfície terrestre corresponde aos mares e oceanos, ou seja, 97\% da água disponível no planeta Terra é salgada. O restante, cerca de 3\%, corresponde à água doce ou potável, sendo esta essencial para vida dos seres vivos. Grande parte da água doce presente no nosso planeta encontra-se na forma sólida, nas geleiras e nas calotas polares, enquanto uma pequena fração do total de água doce disponível $(0,01 \%)$ encontra-se em rios, lagos e lençóis freáticos (BAIRD, 1999).

Inúmeras regiões do mundo sofrem com a escassez de água, o que representa um desafio diário, pois a água é indispensável em diferentes aplicações, tais como: agrícola, industrial, lazer, cuidados e higiene pessoal. Portanto, a qualidade e a quantidade da água necessitam ser cuidadosamente gerenciadas.

Nas últimas décadas, fatores como o crescimento populacional, o desenvolvimento industrial e as alterações climáticas têm contribuído para o aumento da poluição no meio ambiente, em especial nos recursos hídricos. Diariamente são lançados em rios e lagos centenas de compostos orgânicos, tais como: corantes, pesticidas, herbicidas, detergentes, 
agentes tenso-ativos, tintas, conservantes, fármacos, aditivos alimentares, dentre outros, os quais são classificados como poluentes emergentes.

Recentemente, a pesquisa ambiental vem sendo direcionada para a remediação não somente dos poluentes orgânicos convencionais, mas principalmente dos micro-poluentes orgânicos, ou poluentes emergentes. A detecção de substâncias químicas no meio aquático, com concentrações inferiores a $1 \mu \mathrm{g} \mathrm{L}^{-1}$ se tornou evidente com as melhorias recentes em técnicas analíticas avançadas (REEMTSMA; JEKEL, 2006). Os avanços obtidos em técnicas analíticas clássicas como a cromatografia líquida acoplada à espectrometria de massas (CLES), em particular, permitiram a detecção de diversos produtos farmacêuticos e de seus metabólitos (PETROVIC; BARCELÓ, 2006).

No entanto, não existe uma lista completa de compostos que possam ser classificados como "contaminantes emergentes". Muitos destes compostos, na faixa de concentração de $\mu \mathrm{gL}^{-1}$ ou abaixo desta, são os grandes responsáveis pela contaminação do ambiente aquático.

Muitos desses micro-poluentes têm sido encontrados no meio ambiente e detectados na forma de seus intermediários metabólicos, que são muitas vezes espécies mais complexas e tóxicas do que os compostos originais, pois no ambiente aquático podem sofrer diferentes processos, tais como: fotolíticos, hidrológicos, e microbiológicos (Figura 1.1).

A Agência de Proteção Ambiental dos Estados Unidos ("U.S Environmental Protection Agency - USEPA") e o Departamento de Defesa dos Estados Unidos (DoD) definiram em diversas publicações o termo "contaminante emergente" como sendo "um produto químico ou material que se caracteriza como uma ameaça perceptível, potencial ou real, para a saúde humana ou para o ambiente". Um contaminante também pode ser “emergente", graças à descoberta de uma nova fonte a partir de atividades dos seres humanos, ou porque um novo método de detecção ou nova tecnologia de tratamento foi desenvolvida (U.S. DEPARTMENT OF DEFENSE, 2006). Esses contaminantes podem ser produtos farmacêuticos, produtos de cuidado pessoal, drogas ilícitas e produtos químicos que provocam desregulação endócrina, tais como hormônios e esteróides. Outros produtos químicos se destacam como:

benzotiazóis, benzotriazóis, naftalenos policlorados, compostos perfluorados, bifenilas, alcanos policlorados, polidimetilsiloxanos, bisfenol-A, almíscares sintéticos, quaternário de amônio, triclosan, triclocarban, pesticida, produtos veterinários, compostos ou subprodutos industriais, aditivos alimentares e os nanomateriais sintentizados em laboratório (LAPWORTH et al., 2012). 


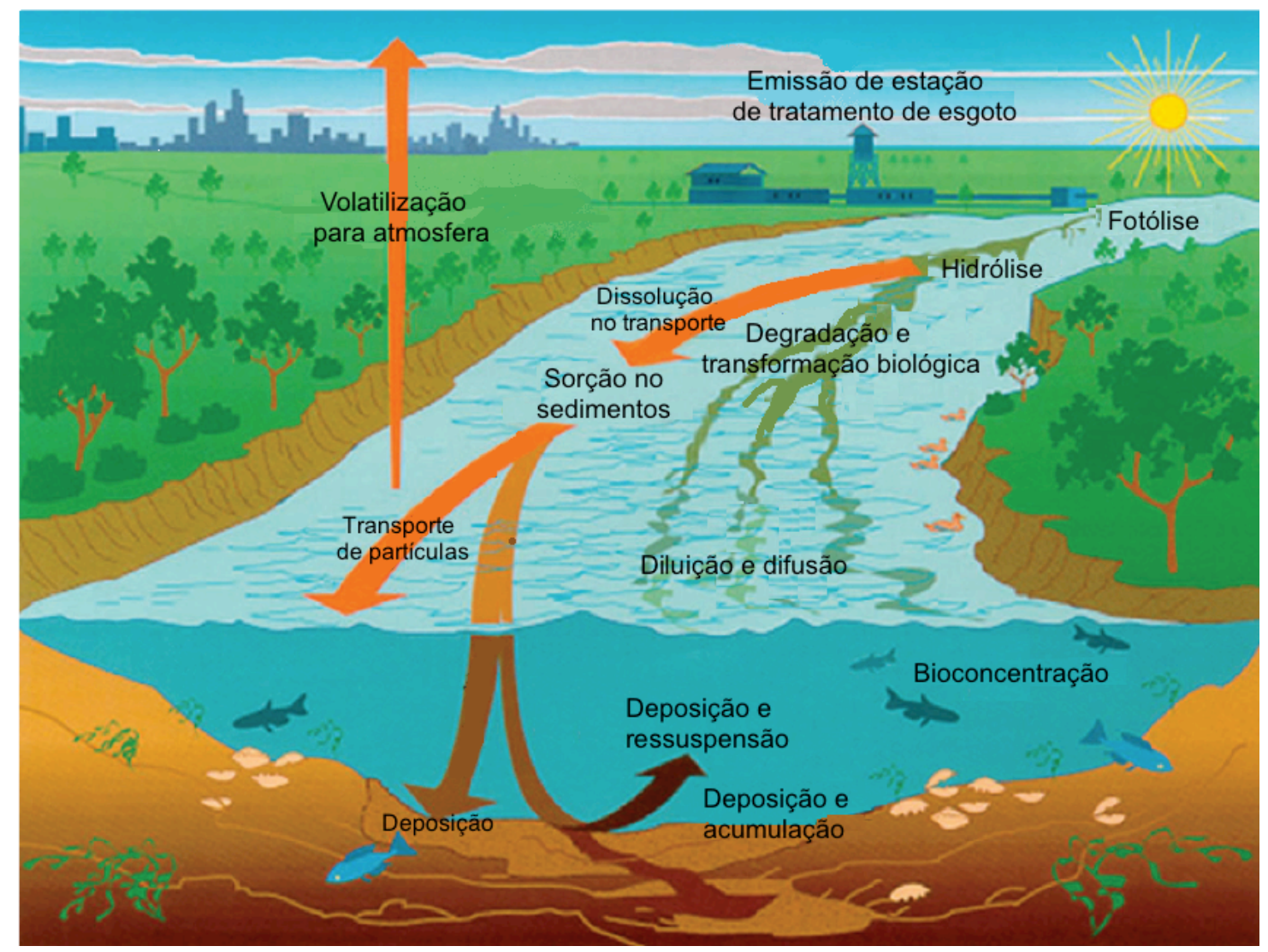

Figura 1.1 - Dispersão de poluentes no ambiente aquático. Adaptado de: US Geological Survey.

Disponível em: < http://toxics.usgs.gov/regional/emc/transport fate.html>. Acesso 18-Dec 2013

Uma característica desses compostos é a de que não necessitam ser persistentes no ambiente para causar efeitos negativos, uma vez que seu alto grau de transformação/eliminação é compensado por seu constante ingresso no ambiente devido ao amplo uso. Estudos sobre os efeitos toxicológicos de grande parte desses contaminantes não foram ainda realizados ou não são conclusivos, assim, torna-se difícil prever quais os impactos da contínua exposição de tais contaminantes sobre a saúde dos seres humanos e de organismos aquáticos (BARCELÓ, 2003).

$\mathrm{Na}$ atualidade, nenhuma outra questão de toxicologia ambiental tem despertado mais interesse da comunidade científica e das agências regulatórias do que os desreguladores endócrinos. De acordo com Agência de Proteção Ambiental dos Estados Unidos (Environmental Protection Agency - EPA), um desregulador endócrino é qualquer substância exógena que interfere na síntese, secreção, transporte, atividade conjugada, metabolismo ou liberação de hormônios naturais, que são responsáveis pela regulação da homeostase dos seres vivos (DICKERSON; GORE, 2007), (DIAMANTI-KANDARAKIS et al., 2009). 
Os itens a seguir apresentam com mais detalhes duas classes de contaminantes emergentes, visto que esses contaminantes são muito diversificados e podem ser agrupados baseando-se na estrutura química, propriedades, efeitos e aplicação.

\subsection{Desreguladores endócrinos}

Os desreguladores endócrinos afetam, especialmente, a reprodução animal (GHISELLI; JARDIM, 2007) Essas substâncias podem ser de origem sintética (xenoestrógenos) ou natural (fitoestrógenos), podendo perturbar o sistema endócrino mesmo em baixas concentrações. Os efeitos adversos dessas substâncias foram associadas às desordens tais como diminuição na eclosão de ovos de pássaros, peixes e tartarugas; feminização de peixes macho (BILA; DEZOTTI, 2007). Eles podem causar problemas neurológicos, no sistema reprodutivo masculino (redução na produção de esperma, aumento do risco de câncer testicular e de próstata, infertilidade e alterações nos níveis hormonais da tireóide), desenvolvimento, perturbações do sistema imunológico e desenvolvimento de tumores (GROVER et al., 2009).

Os desreguladores endócrinos podem agir de diversas formas, tais como: imitando os hormônios endógenos; simulando a formação de mais receptores; atuando como bloqueadores; atuando como desativadores de hormônios; desativadores ou desestruturadores de enzimas. As doses, tempo e duração da exposição em períodos críticos da vida são fatores importantes para se entender os efeitos adversos de um interferente endócrino. Os efeitos podem ser reversíveis ou irreversíveis, imediatos (agudos) ou latentes (BIGSBY et al., 1999).

Como descrito anteriormente, os desreguladores endócrinos podem ser compostos sintetizados ou subprodutos das emissões das indústrias de celulose e de papel, nas fundições de aço, resíduos de veículos automotores, resíduos de incinerações, especialmente de compostos que contenham cloro em sua composição, como o polivinil cloreto (PVC). No entanto, há vários outros produtos que podem ser classificados como desreguladores endócrinos, incluindo cosméticos, ftalatos, fármacos, protetores solares, fragrâncias, pílulas anticoncepcionais, solventes, tenso ativos, pesticidas, herbicidas, dentre outros (MAIA; DEZOTTI, 2007; HAARSTAD; BORCH, 2004; ABDELMALEK et al., 2008; ALONSOMAGDALENA et al., 2006, AFRICA et al., 2006; BIRKHØJ et al., 2004).

A combinação dos desreguladores endócrinos com outro produto químico pode proporcionar um efeito sinérgico, aumentando, consequentemente, sua toxicidade. Um exemplo dessa sinergia é o que ocorre com os herbicidas, pois há situações em que o 
subproduto é mais tóxico do que o precursor (RICHARD et al., 2005); YOUSEF et al., 1995).

\subsection{Produtos farmacêuticos e de cuidados pessoais}

Os produtos de cuidados pessoais são constituídos por uma vasta gama de compostos orgânicos, sendo estes: desodorantes, máscaras faciais, hidratantes, protetores solares, maquiagem, antissépticos bucais, pomadas, perfumes, lubrificantes, xampus, espumas de barbear etc. Tais produtos contêm inúmeros componentes, tais como, tensoativos, conservantes, corantes, fragrâncias, entre outros.

Diariamente, são lançadas no meio ambiente toneladas de compostos industrializados através de diferentes fontes, destacando-se o descarte de efluentes de estações de tratamento de esgoto (ETE), lixo e efluentes domésticos, aterros sanitários etc. Tais compostos são bioacumulativos e podem causar efeitos nocivos à saúde humana (KONIECKI et al., 2011; YANG et al., 2011; ESPLUGAS et al., 2007). Os fármacos são substâncias químicas bem conhecidas e amplamente utilizadas devido às suas atividades biológicas específicas. Fármacos ou medicamentos vêm auxiliando os seres humanos ao longo de séculos, sendo uma das razões que justificam a melhoria da qualidade de vida da humanidade. Os fármacos podem ser classificados de acordo com a sua atividade biológica e finalidade (por exemplo, os antibióticos são utilizados tipicamente para se tratar infecções bacterianas, os analgésicos são utilizados para se reduzir a dor, enquanto os agentes antineoplásicos são usados na terapia anticâncer). Os fármacos também são classificados de acordo com suas estruturas químicas, de acordo com os ingredientes de farmacêuticos ativos e de suas formulações, como no caso dos antibióticos, destacam-se os grupamentos $\beta$-lactâmicos, as cefalosporinas, as penicilinas e as quinolonas. Outras classificações referem-se ao modo de ação relacionado com as estruturas e conformações das moléculas.

É sabido que os produtos farmacêuticos entram no meio ambiente através da atividade humana individual, e também como os resíduos de fabricação, agronegócio, uso veterinários e hospitalares e da comunidade. Os indivíduos podem liberar fármacos para o meio ambiente através da excreção metabólica, disposição imprópria ou processos industriais, sendo também identificada e quantificada sua presença em efluentes de ETE (JELIC et al., 2011), águas de superfície (MIÈGE et al., 2009), água potável (KUMAR; XAGORARAKI, 2010), águas subterrâneas (ELLIS, 2006), biossólido (MCCLELLAN; HALDEN, 2010), adubos agrícolas (MOTOYAMA et al., 2011) e biota (FROMME et al., 1999). Dentre os fármacos que têm sido frequentemente detectados em diferentes compartimentos ambientais, incluem-se: 
antibióticos, analgésicos e anti-inflamatórios, agente reguladores de lipídos, beta bloqueadores, antiepiléticos, contraceptivos, esteroides e hormônios relacionados. Esses fármacos residuais são encontrados no meio ambiente em concentração (ng $\mathrm{L}^{-1}$ ou $\left.\mu \mathrm{g} \mathrm{L}^{-1}\right)$ contudo, mesmo em baixas concentrações, têm potencial para induzirem efeitos tóxicos (RADJENOVIC et al., 2007; VIENO et al., 2007). Em alguns casos, os fármacos têm sido detectadas em grandes concentrações $\left(>1000 \mu \mathrm{g} \mathrm{L} \mathrm{L}^{-1}\right)$ nos efluentes de águas residuais correspondentes à influência proveniente da indústria farmacêutica (LARSSON et al., 2007; PHILLIPS et al., 2010). Todavia, o risco ecológico associado à maioria dos fármacos não está suficientemente esclarecido na literatura.

\subsection{Antibióticos no meio ambiente}

Os antibióticos são um dos principais grupos de produtos farmacêuticos. O termo antibiótico se refere aos medicamentos que matam ou inibem o crescimento de bactérias. São amplamente utilizados na medicina humana, veterinária e na aquicultura, com a finalidade de prevenir ou combater infecções microbianas, entretanto, na pecuária, são utilizados para promover o crescimento dos animais (KÜMMERER, 2008). Eles são compostos polares, não voláteis, hidrofílicos, semissintéticos e sintéticos e com atividade antimicrobial, podendo ser aplicados parenteralmente, oralmente ou topicamente.

Como já descrito anteriormente, os antibióticos representam um grupo diversificado de compostos que podem ser divididos em subgrupos como: $\beta$-lactâmicos, quinolonas tetraciclinas, macrolídeos, sulfonamidas, entre outros. Os princípios ativos dos antibióticos são moléculas complexas que apresentam diferentes funcionalidades. No meio ambiente, tais moléculas podem ser neutras, catiônicas, aniônicas ou zwitteriônicas. Assim, devido às diferentes funcionalidades destes compostos, as suas propriedades físico-químicas e biológicas variam de acordo com os valores de $\mathrm{pH}$, ou seja, propriedades como solubilidade, caráter hidrofóbico e hidrofílico e coeficientes de partição dos antibióticos são essencialmente dependentes do $\mathrm{pH}$.

Os compostos farmacologicamente ativos, especialmente os antibióticos, são moléculas complexas com relação à maioria dos produtos químicos industriais e outros contaminantes ambientais (TRIVEDI; VASUDEVAN, 2007). Os antibióticos podem ser metabolizados de maneira mais ou menos extensiva pelos seres humanos e os animais. Após sua administração, seus metabólitos são excretados e lançados no meio ambiente, podendo chegar às estações de tratamento de esgoto (ETE) (Figura 1.2). Esses produtos são só parcialmente removidos nas ETE, acabando por chegar até mesmo às águas superficiais, 


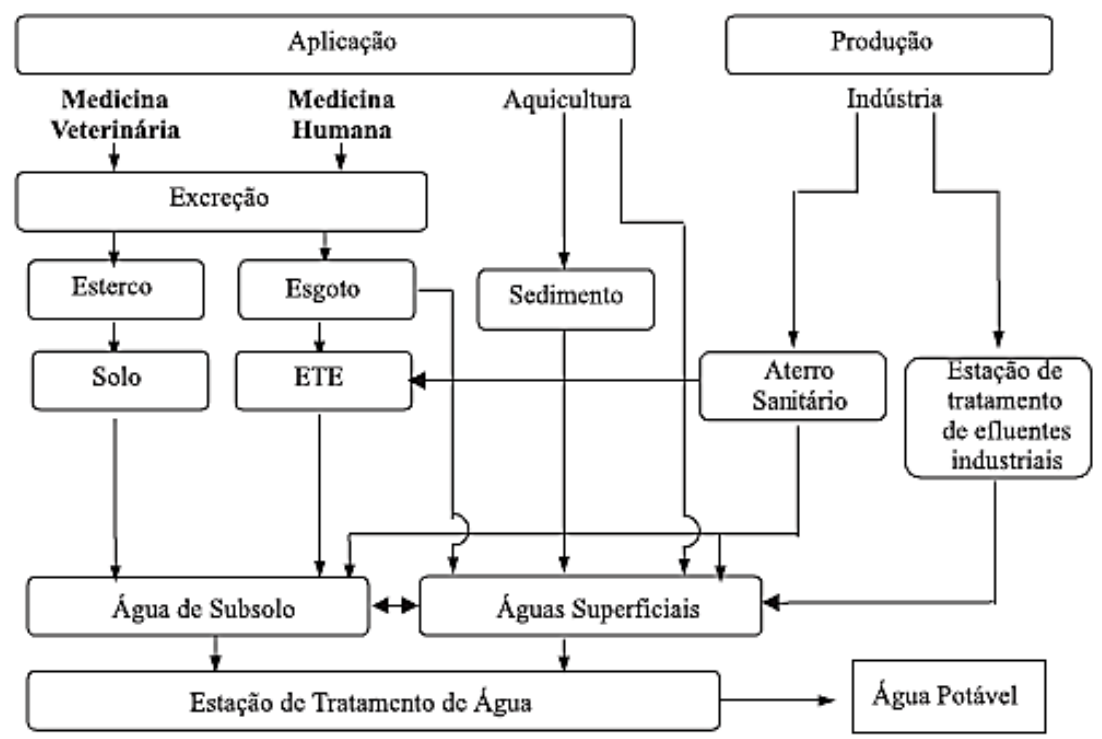

Figura 1.2 - Rotas de entrada e de dispersão de fármacos no meio ambiente.

Fonte: Bila; Dezotti, Fármacos no meio ambiente. Química Nova, 2003. v. 26, p. 523-530,

subterrâneas e os sedimentos. Um exemplo disso é o que ocorre com a descarga direta de resíduos oriundos do processamento de carnes de frangos, que contribuem para o aumento da concentração total de antibióticos em esgotos e em águas superficiais. Alguns antibióticos, por exemplo, são metabolizados quase que totalmente, cerca de $95 \%$, enquanto outros são excretados praticamente inalterados (KÜMMERER; HENNINGER, 2003).

\subsubsection{Presença de Sulfametoxazol (SMX) no meio ambiente e seu efeito toxicológico}

Dentre os inúmeros fármacos existentes e consumidos no Brasil e no mundo, as sulfonamidas e trimetoprima proporcionam um tratamento eficaz contra uma variedade de infecções bacterianas potenciais, pois atuam sinergicamente, causando a inibição das etapas de crescimento e reprodução de bactérias (MASTERS et al., 2003; SKOLD, 2001). O sulfametoxazol é uma sulfonamida de amplo espectro e bem conhecida como 4-amino-N-(5metil-3-isoxazolil) benzenossulfonamida. Apresenta fórmula molecular $\mathrm{C}_{10} \mathrm{H}_{11} \mathrm{~N}_{3} \mathrm{O}_{3} \mathrm{~S}$ e mass molar 253,27 $\mathrm{g} \mathrm{mol}^{-1}$; seu ponto de fusão é de $166-169{ }^{\circ} \mathrm{C}$ e seus pKa 1,85 e 5,60. Na Figura 1.3 está apresentada a estrutura química do SMX.

Após de adiminstração, as sulfonamidas não são completamente metabolizadas, sendo excretadas através da urina (parcialmente), gerando como principais subprodutos. Os produtos derivados de compostos $\mathrm{N}$-acetilados. Tais metabólitos são biologicamente inativos, mas 


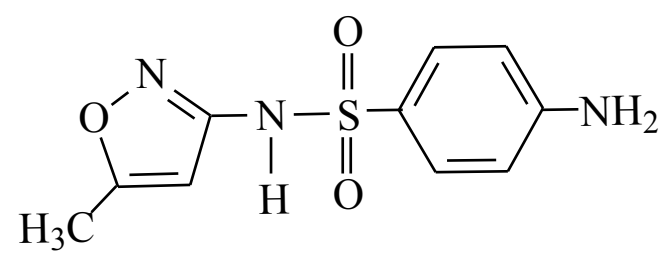

Figura 1.3 - Estrutura química de sulfametoxazol.

alguns estudos mostram que estes podem ser transformados em compostos biologicamente ativos (GOBEL et al., 2005).

O composto sulfametoxazol encontra-se entre as sulfonamidas detectadas com maior frequência em esgotos municipais (BROWN et al., 2006; CHOI et al., 2007; GOBEL et al., 2007; LEVINE et al., 2006; YANG et al., 2005). No entanto, as concentrações desse fármaco em influentes e efluentes de estação de tratamento de água residuais variam consideravelmente, dependendo dos padrões de consumo do antibiótico e dos tipos de tratamento de efluentes que são empregados.

Como exemplo, foi relatada a presença de sulfametoxazol em concentrações tão elevadas quanto $7,91 \mathrm{mg} \mathrm{L}^{-1}$ no influente de esgoto na China, onde o composto é um dos 15 fármacos mais vendidos (PENG et al. 2006). O metabólito acetilado do sulfametoxazol, o N4acetil-sulfametoxazol, geralmente representa mais do que 50\% resíduos detectados na excreção humana, correspondentes a uma dose administrada (GOBEL et al. 2004). Além disso, tal metabólito pode estar presente em influente de estação de tratamento de água residuais em concentrações de 2,5 a 3,5 vezes maior do que as concentrações do composto original (GOBEL et al., 2007), contribuindo para o aumento da toxicidade do meio.

A sulfametoxazol é destruída de maneira incompleta na estação de tratamento de água residuais convencionais e, finalmente, alcança os corpos de água com o potencial de afetar adversamente os organismos aquáticos e terrestres, sendo que pode contaminar os seres humanos através da água potável. A nitrificação é um processo importante no tratamento de águas residuais, permitindo a eliminação da amônia. A segunda etapa da nitrificação corresponde à oxidação do nitrito em nitrato que particularmente sensível. A inibição dessa etapa em condições não controladas pode resultar no acúmulo do nitrogênio do nitrito no efluente industrial, que é uma forma de nitrogênio particularmente tóxica. Foi relatado que o sulfametoxazol inibiu significativamente uma cultura de bactérias oxidantes do nitrito (DOKIANAKIS et al., 2004).

Alguns receptores comuns também foram identificados em plantas e relacionados aos antibióticos que afetam as replicações de cloroplastos, as transcrições e as traduções, sendo 
que as sulfonamidas afetam as vias metabólicas, tais como as vias relacionadas com a biossíntese do ácido fólico (BRAIN et al., 2008). Foi relatado que o sulfametoxazol (SMX) causa efeitos fitotóxicos para o intervalo de concentrações de 0 a $1000 \mu \mathrm{g} \mathrm{L}^{-1}$ (BRAIN et al., 2004). O SMX tem demonstrado toxicidade aguda para bactérias marinhas (Vibrio fischeri), invertebrados de água doce (Daphnia magna) e o peixe japonês da espécie Oryzias latipes (KIM et al., 2007).

Dessa forma, nas últimas décadas, há uma necessidade crescente com relação ao desenvolvimento de tratamentos eficazes, visando a remoção parcial ou completa do antibiótico SMX e de seus metabólitos dos sistemas aquáticos.

Técnicas ou tratamentos convencionais orientados pelos métodos biológicos e físicoquímicos, tais como: coagulação, volatilização, adsorção, sedimentação e filtração são ineficazes para a remoção de fármacos, em especial do SMX (JONES et al., 2005; RAHMAN et al., 2009; SUÁREZ et al., 2008)

Por isso, recentemente, os processos oxidativos avançados (POA) têm sido amplamente estudados, podendo estes apresentar um aumento de eficiência quando acoplados a outros métodos, como nos processos eletroquímicos. Os POA são baseados na formação de radicais hidroxila $(\cdot \mathrm{OH})$, que são espécies radicalares altamente reativas e não seletivas, capazes de oxidar uma ampla variedade de compostos orgânicos.

\subsection{Estudos existentes no tratamento de sulfametoxazol}

Sharma et al. (2006) estudaram a cinética da reação de oxidação entre o íon Fe (VI) e o SMX, em função do $\mathrm{pH}(6,93-9,50)$ e a temperatura $\left(15-45^{\circ} \mathrm{C}\right)$, sendo que a oxidação de SMX pelo Fe(VI) foi de cinética de primeira ordem, com relação a cada reagente. Além disso, as velocidades de reação dependem do $\mathrm{pH}$, tendo sido observada uma meia-vida de 2 min para uma solução de ferrato de potássio $\left[\mathrm{K}_{2} \mathrm{FeO}_{4}\right]$ de concentração igual a $10 \mu \mathrm{mol} \mathrm{L}^{-1}$. Os resultados sugerem que o tratamento oxidativo do $\mathrm{SMX}$ com $\mathrm{K}_{2} \mathrm{FeO}_{4}$, permite realizar de maneira potencial a sua remoção da água.

Dantas et al. (2008) investigaram a ozonização do sulfametoxazol em diferentes valores de $\mathrm{pH}$. Os resultados mostraram que a ozonização é um método eficiente para se degradar o sulfametoxazol. Após 15 min de ozonização (dose correspondente $0,4 \mathrm{~g}$ de ozônio

$\mathrm{L}^{-1}$ ), a degradação quase completa do antibiótico foi obtida, porém, alcançou-se apenas $10 \%$ de mineralização. O perfil toxicológico mostrou que houve um ligeiro aumento na toxicidade aguda na primeira fase de ozonização. A variação do $\mathrm{pH}$ mostrou-se importante na remoção de Carbono Orgânico Total (COT), e na Demanda Química de Oxigênio (DQO). 
No trabalho de Nogueira et al. (2005) foi mostrada a degradação de sulfametoxazol (SMX) por foto-Fenton solar em escala de planta piloto, empregando água destilada e água do mar. Os resultados mostraram que a degradação e a mineralização do SMX foram rápido e efetiva em água destilada, contudo o mesmo compartamento não foi observado em água do mar. Também foi avaliada a influência do $\mathrm{H}_{2} \mathrm{O}_{2}$ e a concentração do ferro na eficiência do processo fotocatalítico. Um aumento na concentração de ferro de 2,6 a 10,4 mg $\mathrm{L}^{-}$ ${ }^{1}$ resultou apenas numa pequena melhoria na degradação do SMX e em sua mineralização. No entanto, o aumento nas concentrações de $\mathrm{H}_{2} \mathrm{O}_{2}$ até $120 \mathrm{mg} \mathrm{L}^{-1}$ durante o processo foto-Fenton em água destilada diminuiu a toxicidade da solução do SMX de $85 \%$ para $20 \%$, de acordo com os resultados dos bioensaios com a Daphnia magna.

Apesar da ocorrência de $45 \%$ de mineralização em água do mar, houve um aumento de $16 \%$ para $86 \%$ na toxicidade como indicado nos bioensaios empregando Vibrio fischeri, o que sugere que os intermediários gerados na água salgada são diferentes daqueles em água destilada.

González et al. (2007) investigaram a degradação de $200 \mathrm{mg} \mathrm{L}^{-1}$ do sulfametoxazol (SMX) em solução através do processo foto-Fenton. O processo foto-Fenton foi bemsucedido, aumentando a biodegradabilidade das águas residuais contendo o SMX. A remoção completa do antibiótico foi realizada ao se empregar o $\mathrm{H}_{2} \mathrm{O}_{2}$ em uma dose de $300 \mathrm{mg} \mathrm{L}^{-1}$. Os testes de toxicidade e de inibição apontam para a mesma direção: os intermediários que foram oxidados, ao se empregar uma dose inicial de $\mathrm{H}_{2} \mathrm{O}_{2}$ acima de $300 \mathrm{mg} \mathrm{L}^{-1}$, não apresentaram toxicidade para bactérias e nenhuma inibição na atividade do lodo ativado.

Wang et al. (2011) examinaram a mineralização do antibiótico sulfametoxazol (SMX) em concentração igual a $300 \mathrm{mg} \mathrm{L}^{-1}$, através do processo foto-eletro-Fenton (PEF), empregando-se cátodo de fibra de carbono ativado e irradiação de UVA. A mineralização comparativa foi estudada através de métodos diferentes: oxidação anódica com $\mathrm{RuO}_{2} / \mathrm{Ti}$ (AO), na presença do $\mathrm{H}_{2} \mathrm{O}_{2}$ eletro-gerado $\left(\mathrm{AO}-\mathrm{H}_{2} \mathrm{O}_{2}\right), A O-\mathrm{H}_{2} \mathrm{O}_{2}$ na presença da irradiação UVA (AO- $\mathrm{H}_{2} \mathrm{O}_{2}$-UVA), processo eletro-Fenton (FE) e processo foto-eletro-Fenton (PFE). $\mathrm{O}$ COT de SMX foi removido com os seguintes processos: PFE, EF, AO- $\mathrm{H}_{2} \mathrm{O}_{2}-\mathrm{UVA}$ e $\mathrm{H}_{2} \mathrm{O}_{2}$ e AO com 80, 63, 36, 28, e 25\% respectivamente. A técnica de HPLC-MS identificou a existência de seis produtos aromáticos que foram obtidos no processo PFE do SMX, assim como foram detectadas algumas espécies inorgânicas, tais como o $\mathrm{NO}_{3}{ }^{-}$e o $\mathrm{NH}_{4}{ }^{+}$.

A transformação fotoquímica do sulfametoxazol (SMX) pela energia solar foi investigada por Trovó et al. (2009) em diferentes matrizes de água, tais como, água destilada e água do mar, a fim de se avaliar sua persistência, toxicidade e forma de degradação. Foram 
observadas diferenças quanto às velocidades de degradação ao se considerar os tipos de matrizes acima, sendo que a velocidade de degradação foi mais lenta na água do mar. Além disso, a presença do nitrato em água (fotólise indireta) não afetou a velocidade de degradação do SMX. A análise por LC/MS permitiu a identificação de até nove produtos gerados durante a fotólise em água destilada. A espécie Daphnia magna foi a mais sensível, o que demonstra o aumento de 60 a 100\% de imobilização após $30 \mathrm{~h}$ de irradiação quando houve desaparecimento do SMX, o que indica uma maior toxicidade dos produtos obtidos com as fotos-transformação.

Dirany et al. (2010) estudaram a redução eletroquímica do antibiótico sulfametoxazol (SMX) a partir de soluções aquosas em pH 3,0, por meio dos processos de oxidação anódica e do eletro-Fenton (EF), ocorrendo a eletro-geração de $\mathrm{H}_{2} \mathrm{O}_{2}$ ao ser utilizado um ânodo de diamante dopado com boro (DDB) e um cátodo de carbono.

A um valor baixo de corrente, a oxidação no ânodo foi predominante; quando o valor da corrente foi elevado, o SMX foi degradado eminentemente no seio da solução. O SMX também foi degradado rapidamente em todas as condições testadas, de acordo com uma cinética de reação de pseudo-primeira ordem. Contudo, a eliminação quase completa do carbono orgânico só foi alcançada na célula de DDB/carbono. Os produtos da reação foram quantificados e a rota da mineralização do SMX pelo processo de EF foi elucidada.

Lin et al. (2013) investigaram a mineralização eletroquímica do sulfametoxazol ( $\mathrm{SMX}$ ) em uma única célula equipada com um ânodo de $\mathrm{Ti} / \mathrm{SnO} \mathrm{S}_{2}-\mathrm{Sb} / \mathrm{Ce}-\mathrm{PbO}_{2}$ e um cátodo de Ti. A cinética da reação foi determinada em função da densidade de corrente aplicada $(0,5-$ $40 \mathrm{~mA} \mathrm{~cm}^{-2}$ ), da concentração inicial do antibiótico SMX (10-400 $\left.\mathrm{mg} \mathrm{L}^{-1}\right)$, do pH inicial (311), e da distância do eletrodo (3-20 mm). Observou-se que a degradação do SMX na água do lago contaminado foi mais rápida do que em água deionizada, de modo que a degradação eletroquímica do SMX obedeceu a uma cinética de pseudo-primeira ordem. A mineralização quase completa do SMX ( $>95 \%$ ) foi alcançada em $60 \mathrm{~min}$, uma vez que a densidade de corrente superior a $10 \mathrm{~mA} \mathrm{~cm}{ }^{-2}$. Foram analisados e quantificados os principais produtos obtidos com a mineralização em solução aquosa. Além disso, foi proposto um mecanismo possível para a mineralização eletroquímica do SMX.

\subsection{Métodos para os tratamentos de águas residuais}

No cenário mundial atual, a questão ambiental mais fundamental é a de preservar os recursos hídricos do possível acúmulo de contaminantes, em especial de antibióticos como o SMX. Atualmente, existe um interesse crescente no desenvolvimento de tecnologias 
inovadoras e economicamente viáveis para o tratamento de águas residuais, possibilitando reduções das quantidades diárias de antibióticos que possam ser eliminados do meio ambiente.

Além disso, há estudos que envolvem a conversão desses contaminantes em intermediários menos tóxicos, tornando-se biodegradáveis. Mais adiante serão discutidos mais detalhadamente os processos que foram utilizados no tratamento de efluentes (objetivo de estudo neste trabalho).

\subsubsection{Processo eletroquímico}

Dentre os inúmeros métodos ou metodologias para tratamento eficaz da remoção de compostos orgânicos, destaca-se o tratamento eletroquímico, devido a algumas de suas características específicas, tais como versatilidade, fácil automação, eficácia, custo energético e taxas de remoção, etc. (IBANEZ et al., 1994).

a) Versatilidade: o métodos eletroquímicos são aplicáveis a uma grande variedade de meios, concentrados ou diluídos, e poluentes, biológicos ou não, encontrados em gases, líquidos e sólidos. Além disso, os tratamentos eletroquímicos podem ser adaptados a diferentes projetos, visando a otimização do espaço físico disponível para as instalações de tratamento, permitindo o tratamento de pequenas quantidades (microlitros) até grandes volumes (milhões de litros).

b) Eficiência energética: esses processos geralmente requerem controle de temperatura, que em geral são baixos (em torno da temperatura ambiente de $25{ }^{\circ} \mathrm{C}$ ) quando comparados às técnicas não eletroquímicas, por examplo incineração térmica. O potencial de célula pode ser controlado facilmente por meio do uso de multímetros, sendo este um parâmetro operacional monitorado com a finalidade de minimizar as perdas de eficiência do processo;

c) Disponibilidade para automação: as variáveis elétricas utilizadas nos processos eletroquímicos, tais como densidade de corrente aplicada e potenciais ( $\left.j a_{p p}, E\right)$, são particularmente ajustadas para facilitar a aquisição de dados, a automação e o controle do processo;

d) Compatibilidade com o meio ambiente: o elétron é um reagente "limpo" e muito efetivo para oxidação de compostos orgânicos, cuja reatividade e eficácia podem ser ajustadas através da escolha de um material eletródico adequado;

e) Relação custo/benefício: os equipamentos e as operações necessárias são geralmente simples e de baixo custo. Todavia, diversas considerações devem ser estudadas para se 
obter o máximo de eficiência. Com base nas razões expostas acima, a técnica eletroquímica pode ser considerada como uma alternativa para se prevenir problemas relacionados à poluição ambiental. Assim, continuam ocorrendo atividades intensas de pesquisa com o objetivo de se descobrir técnicas mais eficientes, processos, materiais, tecnologias e aplicações eletroquímica com o intuito de realizar a biorremediação.

As tecnologias eletroquímicas vêm ganhando importância no mundo durante as duas últimas décadas, uma vez que, ao não ser comparáveis com outras tecnologias somente em termos de custo, podem se apresentar às vezes mais eficientes e compactas. A mais comum das tecnologias eletroquímicas é a oxidação eletroquímica, apresentando-se como uma alternativa para se realizar o tratamento de águas residuárias. A oxidação eletroquímica pode ser dividida em basicamente três formas: oxidação direta, oxidação indireta - mediada por radicais hidroxila $\left({ }^{\bullet} \mathrm{OH}\right)$ - e oxidação indireta, mediada por outras espécies oxidantes advindas de sais inorgânicos. Os mecanismos estão descritos no item a seguir.

\subsubsection{Mecanismos de oxidação eletroquímica}

A eletro-oxidação de poluentes orgânicos pode ser realizada de diversas maneiras, dentre elas, destacam-se as oxidações direta e indireta, de acordo com a Figura 1.4, Além disso, tem-se observado de maneira geral que a natureza do material do eletrodo, as condições experimentais e a composição do eletrólito, influenciam significativamente o mecanismo da oxidação (PANIZZA, 2010).

Na eletrólise direta, os poluentes são oxidados após ocorrer sua adsorção na superfície do ânodo ou eletrodo de trabalho, não sendo necessário, o envolvimento de quaisquer outras substâncias além do elétron, pois baseia-se num mecanismo de transferência direta de carga. Assim, a eletro-oxidação direta é favorecida para valores baixos de corrente ou potencial, antes que comecem a ocorrer as chamadas reações paralelas, tais como geração de $\mathrm{O}_{2}$ ou formação de $\mathrm{H}_{2} \mathrm{O}_{2}$.

A cinética das reações de oxidação depende da atividade eletrocatalítica do ânodo, bem como da reatividade dos intermediários formados. Os valores elevados da velocidade de reação para oxidação de compostos orgânicos, em que são utilizados métodos eletroquímicos, têm sido observados em estudos onde são empregados como ânodo metais nobres como a platina, paládio. 

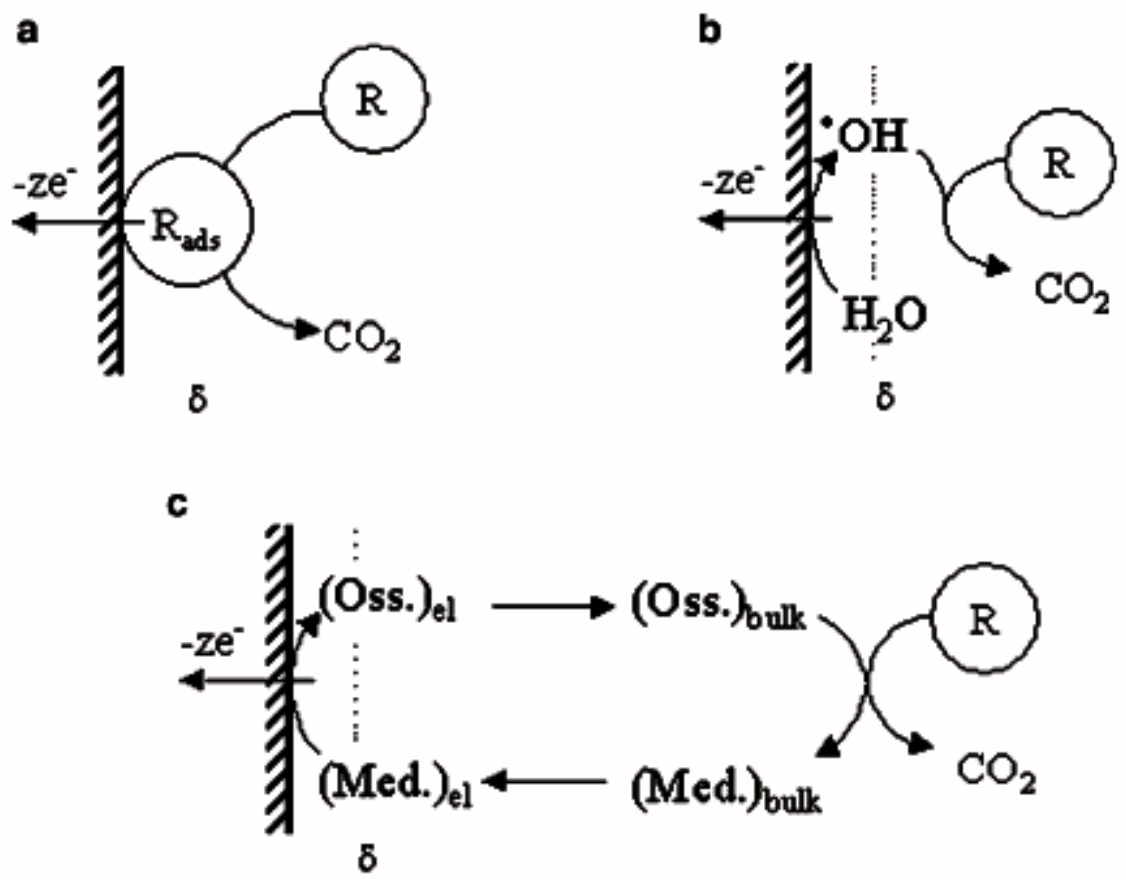

Figura 1.4 - Esquema dos processos eletroquímicos que permitem a remoção de compostos orgânicos

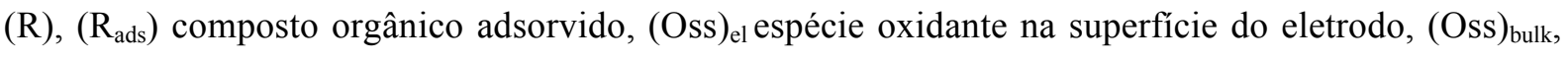
espécie oxidante na seio da solução, (Med) el $_{\text {na superfície do eletrodo (Med) bulk }}$ na seio da solução

(a) eletrólise direta; (b) via radicais hidroxila produzido pela aplicação de descarga elétrica da água; (c) via mediadores inorgânicos.

Fonte: Panizza, M. Importance of electrode material in the electrochemical treatment of wastewater containing organic pollutants. in: Comninellis, C.; Chen G.H. (Eds.), Electrochemistry for the Environment, Springer, New York, 2010, p. 25, Ch. 2.

Os ânodos constituídos por óxidos metálicos mistos, como no caso do dióxidos de irídio, o dióxido de rutênio-titânio e o dióxido de irídio-titânio que são os conhecidos ânodos dimensionalmente estáveis (ADE).

No entanto, o principal problema associado à eletro-oxidação anódica é a diminuição da atividade catalítica ao longo do processo, o que é comumente chamado de envenenamento, devido à formação de uma camada polimérica sobre a superfície do eletrodo.

$\mathrm{Na}$ eletrólise indireta, os poluentes são oxidados por meio de reações que ocorrem através da mediação de algumas espécies redox, tais como os radicais hidroxila, que são denominados intermediários reativos. As principais exigências para se obter eficiência elevada em processos eletroquímicos são:

a) O potencial de geração das espécies intermediárias não deve ser próximo àquele em que as reações paralelas começam a ocorrer;

b) A velocidade de geração das espécies eletroativas deve ser elevada; 
c) A adsorção de poluentes deve ser minimizada.

Os mediadores de oxidação podem ser redox metálicos, tais como: $\mathrm{Ag}(\mathrm{II}), \mathrm{Ce}(\mathrm{IV})$, $\mathrm{Co}(\mathrm{III}), \mathrm{Fe}(\mathrm{III})$, e o $\mathrm{Mn}(\mathrm{III})$, ou agentes oxidantes fortes como: cloro ativo, ozônio, peróxido de hidrogênio, persulfato $\left(\mathrm{S}_{2} \mathrm{O}_{8}{ }^{2-}\right)$, percarbonato $\left(\mathrm{C}_{2} \mathrm{O}_{6}{ }^{2-}\right)$ e o perfosfato $\left(\mathrm{P}_{2} \mathrm{O}_{8}{ }^{4-}\right)$ (PANIZZA; CERISOLA, 2009).

Como já discutido anteriormente, a natureza do material constituinte do eletrodo influencia tanto a seletividade como a eficiência do processo. Alguns ânodos favorecem as oxidações parciais e seletivas de alguns tipos de poluentes, enquanto outros favorecem a combustão completa ou mineralização, como é o caso dos eletrodos de diamante dopado como boro (DDB), e os eletrodos pode ser classificados como eletrodos ativos e inativos (COMNINELLIS, 1994; COMNINELLIS; DEBATTISTI, 1996; SIMOND et al., 1997; FÓTI 1999).

Como regra geral, os ânodos com um baixo sobrepotencial de evolução de oxigênio, ou seja, os ânodos que são bons catalisadores como o $\mathrm{IrO}_{2}, \mathrm{RuO}_{2}$, ou platina, apresentam comportamento "ativo" e permitem que ocorra somente a oxidação parcial de compostos orgânicos. Já os ânodos com um elevado sobrepotencial de evolução de oxigênio - o óxido de estanho dopado com antimônio, o dióxido de chumbo ou o diamante dopado com boro (DDB) - , apresentam comportamento "inativo" e favorecem a oxidação completa dos compostos orgânicos a $\mathrm{CO}_{2}$, sendo eletrodos ideais para que se realize o tratamento de efluentes. Comninellis (1994) propôs um modelo teórico para a oxidação dos compostos orgânicos, que é descrito por meio das equações $(1.1-1.4)$ :

$\mathrm{MO}_{x}+\mathrm{H}_{2} \mathrm{O} \rightarrow \mathrm{MO}_{x}(\mathrm{HO} \bullet)+\mathrm{H}^{+}+e^{-}$

(a) Em eletrodos ativos há inicialmente a formação de radicais hidroxila adsorvidos sob a superfície em presença de água (equação 1.1). Posteriormente, os óxidos superiores podem ser formados devido à interação entre o ânodo e os radicais hidroxila adsorvidos (equação $1.2)$.

$M O_{x}(H O \bullet) \rightarrow M O_{x+1}+H^{+}+e^{-}$

$\mathrm{O}$ par redox $\mathrm{MO}_{\mathrm{x}} / \mathrm{MO}_{\mathrm{x}+1}$, denominado por "oxigênio ativo" e quimicamente adsorvido pode atuar como mediador da oxidação seletiva de compostos orgânicos em ânodos ativos:

$M O_{x+1}+R \rightarrow M O_{x}+R O$

(b) Em eletrodos não ativos, onde não há formação de óxidos superiores, os radicais hidroxila adsorvidos, conhecidos por "oxigênios ativos" fisicamente adsorvidos, assim como os íons 
metálicos oxidados podem provocar a oxidação não seletiva de compostos orgânicos, sendo possível levar até à combustão completa a $\mathrm{CO}_{2}$ :

$M O_{x}(\mathrm{HO} \bullet)+R \rightarrow \mathrm{MO}_{x}+m \mathrm{CO}_{2}+n \mathrm{H}_{2} \mathrm{O}+\mathrm{H}^{+}+e^{-}$

Entretanto, ambos os mecanismos podem competir com a reação de evolução de oxigênio, reduzindo a eficiência da oxidação anódica.

\subsubsection{2 Ânodos dimensionalmente estáveis}

Os ânodos dimensionalmente estáveis (ADE), descobertos por Beer em 1960, são constituídos por uma base metálica de titânio recoberta por uma fina camada condutora de um óxido metálico ou mistura de óxidos metálicos que podem ser ativos ou inativos, dependendo de sua natureza química.

$\mathrm{O}$ desenvolvimento dos ânodos revestidos com camadas de $\mathrm{RuO}_{2}$ e $\mathrm{TiO}_{2}$ trouxe melhorias significativas para a indústria de produção de cloro e soda $\left(\mathrm{ADE}-\mathrm{Cl}_{2}\right)$ Trasatti (2000), enquanto ânodos revestidos com $\mathrm{IrO}_{2}$ são utilizados comercialmente para a realização de reações de evolução de oxigênio $\left(\right.$ ADE- $\left.\mathrm{O}_{2}\right)$ em meios ácidos, como também nos processos eletroquímicos de eletrólise da água e a extração eletroquímica de metais.

Recentemente, os ânodos do tipo $\mathrm{ADE}$, com um revestimento de composição diferente, também têm sido estudados para aplicações relacionadas às oxidações de compostos orgânicos. Eletrodos com composição $\mathrm{Ti} / \mathrm{Ru}_{0,3} \mathrm{Ti}_{0,7} \mathrm{O}_{2}$ são utilizados na indústria de produção de cloro soda há muitos anos, onde o óxido de rutênio é o catalisador, proporcionando também uma maior condutividade elétrica e melhorando a atividade eletrocatalítica relacionada à reação de liberação do cloro, sendo que o titânio proporciona estabilidade mecânica.

As espécies de cloro e cloro-oxigênio, tais como $\mathrm{HClO}$ e $\mathrm{ClO}^{-}$, são formadas durante o processo eletroquímico quando se utiliza ânodos do tipo ADE, assim, são uma alternativa para a oxidação indireta de compostos orgânicos, e ainda apresentam algumas vantagens (RAJESHWAR; IBANEZ 1997; MARTÍNEZ-HUITLE; BRILLAS 2008).

- Evitam que ocorra o transporte e o armazenamento do cloro, que é tóxico;

- Facilitam uma mineralização mais rápida da matéria orgânica.

A principal desvantagem desse tipo de oxidação indireta é que provavelmente haverá formação de compostos orgânicos clorados, resultando em uma maior toxicidade da solução ou do efluente final. Em um estudo de Panizza; Cerisola (2003) foi relatado a detecção de uma pequena quantidade de compostos organoclorados durante a eletrólise do 2-naftol que 
estavam presentes em concentrações máximas, em torno de $9 \mathrm{~A} \mathrm{~h} \mathrm{dm}^{-3}$.

Por outro lado, foi demonstrado que ao se otimizar algumas condições experimentais, a glicose pôde ser incinerada por meio da eletrólise mediada pelo cloro, sem que houvesse formação de compostos clorados (BONFATTI et al., 2000). Em outro estudo recente realizado por Malpass et al. (2011), revelou-se que nenhuma toxicidade foi observada em amostras de herbicida atrazina, tratada com o método eletroquímico fotoassistido em ânodos de ADE, utilizando cloreto de sódio ou sulfato de sódio como eletrólitos suporte.

Apesar da ampla utilização de espécies cloradas, como mediadoras redox, os mecanismos das reações químicas e eletroquímicas que ocorrem para oxidação de poluentes em meios que contenham cloro são complexos.

De fato, a transferência de oxigênio para as moléculas orgânicas pode ser alcançada, tanto na superfície do elétrodo, por de adsorção dos espécies de cloro e oxychloro quanto no seio da solução, por meio de oxidantes estáveis (tais como cloro, ácido hipocloroso ou hipoclorito), anodicamente gerados através da oxidação dos íons cloreto, de acordo com as reações $(1.5-1.8)$.

$$
\begin{aligned}
& 2 \mathrm{Cl}^{-} \rightarrow \mathrm{Cl}_{2}+2 e^{-} \\
& 2 \mathrm{H}_{2} \mathrm{O} \rightarrow 2 \mathrm{OH} \cdot+2 \mathrm{H}^{+}+2 e^{-} \\
& \mathrm{Cl}_{2}+\mathrm{H}_{2} \mathrm{O} \rightarrow \mathrm{HOCl}+\mathrm{H}^{+}+\mathrm{Cl}^{-} \\
& \mathrm{HOCl} \rightarrow \mathrm{H}^{+}+\mathrm{OCl}^{-}
\end{aligned}
$$

A explicação da função dos íons cloreto como mediadores e um possível mecanismo de reação para a oxidação de compostos orgânicos foi proposta por alguns pesquisadores, de acordo com o esquema apresentado na Figura 1.5 (BONFATTI et al., 2000).

O mecanismo é uma adaptação do estudo de reações da transferência eletroquímica do oxigênio proposto por Comninellis (1994), considerando que a transferência de oxigênio é realizada por meio das espécies oxi-cloro adsorvidas, que são intermediários relacionados com as reações em que há liberação de cloro, ao invés dos radicais hidroxila. 


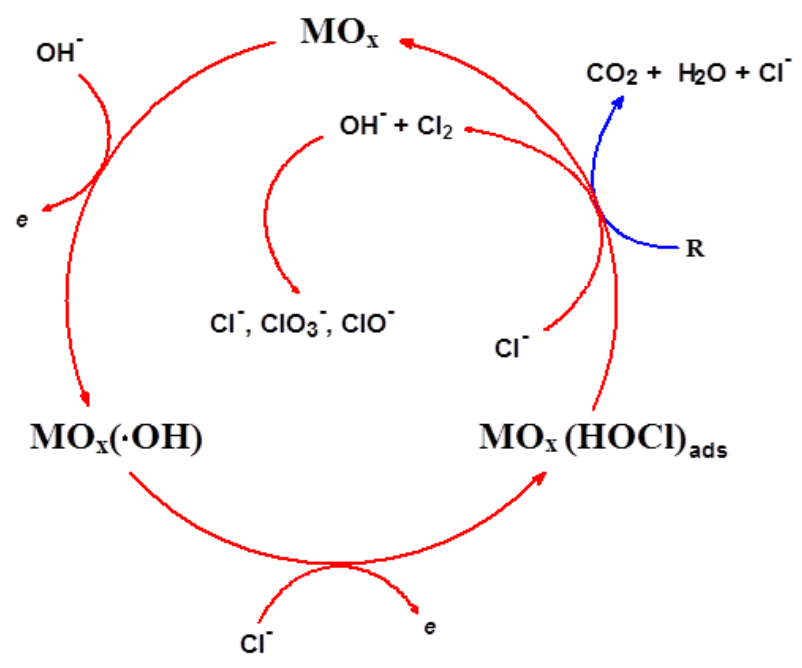

Figura 1.5 - Esquema do mecanismo de oxidação de orgânico na ADE no meio cloreto.

Fonte: Electrochemical Incineration of Glucose as a Model Organic Substrate. II. Role of Active Chlorine Mediation. F. Bonfatti, S. Ferro, F. Lavezzo, M. Malacarne, G. Lodil and A. De Battisti J. Electrochem. Soc. 2000 volume 147, issue 2, 592-596

A presença dos íons cloreto aparentemente inibe a reação de evolução do oxigênio, resultando em um aumento do potencial no ânodo e, por conseguinte, sendo registrada uma maior reatividade dos radicais cloreto-oxi-cloreto adsorvidos. Observou-se também que a oxidação dos compostos orgânicos na presença de íons cloreto depende principalmente da concentração do clorito, da temperatura da solução e do pH.

$\mathrm{Na}$ literatura está descrito que os eletrodos mais utilizados para geração in situ de espécies de cloro ativo são os de platina ou de mistura de óxidos metálicos (por exemplo: $\mathrm{RuO}_{2}, \mathrm{TiO}_{2}$, e $\mathrm{IrO}_{2}$ ), pois estes apresentam boas propriedades eletrocatalíticas e estabilidade mecânica e química, permitindo uma liberação significativa do cloro, especialmente quando se utiliza solução de $\mathrm{NaCl}$ como um eletrólito suporte (RAJKUMAR; KIM 2006; CHEN et al., 2011). Assim, devido a essas características e potencial eficiência no tratamento eletroquímico, tais eletrodos vêm sendo empregados em inúmeras degradações de compostos orgânicos em nosso grupo, tais como a atrazina (MALPASS et al., 2010), carbaril (MALPASS et al., 2009), corantes (MALPASS et al., 2008), entre outros.

\subsubsection{Processo foto-eletroquímico}

A eficiência de um processo eletroquímico pode ser aumentada através do acoplamento com a radiação ultravioleta (UV), sendo que tal processo é conhecido como processo foto-eletroquímico ou foto-eletrocatalítico. 
Há vários semicondutores como $\mathrm{TiO}_{2}, \mathrm{ZnO}, \mathrm{WO}_{3}$ etc, que podem ser utilizados no processo fotocatalítico na forma de suspensão, sendo que o processo não depende muito da transferência de massa. No entanto, é necessário realizar a filtração da suspensão semicondutora na fase final, o que corresponde a uma etapa difícil, considerando-se uma escala industrial.

A forma nanocristalina do $\mathrm{TiO}_{2}$, conhecida como anatase, é um material semicondutor empregado em processos foto-catalíticos para oxidação de poluentes orgânicos em águas residuárias. Esse tipo de aplicação apresenta algumas vantagens, tais como: baixo custo, baixa toxicidade e boa estabilidade, além de impedir a ocorrência da foto-corrosão (PERALTAHERNÁNDEZ et al., 2006).

A fotocatálise envolve a irradiação das nanopartículas coloidais de $\mathrm{TiO}_{2}$ da anatase em suspensão ou depositadas na forma de um filme fino sobre o Ti, pelos fótons da radiação UV de energia suficiente $(\lambda<380 \mathrm{~nm})$, de tal forma que haja a promoção de um elétron da banda de valência para a banda de condução $\left(e_{b c}^{-}\right)$, gerando lacuna (do inglês hole, que também tem sido traduzido como buraco) de carga positiva $\left(h_{b v}^{+}\right)$, como indicado abaixo (PERALTAHERNÁNDEZ et al.. 2006; ROBERT; MALATO, 2002).

$$
\mathrm{TiO}_{2}+h v \rightarrow e_{b c}^{-}+h_{b v}^{+}
$$

Os compostos orgânicos podem ser oxidados diretamente pela lacuna ou através do radical hidroxila formado a partir da reação entre a lacuna fotogerada e molécula de água adsorvida.

$$
h_{b v}^{+}+H_{2} O_{(a d s)} \rightarrow H O_{(a d s)}+H_{(a d s)}^{+}
$$

Além disso, espécies menos reativas como o íon radical superóxido $\mathrm{O}^{2-} \bullet, \mathrm{HO}_{2} \bullet, \mathrm{H}_{2} \mathrm{O}_{2}$, além do radical $\bullet \mathrm{OH}$ podem ser produzidos a partir dos elétrons foto-gerados, de acordo com as equações abaixo descritas (XIE; LI, 2006).

$$
\begin{aligned}
& \mathrm{O}_{2(a d s)}+e_{b c}^{-} \rightarrow \mathrm{O}_{2(a d s)}^{--} \\
& \mathrm{O}_{2(a d s)}^{--}+\mathrm{H}^{+} \leftrightarrow \mathrm{HO}_{2(a d s)}^{-} \\
& 2 \mathrm{HO}_{2(a d s)} \rightarrow \mathrm{H}_{2} \mathrm{O}_{2(a d s)}+\mathrm{O}_{2}
\end{aligned}
$$




$$
\begin{aligned}
& \mathrm{H}_{2} \mathrm{O}_{2}+h v \rightarrow 2 \mathrm{HO} . \\
& \mathrm{H}_{2} \mathrm{O}_{2}+\mathrm{O}_{2(\text { ads })}^{-} \rightarrow \mathrm{O}_{2}+\mathrm{HO}^{-}
\end{aligned}
$$

Uma redução na eficiência da fotocatálise pode ser justificada pela recombinação dos elétrons promovidos à banda de condução, ou graças às "lacunas" que não tenham reagido com os radicais hidroxila adsorvidos (PERALTA-HERNÁNDEZ et al., 2006).

$$
\begin{aligned}
e_{b c}^{-}+h_{b v}^{+} & \rightarrow \mathrm{TiO}_{2}+\text { Calor } \\
e_{b c}^{-}+\mathrm{HO} & \rightarrow \mathrm{HO}^{-}
\end{aligned}
$$

A tecnologia eletroquímica pode ser associada ao processo fotolítico para proporcionar um aumento na eficiência (sinergismo) de tratamentos aplicados para remediação de águas residuárias. Esse processo acoplado é denominado método foto assistido, que consiste na aplicação de um valor constante de corrente (i) ou de um potencial anódico $\left(E_{\text {anod }}\right)$ a um ânodo de $\mathrm{TiO}_{2}$, tal como o $\mathrm{ADE}^{\circledR}$, o qual é submetido à irradiação UV.

Durante o processo de geração de elétrons fotoinduzidos, pode ocorrer inibições das reações (1.11 - 1.16), além do favorecimento da produção de uma maior quantidade de "lacunas" a partir da reação $(1.9)$ e da espécie $(\bullet \mathrm{OH})$ relacionada à reação heterogênea $(1.10)$, aumentando significativamente as oxidações dos compostos orgânicos se comparados à fotocatálise (XIE; LI, 2006; ZANONI et al., 2003; PERALTA-HERNÁNDEZ et al., 2006).

Os ânodos foto ativo mais típicos e utilizados são redes de Ti ou placas revestidas com $\mathrm{TiO}_{2}$ (CARNEIRO et al., 2005; ZAINAL et al., 2005; CARNEIRO et al., 2004), ou o $\mathrm{Ti} / \mathrm{Ru}_{0,3} \mathrm{Ti}_{0,7} \mathrm{O}_{2}$ (SOCHA et al., 2005; SOCHA et al. 2006; SOCHA et al., 2007; PELEGRINI et al., 1999; CATANHO et al., 2006b), que podem ser utilizados em uma célula constituída por três eletrodos sob condições potenciostáticas, pois são estáveis quando submetidos a valores de baixas densidades de corrente, e também podem ser utilizados em reatores com dois eletrodos. Nesses processos, as eficiências da degradação e mineralização são determinadas pelas porcentagens de remoção do DQO e/ou COT.

Diversos parâmetros podem influenciar na eficiência da degradação fotoeletroquímica, dentre eles, tem-se o $\mathrm{pH}$ e a concentraçãos dos poluentes, sendo o mais importante a natureza do eletrólito suporte. Vários estudos descrevem que os eletrodos do tipo $\mathrm{ADE}^{\circledR}$ é um dos mais eficientes para a remoção de compostos orgânicos na presença do $\mathrm{NaCl}$, devido à formação de espécies oxidantes secundárias, conforme observado nas equações 1.18 a 1.20. (FENG et al., 2007; CATANHO et al., 2006b) 


$$
\begin{aligned}
& \mathrm{Cl}-\mathrm{OH}+h v \rightarrow \mathrm{Cl} \bullet+\bullet \mathrm{OH} \\
& \mathrm{Cl}-\mathrm{O}-+h v \rightarrow \mathrm{Cl}+\mathrm{O}^{\bullet} \\
& \mathrm{Cl}-\mathrm{Cl}+\mathrm{hv} \rightarrow 2 \mathrm{Cl} \bullet
\end{aligned}
$$

Os radicais livres oxidam e mineralizam as substâncias orgânicas, o que é mais eficiente do que o processo eletroquímico puro. Além disso, as substâncias fotoativas podem sofrer clivagem em solução, o que aumenta a velocidade e a eficiência da reação de oxidação, além de permitir as rupturas das ligações $\mathrm{C}-\mathrm{Cl}$ em compostos orgânicos clorados. Tal fato origina espécies que são oxidantes fortes, aumentando assim a eficiência do processo.

A combinação do processo eletroquímico e da radiação UV colabora para um efeito sinérgico significativo no processo acoplado, e esse sinergismo pode ser explicado segundo alguns fatores, a saber:

a) Devido à presença de fótons com alta energia (raios UV), o potencial aplicado externamente pode contribuir para que ocorra a diminuição do processo de recombinação do pares elétron/lacuna $(\mathrm{e}-/ \mathrm{h}+)$;

b) Os fótons da radiação UV atingem a superfície do eletrodo durante as etapas eletroquímicas, podendo formar os radicais no estado excitado, representados como $\mathrm{MO}_{\mathrm{X}}(\bullet \mathrm{OH})$, podendo estes aumentar a degradação;

$M O_{x}(\cdot \mathrm{OH})+h v \rightarrow M O_{x}(\cdot \mathrm{OH})^{*}$

c) A fotoativação das espécies oxidantes secundárias geradas eletroquimicamente, o $\mathrm{H}_{2} \mathrm{O}_{2} \mathrm{e}$ $\mathrm{O}_{3}$, de acordo com as seguintes equações:

$\mathrm{H}_{2} \mathrm{O}_{2} \rightarrow 2 \cdot \mathrm{OH}$

$\mathrm{H}_{2} \mathrm{O}+\mathrm{O}_{3} \rightarrow 2 \cdot \mathrm{OH}+\mathrm{O}_{2}$

As duas primeiras possibilidades estão relacionadas à catálise heterogênea, enquanto a última está relacionada com a catálise homogênea. O processo eletroquímico fotoassistido, em geral, é mais eficiente do que o eletroquímico, permitindo a oxidação eficiente de diversos contaminantes orgânicos (PELEGRINI; BERTAZZOLI, (2002); ALVES et al., 2010). 


\subsubsection{Processo fotoquímico}

A energia da luz corresponde a uma alternativa importante para se realizar o tratamento de águas residuárias, considerando-se que a maioria das substâncias químicas absorvem a luz, de forma que podem ocorrer reações fotoquímicas e as degradações de moléculas orgânicas. Ao se trabalhar com os processos foto-assistidos, como o foto-Fenton e os foto-eletroquímicos, é essencial que se faça o estudo da influência da fotólise separadamente.

A decomposição ou a dissociação fotoquímica de compostos químicos é causada pela luz natural ou artificial, sendo que dois tipos de processos foto-induzidos são comumente aplicados, ou seja, processos de fotólise direto e indireto. No caso da fotólise direta, os compostos orgânicos absorvem a luz ultravioleta e podem reagir com os componentes da água (matriz) ou sofrer autodecomposição (BOREEN et al., 2004; GIOKAS; VLESSIDIS, 2007, JIAO et al., 2008; TROVÓ et al., 2009).

Já a fotólise indireta envolve a foto-degradação de compostos orgânicos graças à presença de fotossensibilizadores, como o oxigênio, radical hidroxila ou grupo peroxil (ARSLAN-ALATON; DOGRUEL, 2004; GIOKAS; VLESSIDIS, 2007). Esses oxidantes podem ser produzidos através das fotólises de substâncias húmicas e inorgânicas presentes na água, através da adição do peróxido de hidrogênio (clivagem homolítica do peróxido de hidrogênio, produzindo os radicais hidroxila) ou através do ozônio. Embora ambos os processos (diretos e indiretos) possam ocorrer simultaneamente, a fotólise indireta desempenha o papel mais importante, em termos de meia-vida dos contaminantes (GIOKAS; VLESSIDIS, 2007).

O desempenho da fotólise depende do espectro de absorção do composto alvo, da intensidade da radiação e da frequência, das concentrações de espécies como $\mathrm{H}_{2} \mathrm{O}_{2}$ e $\mathrm{O}_{3}$ (quando empregados) e do tipo de matriz. As águas naturais contêm diferentes substâncias que podem inibir ou estimular o processo de degradação (matéria orgânica), ou que podem gerar espécies oxidantes (substâncias húmicas e as inorgânicas, como os metais dissolvidos).

Essa técnica provou ser a menos eficaz do que as outras, mas quando a radiação é combinada com o peróxido de hidrogênio, o ozônio ou catalisadores e assim, vem sendo considerada como um método eficiente para a degradação de antibióticos no ambiente aquático (HOMEM; SANTOS, 2011). 
A fotólise também pode realizada com radiação solar, em que somente os compostos fotossensíveis são facilmente degradados (JIAO et al. 2008). Foram testadas as influências da matéria orgânica dissolvida, particularmente dos ácidos húmicos, no tratamento com fotólise.

Essas pesquisas provaram que a fotólise foi aumentada quando a matéria orgânica estava presente em baixas concentrações (HOMEM; SANTOS, 2011). No entanto, para valores de concentrações relativamente elevados, houve um efeito inibitório, pois os ácidos húmicos se comportaram como filtros para a irradiação. Alguns autores descrevem a degradação de vários antibióticos através da fotólise, tais como as quinolonas e as sulfonamidas, entretanto, a porcentagem das remoções são baixas (ARSLAN-ALATON; DOGRUEL, 2004).

Ao se comparar o método fotoquímico com outros como foto-Fenton, catalise hetrogêneo, nota-se que ele é relativamente ineficaz quanto aos tratamentos das matrizes aquosas contaminadas com antibióticos. Essa tecnologia só é aplicável às águas residuárias contendo compostos fotossensíveis e águas com valores baixos de concentração de DQO, por exemplo, as águas de rios e a água potável (HOMEM; SANTOS, 2011).

\subsubsection{Processos Fenton e foto-Fenton}

Em 1894, Henry John Horstman Fenton desenvolveu o reagente de Fenton, que é uma solução de peróxido de hidrogênio com íons ferrosos com propriedades oxidantes muito fortes. A oxidação do tipo Fenton pode ocorrer em sistemas homogêneos ou heterogêneos, embora a oxidação homogênea seja a mais empregada (FENTON, 1894) .

A partir deste reagente os radicais hidroxila são formados através de um mecanismo radicalar. As principais etapas relacionadas ao mecanismo reacional $(1.24$ a 1.28), (ANDREOZZI et al., 1999; ARSLAN-ALATON; GURSES, 2004; BRITTO; RANGEL, 2008).

$$
\begin{aligned}
& \mathrm{Fe}^{2+}+\mathrm{H}_{2} \mathrm{O}_{2} \rightarrow \mathrm{Fe}^{3+}+\mathrm{OH}^{-}+\cdot \mathrm{OH} \\
& \mathrm{Fe}^{3+}+\mathrm{H}_{2} \mathrm{O}_{2} \rightarrow \mathrm{H}^{+}+\mathrm{Fe}(\mathrm{OOH})^{2+} \\
& \mathrm{Fe}\left(\mathrm{OH}_{2}\right)_{2} \rightarrow \mathrm{Fe}^{2+}+\mathrm{HO}_{2} \cdot \\
& \mathrm{FeOH}{ }^{2+}+\mathrm{H}_{2} \mathrm{O}_{2} \rightarrow \mathrm{Fe}(\mathrm{OH})\left(\mathrm{HO}_{2}\right)^{+}+\mathrm{H}^{+} \\
& \mathrm{Fe}(\mathrm{OH})\left(\mathrm{HO}_{2}\right)^{+} \rightarrow \mathrm{Fe}^{2+}+\mathrm{HO}_{2}+\mathrm{OH}^{-} \\
& \bullet \mathrm{OH}+\text { matéria orgânica } \rightarrow \mathrm{H}_{2} \mathrm{O}+\text { produtos de degradação } \rightarrow \mathrm{CO}_{2}+\mathrm{H}_{2} \mathrm{O}
\end{aligned}
$$


A eficiência do processo está intimamente relacionada ao $\mathrm{pH}$ da solução, cujos valores ideais estão entre 2 e 4, assim como a concentração do $\mathrm{H}_{2} \mathrm{O}_{2}$, que é o catalisador do meio reacional. As otimização de concentração do catalisador e do agente oxidante em relação à quantidade de poluente no efluente, faz com que esse processo seja adequado para se tratar efluentes hospitalares, por exemplo. Na maioria dos casos, a oxidação Fenton é capaz de resultar na mineralização de uma fração significativa do poluentes, provocando a formação de efluentes que estão menos tóxicos, podendo então ter sua eficiência aumentada quando acoplado a outros processos, como o biológico.

Geralmente, a maioria dos estudos relacionados com a aplicação dos processos Fenton e foto-Fenton para remediação de efluentes que contenham fármacos, consiste em sistemas reacionais homogêneos. Assim, há algumas preocupações quanto ao uso de sais ferrosos ou férricos, uma vez que há desvantagens relacionadas à faixa de $\mathrm{pH}$, a qual deve estar em torno de 2 a 4 para evitar a formação e posteriores precipitações dos oxi-hidróxidos de ferro (MELO et al., 2009).

Há também a questão do ferro residual que permanece no meio reacional. Assim, a imobilização do catalisador heterogêneo Fenton em uma determinada matriz torna possível seu emprego sob condições sem a necessidade de controle de $\mathrm{pH}$, facilitando também a recuperação desse catalisador no efluente tratado.

A eficiência do processo Fenton é aumentada pela combinação com radiação UV, sendo que o processo é chamado de foto-Fenton (BAUTITZ; NOGUEIRA, 2010). O emprego da radiação pode aumentar a eficiência do processo devido principalmente à regeneração do íon ferroso e à produção adicional de radicais hidroxila (Equação 1.30):

$\mathrm{Fe}(\mathrm{OH})^{2+}+h v \rightarrow \mathrm{Fe}^{2+}+\mathrm{HO}$

Também é possível que ocorra a produção de radicais hidroxila diretamente através da fotólise do tipo $\mathrm{H}_{2} \mathrm{O}_{2} / \mathrm{UV}$. Assim, a utilização da radiação solar constitui uma vantagem, uma vez que diminui significativamente o custo total do tratamento. Como descrito anteriormente, as eficiências desses processos são afetadas principalmente pelos seguintes fatores: $\mathrm{pH}$, temperatura, catalisador, o peróxido de hidrogênio e a concentração do poluente a ser degradado. De fato, o $\mathrm{pH}$ é uma variável extremamente importante que pode influenciar a eficiência dos processos Fenton e foto-Fenton.

Para os valores de pH abaixo de 3, a reação de Fenton (Equação 1.24) é afetada severamente, resultando na redução das quantidades dos radicais hidroxila em solução. $\mathrm{O}$ peróxido de hidrogênio é mais estável em valores baixos de $\mathrm{pH}$, devido às formação dos 
íons oxônio $\left(\mathrm{H}_{3} \mathrm{O}^{+}\right)$, o que aumenta sua estabilidade e, presumivelmente, reduz muito sua reatividade com os íons ferrosos.

Alguns autores também sugerem que em valores baixos de $\mathrm{pH}$ a quantidade da espécie $\mathrm{Fe}^{3+}$, que é solúvel, diminui, inibindo a formação do radical $\bullet \mathrm{OH}$. Por outro lado, o valor de $\mathrm{pH}$ igual a 1, 2, provoca uma inibição da formação de radicais hidroxila, devido a um consumo de íons $\mathrm{H}^{+}$(LUCAS; PERES, 2006).

$\mathrm{HO} \bullet+\mathrm{H}^{+}+e^{-} \rightarrow \mathrm{H}_{2} \mathrm{O}$

Para valores de $\mathrm{pH}$ acima de que 4, ocorre precipitações de oxi-hidróxidos, o que inibe tanto a regeneração de espécies ativas de $\mathrm{Fe}^{2+}$, quanto a formação de radicais hidroxila (ELDESOKY et al. 2010). Além disso, um aumento excessivo no $\mathrm{pH}$ promove a formação do íons $\mathrm{HO}^{2-}$ e o consumo dos radicais $\bullet \mathrm{OH}$, isso em razão dos íons carbonato e bicarbonato. Tal faixa operacional de $\mathrm{pH}$ - que é estreita - constitui uma desvantagem, assim como a necessidade comum de se recuperar o catalisador dissolvido. O sistema heterogêneo preenche essas lacunas, pois o catalisador é imobilizado na matriz heterogênea, o que permite que se possa trabalhar em toda a faixa de valores de $\mathrm{pH}$, além de permitir a recuperação do catalisador do efluente tratado (BOBU et al. 2008).

Geralmente, o aumento da temperatura afeta positivamente os processos Fenton e foto-Fenton, pois também resulta num aumento da energia cinética, acelerando, consequentemente, a velocidade da reação. No entanto, também é possível acelerar o processo de decomposição do peróxido de hidrogênio ao se diminuir a quantidade disponível que pode reagir como:

$2 \mathrm{H}_{2} \mathrm{O}_{2} \rightarrow 2 \mathrm{H}_{2} \mathrm{O}+\mathrm{O}_{2}$

A redução da eficiência do processo também pode ocorrer se for empregado um excesso de peróxido de hidrogênio. Assim, tem-se que as recombinações dos radicais hidroxila (Equações 1.33 e 1.35) e a reação entre eles e o peróxido de hidrogênio (Equação 1.35) poderiam explicar este fato:

$$
\begin{aligned}
& \mathrm{HO} \bullet+\mathrm{HO} \rightarrow \mathrm{H}_{2} \mathrm{O}_{2} \\
& \mathrm{HO} \bullet+\mathrm{HO}_{2} \bullet \rightarrow \mathrm{H}_{2} \mathrm{O}+\mathrm{O}_{2} \\
& \mathrm{HO} \bullet+\mathrm{H}_{2} \mathrm{O}_{2} \rightarrow \mathrm{HO}_{2} \bullet+\mathrm{H}_{2} \mathrm{O}
\end{aligned}
$$


Os processos de Fenton e foto-Fenton são atraentes, pois neles há o emprego de reagentes que apresentam custos baixos, além do fato de que o ferro é abundante e é um elemento que não é tóxico. Além disso, o peróxido de hidrogênio pode ser manuseado de uma maneira simples. Diversos estudos têm sido realizados em termos da aplicabilidade dessas duas técnicas em classes diferentes de antibióticos, tais como: $\beta$-lactâmicos (ARSLANALATON; DOGRUEL, 2004; TROVÓ et al., 2008; SHEMER et al., 2006; BAUTITZ; NOGUEIRA, 2007), quinolonas (BOBU et al., 2008), sulfomidas (PÉREZ-MOYA et al., 2010), tetraciclinas (BAUTITZ; NOGUEIRA, 2010).

Pode-se ver que, embora o processo Fenton produza bons resultados (eficiência da degradação acima de $53 \%$, remoção do DQO > 44 \%, remoção do COT>20\% e um aumento ligeiro na biodegradabilidade), o processo foto-Fenton parece ser mais eficiente (eficiência de degradação acima de $74 \%$, DQO $>56 \%$, e remoção do COT> 50\%). Comparando-se nas mesmas condições o processo Fenton no escuro com o processo foto-Fenton, torna-se evidente que o último método conduz a elevadas taxas de degradação, ocorrendo uma melhoria em termos da biodegradabilidade e da mineralização (PÉREZ-MOYA et al., 2010). Também concluiu-se pelos testes com o foto-Fenton que as toxicidades aumentaram durante as primeiras etapas da reação, diminuindo gradualmente ao longo do tempo.

Uma conclusão contrária foi defendida por Guinea et al. (2009), em que estudaram a degradação da enrofloxacina (quinolona) através da oxidação Fenton. Eles concluíram que as fases iniciais do processo foram muito eficientes, enquanto o processo proporcionou a formação rápida de compostos refratários e aumento da toxicidade dos efluentes. Em geral, parece que a presença de radiação UV no processo Fenton (foto-Fenton) melhora o tratamento.

No entanto, o processo foto-Fenton é geralmente menos eficiente para águas residuárias com elevado teor de matéria orgânica (concentrações elevadas de DQO, o que pode ser detectado nas águas residuárias municipais, hospitalares e de indústrias de fármacos), uma vez que a turbidez impede a penetração da radiação UV (HOMEM; SANTOS, 2011).

Embora o processo Fenton apresente uma eficiência menor em termos da remoção e mineralização de poluentes, ele parece potencialmente aplicável para tratar essas matrizes. No entanto, os processos Fenton e foto-Fenton são aplicáveis às matrizes com concentrações baixas de DQO, sendo que as águas contendo concentrações elevadas de íons (por exemplo a

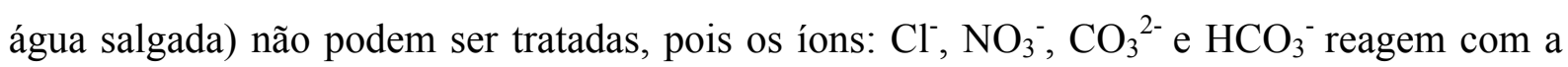
espécie OH- (TROVÓ et al., 2009). Como mencionado acima, é importante se controlar a 
faixa operacional de valores de $\mathrm{pH}$ em ambos os casos, a fim de se evitar que sejam formados os precipitados (oxi-hidróxidos).

\subsection{Objetivos}

O objetivo deste trabalho foi o de estudar comparativamente a degradação do antibiótico sulfametoxazol por processos eletroquímicos, eletroquímico foto assistido, fotoquímico, Fenton, foto-Fenton, a fin de obter um método para remover o antibiótico de forma eficiente, com baixo custo e de fácil automação. Também se buscou avaliar os efeitos dos diversos parâmetros que influenciam aos processos de degradação, além da identificação e avaliação dos principais intermediários de degradação do antibiótico SMX durante os processos. 


\section{Capítulo 2}

\section{Experimental}

\subsection{Reagentes Químicos}

Os reagentes utilizados nos experimentos foram: sulfametoxazol (SMX, 99,5\%), sulfato de sódio $\left(\mathrm{Na}_{2} \mathrm{SO}_{4} 99 \%\right)$, cloreto de sódio $(\mathrm{NaCl}, 99,8 \%)$, cloreto de amónio $\left(\mathrm{NH}_{4} \mathrm{Cl}\right.$ 99,5\%), sulfato ferroso heptahidratado $\left(\mathrm{Fe}_{2} \mathrm{SO}_{4} \cdot 7 \mathrm{H}_{2} \mathrm{O}, 99 \%\right)$, sulfito de sódio $\left(\mathrm{Na}_{2} \mathrm{SO}_{3}, 97 \%\right)$, tampão fosfat monopotássico $\left(\mathrm{KH}_{2} \mathrm{PO}_{4}, 98 \%\right)$, adquiridos junto à Sigma-Aldrich (EUA); acetonitrila (grau cromatográfico) da marca Panreac Química (Espanha). Ácido sulfúrico (98\%) da marca J.T. Baker EUA). Peróxido de hidrogénio (30\%) e hidróxido de sódio ( $\mathrm{NaOH}$ 97\%) da marca Synth (Brasil). Todos os reagentes químicos foram utilizados sem purificação prévia.

Todas as soluções foram preparadas utilizando-se água ultrapura, obtida com o uso de um sistema de ultrapurificação de água (Millipore, modelo Milli-Q), a qual apresenta resistividade nominal de $18 \Omega \mathrm{cm}^{-1}$ a $25^{\circ} \mathrm{C}$. Todas as soluções dos diferentes sais utilizados foram feitas de modo a manter a força iônica constante $(\mu) \mathrm{em} 0,1 \mathrm{~mol} \mathrm{~L}^{-1}$, tanto nos ensaios eletroquímico quanto nos eletroquímico foto assistido. Os valores de $\mathrm{pH}$ das soluções foram ajustados com a adição de pequenas quantidades de $\mathrm{H}_{2} \mathrm{SO}_{4}(98 \%)$ ou $\mathrm{NaOH}(97 \%)$, sem alteração significativa da força iônica das soluções. 


\subsection{Dispositivos Experimentais}

\subsubsection{Reator eletroquímico}

Os experimentos eletroquímicos foram realizados em um reator descrito anteriormente por (MALPASS et al., 2008), o qual consiste em uma célula eletroquímica de fluxo, com compartimento único, do tipo filtro-prensa. A Figura 2.1 apresenta o diagrama esquemático da montagem da célula e do sistema eletroquímico e a Figura 2.2 mostra o registro fotográfico do sistema eletroquímico em operação. O eletrodo de trabalho utilizado foi um ânodo dimensionalmente estável (ADE - do inglês Dimensionally Stable Anode - DSA ${ }^{\circledR}$ ) comercial, com composição nominal de $\mathrm{Ti} / \mathrm{Ru}_{0,3} \mathrm{Ti}_{0,7} \mathrm{O}_{2}$, adquirido da empresa De Nora do Brasil, com área geométrica exposta para a solução é de $14 \mathrm{~cm}^{2}$. O eletrodo de trabalho foi ativado aplicando-se densidade de corrente de $50 \mathrm{~mA} \mathrm{~cm}^{-2}$ por um período de 15 min antes de cada experimento. O contra eletrodo utilizado foi uma chapa de titânio de mesma área. Um eletrodo reversível de hidrogênio (ERH) foi utilizado como eletrodo de referência. O contato elétrico entre a célula eletroquímica e o eletrodo de referência foi feito com uma membrana (IONAC) mergulhada externamente em uma solução de $\mathrm{H}_{2} \mathrm{SO}_{4} 0,5 \mathrm{~mol} \mathrm{~L}^{-1}$.

A célula foi montada posicionando os eletrodos entre isoladores de Viton $^{\circledR} \mathrm{e}$ espaçadores de Teflon ${ }^{\circledR}$ e conectando-a com um reservatório de solução com capacidade de $600 \mathrm{~mL}$ por uma bomba peristáltica (modelo 77601-10 da Masterflex).

Solução aquosa de Sulfametoxazol $\left(200 \mathrm{mg} \mathrm{L}^{-1}\right)$, correspondente a $100 \mathrm{mg} \mathrm{L}^{-1} \mathrm{de}$ carbono, foi bombeada verticalmente através da célula, com vazão de $425 \mathrm{~cm}^{3} \mathrm{~min}^{-1}$. No processo eletro-oxidativo, a corrente aplicada através de uma fonte (modelo MPL-3303 Minipa) foi mantida constante ao longo de todo o experimento. O reservatório da solução foi conectado ao banho termostático (RTE-221 Neslab) para manter a temperatura constante.

\subsubsection{Reator eletroquímico foto assistido}

O mesmo ADE mencionado acima foi utilizado como eletrodo de trabalho para os experimentos eletroquímico foto assistido. O contra eletrodo (CE) utilizado foi uma tela de titânio, de forma a possibilitar a irradiação da superfície do ânodo, através de uma janela de quartzo. Um eletrodo reversível de hidrogênio (ERH) foi utilizado como eletrodo de referência (ALVES et al., 2010). Os espaçadores foram abertos no meio, de tal forma que a radiação ultravioleta fosse capaz de atingir a superfície do anodo, através do vidro de quartzo e da tela de titânio. 


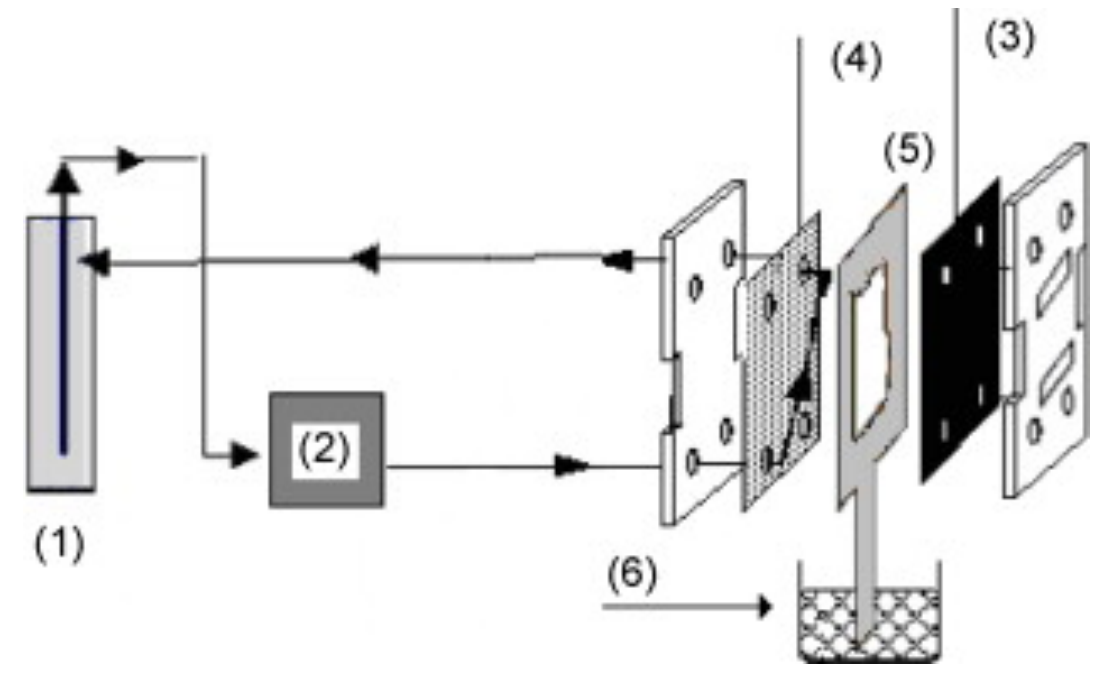

Figura 2.1. Conjunto de reator e componentes: (1) reservatório do eletrólito; (2) bomba peristáltica; (3) ADE; (4) catodo de Titânio; (5) membrana; (6) eletrodo de referência.

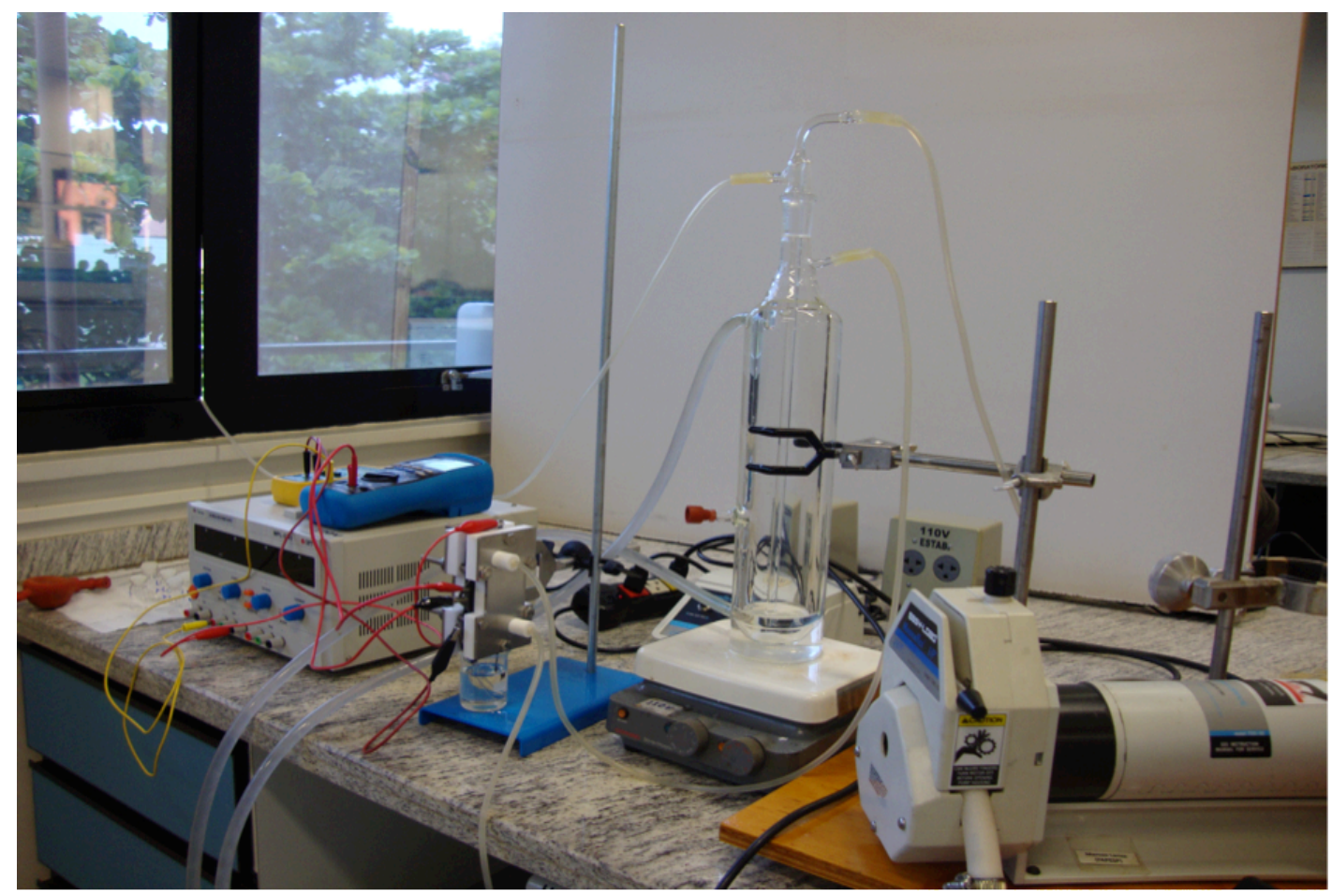

Figura 2.2. Registro fotográfico do sistema eletroquímico em operação com indicação do reator eletroquímico.

A irradiação do ânodo foi feita com o filamento de uma lâmpada de vapor de mercúrio de $250 \mathrm{~W}$ (Osram) que emiti uma radiação do comprimento de onda do ultravioleta (200 - 400 nm) (CATANHO et al., 2006a). A distância entre a lâmpada e o eletrodo foi de $7 \mathrm{~cm}$. O reator foi colocado em uma caixa de madeira que estava equipado com um ventilador de exaustão a fim de dissipar o calor produzido pela lâmpada. 


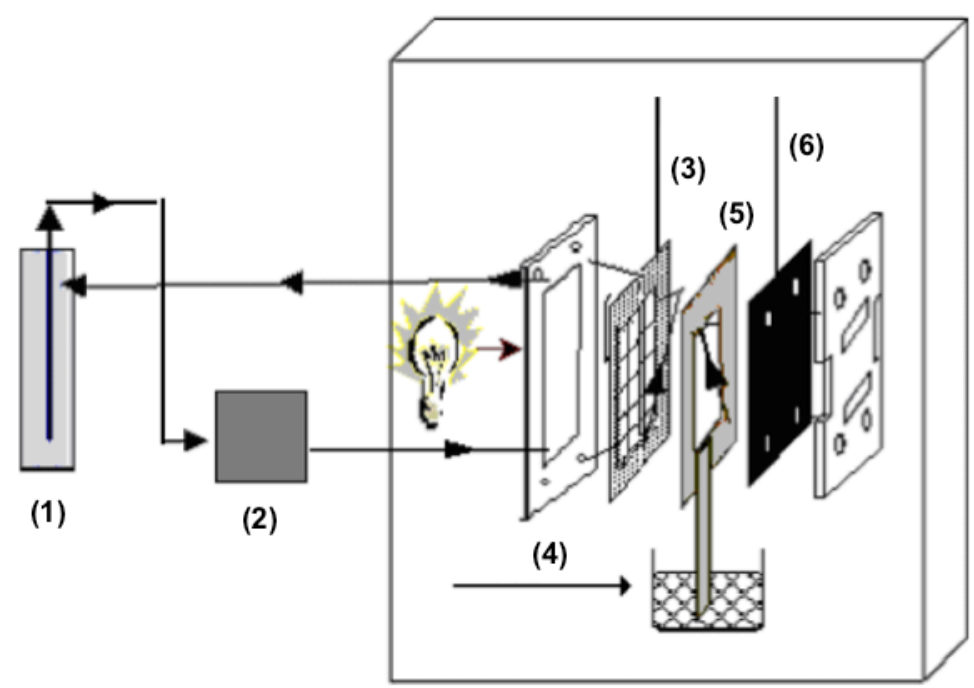

Figura 2.3. Esquema do reator eletroquímico foto assistido: (1) reservatório do eletrólito; (2) bomba peristáltica; (3) contra eletrodo; (4) eletrodo de referência; (5) membrana; (6) eletrodo de trabalho.

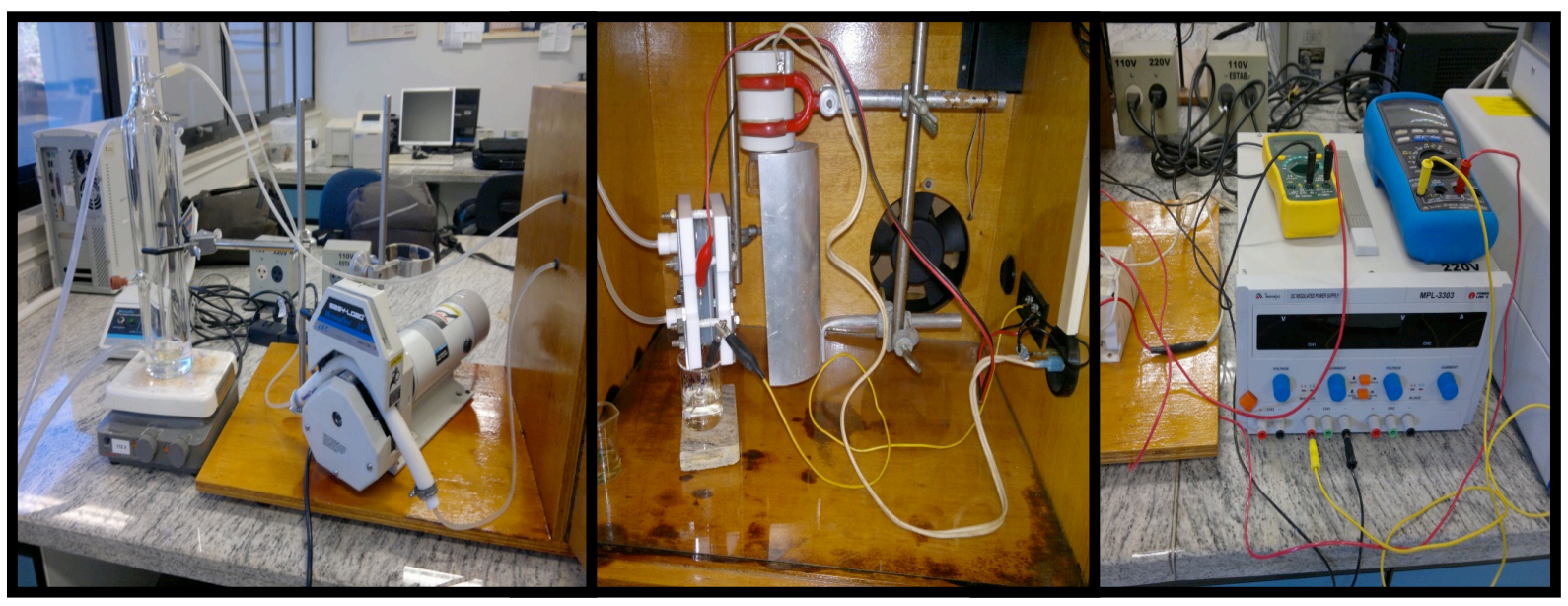

(a)

(b)

(c)

Figura 2.4. Registro fotográfico do sistema eletroquímica foto assistida (a) bomba peristáltica e reservatório (b) célula eletroquímica e fonte de radiação UV com compartimento de madeira para proteção do ambiente externo (c) fonte para aplicar a corrente.

A Figura 2.3 representa o diagrama esquemático da célula e do sistema fotoeletroquímico e Figura 2.4 mostra o registro fotográfico do sistema eletroquímico foto assistido dividido em três imagens.

O eletrodo de trabalho foi ativado pela aplicação de $50 \mathrm{~mA} \mathrm{~cm}^{-2}$ por $15 \mathrm{~min}$ antes de cada experimento. Para circulação da solução entre o reservatório e a célula foi utilizada uma bomba peristáltica com vazão de $425 \mathrm{~cm}^{3} \mathrm{~min}^{-1}$. O reservatório da solução foi conectado ao banho termostático (RTE-221 Neslab) para manter a temperatura constante. 
Alíquotas de $10 \mathrm{~mL}$ foram retiradas em intervalos pré-determinados e extraídos utilizando-se cartucho Sep-Pak $\mathrm{C}_{18}$ Waters, Strata X, Phenomenex e Oasis HLB Waters, e em seguida, analisados por CLAE.

\subsubsection{Reator fotoquímico}

As oxidações envolvendo os experimentos químicos (Fenton) e fotoquímicos (fotólise, foto-Fenton) foram realizadas em um reator de vidro encamisado com $8 \mathrm{~cm}$ de diâmetro interno e $20 \mathrm{~cm}$ de altura. A Figura 2.5 mostra o diagrama esquemático do sistema fotoquímico. Para cada experimento, o reator foi preenchido com $600 \mathrm{~mL}$ de solução aquosa contendo $200 \mathrm{mg} \mathrm{L}^{-1}$ de SMX, sendo que a temperatura foi mantida constante através da recirculação da água (passando pelo encamisamento do reator) com auxilio de um banho termostático (RTE-221 Neslab). O agitador magnético foi colocado na parte inferior do reator para homogeneizar a solução durante o experimento.

$\mathrm{O}$ pH da solução foi ajustado para o valor desejado adicionando-se hidróxido de sódio ou ácido sulfúrico e, em seguida, quantidades pré-estabelecidas de sulfato ferroso heptahidratado e peróxido de hidrogênio foram introduzidas à solução para promover a geração de radicais hidroxila. Nos experimentos fotoquímicos (fotólise e foto-Fenton) a solução foi irradiada com uma lâmpada fluorescente germicida da marca Philips de $4 \mathrm{~W}(\lambda=$ $254 \mathrm{~nm}$ ), que foi inserida no tubo de quartzo posicionada no meio da solução.Durante os experimentos, em intervalos de tempo pré-determinados, alíquotas de $10 \mathrm{~mL}$ foram retiradas, e uma gota de sulfito de sódio foi adicionada para parar a reação. As amostras foram filtradas em membrana $0,45 \mu \mathrm{m}$ e analisadas por CLAE e COT.

\subsection{Análise Instrumental}

\subsection{1 pH}

As medidas de $\mathrm{pH}$ foram realizadas antes e depois da retirada de cada alíquota, utilizando-se um medidor de pH modelo 8010 (Qualxtron), o qual foi calibrado através de soluções padrões ( $\mathrm{pH}$ de 4, 7 e 9).

\subsubsection{Espectroscopia de ultravioleta-visível (UV-vis)}

A avaliação qualitativa da degradação do Sulfametoxazol foi estimada utilizando-se a técnica de espectrofotometria de absorção molecular na região de UV-vis. As análises foram 


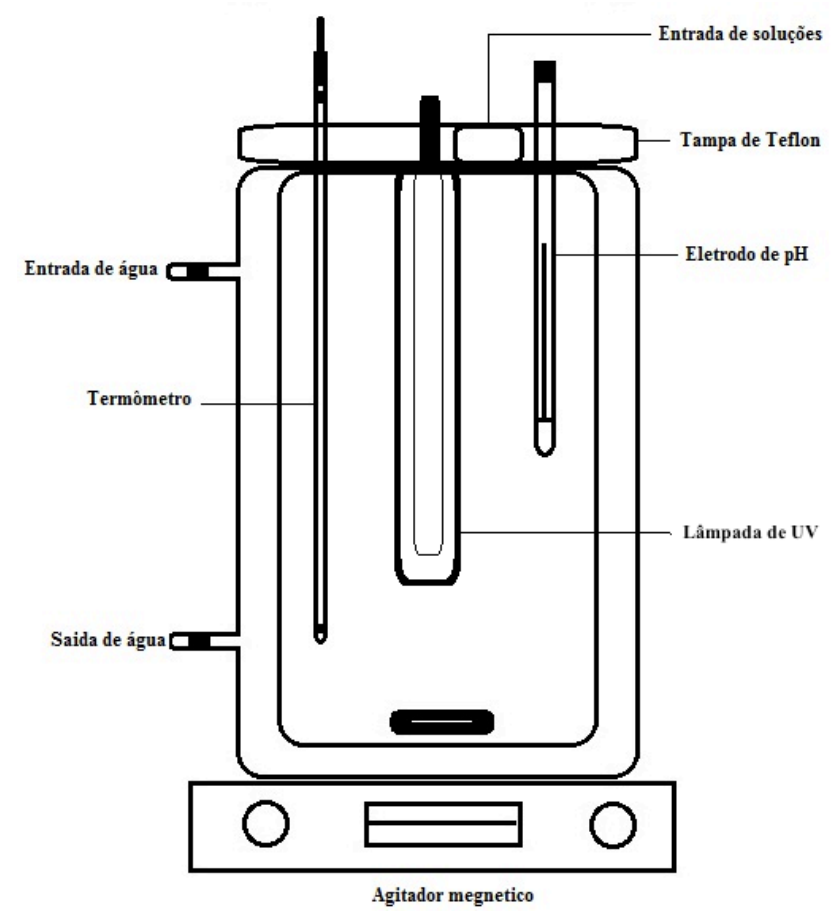

Figura 2.5 - Diagrama esquemático do reator fotoquímico (fotólise, foto-Fenton e Fenton).

realizadas por espectrofotométria UV-Visível (MultiSpec-1501 da Shimadzu). As medidas de absorbância foram feitas de 200 a 600 nm, com correção da linha de base. Todas as análises foram realizadas com as soluções dos analitos com prévia diluição. Foi utilizada uma cubeta de quartzo de caminho ótico de $1 \mathrm{~cm}$.

\subsubsection{Carbono Orgânico Total (COT)}

Um analisador de Carbono Orgânico Total (TOC-VCPH da Shimadzu) foi utilizado para medir a remoção de carbono orgânico total (COT). As análises foram realizadas pela técnica de oxidação catalítica á altas temperaturas $650-900{ }^{\circ} \mathrm{C}$ e a combustão da amostra ocorreu sob fluxo de oxigênio constante. Nesta técnica o COT foi calculado através da diferença de carbono total (CT) e carbono inorgânico (CI).

\subsubsection{Cromatografia líquida de alta eficiência (CLAE)}

A diminuição da concentração de SMX foi analisada por CLAE (SHIMAZU modelo LC-10ADVP) com detector de UV (SPD-10A VP da Shimadzu) equipados com coluna analítica de fase reversa $\mathrm{C}_{18}$ (dimensões $4,6 \times 150 \mathrm{~mm}$, e $5 \mu \mathrm{m}$ de tamanho da partícula, da marca Restek technologies). 
Para a análise do SMX, foram utilizadas as seguintes condições: eluição isocrática de acetonitrila/tampão de fosfato monopotássico (30:70), vazão de $0,5 \mathrm{~mL} \min ^{-1}$, volume de injeção de $20 \mu \mathrm{L}$ e monitoramento em $270 \mathrm{~nm}$. Com estas condições, o SMX foi detectado no tempo de retenção de 7 min e o limite de quantificação foi inferior a $0,1 \mathrm{mg} \mathrm{L}^{-1}$.

\subsubsection{Cromatografia líquida de alta eficiência e espectrometria de massa (CLAE/EM)}

Os intermediários de degradação do SMX foram identificados por cromatografia líquida acoplado a um espectrômetro de massas. As análises por espectrometria de massa foram realizadas em um equipamento micro-TOF Quadripolo Q-II tempo-de-voo (Bruker Daltonics), conectado a um cromatógrafo líquido (Shimadzu serie 20A) utilizando uma coluna analítica $\mathrm{C}_{18}(4,6 \times 150 \mathrm{~mm}, 5 \mu \mathrm{m}$, Restek Technologies). Como fase móvel foi utilizado um gradiente de acetonitrila em água com $0,1 \%$ de ácido fórmico, a uma vazão de $1,0 \mathrm{ml} \mathrm{min}{ }^{-1}$. O gradiente foi iniciado com $10 \%$ de acetonitrila (mantido por $5 \mathrm{~min}$ ), seguido de um aumento linear de $10 \%$ para $100 \%$ em 50 min, sendo mantido os $100 \%$ por 3 min. Finalmente, o gradiente foi retornado ao estado inicial de $10 \%$ de acetonitrila, permanecendo assim por 2 min para permitir o equilíbrio. O volume de injeção foi de $20 \mu \mathrm{L}$. Sob estas condições, o tempo de retenção do SMX foi de 15,3 minutos. O analisador do espectrofotômetro de massas foi operado em modo de ionização positiva de capilar $4500 \mathrm{~V}$; nebulizador 4 bar; fluxo de gás de secagem $8,0 \mathrm{~L}^{-1}$; temperatura do gás a $200{ }^{\circ} \mathrm{C}$.

Após a retirada de cada alíquota, uma gota de solução de sulfito foi adicionada para interromper a reação. Depois da interrupção as amostras foram centrifugadas e filtradas em membrana de $0,45 \mu \mathrm{m}$ em seguida serem analisados por espectrometria de massas.

\subsubsection{Cromatografia Iônica}

O sulfametoxazol foi mineralizado à vários íons inorgânicos, tais como: $\mathrm{NH}_{4}{ }^{+}, \mathrm{NO}_{3}{ }^{-}$, $\mathrm{NO}_{2}{ }^{-}, \mathrm{e} \mathrm{SO}_{4}{ }^{2-}$. Os íons foram quantificados por cromatografia de íons (850 Professional IC da Metrohm). O sistema foi equipado com um auto-amostrador (Modelo-863 Compact), uma bomba, um degaseificador, uma coluna de guarda, uma coluna de separação operada em 30 ${ }^{\circ} \mathrm{C}$ e o volume de injeção foi de $20 \mu \mathrm{L}$. Para a determinação dos ânions, o sistema foi equipado com uma coluna ânionica Star-Ion -A300, (4,6 mm x $100 \mathrm{~mm})$. A fase móvel foi

constituída por $1,7 \mathrm{mmol} \mathrm{L}^{-1}$ de $\mathrm{NaHCO}_{3}$ e $1,8 \mathrm{~mol} \mathrm{~L}^{-1}$ de $\mathrm{Na}_{2} \mathrm{CO}_{3}$, e a vazão foi fixada em 1,5 $\mathrm{mL} \mathrm{min}^{-1}$. Para a determinação dos cátions, o sistema foi equipado com uma coluna de 
separação MetrohmSep $C_{2}(4 \mathrm{~mm}$ x $150 \mathrm{~mm})$. Uma solução de ácido oxálico 2,7 mmol L $\mathrm{m}^{-1}$ foi utilizada como fase móvel com vazão de $1,5 \mathrm{~mL} \mathrm{~min}^{-1}$.

\subsubsection{Voltametria cíclica}

A técnica de voltametria cíclica (VC) foi utilizada para caracterização voltamétrica (resposta eletroquímica) de ADE. As medidas de voltametria cíclica foram realizadas com o uso de um potenciostato/galvanostato (EG\&G/PAR modelo 273). Estes experimentos foram realizados a temperatura ambiente $\left(26 \pm 1{ }^{\circ} \mathrm{C}\right)$ na mesma célula de fluxo que foi usada para os experimentos de degradação. Para realizar voltamogramas cíclicos, foi usada uma membrana Ionac AM 3470 (M) perfurada em seu interior e em contato com uma solução externa e com o eletrodo de referência por uma tira. $\mathrm{O}$ voltamogramas cíclicos (10 varreduras em $50 \mathrm{mVs}^{-1}$ ) foram obtidos com soluções de $\mathrm{NaCl} 0,1 \mathrm{~mol} \mathrm{~L}^{-1}, \mathrm{Na}_{2} \mathrm{SO}_{4} 0,033 \mathrm{~mol} \mathrm{~L}^{-1}$, e $\mathrm{H}_{2} \mathrm{SO}_{4}$ 0,033 mol L ${ }^{-1}$ em presença e ausência de $\mathrm{SMX}\left(200 \mathrm{mg} \mathrm{L}^{-1}\right)$. As medidas de voltametria cíclica também foram realizadas na ausência e presença de radiação UV para o processo foto-eletroquímico.

\subsection{Cálculo de parâmetros analíticos}

\subsubsection{Determinação de consumo energético}

Há uma série de fatores importantes na escolha de uma tecnologia de tratamento de resíduos, incluindo custos, regulamentos, operação (manutenção, controle, segurança). Embora esses fatores sejam importantes, a economia é muitas vezes fundamental. Os processos, fotoquímico, eletroquímico e foto-eletroquímico são processos baseados em energia elétrica que podem representar uma grande fração dos custos operacionais. Dessa forma, o consumo energético é um parâmetro muito importante para se avaliar a eficiência destes processos. Segundo Bolton et al. (2001) o consumo elétrico é calculado como uma “energia elétrica por ordem” $\left(\mathrm{E}_{\mathrm{EO}}\right)$. Entretanto, esta figura de mérito só pode ser aplicada a um sistema que obedece a uma cinética de reação de primeira ordem. A $\mathrm{E}_{\mathrm{EO}}$ é definida como a energia elétrica em quilowatts hora, necessária para degradar um contaminante (C) em uma ordem de grandeza. Tem como unidade o $\mathrm{kW} \mathrm{m}^{3} \mathrm{ordem}^{-1}$ e é calculada pelo equações $(2.1$ 2.3)

$$
\begin{aligned}
& E_{E O}=\frac{P \times t \times 1000}{V \times 60 \times \log \left(C_{i} / C_{f}\right)} \\
& \ln \left(\frac{\mathrm{C}_{\mathrm{i}}}{\mathrm{C}_{\mathrm{f}}}\right)=k_{1}^{\prime} \times t
\end{aligned}
$$


onde $\mathrm{P}$ é a potência $(\mathrm{kW})$ do sistema, t é o tempo (min), V é o volume (L) do reator, $\mathrm{C}_{\mathrm{i}}$ e $\mathrm{C}_{\mathrm{f}}$ são as concentrações iniciais e finais do poluente, respectivamente, e $k_{1}^{\prime}$ é a constante de reação de pseudo-primeira ordem para o decaimento das concentração de poluentes. A partir de equações (2.1) e (2.2) o parâmetro $E_{E O}$ pode-se calculado por equação (2.3), e 38,4 em equação (2.3) é o fator de conversão $1000 \ln (10) / 60$ (BOLTON et al., 2001; CATER et al., 2000; DANESHVAR; ALEBOYEH, et al., 2005)

$$
E_{E O}=\frac{38,4 \times P}{\mathrm{~V} \times k_{1}^{\prime}}
$$

\subsubsection{Constante de velocidade}

A equação cinética de primeira ordem (2.4) foi aplicada para calcular a constante de velocidade, $k$,

$$
\ln \frac{C_{o}}{C}=k t
$$

onde $C o$ é a concentração inicial $\left(\mathrm{mg} \mathrm{L}^{-1}\right), C$ é a concentração no tempo $t\left(\mathrm{mg} \mathrm{L}^{-1}\right), t$ é o tempo em minutos e $k$ é a constante de velocidade. O tempo experimental de meia-vida da reação foi calculado utilizando a equação (2.5).

$$
t_{1 / 2}=\frac{0,693}{k}
$$




\section{Capítulo 3}

\section{Degradação eletroquímica do sulfametoxazol}

Este capítulo é dedicado ao estudo da degradação de SMX por processo eletroquímico utilizando um ânodo do tipo ADE. Foram estudadas as distintas variáveis que influenciam no processo, a saber eletrólito suporte, $\left(\mathrm{NaCl}\right.$ e $\left.\mathrm{Na}_{2} \mathrm{SO}_{4}\right)$, concentração de $\mathrm{Cl}^{-}(0,002-0,1 \mathrm{~mol} \mathrm{~L}$ $\left.{ }^{1}\right)$, pH inicial da solução $(2,5-9,0)$, densidade de corrente $\left(10-60 \mathrm{~mA} \mathrm{~cm}{ }^{-2}\right)$, concentração inicial do $\operatorname{SMX}\left(50-200 \mathrm{mg} \mathrm{L}^{-1}\right)$ e temperatura da solução $\left(25-45^{\circ} \mathrm{C}\right)$. No final deste capitulo é apresentada uma breve explicação dos intermediário orgânicos e inorgânicos de degradação e a possível rota de degradação do SMX.

\subsection{Caracterizações in situ do ânodo}

A voltametria cíclica é uma técnica útil para se investigar processos que ocorrem ao longo da interface eletrodo/solução, nos quais a corrente varia em função do potencial aplicado, fornecendo informações valiosas sobre as reações que ocorrem na superfície do eletrodo. Assim, a técnica de voltametria cíclica permite uma caracterização in situ sensível de superfícies compostas por óxidos metálicos. 


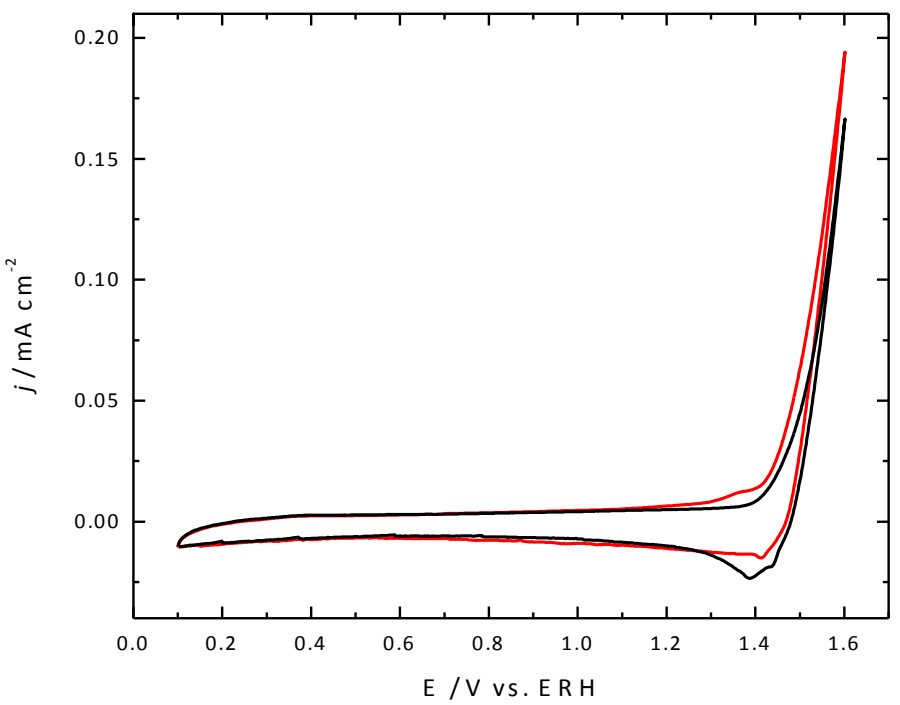

Figura 3.1 - Curvas voltamétricas $\left(10^{\circ}\right.$ Ciclo) do eletrodo de ADE a $0,1 \mathrm{~mol} \mathrm{~L}^{-1}$ de $\mathrm{NaCl}$, (-) na presença e (-) na ausência de SMX. $v=50 \mathrm{mV} \mathrm{s}^{-1}, \mu=0,1 \mathrm{~mol} \mathrm{~L}^{-1}$.

As caracterizações in situ do eletrodo $\mathrm{Ti} / \mathrm{Ru}_{0,3} \mathrm{Ti}_{0,7} \mathrm{O}_{2}$ comercial utilizado neste trabalho foram realizadas por meio de voltametria cíclica (VC), utilizando $\mathrm{NaCl}, \mathrm{Na}_{2} \mathrm{SO}_{4} \mathrm{e}$ $\mathrm{H}_{2} \mathrm{SO}_{4}$ como eletrólitos suporte, na presença e ausência do antibiótico sulfametoxazol. Pelas Figuras 3.1 a 3.3, pode ser observado que o eletrodo de óxido apresenta um comportamento voltamétrico típico para os três eletrólitos, ou seja, uma região sem alterações de corrente entre $+0,4 \mathrm{e}+1,2 \mathrm{~V}$, seguida por um rápido aumento da corrente para os valores de potencial superiores a $+1,2 \mathrm{~V}$, o que corresponde ao início da reação de desprendimento de oxigênio. Também é observado nas Figuras 3.1 a 3.3 que, devido à adição do antibiótico ocorre uma diminuição do intervalo de potencial correspondente à região de desprendimento de oxigênio, sendo esta diminuição muito pequena no caso do $\mathrm{H}_{2} \mathrm{SO}_{4}$, em comparação aos demais eletrólitos suporte. Isso indica a adsorção preferencial e interação dos moléculas de SMX na superfície de $\mathrm{Ti} / \mathrm{Ru}_{0.3} \mathrm{Ti}_{0.7} \mathrm{O}$.

Utilizando $\mathrm{NaCl}$ como eletrólito suporte (Figura 3.1), a curva na presença do SMX exibe densidade de corrente anódica e catódica ligeiramente maior do que para os demais eletrólitos suporte (em torno de $+1,4 \mathrm{~V}$ vs. ERH), provavelmente devido à reação entre o SMX e o $\mathrm{Cl}_{2}$ gerado e a possível geração de subprodutos na superfície do eletrodo (MALPASS et al., 2007). Por outro lado, as curvas voltamétricas relacionadas aos demais eletrólitos suporte estudados, $\mathrm{Na}_{2} \mathrm{SO}_{4}$ e $\mathrm{H}_{2} \mathrm{SO}_{4}$, com e sem adição de $\mathrm{SMX}$ (Figuras 3.2 e 3.3), não exibiam qualquer diferença, 


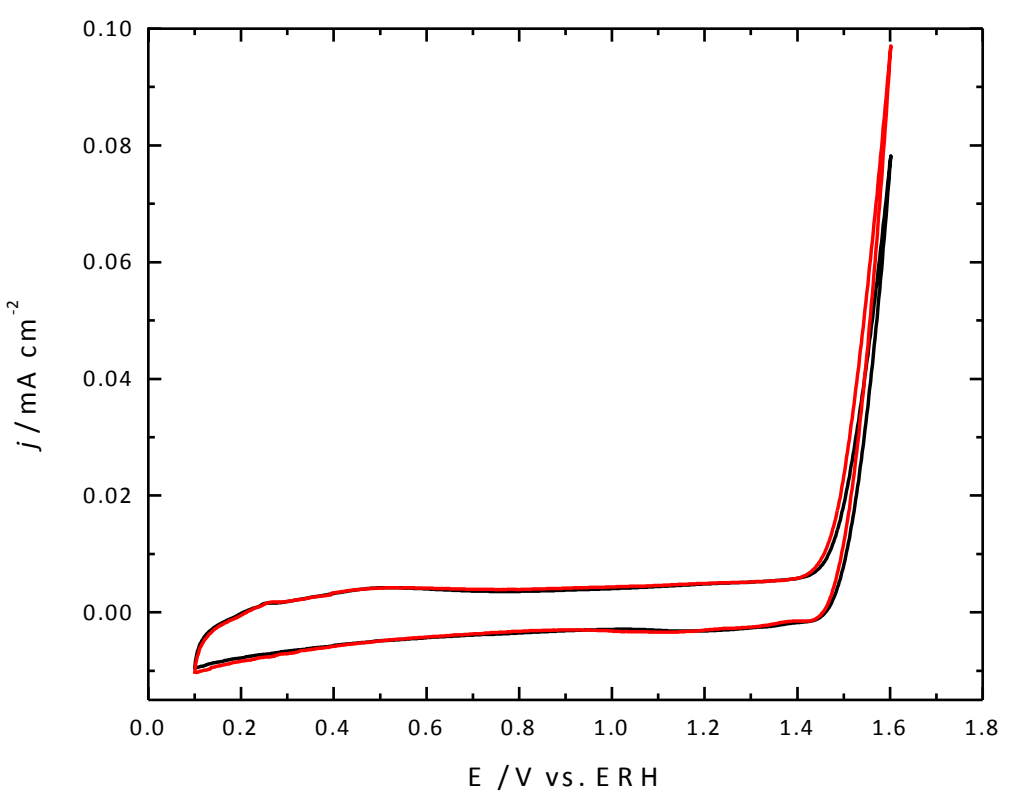

Figura 3.2 - Curvas voltamétricas $\left(10^{\circ}\right.$ Ciclo) do eletrodo de ADE a $0,033 \mathrm{~mol} \mathrm{~L}^{-1}$ de $\mathrm{Na}_{2} \mathrm{SO}_{4}$, (-) na presença e (-) na ausência de SMX. $v=50 \mathrm{mV} \mathrm{s}^{-1}, \mu=0,1 \mathrm{~mol} \mathrm{~L}^{-1}$.

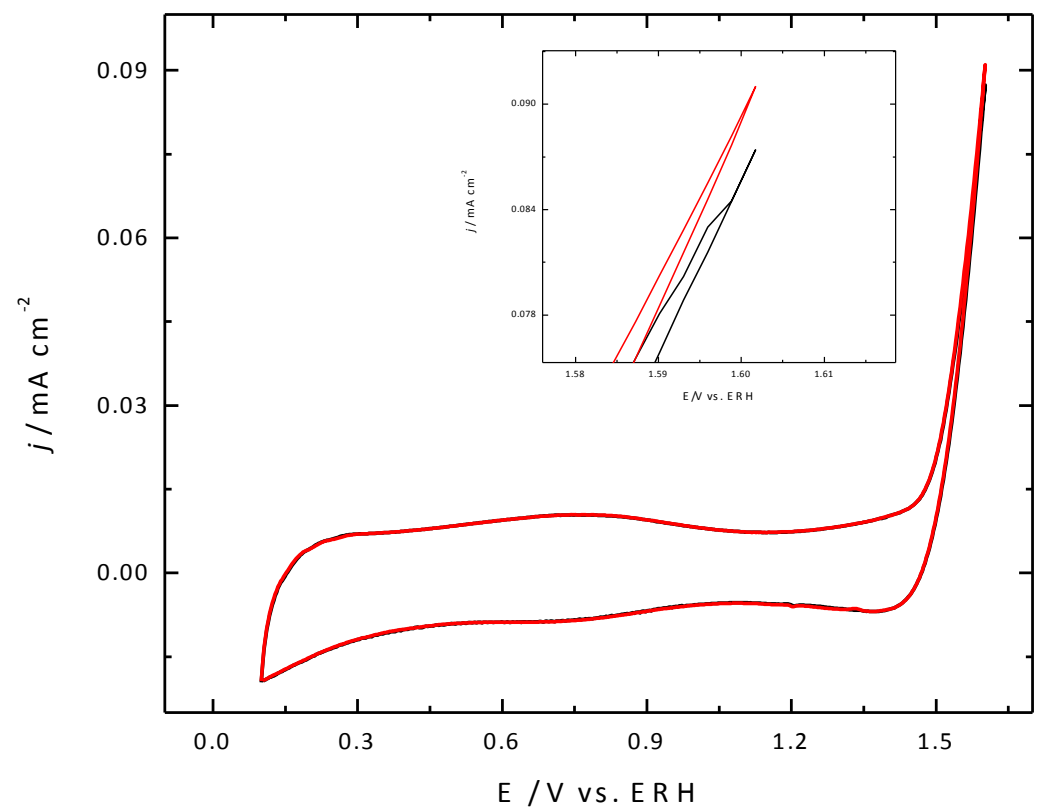

Figura 3.3 - Curvas voltamétricas $\left(10^{\circ}\right.$ Ciclo) do eletrodo de ADE a $0,033 \mathrm{~mol} \mathrm{~L}^{-1} \mathrm{de}_{2} \mathrm{SO}_{4}$, (-) na presença e (-) na ausência de SMX, $v=50 \mathrm{mV} \mathrm{s}^{-1}, \mu=0,1 \mathrm{~mol} \mathrm{~L}^{-1}$.

significando que o SMX não se oxida nesta faixa de potencial, por não ter sofrido qualquer modificação estrutural. 


\subsection{Degradação eletroquímica de SMX}

\subsubsection{Efeito da natureza do eletrólito na degradação do SMX}

Inicialmente, uma série de experimentos foram realizados com os diferentes eletrólitos suporte, aplicando $40 \mathrm{~mA} \mathrm{~cm}^{-2}$ de densidade de corrente e utilizando $200 \mathrm{mg} \mathrm{L}^{-1}$ de SMX. Os resultados apresentados na Figura 3.4 mostram que em meio de $\mathrm{Na}_{2} \mathrm{SO}_{4}$, ocorre a degradação parcial do composto, com apenas de 5\% de mineralização dados de COT após 2 horas de eletrólise. Nos estudos com $\mathrm{H}_{2} \mathrm{SO}_{4}$, após 2 horas de experimento, não houve a degradação ou mineralização do composto, o que pode ser atribuído a ineficiência das espécies oxidatntes geradas para degradar o SMX, assim como, a ausência de oxidação direta na superfície do ânodo.

Durante as eletrólises, o aumento da densidade de corrente resultou em aumento do transporte de massa, sendo que nenhuma mudança significativa foi observada com relação à degradação e à remoção de COT. No entanto, com a adição de $\mathrm{NaCl}$, ocorre um processo de degradação completa, além de aumento considerável na remoção do COT. Neste caso, a degradação de SMX ocorre devido a geração eletroquímica das espécies oxidantes cloro/hipoclorito, através de um mecanismo indireto, de acordo com as reações mencionadas na capítulo de introdução desta tese (Equações 1.5 a 1.8). A Figura 3.4 apresenta os perfis de degradação de SMX e de remoção de COT em função do tempo de eletrólise. Pode-se observar que o SMX é completamente degradado após 30 minutos de eletrólise, sendo que a remoção de COT foi de até $28 \%$, após 120 minutos de eletrólise, quando na presença de $\mathrm{NaCl}$.

Os resultados obtidos estão de acordo com Miwa et al. (2006) em que eles mostram que $\mathrm{H}_{2} \mathrm{SO}_{4}$ e $\mathrm{Na}_{2} \mathrm{SO}_{4}$ não são eficazes para a degradação de compostos orgânicos como carbaril, utilizando o eletrodo de $\mathrm{Ti} / \mathrm{Ru}_{0,3} \mathrm{Ti}_{0,7} \mathrm{O}_{2}$.

Em outro estudo Malpass et al. (2006), observaram a remoção da atrazina muito baixa nas presenças de: $\mathrm{Na}_{2} \mathrm{SO}_{4}, \mathrm{NaNO}_{3}, \mathrm{NaClO}_{4}, \mathrm{H}_{2} \mathrm{SO}_{4}$ como eletrólitos suporte, após 2 horas de eletrólise. No entanto, na presença do $\mathrm{NaCl}$, a atrazina foi degradada completamente após uma hora de eletrólise.

\subsubsection{Efeito da concentração de $\mathrm{NaCl}$}

De acordo com os resultados obtidos a partir do estudo com os diferentes eletrólitos suporte, decidiu-se verificar a influência do $\mathrm{NaCl}$ na degradação de $\mathrm{SMX}$, mantendo a força 


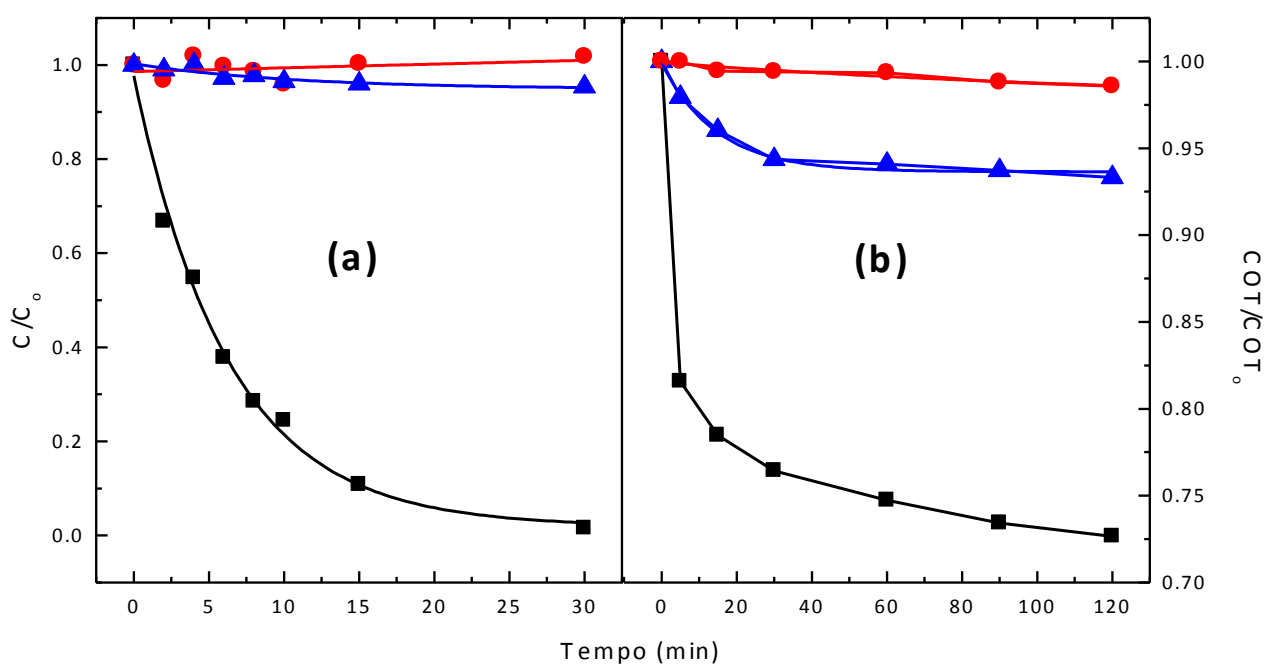

Figura 3.4 - Efeito da natureza do eletrólito suporte: $0,033 \mathrm{~mol} \mathrm{~L}^{-1} \mathrm{H}_{2} \mathrm{SO}_{4}(\bullet), 0,033 \mathrm{~mol} \mathrm{~L}^{-1} \mathrm{Na}_{2} \mathrm{SO}_{4}$ $(\boldsymbol{\Delta}), 0,1 \mathrm{~mol} \mathrm{~L}^{-1} \mathrm{NaCl}(\boldsymbol{\square})$ na (a) degradação e (b) remoção de $\mathrm{COT}$ (condições: $\mathrm{pH}_{\mathrm{i}}=3, \mathrm{~T}=25^{\circ} \mathrm{C}$, $\mathrm{C}_{\mathrm{smx}}=200 \mathrm{mg} \mathrm{L}^{-1}$, e $\left.i=40 \mathrm{~mA} \mathrm{~cm}^{-2}\right)$.

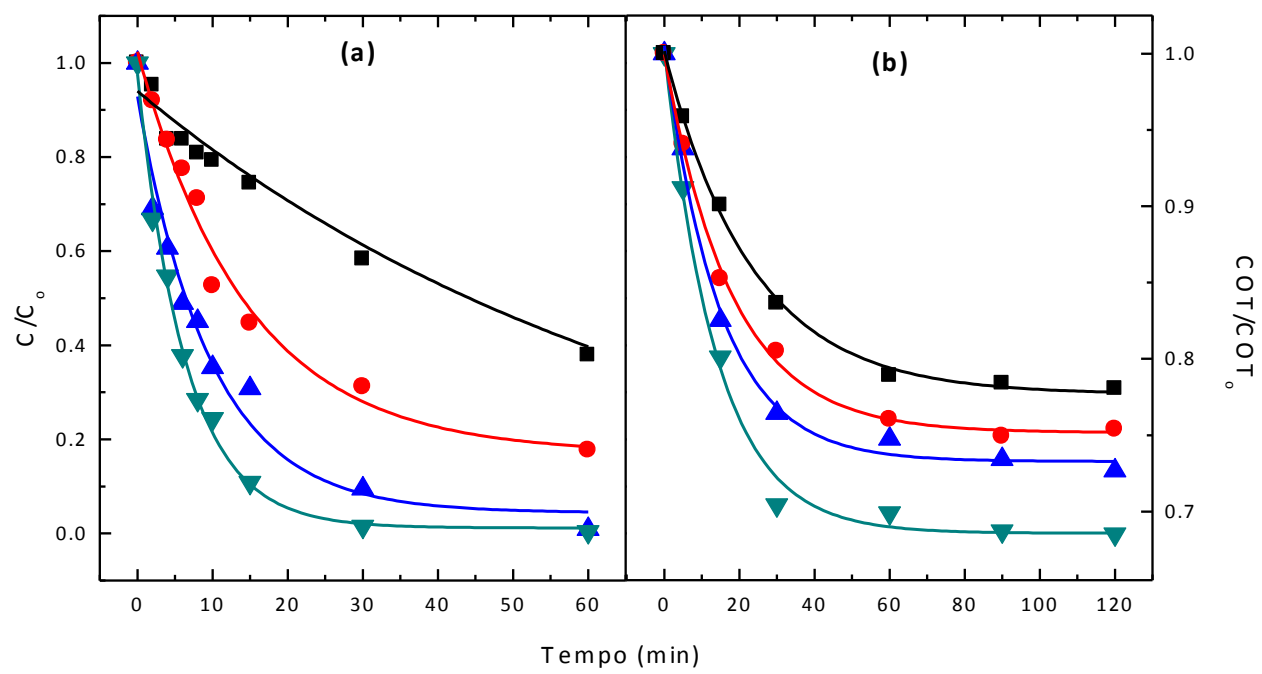

Figura 3.5 - Efeito da concentração de NaCl: (⿴) $0,02 \mathrm{~mol} \mathrm{~L}^{-1},(\bullet) 0,04 \mathrm{~mol} \mathrm{~L}^{-1},(\boldsymbol{\Delta}) \quad 0,08 \mathrm{~mol} \mathrm{~L}^{-1}$, ( $\nabla$ ) $0,1 \mathrm{~mol} \mathrm{~L}^{-1}$ (a) na degradação e (b) remoção do COT (Condições: $\mathrm{pH}_{\mathrm{i}}=3, \mathrm{~T}=25^{\circ} \mathrm{C}, \mathrm{C}_{\mathrm{smx}}=200$ $\mathrm{mg} \mathrm{L}^{-1} \mathrm{e} i=40 \mathrm{~mA} \mathrm{~cm}^{-2}$ ).

Iônica constante $\left(\mu=0,1 \mathrm{~mol} \mathrm{~L}^{-1}\right)$. A Figura 3.5 (a) apresenta o efeito da variação da concentração de $\mathrm{NaCl}$ na degradação do SMX. É evidente que com o aumento na concentração do íon cloreto, ocorre a degradação e eliminação completa do SMX em 30 e 60 


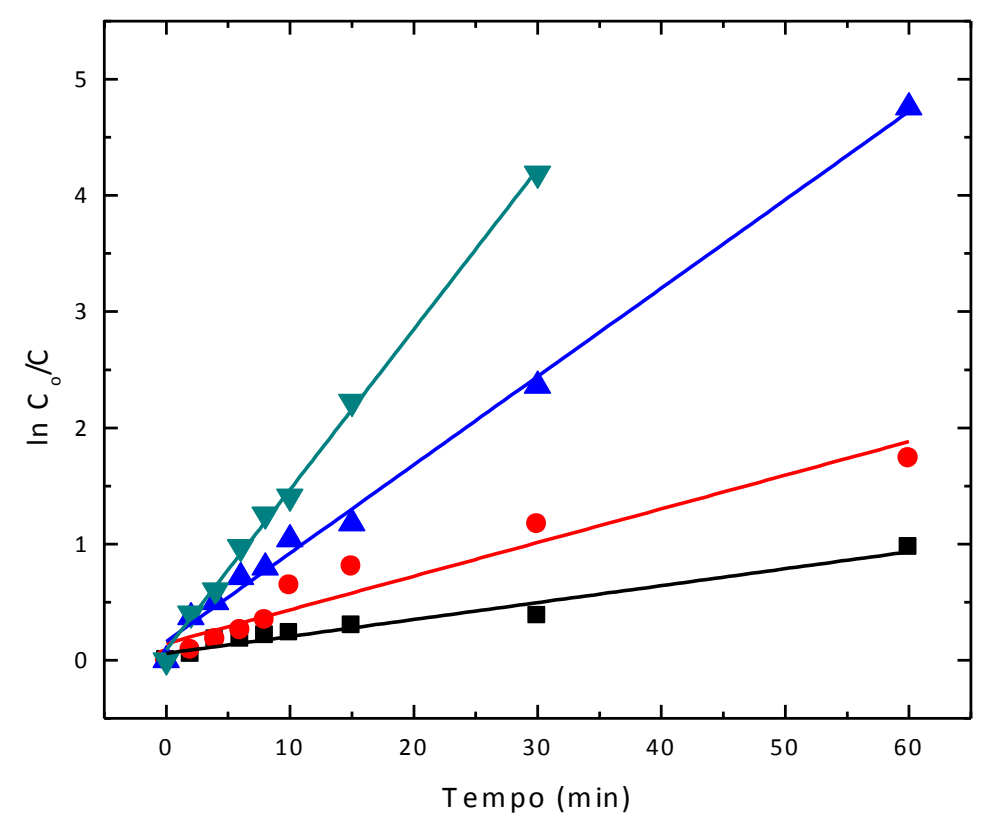

Figura 3.6 - Variação do $\ln \left(\mathrm{C}_{\mathrm{o}} / \mathrm{C}\right)$ em função do tempo de eletrólise em diferentes concentrações de

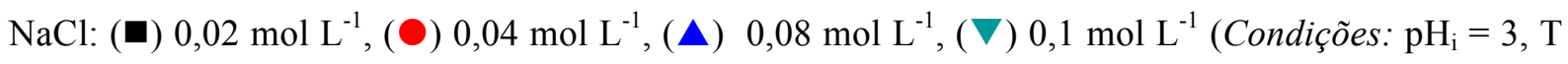
$=25^{\circ} \mathrm{C}, \mathrm{C}_{\mathrm{smx}}=200 \mathrm{mg} \mathrm{L}^{-1} \mathrm{e} i=40 \mathrm{~mA} \mathrm{~cm}^{-2}$ ).

minutos para as soluções de $\mathrm{NaCl}$, com valores de concentração iguais a 0,1 e $0,08 \mathrm{~mol} \mathrm{~L}^{-1}$, respectivamente. Nos casos dos valores de concentração de $\mathrm{NaCl}$ de 0,04 e $0,02 \mathrm{~mol} \mathrm{~L}^{-1}$, a degradação verificada foi de apenas 80 e $58 \%$, respectivamente.

Isso ocorre devido ao fato de que quanto maior for a concentração de $\mathrm{NaCl}$, mais espécies como o cloro/hipoclorito são geradas, o que aumenta a degradação. Com o aumento da concentração de $\mathrm{NaCl}$ há também aumento da condutividade do meio, o que resulta, por sua vez, em aumento da velocidade de reação entre as espécies oxidantes e o SMX. A Figura 3.5 (b) apresenta o perfil da remoção de COT em função da concentração de cloro, podendo ser observado que, ao se aumentar a concentração do $\mathrm{NaCl}$ de 0,02 a $0,1 \mathrm{~mol} \mathrm{~L}^{-1}$, a taxa de remoção de COT cresceu de $19 \%$ até $28 \%$, após 120 minutos de eletrólise.

Vários estudos se reportaram à questão de que a degradação de compostos orgânicos, tais como corantes utilizados em indústrias têxteis, aumenta com o aumento da concentração de $\mathrm{NaCl}$ (RAJKUMAR et al., 2007; MALPASS et al., 2008; GOMES et al., 2011).

A Figura 3.6 mostra o perfil da curva cinética de degradação do SMX para os diferentes valores de concentração de $\mathrm{NaCl}$. Pode-se observa uma relação linear no gráfico do logaritmo natural da concentração do SMX em função do tempo de degradação. O estudo cinético da degradação eletroquímica demonstrou que na presença de $\mathrm{NaCl}$, a reação segue 
uma cinética de pseudo-primeira ordem, Os valores da constante de velocidade e do coeficiente linear $\left(R^{2}\right)$ estão indicados na Tabela 3.1, onde pode ser constatado que o constante de velocidade aumenta com a concentração $\mathrm{NaCl}$.

Os resultados da energia por ordem $\left(\mathrm{E}_{\mathrm{EO}}\right)$ para as concentrações de $\mathrm{NaCl}$ estão indicados na Tabela 3.1, podendo ser observado que, com a adição do $\mathrm{NaCl}$, há redução do potencial de célula e, consequentemente, o consumo de energia é menor, como relatado anteriormente por MALPASS et al., 2007. Esses resultados indicam que a degradação de SMX é energeticamente menos eficiente para valor baixos da concentração do sal. Desta forma, decidiu-se pelo uso do valor de $0,1 \mathrm{~mol} \mathrm{~L}^{-1}$ de $\mathrm{NaCl}$ como sendo a concentração mais adequada, considerando a viabilidade energética do processo.

\subsubsection{Efeito da densidade de corrente aplicada}

A densidade de corrente é o fator determinante da eficiência de um processo eletroquímico. Com o objetivo de avaliar o efeito dessa variável, diferentes valores de densidade de corrente entre 10 a $60 \mathrm{~mA} \mathrm{~cm}^{-2}$ foram aplicados para o tratamento eletroquímico de $200 \mathrm{mg} \mathrm{L}^{-1}$ de solução de $\mathrm{SMX}$ com $\mathrm{pH}=3$, em uma célula do tipo filtro prensa. A Figura 3.7 ilustra o efeito da densidade de corrente aplicada sobre a degradação de SMX e remoção de COT. A taxa de degradação do SMX aumenta significativamente com o aumento da densidade de corrente aplicada, sendo que o SMX é removido completamente para os valores de densidade da corrente de 40 e $60 \mathrm{~mA} \mathrm{~cm}^{-2}$, em 30 minutos. Entretanto, para os valores de 10 e $20 \mathrm{~mA} \mathrm{~cm}^{-2}$, a degradação avaliada foi de apenas 52 e $78 \%$, respectivamente.

A variação de COT (Figura 3.7(b)) demonstra que houve um aumento na remoção do COT em função da densidade de corrente aplicada, tem sido relatados valores percentuais de mineralização de 18,69, 22,67, 27,33, 28,49 \% após 120 minutos de eletrólise, correspondentes aos valores de densidade de corrente de 10,20, 40 e $60 \mathrm{~mA} \mathrm{~cm}^{-2}$. O fato de que a maior taxa de degradação e de mineralização foi alcançada para maiores valores de densidade de corrente pode ser atribuído ao aumento da produção in-situ de cloro/hipoclorito, através do processo de oxidação mediado indiretamente.

Um parâmetro importante a ser avaliado no processo de tratamento eletroquímico é o consumo de energia. Assim, tal magnitude foi calculada de acordo com a equação (2.7), enquanto que a Tabela 3.1 relaciona o consumo de energia, ou seja, a energia elétrica por 


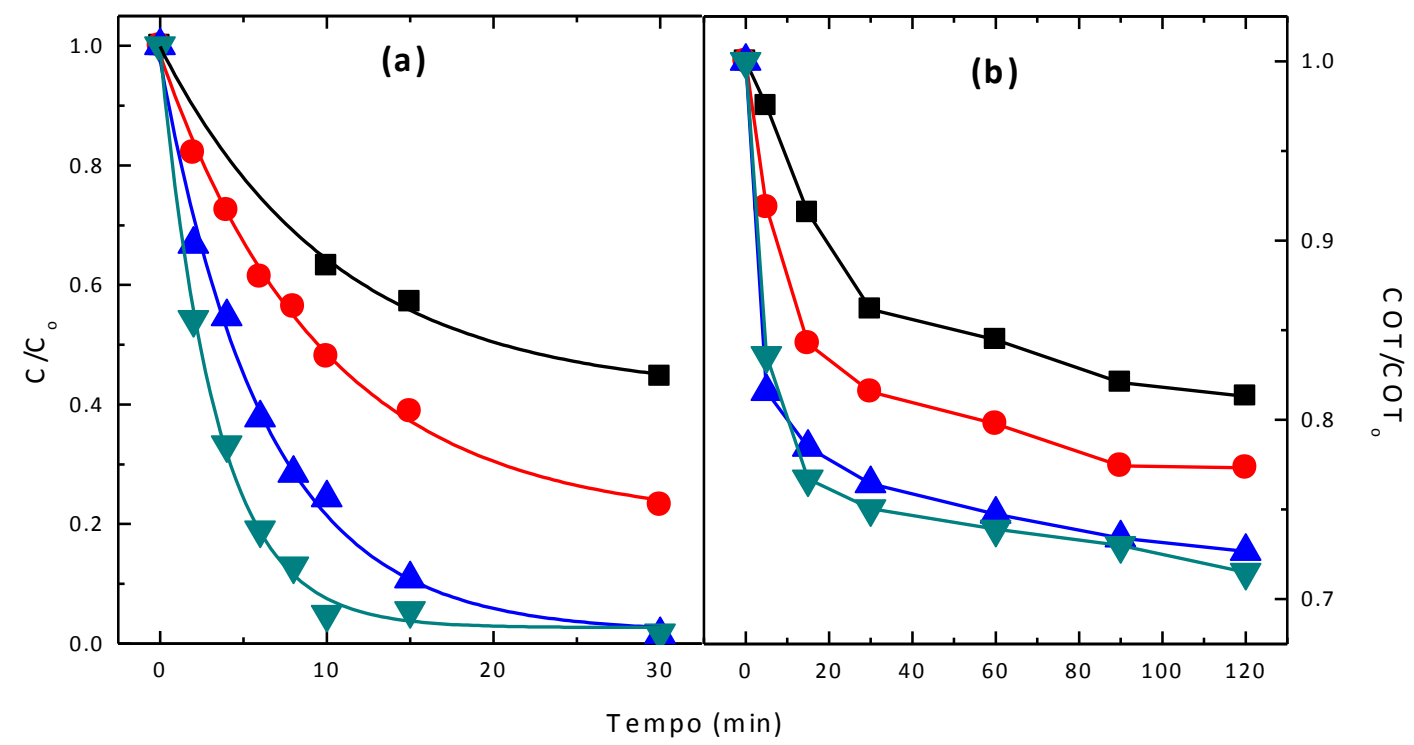

Figura 3.7 - Efeito da densidade de corrente: (ロ) $10 \mathrm{~mA} \mathrm{~cm}{ }^{-2}$, (Ө) $20 \mathrm{~mA} \mathrm{~cm}{ }^{-2}$, (A) $40 \mathrm{~mA} \mathrm{~cm}{ }^{-2}$, ( $\nabla) 60 \mathrm{~mA} \mathrm{~cm}{ }^{-2}$ na (a) degradação e (b) remoção do COT (Condições: $\mathrm{pH}_{\mathrm{i}}=3, \mathrm{~T}=25^{\circ} \mathrm{C}, \mathrm{C}_{\mathrm{smx}}=$ $200 \mathrm{mg} \mathrm{L}^{-1} \mathrm{e} \mathrm{C}_{\mathrm{NaCl}}=0,1 \mathrm{~mol} \mathrm{~L}^{-1}$ ).

Tabela 3.1 - Parâmetros cinéticos e de consumo de energia para o processo degradação eletroquímico de SMX

\begin{tabular}{cccccc}
\hline \hline Parâmetros & $\mathbf{k}\left(\mathbf{m i n}^{-1}\right)$ & $\mathbf{t}_{\mathbf{1} / \mathbf{2}}\left(\mathbf{m i n}^{-1}\right)$ & $\mathbf{R}_{\mathbf{2}}$ & $\mathbf{E}_{\mathbf{c e l l}}(\mathbf{V})$ & $\mathbf{E}_{\mathbf{E O}}\left(\mathbf{k W h} \mathbf{~ m}^{-3} \mathbf{o r d e r}^{-1}\right)$ \\
\hline \hline $\boldsymbol{i}\left(\mathbf{m} \mathbf{A ~ c m} \mathbf{~ m}^{-\mathbf{2}}\right)$ & & & & & \\
10 & 0,0292 & 23,708 & 0,904 & 0,45 & 0,981 \\
20 & 0,0471 & 14,697 & 0,951 & 1,10 & 1,482 \\
40 & 0,1379 & 5,024 & 0,997 & 3,25 & 1,507 \\
60 & 0,2840 & 2,439 & 0,981 & 7,35 & 1,655 \\
{$[\mathbf{N a C l}] \mathbf{( m o l ~ \mathbf { L } ^ { - 1 } )}$} & & & & & \\
0,02 & 0,0145 & 47,563 & 0,958 & 5,152 & 22,630 \\
0,04 & 0,0289 & 23,921 & 0,920 & 4,704 & 10,391 \\
0,08 & 0,0760 & 9,114 & 0,994 & 4,480 & 3,771 \\
0,10 & 0,1379 & 5,024 & 0,997 & 3,25 & 1,507 \\
$\mathbf{p H}$ & & & & & \\
2,5 & 0,2666 & 2,599 & 0,941 & 3,360 & 0,806 \\
5 & 0,1727 & 4,012 & 0,948 & 3,360 & 1,245 \\
7 & 0,1325 & 5,23 & 0,969 & 3,304 & 1,595 \\
9 & 0,1206 & 5,743 & 0,979 & 3,192 & 1,693 \\
\hline \hline
\end{tabular}


ordem $\left(\mathrm{E}_{\mathrm{EO}}\right)$, para os diferentes valores de densidades de corrente. Torna-se evidente, a partir da Tabela 3.1, que com o aumento da densidade de corrente há também um aumento no valor do potencial operacional do sistema, o qual resulta em um aumento do consumo energético, os resultados obtidos para $\mathrm{E}_{\mathrm{EO}}$ está de acordo com Malpass et al. (2006).

Já para menor valor de densidade da corrente, o tempo de eletrólise é maior. A condição otimizada em termos de tempo e de energia foi determinada, sendo o valor de densidade de corrente igual a $40 \mathrm{~mA} \mathrm{~cm} \mathrm{~cm}^{-2}$, a fim de se obter o máximo de degradação e remoção de COT no menor tempo possível e menos gasto de energia.

A Figura 3.8 representa a cinética de degradação SMX para vários valores de densidade de corrente, sendo que as inclinações das linhas retas estão associadas aos valores da constante de velocidade aparente $\left(\mathrm{k} \mathrm{em} \mathrm{min}^{-1}\right)$. Uma análise dos valores de $\mathrm{k}$ indica que a constante de velocidade aumenta com o aumento da densidade de corrente, e as reações de degradação seguem uma cinética de pseudo-primeira ordem.

Pode-se observar também na Tabela 3.1 que os valores de meia-vida experimental $\left(\mathrm{t}_{1 / 2}\right)$ de degradação do SMX são de 23,7, 14,69, 5,024 e 2,44 minutos, para valores de densidade de corrente de 10,20, 40 e $60 \mathrm{~mA} \mathrm{~cm}^{-2}$, respectivamente. Obviamente, os valores de $\mathrm{t}_{1 / 2}$ foram significativamente menores quando a densidade da corrente foi aumentado, devido à maior taxa de degradação.

Lin et al. (2013) também observaram uma aumento de constante de velocidade da reação de mineralização de $\mathrm{SMX}$ utilizando anodo de $\mathrm{Ti} / \mathrm{SnO}_{2}-\mathrm{Sb} / \mathrm{Ce}-\mathrm{PbO}_{2}$ e tendo mostrado que os valores de meio-vida experimental $\left(\mathrm{t}_{1 / 2}\right)$ diminuem significativamente com aumento de densidade de corrente.

\subsubsection{Efeito do pH inicial}

A influência do pH inicial da solução nos processos de degradação e mineralização foi estudada, considerando-se o intervalo de $\mathrm{pH}$ compreendido entre 2,5 a 9. Observa-se na Figura 3.9 (a) que com o aumento do pH inicial da solução, os processos de degradação e mineralização diminuíram, indicando que a condição ácida favorece a degradação e a remoção do COT do fármaco.

A razão para tal pode ser justificada pelo valor de $\mathrm{pKa}$ do SMX, Os valores de $\mathrm{pKa}_{1} \mathrm{e}$

$\mathrm{pKa}_{2}$ do SMX são 1,8 e 5,6, respectivamente, o que significa que o SMX está presente na forma catiônica em valores de $\mathrm{pH}<1,6$, enquanto que está presente na forma aniônica para 


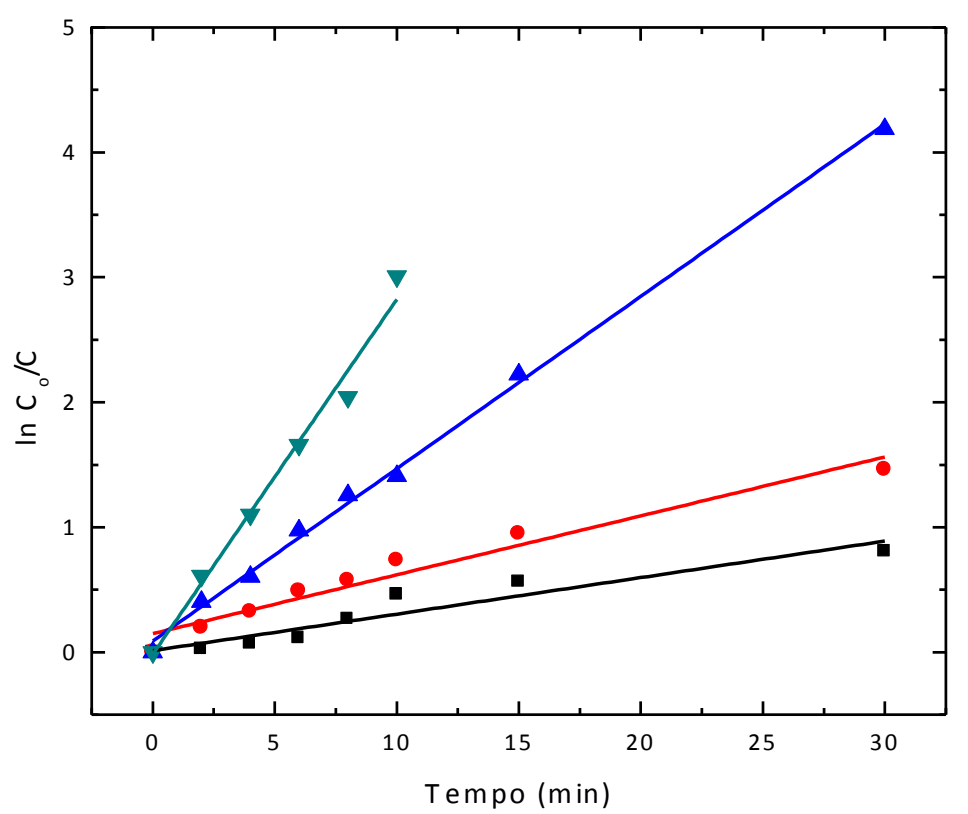

Figura 3.8 - Variação de $\ln \left(\mathrm{C}_{\mathrm{o}} / \mathrm{C}\right)$ em função do tempo de eletrólise para valores diferentes de

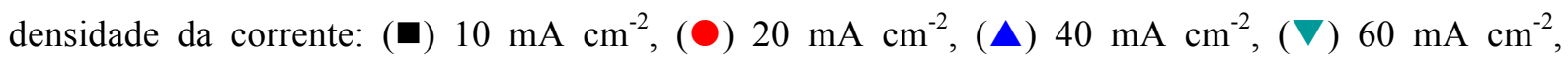
(Condições: $\mathrm{pH}_{\mathrm{i}}=3, \mathrm{~T} 25^{\circ} \mathrm{C}, \mathrm{C}_{\mathrm{smx}}=200 \mathrm{mg} \mathrm{L}^{-1} \mathrm{e}_{\mathrm{NaCl}}=0,1 \mathrm{~mol} \mathrm{~L}^{-1}$ ).

valores de $\mathrm{pH}>5,7$. Estes estados iônicos influenciam a reatividade do SMX, sendo que em valores de $\mathrm{pH}$ ácido, o SMX permanece na forma neutra, que é mais reativa Mouamfon et al. (2010a).

Devido a estas propriedades, o SMX foi degradado rapidamente nos valores de $\mathrm{pH}$ 2,5 e 5, quando comparado aos valores de $\mathrm{pH}$ iguais a 7 e 9, como presente na Figura 3.9(a). Além disso, na faixa de $\mathrm{pH}$ ácido, o cloro está presente na forma do ácido hipocloroso, o qual apresenta maior potencial de oxidação $(1,49 \mathrm{~V})$ do que o de hipoclorito $(0,94 \mathrm{~V})$ RAJKUMAR et al., (2007), o que resulta em um aumento da velocidade de degradação do SMX.

A Figura 3.9(b) mostra o perfil da remoção de COT em função do $\mathrm{pH}$ inicial da solução, ficando evidente que na condição básica não ocorre melhoria quanto à mineralização do SMX. Assim, pequenas porcentagens de remoção de COT foram obtidas 13, 15, 25 e 30\%, considerando-se valores de $\mathrm{pH}$ iguais a: 7, 9, 5 e 2,5, respectivamente. Isso significa que as espécies de maior potencial de oxidação, tais como, o $\mathrm{HOCl}$ e $\mathrm{Cl}_{2}$, estão em meio ácido, o qual é responsável pelo aumento da mineralização do SMX. As demais experiências foram realizadas com o valor $\mathrm{pH}$ igual a 3,0.

A Figura 3.10 apresenta a relação cinética de pseudo-primeira ordem para a degradação do SMX em valores diferentes de pH inicial da solução. Assim, pode ser 


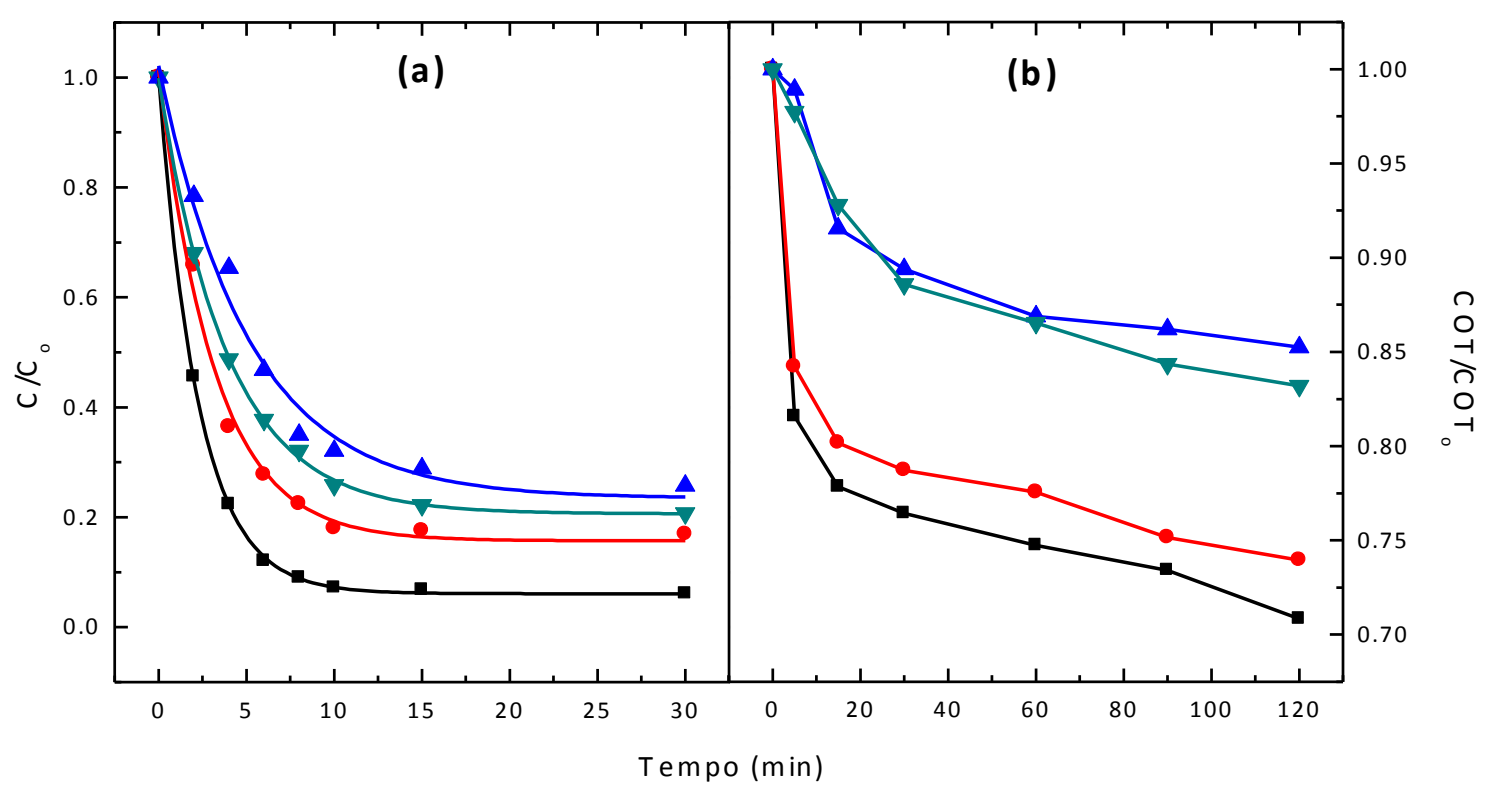

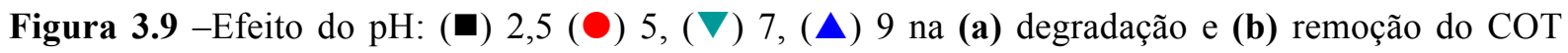
(Condições: $\mathrm{T}=25^{\circ} \mathrm{C}, \mathrm{C}_{\mathrm{smx}}=200 \mathrm{mg} \mathrm{L}^{-1}, \mathrm{C}_{\mathrm{NaCl}}=0,1 \mathrm{~mol} \mathrm{~L}^{-1} \mathrm{e} i=40 \mathrm{~mA} \mathrm{~cm}^{-2}$ ).

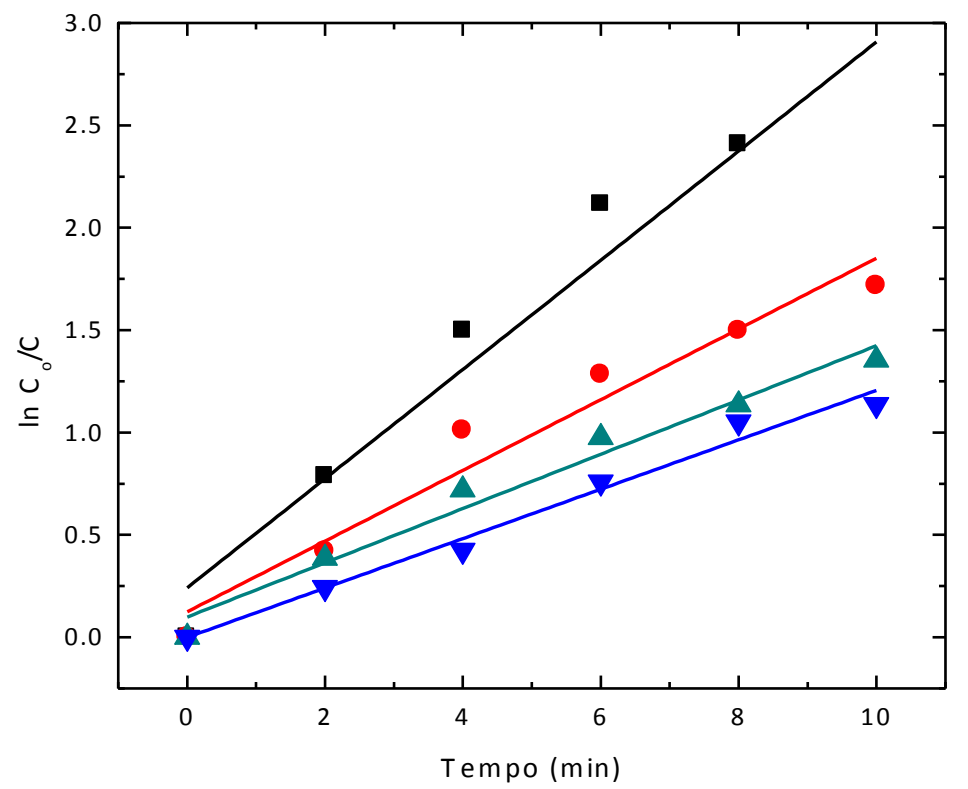

Figura 3.10 - Variação do $\ln \left(\mathrm{C}_{\mathrm{o}} / \mathrm{C}\right)$ em função do tempo de eletrólise para diferentes valores de $\mathrm{pH}$ :

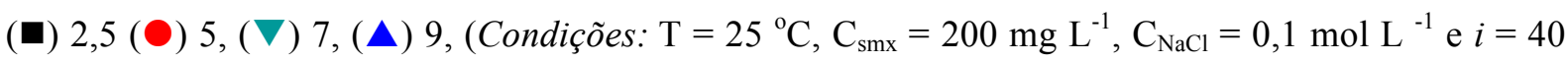
$\mathrm{mA} \mathrm{cm}{ }^{-2}$ ).

observado que o processo de degradação foi muito rápido em valores de $\mathrm{pH}$ iguais a 2,5 e 5, tornando-se lento em valores de $\mathrm{pH}$ iguais a 7 e 9. A Tabela 3.1 reúne os valores da constante 
de velocidade $(k)$, coeficiente linear $\left(\mathrm{R}^{2}\right)$ e os valores de $\mathrm{t}_{1 / 2}$ obtidos em diferentes $\mathrm{pH}$ iniciais.

Os valores da constante (k) são maiores para os valores de $\mathrm{pH}$ inicial iguais a 2.5 e 5 , tendo reduzido gradualmente quando o $\mathrm{pH}$ inicial da solução foi aumentado. Além disso, o processo de degradação para diferentes valores de $\mathrm{pH}$ inicial obedece uma cinética de pseudoprimeira ordem, enquanto que os valores de $t_{1 / 2}$ são menores em condições ácidas do que em condições básicas.

A Tabela 3.1 também apresenta os dados de energia por ordem $\left(\mathrm{E}_{\mathrm{EO}}\right)$, podendo ser observado que os valores do $\mathrm{E}_{\mathrm{EO}}$ são muito baixo para os valores 2,5 e 5, o que permite a avaliação do processo de degradação em termos de eficiência e de viabilidade. Os valores de $\mathrm{E}_{\mathrm{EO}}$ aumentaram para valores de $\mathrm{pH}$ elevado como 7 e 9 , o que resulta diminuição da eficiência do processo, conforme descrito no estudo anterior do nosso grupo de pesquisa (ALVES et al., 2010; MALPASS et al., 2007).

\subsubsection{Efeito da concentração inicial de SMX}

O efeito da concentração inicial do SMX no processo eletroquímico foi estudado para a faixa de concentração compreendida entre 50 a $200 \mathrm{mg} \mathrm{L}^{-1}$, utilizando-se uma densidade de corrente constante de $40 \mathrm{~mA} \mathrm{~cm}{ }^{-2}$, a pH 3, temperatura de $25{ }^{\circ} \mathrm{C}$ e concentração de eletrólito suporte $0,1 \mathrm{~mol} \mathrm{~L}^{-1}$.

Figura 3.11(a) indica que para os valores de concentração de SMX iguais a 50 e 100 $\mathrm{mg} \mathrm{L} \mathrm{L}^{-1}$, a degradação foi muito rápida, sendo que para a concentração de $100 \mathrm{mg} \mathrm{L}^{-1}$, a degradação foi praticamente completa após 8 minutos de tratamento. Já nos casos dos valores de concentração inicial de SMX iguais a 150 e $200 \mathrm{mg} \mathrm{L}^{-1}$, a degradação completa ocorreu após 15 e 30 minutos, respectivamente. A Figura 3.11 (a) demonstra que a degradação diminuiu com o aumento da concentração inicial do SMX, e isso pode ser explicado pelo fato de que, em condição galvanostático, a velocidade de produção de cloro/hipoclorito é constante. No entanto, o cloro ativo não é seletivo, o que significa que ele pode atacar qualquer um dos intermediários produzidos na solução. Um comportamento semelhante também foi observado por Lin et al. (2013) para a degradação de sulfametoxazol entre faixa de 10 a $400 \mathrm{mg} \mathrm{L}^{-1}$, usando anodo de $\mathrm{Ti} / \mathrm{SnO}_{2}-\mathrm{Sb} / \mathrm{Ce}-\mathrm{PbO}_{2}$.

A Figura 3.11(b) mostra que há menor redução de COT para um valor menor da concentração inicial do SMX. Assim, após 120 minutos de eletrólise, por exemplo, o COT foi reduzido de $10 \%, 14 \%, 17 \%$ e $28 \%$, para os valores de concentração iniciais de SMX de $50,100,150$ e $200 \mathrm{mg} \mathrm{L}^{-1}$, respectivamente. Essa tendência indica que houve formação de 


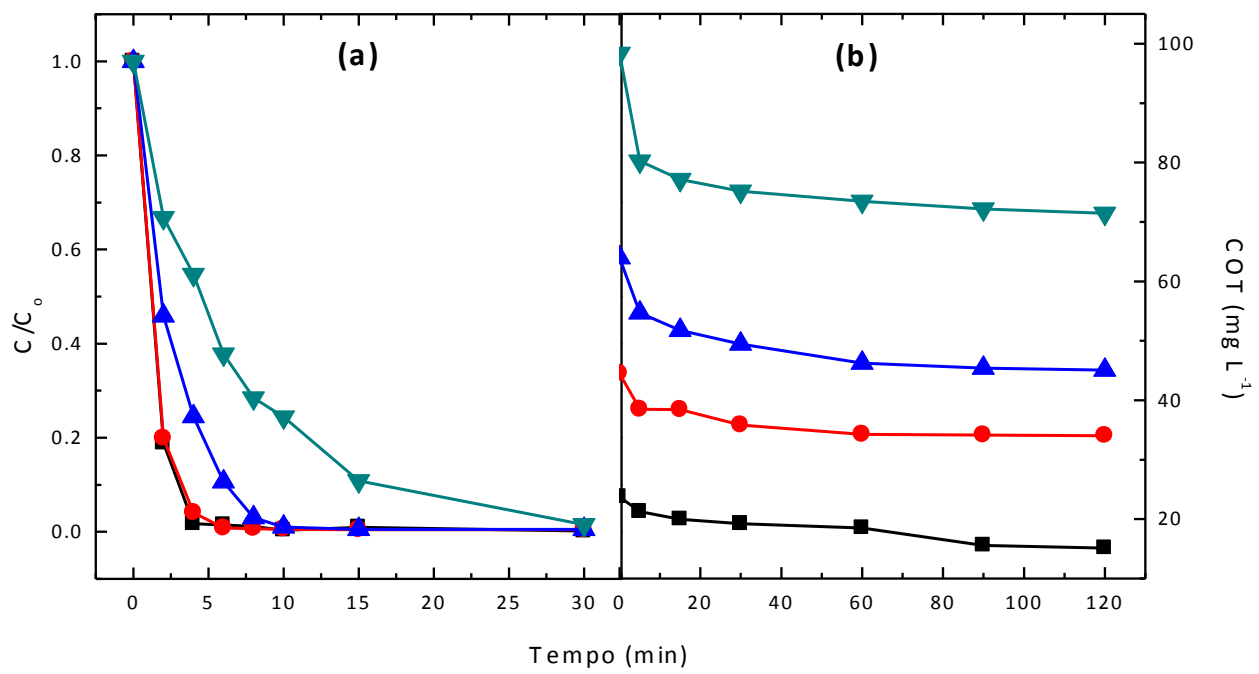

Figura 3.11 - Efeito da concentração inicial de SMX: (ロ)50 $\mathrm{mg} \mathrm{L}^{-1},(\bullet) 100 \mathrm{mg} \mathrm{L}^{-1},(\boldsymbol{\Delta}) 150 \mathrm{mg} \mathrm{L}^{-1}$, $(\boldsymbol{\nabla}) 200 \mathrm{mg} \mathrm{L}^{-1}$ na (a) degradação e (b) remoção do $\mathrm{COT}$ (condições: $\mathrm{T}=25^{\circ} \mathrm{C}, \mathrm{pH}_{\mathrm{i}}=3, \mathrm{C}_{\mathrm{NaCl}}=0,1$ $\mathrm{mol} \mathrm{L}^{-1} \mathrm{e} i=40 \mathrm{~mA} \mathrm{~cm}^{-2}$ ).

uma grande quantidade de subprodutos recalcitrantes em baixo concentrações de SMX.

Em contrapartida, foi observada uma remoção rápida de COT em até 30 minutos, tornando-se em seguida constante (Figura 3.11(b)), significando que o SMX foi degradado completamente até os limites de detecção de equipamento e que algumas outras substâncias intermediárias foram formadas, as quais são mais difíceis de serem destruídas nas condições empregadas.

\subsubsection{Efeito da temperatura na degradação eletroquímica}

Com o objetivo de se avaliar o efeito da temperatura na degradação e mineralização do SMX, uma série de experimentos foi realizada, utilizando-se densidade de corrente constante e igual a $40 \mathrm{~mA} \mathrm{~cm}{ }^{-2}$, obtendo os resultados que estão indicados na Figura 3.12. Pode-se observar que o aumento de temperatura de $25{ }^{\circ} \mathrm{C}$ para $45{ }^{\circ} \mathrm{C}$ exerce um efeito não significativo na degradação e remoção do COT. Assim, a taxa de degradação do SMX é quase semelhante para os valores de temperatura de 25 e $45{ }^{\circ} \mathrm{C}$.

A análise da Figura 3.12(a) confirma que a temperatura exerce um pequeno efeito sobre a taxa de degradação do SMX, assim ocorre um pequeno aumento na remoção do COT quando a temperatura é aumentada de 25 para $45{ }^{\circ} \mathrm{C}$. Torna-se evidente na Figura 3.12 que para os casos em que o SMX foi degradado completamente, o COT foi removido em até $25 \%$ para os valores de temperatura de 25 e $35^{\circ} \mathrm{C}$, enquanto que foi removido em $28 \%$ a $45^{\circ} \mathrm{C}$. 


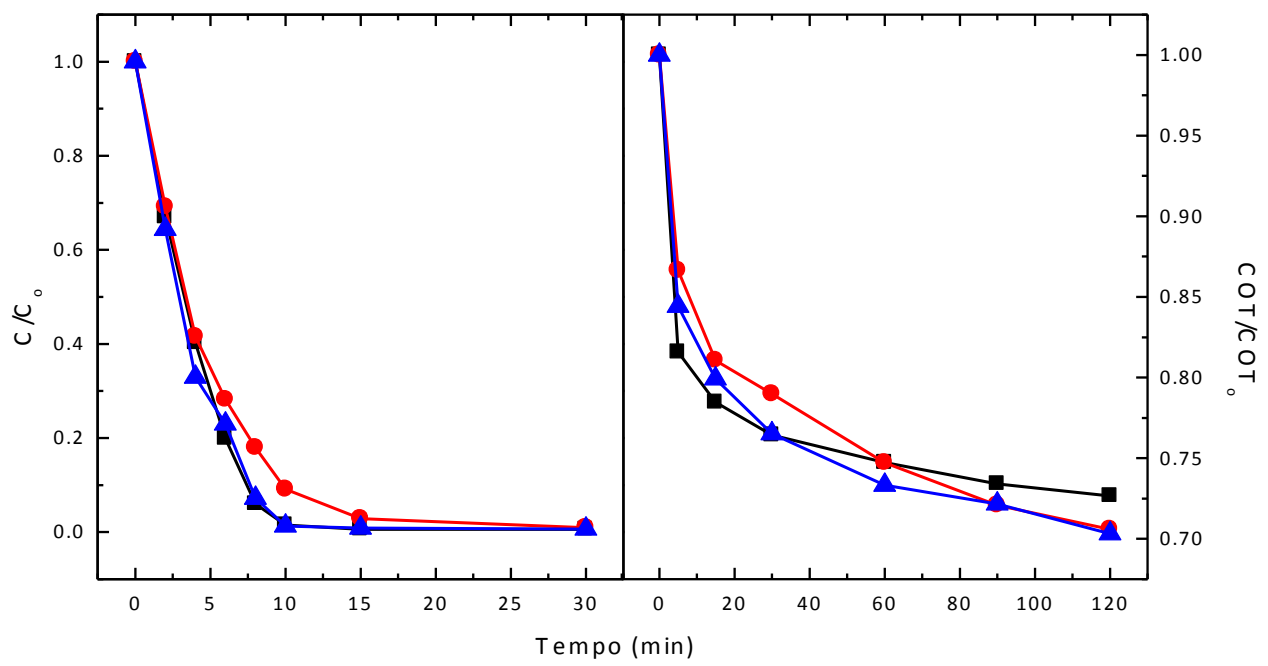

Figura 3.12 - Efeito da temperatura: $(\square) 25{ }^{\circ} \mathrm{C},(\bullet) 35{ }^{\circ} \mathrm{C},(\boldsymbol{\Delta}) 45^{\circ} \mathrm{C}$ na (a) degradação e (b) remoção do COT (Condições: $\mathrm{C}_{\mathrm{smx}}=200 \mathrm{mg} \mathrm{L}^{-1}, \mathrm{pH}_{\mathrm{i}}=3, \mathrm{C}_{\mathrm{NaCl}}=0,1 \mathrm{~mol} \mathrm{~L}^{-1} \mathrm{e} i=40 \mathrm{~mA} \mathrm{~cm}{ }^{-2}$ ).

\subsubsection{Monitoramento da degradação eletroquímica de SMX por UV-Vis e CLAE}

Durante as eletrólises, a cor da solução inicialmente variou de maneira regular, saindo de uma coloração rósea (até 15 minutos de experimento) para uma coloração amarela, indicando o progresso da reação. Após 120 minutos, as soluções se tornaram quase incolores, o que foi associado a destruição completa do SMX.

Um espectro de UV-Vis da solução diluída (4 vezes) do SMX está mostrado na Figura 3.13(a). O pico de absorção máxima do SMX encontra-se localizado em $270 \mathrm{~nm}$, de forma que o mesmo diminuiu rapidamente ao longo da eletrólise, desaparecendo após 60 minutos.

Por meio da Figura 3.13(b) é possível verificar o perfil do cromatograma de CLAE para o fármaco estudado. É evidente que o pico característico de SMX no cromatograma apareceu em um tempo de retenção de 9 minutos, sendo que, com passar do tempo da eletrólise, a intensidade desse pico diminuiu, desaparecendo completamente após 60 minutos. Por outro lado, os picos característicos de compostos intermediários são observados depois de iniciada a eletrólise em tempos de retenção diversos.

\subsubsection{Condições otimizadas}

Após a determinação das condições experimentais otimizadas $\left(40 \mathrm{~mA} \mathrm{~cm}{ }^{-2}, \mathrm{pH} 3\right.$, solução de $\mathrm{NaCl} 0,1 \mathrm{~mol} \mathrm{~L}^{-1}, 200 \mathrm{mg} \mathrm{L}^{-1}$ de SMX), foi realizada uma eletrólise por um 


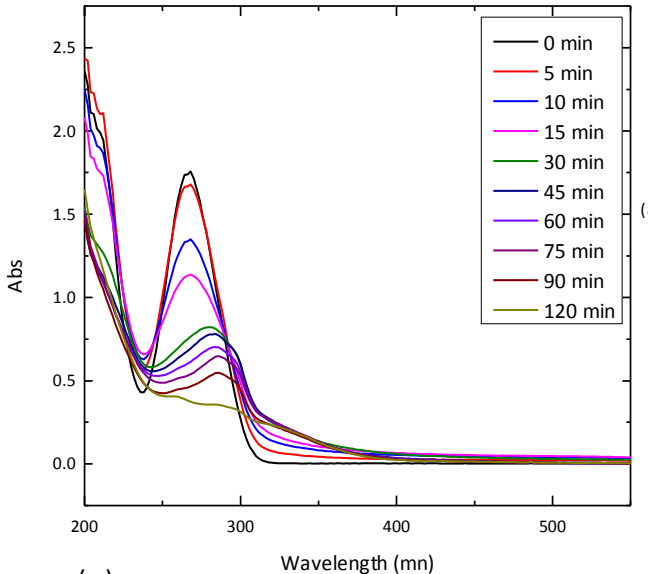

(a)

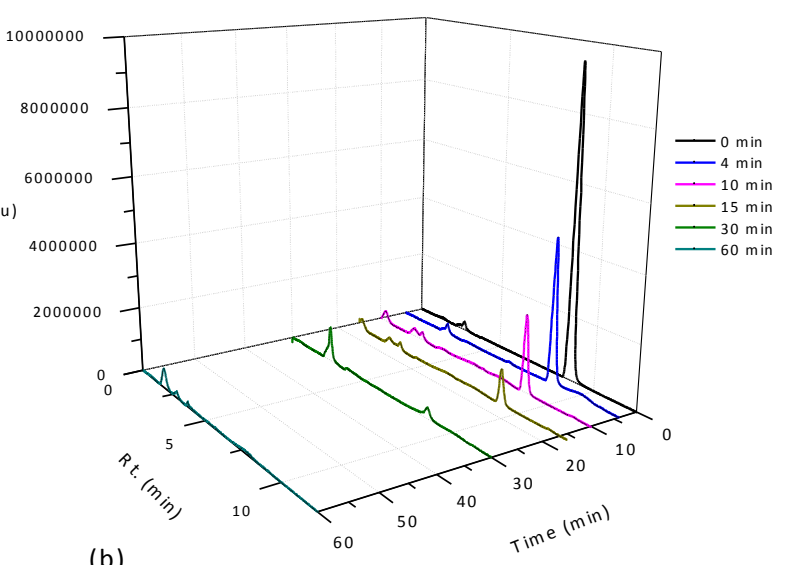

(b)

Figura 3.13 - (a) Espectros de UV-Vis das soluções (SMX 4 diluições em volume) para a degradação (b) cromatograma de CLAE (Condições: $\mathrm{C}_{\mathrm{smx}}=200 \mathrm{mg} \mathrm{L}^{-1}, \mathrm{~T}=25^{\circ} \mathrm{C}, \mathrm{pH}_{\mathrm{i}}=3, \mathrm{C}_{\mathrm{NaCl}}=0,1 \mathrm{~mol} \mathrm{~L}^{-1} \mathrm{e} i$ $=40 \mathrm{~mA} \mathrm{~cm}{ }^{-2}$ ).

tempo prolongado (240 min). Pode ser verificado pela Figura 3.14 que os decréscimos de SMX e de COT ocorrem simultaneamente, tendo sido atingido cerca de 29 \% da remoção de COT ao final da eletrólise. Foi calculado através da razão entre as porcentagens de remoção do $\operatorname{COT}$ e do $\operatorname{SMX}(\varphi)$, um parâmetro interessante, considerado como a extensão de remoção total ou completa por combustão, como discutido na literatura (MIWA et al., 2006).

$$
\phi=\frac{\%[C O T]_{\text {removido }}}{\%[S M X]_{\text {removido }}}
$$

$\mathrm{O}$ parâmetro $\varphi$ pode assumir valores entre 0 e 1, isto é, nenhuma combustão ou combustão total com relação ao poluente, respectivamente. Observou-se que a eletro-oxidação do SMX ocorreu com a mineralização, em que se obteve $\varphi=\sim 0,3$, após 240 minutos de eletrólise. O decréscimo do SMX com o tempo de eletrólise mostra que o SMX foi removido completamente, enquanto que foi mineralizado parcialmente. $\mathrm{O}$ consumo energético necessário para se conseguir $30 \%$ de remoção do COT e $100 \%$ de degradação foi o de 1.507 $\mathrm{kW} \mathrm{h} \mathrm{m}{ }^{-3}$ ordem $^{-1}$.

O remoção de COT está quase igual com os valores reportados por Wang et al. (2011) no processos de $\mathrm{AO}$ (oxidação anódica), $\mathrm{AO}-\mathrm{H}_{2} \mathrm{O}_{2}$, e $\mathrm{AO}-\mathrm{H}_{2} \mathrm{O}_{2}-\mathrm{UVA}$. Os valores de energia por ordem ( $\left.\mathrm{E}_{\mathrm{EO}}\right)$ estão acima do reportado por Miwa et al. (2006) para degradação de carbaril com eletrodo de óxido, mas estão baixo do citado por MALPASS et al., 2008. 


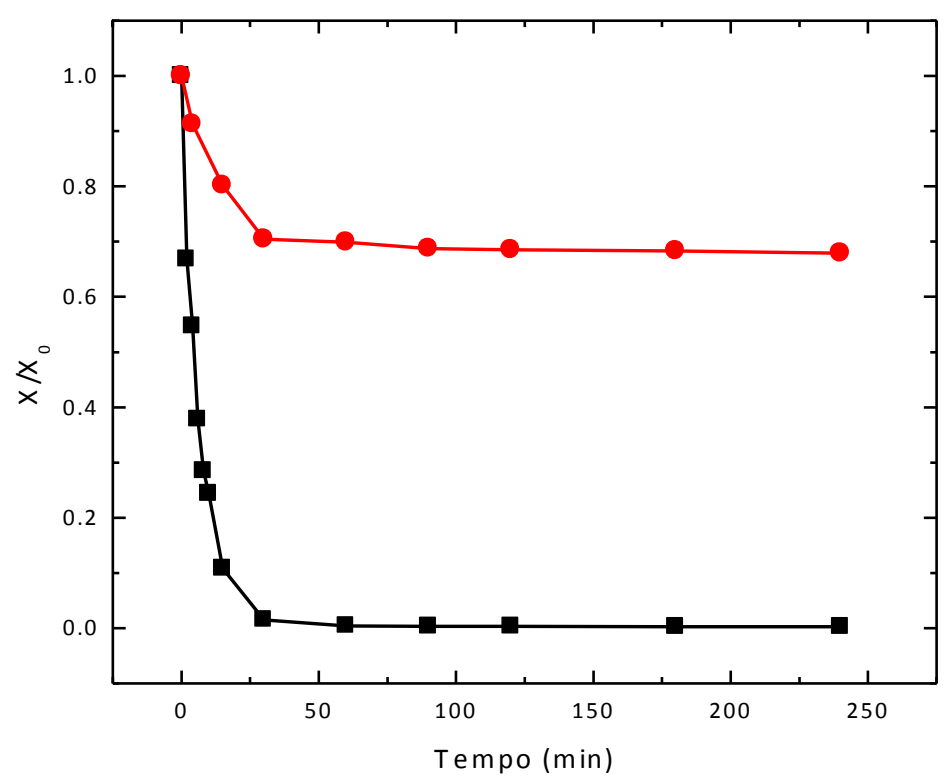

Figure 3.14 - Decréscimo relativo de COT (-) e concentração de SMX (-) em função do tempo de eletrólise (Condições: $i=40 \mathrm{~mA} \mathrm{~cm}{ }^{-2}, \mathrm{pH}_{\mathrm{i}}=3, \mathrm{C}_{\mathrm{NaCl}}=0,1 \mathrm{~mol} \mathrm{~L}^{-1} \mathrm{e} \mathrm{C}_{\mathrm{smx}}=200 \mathrm{mg} \mathrm{L}^{-1}$ ). A força iônica foi mantida a $0,1 \mathrm{~mol} \mathrm{~L}^{-1}$ sob adição de $\mathrm{Na}_{2} \mathrm{SO}_{4}$.

\subsection{Identificação dos intermediários formados durante a degradação eletroquímica de SMX}

A detecção e identificação de fármacos e seus metabólitos no ambiente, bem como os intermediários dos processos de degradação, realizada através da técnica de Cromatografia Líquida de Alta Eficiência acoplada à Espectrometria de Massas (CLAE-EM), (PETROVIC; BARCELÓ, 2006). Essa técnica apresenta algumas vantagens em relação à Cromatografia Gasosa acoplada à Espectrometria de Massas (CG-EM), pois, tanto os fármacos como seus metabólitos ou intermediários formados, são moléculas polares que apresentam pouca volatilidade e necessitam de derivatização para serem analisadas por CG-MS.

A derivatização representa uma desvantagem, pois a análise de fármacos normalmente é feita de forma simultânea com os fármacos de grupos funcionais muito diferentes (PETROVIC; BARCELÓ, 2006). Além disso, a técnica de CG-MS também não é indicada para análise de compostos termicamente instáveis, como é o caso do SMX (RADJENOVIĆ et al., 2009).

Para investigar os intermediários de degradação e proposição da possível rota de degradação para as amostras de SMX foram analisados por LC-MS, de modo que as amostras analisadas correspondem ao processo de degradação realizado em condições otimizadas: (40 mA cm $\mathrm{cm}^{-2} \mathrm{pH} \mathrm{3,} \mathrm{e} 0,1 \mathrm{~mol} \mathrm{~L}^{-1} \mathrm{NaCl}, 200 \mathrm{mg} \mathrm{L}^{-1}$ de SMX). Durante os 
experimentos, alíquotas foram retiradas em intervalos pré-determinados, e extraídas de acordo com a técnica de extração em fase sólida, utilizando-se cartuchos Sep-Pak $\mathrm{C}_{18}$ da Waters, Strata X, Phenomenex e Oasis HLB Waters, sendo em seguida analisados.

$\mathrm{O}$ espectro $\mathrm{LC}-\mathrm{MS} / \mathrm{ESI}_{(+)}$referente ao composto principal pode ser observado na Figura 3.15. O composto apresenta massa molar (M) 253 e íon molecular protonado $[\mathrm{M}+\mathrm{H}]^{+}$ de relação massa/carga (m/z) de 254, localizado em 15,3 min. A Figura 3.16 corresponde ao cromatograma de LC-MS, apresentando os nove principais intermediários que foram formados durante o processo de degradação do fármaco SMX. No cromatograma também aparecem outros produtos de degradação e também os sinais correspondentes à formação de dímeros.

O pico principal do SMX foi detectado no tempo de retenção de 15,3 min, como o que foi descrito na Figura 3.16. Na Tabela 3.2 são apresentados os principais compostos intermediários, com suas respectivas relações massa/carga $(\mathrm{m} / \mathrm{z})$, fórmulas moleculares e estruturas químicas e os espectras de massas referentes aos intermediário principais apresentados nas Figuras 3.18-3.25.

Os produtos de degradação foram analisados por LC/MS e, em geral, os mecanismos envolvem inserção dos radicais hidroxila $\left({ }^{\circ} \mathrm{OH}\right)$ e cloro $\left(\mathrm{Cl}^{\circ}\right)$, uma vez que foi utilizado $\mathrm{NaCl}$ como eletrólito suporte. Figura 3.15 mostra a caracterização do composto padrão SMX, o qual apresenta tempo de retenção (LC-UV) em 15,3 minutos, e fragmento $\mathrm{m} / \mathrm{z}=254$ como principal íon molecular.

Um dos intermediários reativos formados e identificados é o fragmento $\mathrm{m} / \mathrm{z}=273$, proveniente da adição do radical hidroxila ao anel aromático e correspondente à fração anilina do composto. $\mathrm{O}$ composto referente à $\mathrm{m} / \mathrm{z}=271$ também foi identificado como subproduto de degradação (TROVÓ et al., 2009).<smiles>Cc1cc(NS(=O)(=O)c2ccc(N)cc2)no1</smiles>

Sulfametoxazol<smiles>Cc1cc(NS(=O)(=O)c2ccc(N)c(O)c2)no1</smiles>

$\mathbf{m} / \mathrm{z}=\mathbf{2 7 1}$

detectado 272

[+H] 

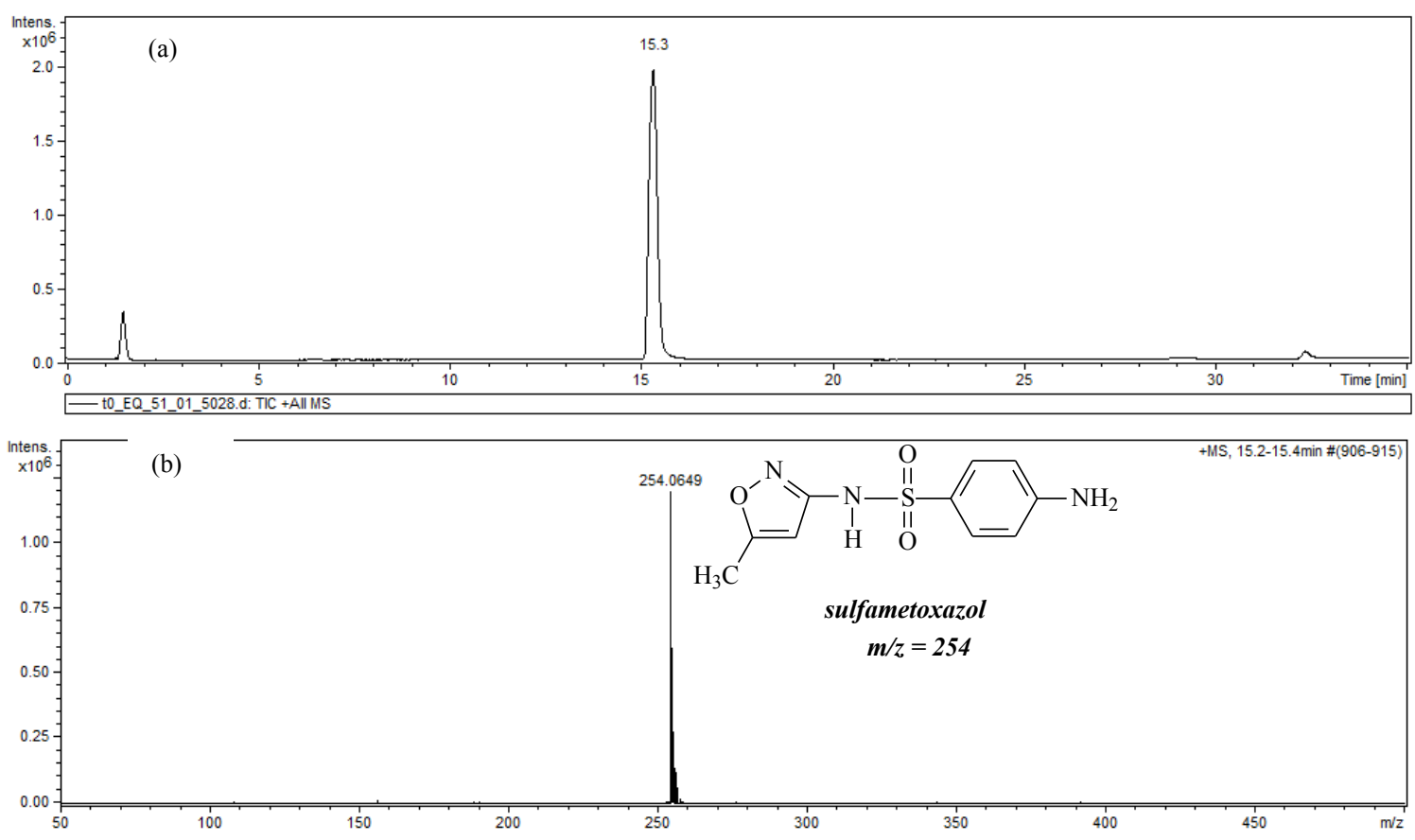

Figura 3.15 - (a) LC-UV cromatograma de padrão de SMX; (b) espectro de massa de SMX m/z = $254\left(\mathrm{C}_{10} \mathrm{H}_{11} \mathrm{~N}_{3} \mathrm{SO}_{3}\right)$.

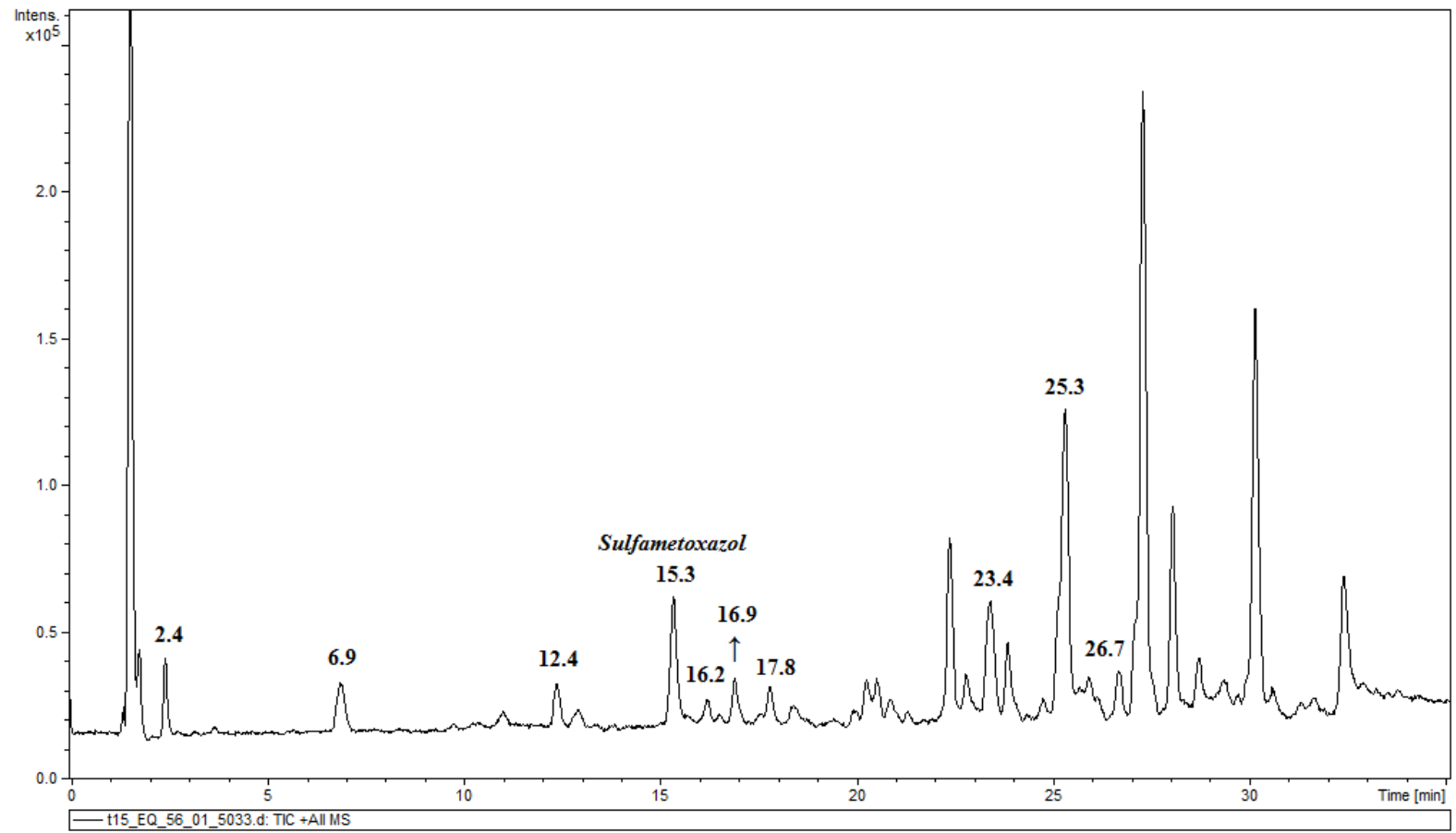

Figura 3.16 - Cromatograma de LC-MS da amostra retirada após 15 min de eletrólise de SMX. (Condições: $i=40 \mathrm{~mA} \mathrm{~cm}{ }^{-2}, \mathrm{pH}_{\mathrm{i}} 3, \mathrm{C}_{\mathrm{NaCl}}=0,1 \mathrm{~mol} \mathrm{~L}^{-1} \mathrm{e} \mathrm{C}_{\mathrm{smx}}=200 \mathrm{mg} \mathrm{L}^{-1}$ ). 
Tabela 3.2 - Principais intermediários formados durante degradação de SMX através do processo eletroquímico

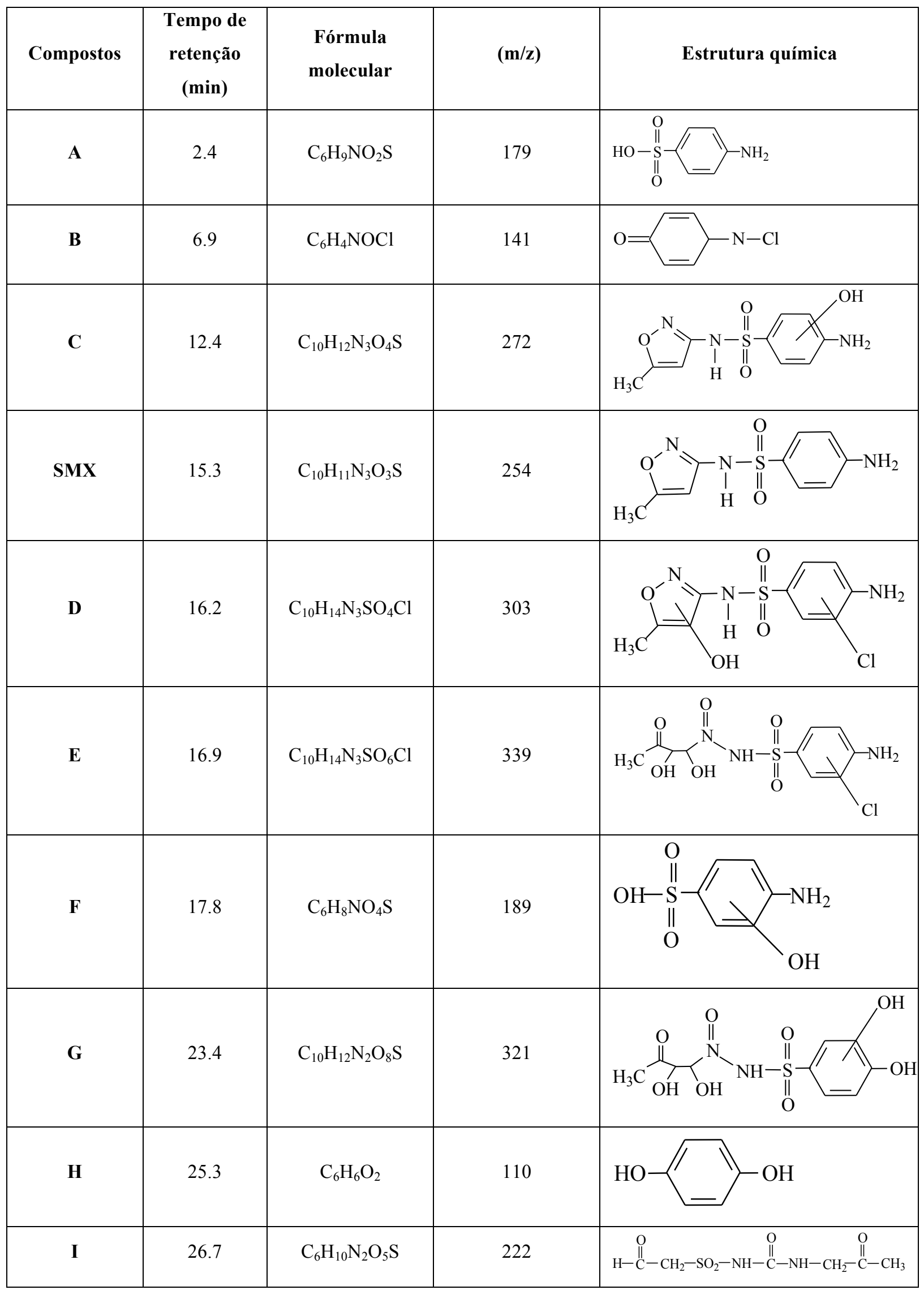




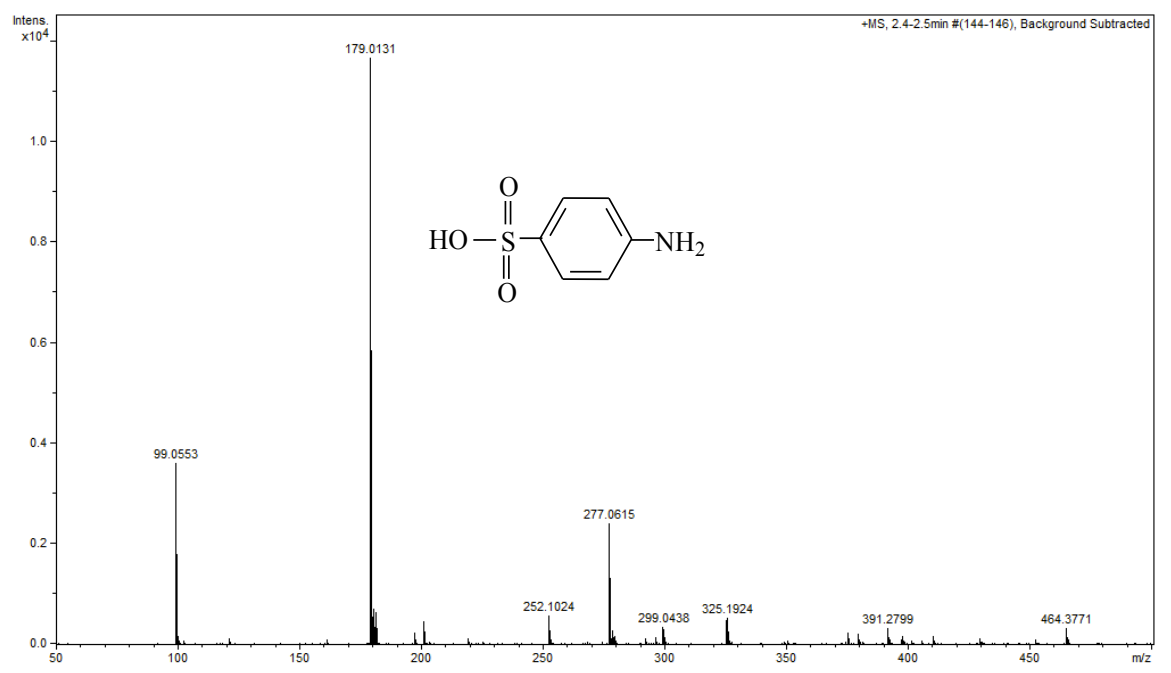

Figura 3.17 - Espectros de massas referentes aos intermediários, condizente à m/z $=179$.

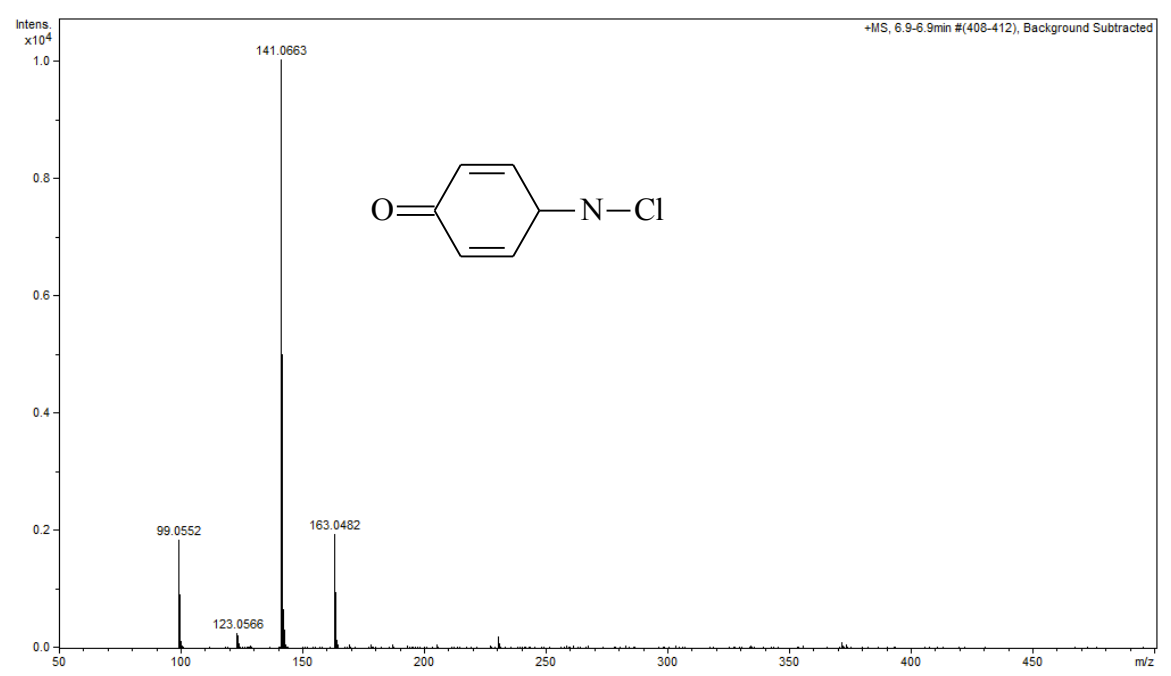

Figura 3.18 - Espectros de massas referentes aos intermediários, condizente à m/z $=141$.

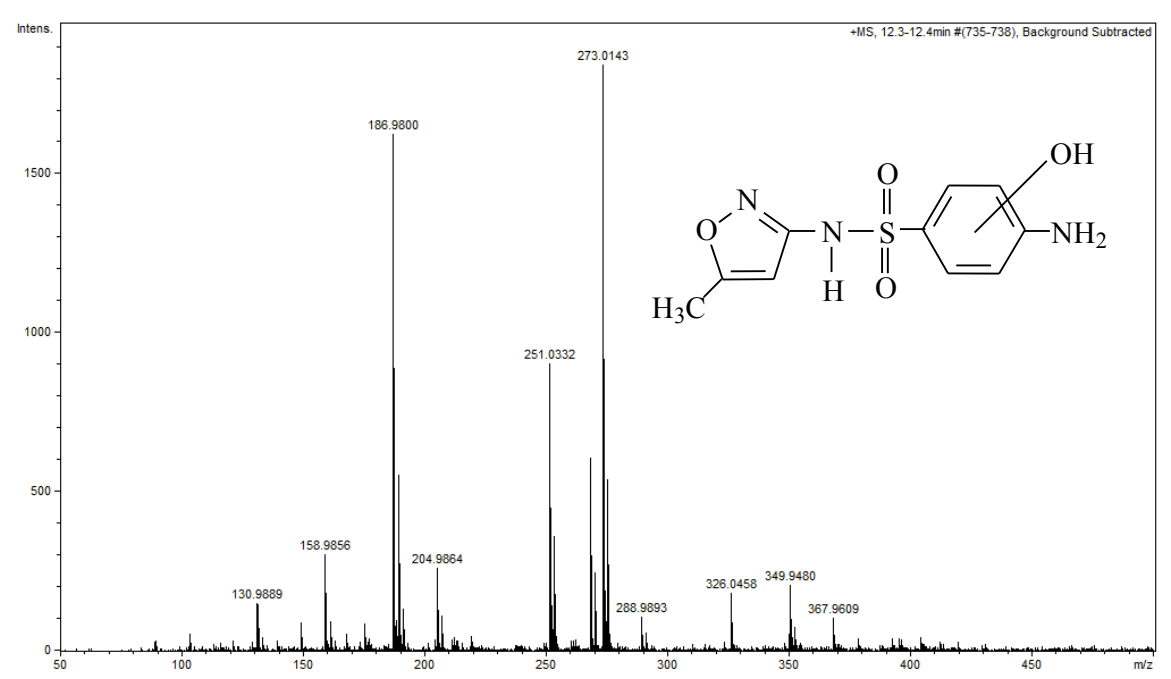

Figura 3.19 - Espectros de massas referentes aos intermediários, condizente à m/z $=274$. 


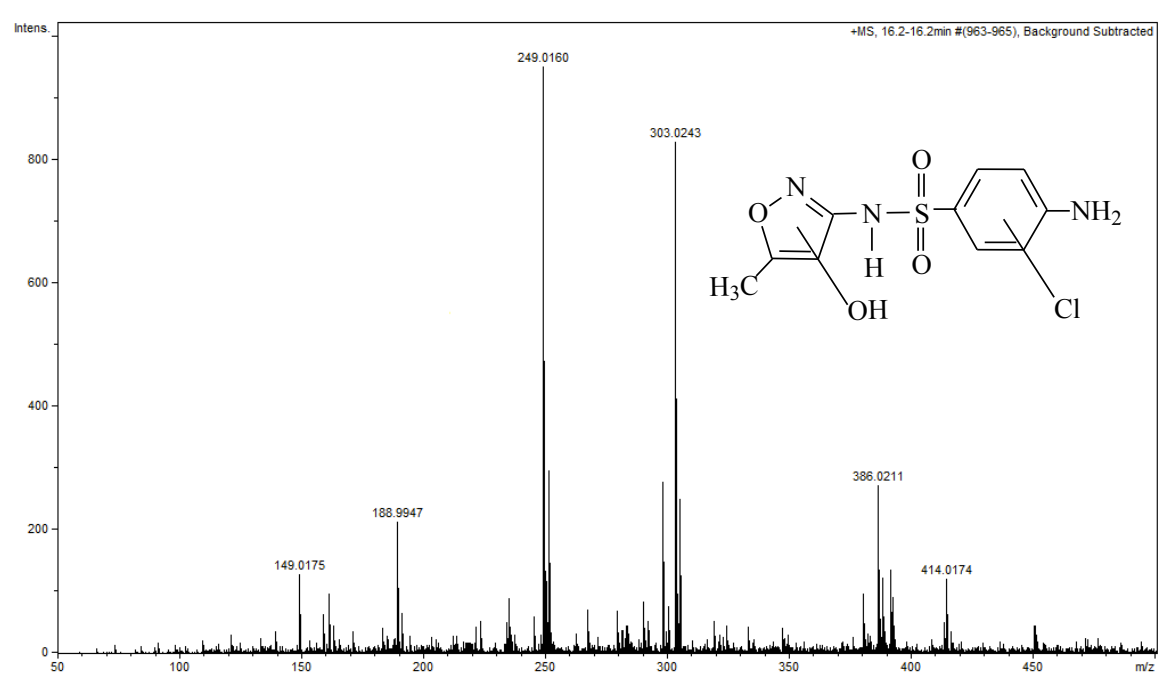

Figura 3.20 - Espectros de massas referentes aos intermediários, condizente à m/z $=303$.

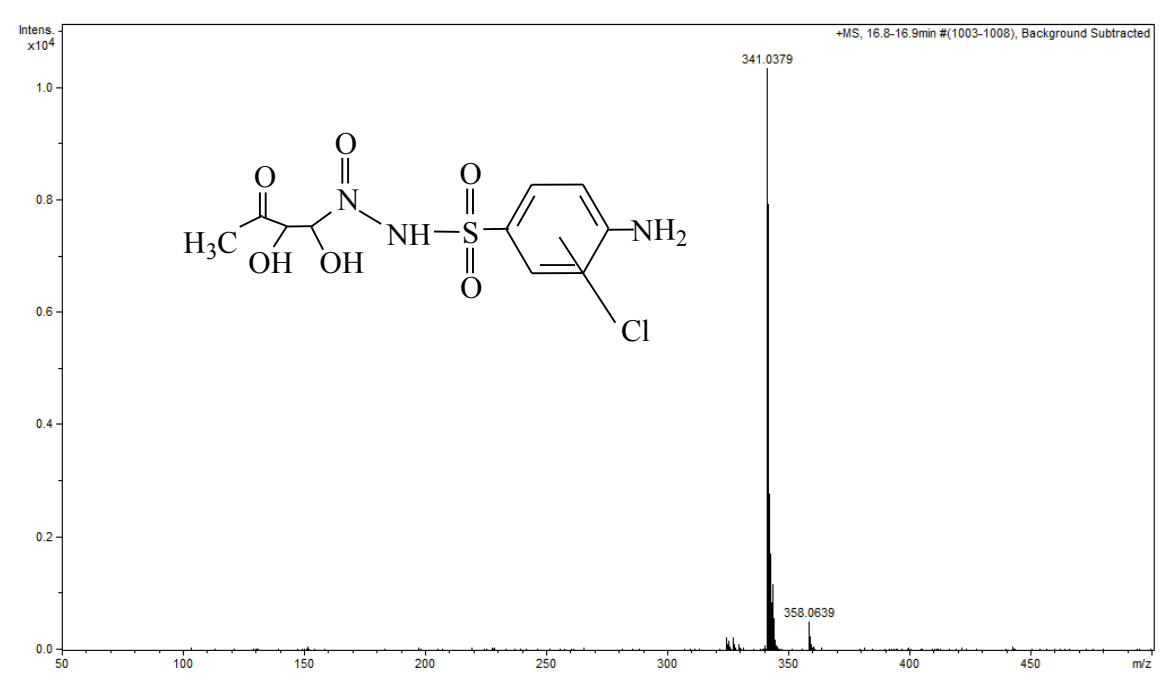

Figura 3.21 - Espectros de massas referentes aos intermediários, condizente à m/z $=341$.

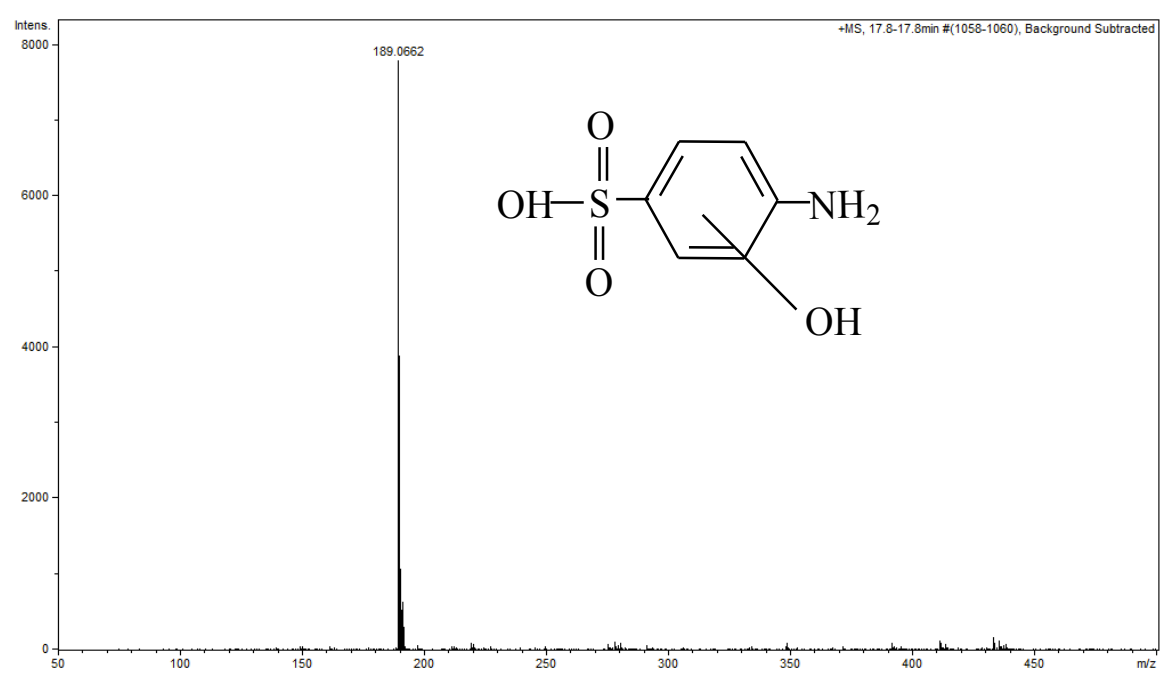

Figura 3.22 - Espectros de massas referentes aos intermediários, condizente à m/z $=189$. 


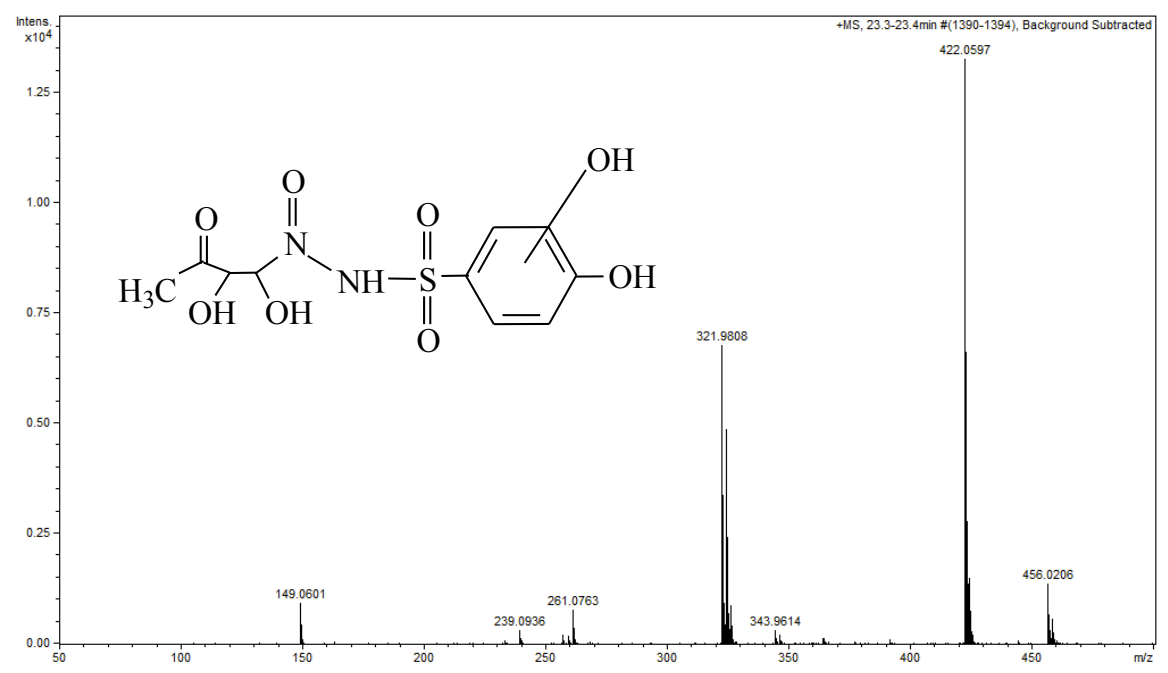

Figura 3.23 - Espectros de massas referentes aos intermediários, condizente à m/z $=321$.

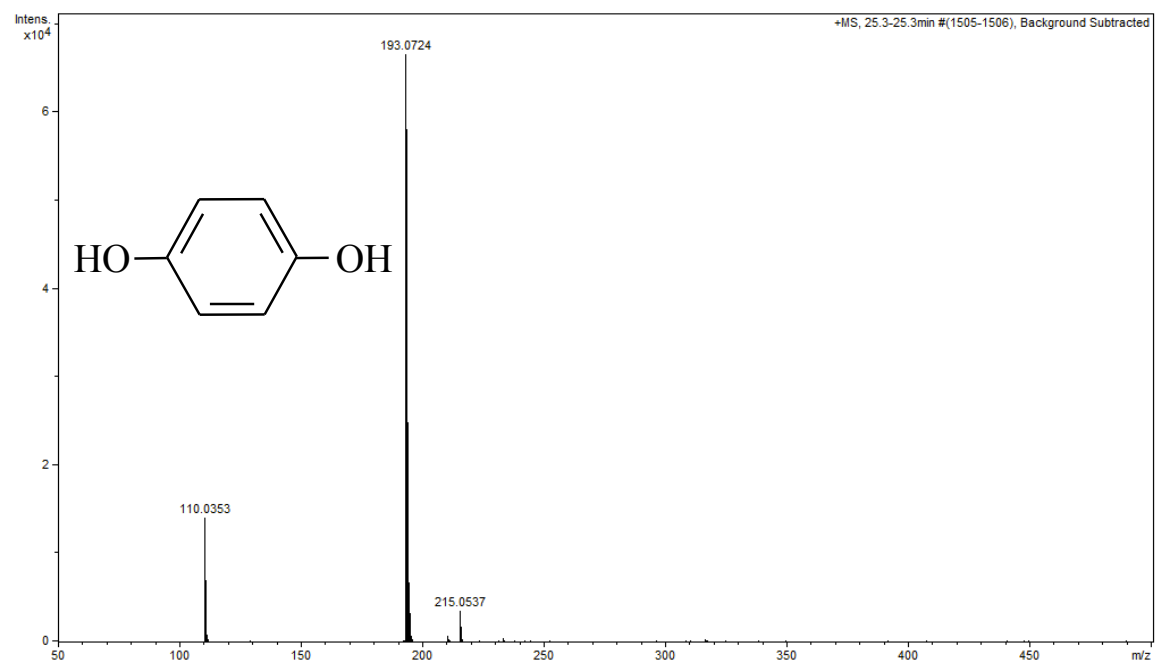

Figura 3.24 - Espectros de massas referentes aos intermediários, condizente à m/z $=110$.

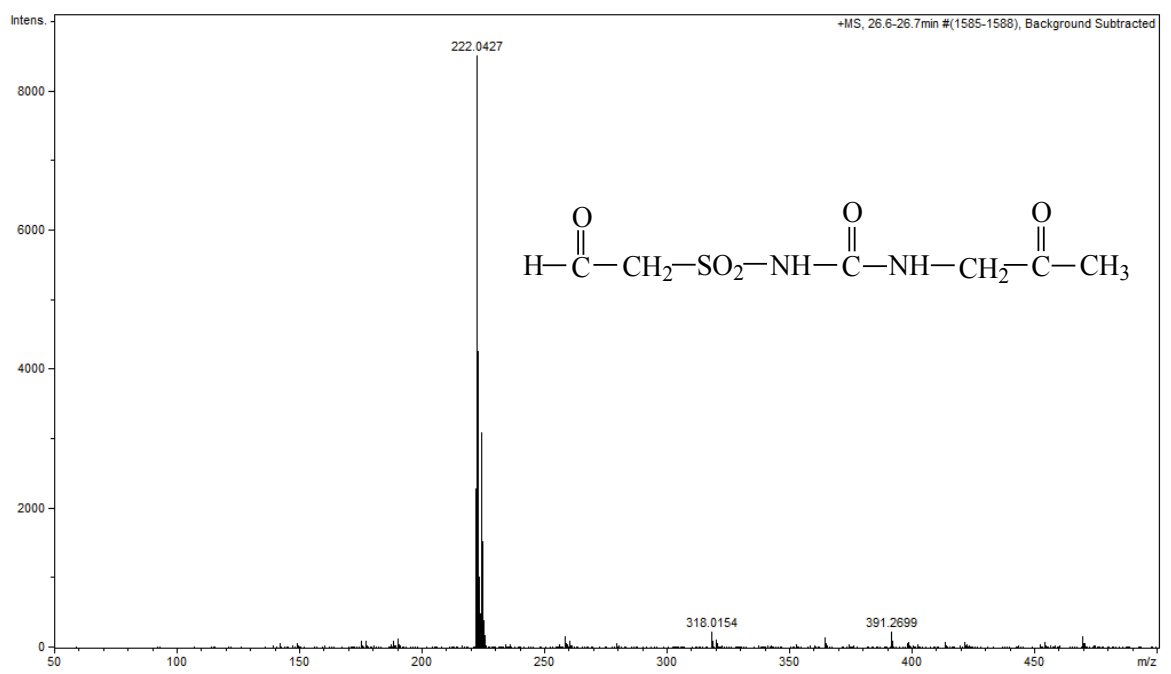

Figura 3.25 - Espectros de massas referentes aos intermediários, condizente à m/z $=222$. 
Pode ocorrer também a eliminação do agrupamento $\mathrm{NH}_{2}$ na forma de $\mathrm{NH}_{3(\mathrm{~g})}$, seguido por uma hidroxilação ou inserção de radical hidroxila ao anel aromático, formando o intermediário $\mathrm{m} / \mathrm{z}=242$ também detectado. Como há espécies de cloro ativo no meio, pode ocorrer a inserção deste radical ao anel aromático, gerando, portanto, o fragmento $\mathrm{m} / \mathrm{z}=277$.<smiles>Cc1cc(NS(=O)(=O)c2ccc(N)cc2)no1</smiles>

Sulfametoxazol

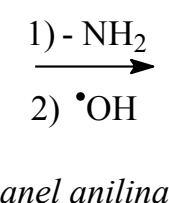

anel anilina<smiles>Cc1cc(NS(=O)(=O)c2ccc(O)cc2)no1</smiles>

$\mathrm{m} / \mathrm{z}=\mathbf{2 4 2}$<smiles>Cc1cc(NS(=O)(=O)c2ccc(O)c(Cl)c2)no1</smiles>

Os fragmentos $\mathrm{m} / \mathrm{z}=288 \mathrm{e} \mathrm{m} / \mathrm{z}=303$ foram identificados no espectro de massas e atribuídos à inserção de um cloro radical ao anel aromático do composto padrão (DODD; HUANG, 2004), seguido pela inserção do radical hidroxila, possivelmente na fração oxazolídica desse composto, como se verifica no esquema abaixo descrito.<smiles>Cc1cc(NS(=O)(=O)c2ccc(N)cc2)no1</smiles>

Sulfametoxazol<smiles>Cc1cc(NS(=O)(=O)c2ccc(N)c(Cl)c2)no1</smiles>

$\mathbf{m} / \mathbf{z}=\mathbf{2 8 8}$<smiles>[Y][CH]</smiles><smiles>Cc1onc(NS(=O)(=O)c2ccc(N)c(Cl)c2)c1O</smiles>

$\mathbf{m} / \mathbf{z}=\mathbf{3 0 5}$

detectado 303

Outra possibilidade de reação é a dupla inserção dos radicais de cloro ao anel aromático da fração piridínica do fármaco, gerando assim o fragmento m/z $=326$. 
<smiles>Cc1cc(NS(=O)(=O)c2ccc(N)cc2)no1</smiles>

Sulfametoxazol<smiles>Cc1cc(NS(=O)(=O)c2cc(Cl)c(N)c(Cl)c2)no1</smiles>

$\mathbf{m} / \mathbf{z}=\mathbf{3 2 4}$

detectado $326[+2 \mathrm{H}]$

Na molécula de SMX pode ocorrer a ruptura da ligação N-S, ocorrendo então a liberação de fragmentos correspondentes aos anéis oxazolídico e anilina, pertencentes a este composto. Dessa forma, dois fragmentos com $\mathrm{m} / \mathrm{z}=98$ e $\mathrm{m} / \mathrm{z}=158$ foram identificados.<smiles>Cc1cc(NS(=O)(=O)c2ccc(N)cc2)no1</smiles>

Sulfametoxazol ruptura da ligação

$\mathrm{N}-\mathrm{S}$<smiles></smiles>

$\mathbf{m} / \mathbf{z}=98$

Considerando-se o fragmento $\mathrm{m} / \mathrm{z}=158$, pode ocorrer a eliminação de $\mathrm{NH}_{2}$, seguida por um processo de hidroxilação, formando-se, dessa forma, o intermediário $\mathrm{m} / \mathrm{z}=110$ que é identificado. Nesse intermediário pode ocorrer ruptura do anel aromático, a chamada ruptura oxidativa e, a partir deste ponto, compostos alifáticos passam a ser identificados. $\mathrm{O}$ fragmento $\mathrm{m} / \mathrm{z}=149$ foi identificado e corresponde ao ácido tartárico, que é um ácido alifático e rota esta apresentada em Figura 3.26. Após a ruptura do anel, poderá ocorrer a inserção de espécies cloro radicais à dupla ligação, e então se observa a formação do fragmento $\mathrm{m} / \mathrm{z}=282$. Já o fragmento $\mathrm{m} / \mathrm{z}=163$ é atribuído à inserção de cloro radical e ao radical hidroxila ao anel aromático (esquema de baixo).

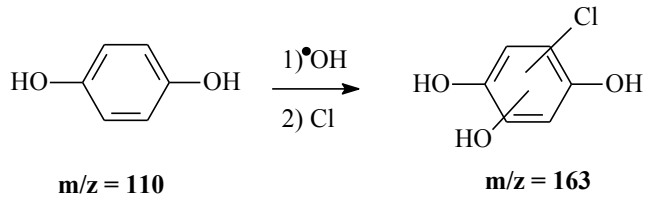

ou
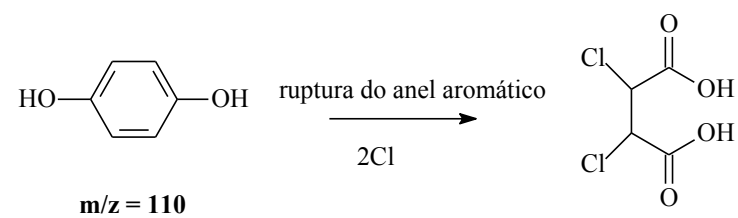

$\mathrm{m} / \mathrm{z}=\mathbf{2 8 2}$

Outra possibilidade reacional consiste na inserção de cloro radical ao grupamento $\mathrm{NH}_{2}$ do intermediário formado $p$-hidróxi-anilina, o qual é proveniente dos processos consecutivos 


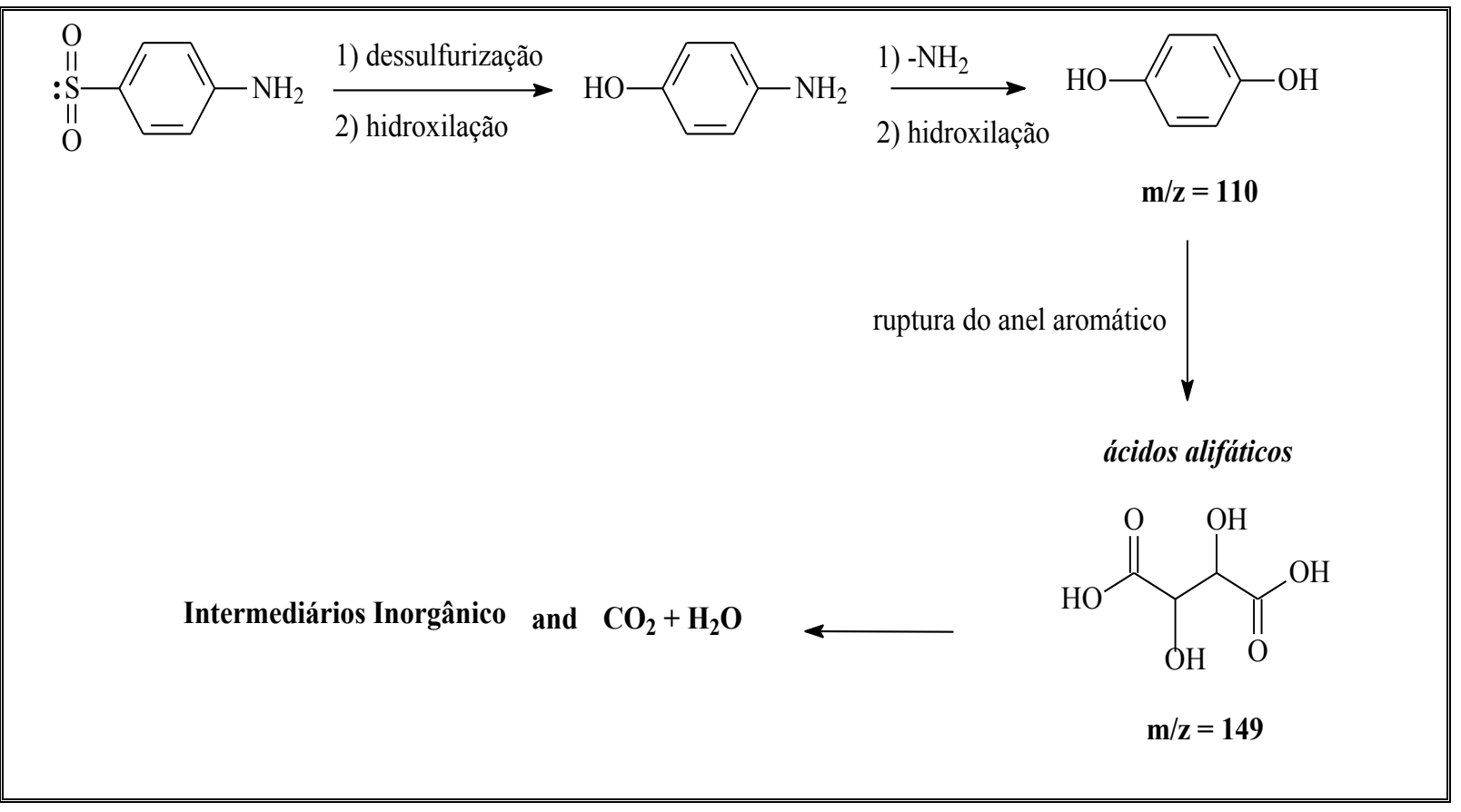

Figura 3.26 - Rota de degradação e conversão de SMX por processo eletroquímico para os compostos de baixo peso molecular e referentes a $\mathrm{m} / \mathrm{z}=110,149$.

de dessulfurização e hidroxilação, já descritos anteriormente, de tal forma que os fragmentos $\mathrm{m} / \mathrm{z}=141$ e $\mathrm{m} / \mathrm{z}=179$ foram detectados.

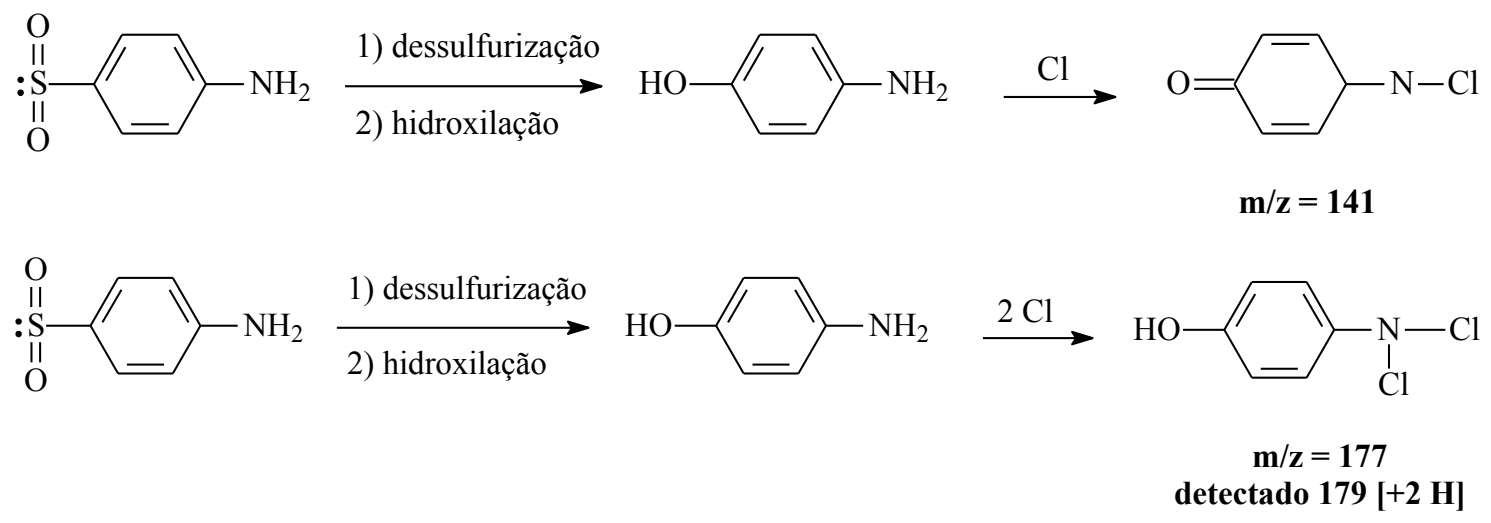

Pode também ocorrer a inserção de radical hidroxila ao grupamento sulfônico, verificando-se a formação do fragmento $\mathrm{m} / \mathrm{z}=179$.

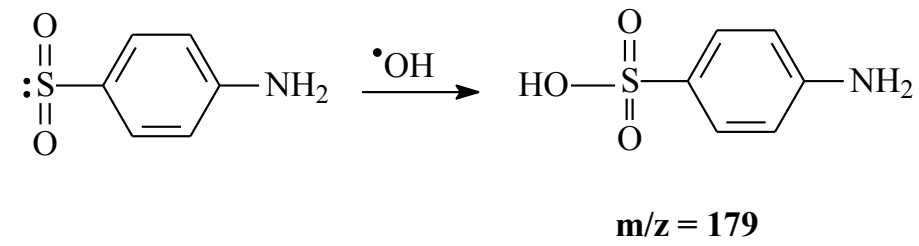


Considerando-se o fragmento 179 , pode ocorrer a substituição do grupamento $\mathrm{NH}_{2}$ por um $\mathrm{OH}$ e, em seguida, anel aromático, pode ocorrer a inserção do radical hidroxila, em que $\mathrm{m} / \mathrm{z}=187$ foi detectado.
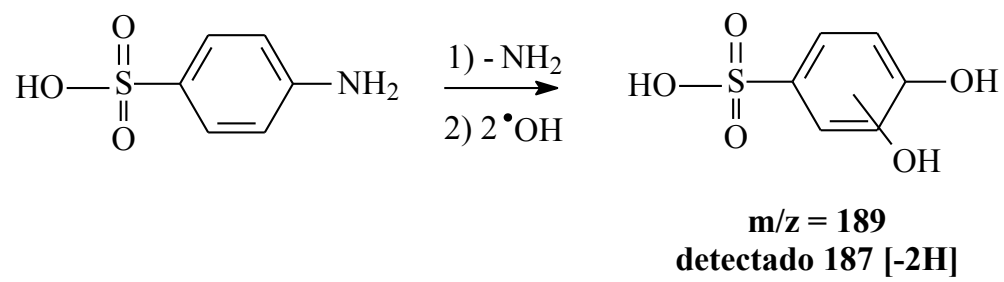

Considerando-se o fragmento $\mathrm{m} / \mathrm{z}=98$, observa-se que ocorre o processo de hidroxilação, seguido por um rearranjo que causa a ruptura do anel oxazolídico, onde o fragmento $\mathrm{m} / \mathrm{z}=132$ é detectado, e então, os ácidos alifáticos passam a ser identificados.<smiles>Cc1cc(N=[V])no1</smiles><smiles>CC1ONC(O)(O)[C@H]1O</smiles>
$\longrightarrow$ ruptura do anel<smiles>CC(=O)C(O)C(=O)NO</smiles>
$\mathbf{m} / \mathbf{z}=132$

\section{Intermediários Inorgânico}

detecção de compostos alifáticos

Ainda considerando-se o fragmento $\mathrm{m} / \mathrm{z}=98$, observa-se que pode ocorrer a inserção do radical hidroxila ao grupamento $\mathrm{NH}_{2}$, e também a inserção de um cloro radical à dupla ligação pertencente ao anel ozaxolídico, de tal forma que o fragmento $\mathrm{m} / \mathrm{z}=149$ característico foi detectado.

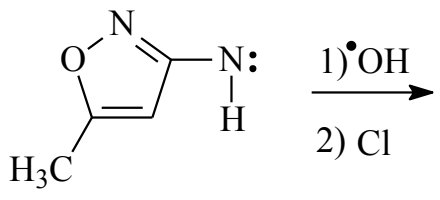<smiles>CC1ON=C(NO)C1Cl</smiles>

A Figura 3.27 apresenta uma outra possibilidade é a ruptura do anel oxazolídico do composto original, seguido por um processo de hidroxilação que resulta na formação do fragmento $\mathrm{m} / \mathrm{z}=303$. Então, à dupla ligação ocorre a inserção de duas hidroxilas, e o fragmento $\mathrm{m} / \mathrm{z}=341$ é identificado. Em seguida, pode ocorrer a eliminação do grupo $\mathrm{NH}_{2}$ da parte anilínica, seguida por um processo de hidroxilação que resulta no fragmento $\mathrm{m} / \mathrm{z}=321$. 


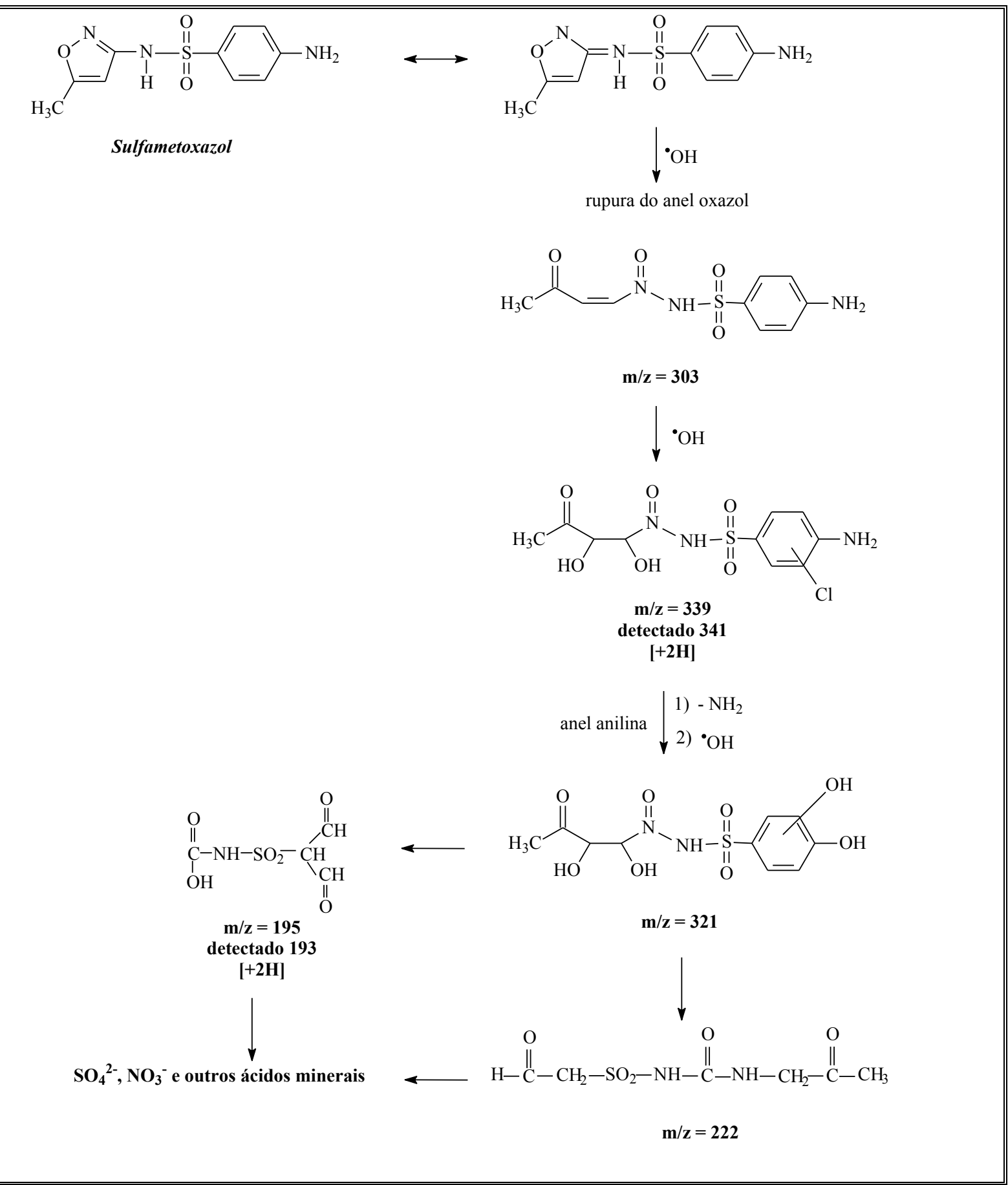

Figura 3.27 - Sequencia reacional de degradação e conversão de SMX por processo eletroquímico.

Após o ataque de um radical na posição 2 ou 6 do composto m/z 321, formam-se outros compostos com $\mathrm{m} / \mathrm{z}=222 \mathrm{e} \mathrm{m} / \mathrm{z}=195$. Nos estudos propostos por Abellán et al. (2007), tais autores observaram a presença do composto $\mathrm{m} / \mathrm{z}=222$ na degradação de SMX por processo fotocatalítico. A oxidação subsequente dos compostos envolve a formação de ácidos minerais, ânions e cátions, que foram detectados experimentalmente por cromatografia de íons. 


\subsubsection{Detecção dos intermediários inorgânicos de SMX}

O antibiótico SMX é um composto heteroatômico, isto é, apresenta em sua composição vários átomos, tais como $\mathrm{S}, \mathrm{N}$ e $\mathrm{O}$. Assim, após a mineralização, o $\mathrm{SMX}$ transforma-se em $\mathrm{CO}_{2}, \mathrm{H}_{2} \mathrm{O}$ e outras espécies inorgânicas como $\mathrm{NO}_{2}{ }^{-}, \mathrm{NO}_{3}{ }^{-}, \mathrm{NH}_{4}{ }^{+}$e $\mathrm{SO}_{4}{ }^{2-}$.

A estrutura de SMX na Figura 3.15 (b) e Tabela 3.2 claramente indica que o átomo de $\mathrm{S}$ pode separar-se da molécula principal na forma de sulfato $\left(\mathrm{SO}_{4}{ }^{2-}\right)$. Da mesma forma, o nitrogênio também está presente na molécula de SMX, de modo que, depois da incineração eletroquímica serão detectados os íons inorgânicos correspondentes $\left(\mathrm{NO}_{2}^{-}, \mathrm{NO}_{3}{ }^{-}, \mathrm{NH}_{4}{ }^{+}\right)$.

Durante os ensaios eletroquímicos, o COT foi monitorado continuamente. Observouse que o SMX foi parcialmente mineralizado, alcançando-se assim a remoção de aproximadamente $30 \%$ de COT, de tal forma que pode-se concluir que o SMX foi liberados as substâncias inorgânicas.

Os íons inorgânicos foram quantificados por cromatografia iônica nas condições

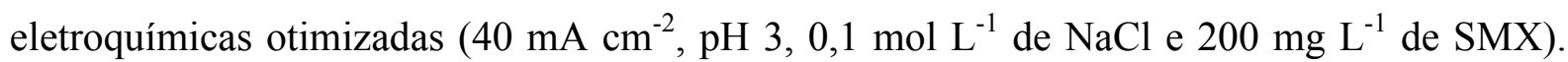
Nota-se que os traços de $\mathrm{NH}_{4}{ }^{+}$foram detectados, mas não foi possível quantificá-los devido aos limites de detecção do instrumento e também ao uso de $\mathrm{NaCl}$ como eletrólito suporte, fatores estes que interrompem, por sua vez, a detecção de $\mathrm{NH}_{4}{ }^{+}$.

Por outro lado, o íon $\mathrm{NO}_{2}^{-}$foi observado, mas sua concentração não foi monitorada devido ao procedimento instrumental. A Figura 3.28 apresenta a liberação dos íons $\mathrm{NO}_{3}{ }^{-}$e $\mathrm{SO}_{4}{ }^{2-}$ durante as eletrólises. Um aumento gradual de concentração de ambos os íons (nitrato e sulfato) foi observado durante o processo de degradação. Após 120 minutos de tratamento, 10 $\mathrm{mg} \mathrm{L}^{-1}$ de $\mathrm{NO}_{3}{ }^{-}$foram recuperados, o que significa a mineralização incompleta de SMX e a formação de outras espécies nitrogenadas de difícil degradação. Segundo Abellán et al. (2007), a liberação de nitrogênio molecular pode ser realizada em três fases, o que poderá corresponder a:

(1) clivagem da molécula que dá origem à abertura do anel oxazolídico; (2) conversão do nitrogênio do anel oxazolídico; (3) conversão do nitrogênio presente no anel aromático da anilina. As moléculas orgânicas que possuem uma amina primária terminal formam predominantemente o íon $\mathrm{NH}_{4}{ }^{+}$. No caso do SMX, existem dois grupos suscetíveis para a formação de tal íon $\left(\mathrm{NH}_{4}{ }^{+}\right)$, e apenas um nitrogênio que pode ser convertido em $\mathrm{NO}_{3}{ }^{-}$ (nitrogênio na posição 2 do anel oxazolídico). 


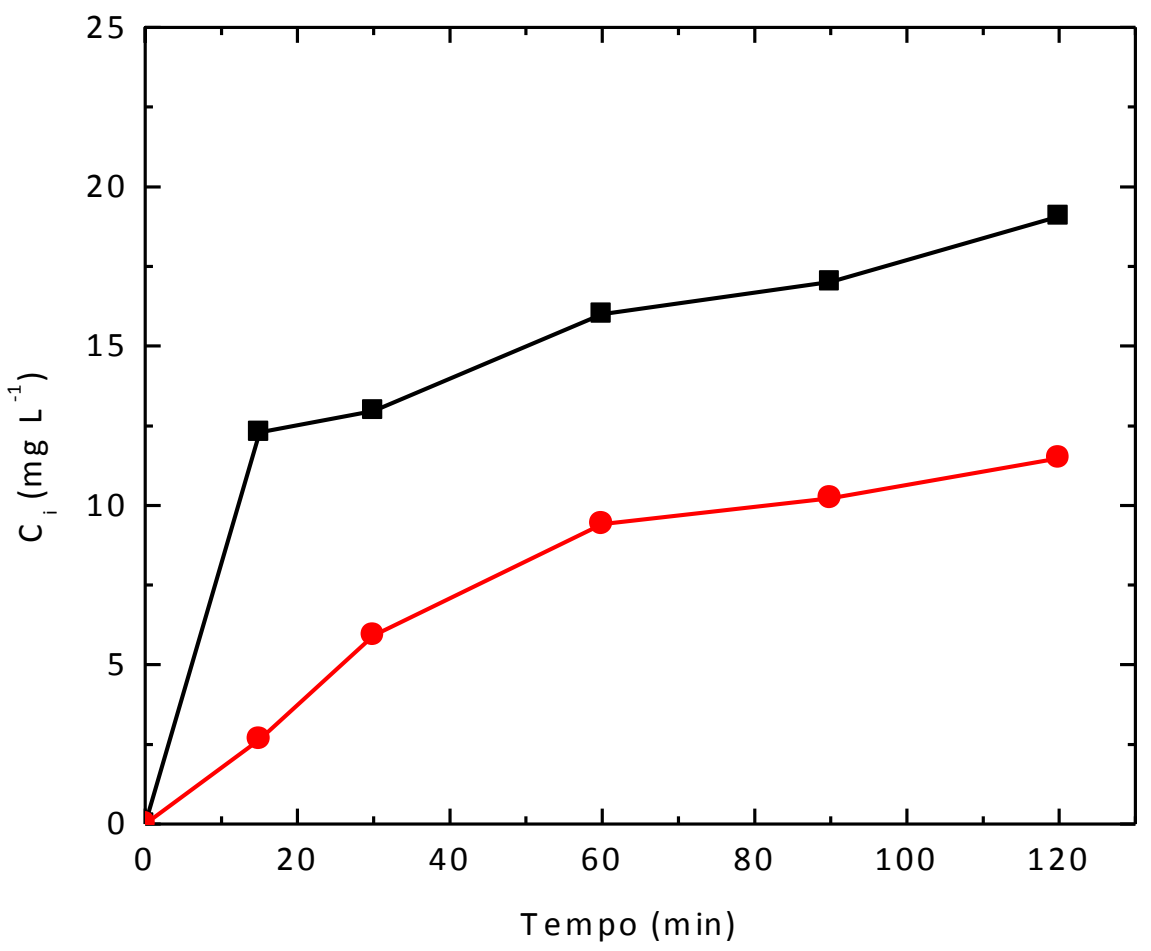

Figura 3.28 - Variação de concentração de intermediários inorgânicos como (O) $\mathrm{NO}_{3}{ }^{-}$e (⿴囗十) $\mathrm{SO}_{4}{ }^{2-}$ em função do tempo de eletrólise (Condições: $i=40 \mathrm{~mA} \mathrm{~cm}^{-2}, \mathrm{pH}_{\mathrm{i}}=3, \mathrm{~T}=25^{\circ} \mathrm{C}, \mathrm{C}_{\mathrm{NaCl}}=0,1 \mathrm{~mol} \mathrm{~L}^{-1}$ e $\mathrm{C}_{\mathrm{smx}} 200 \mathrm{mg} \mathrm{L}^{-1}$ ).

Observa-se a partir da Figura 3.28 que a quantidade de $\mathrm{SO}_{4}{ }^{2-}$ liberada aumenta mais rapidamente do que a quantidade de $\mathrm{NO}_{3}{ }^{-}$, e atingindo até $12 \mathrm{mg} \mathrm{L}^{-1}$ após 15 minutos de eletrólise. Em seguida, a formação de $\mathrm{SO}_{4}{ }^{2-}$ torna-se mais lenta devido à formação de alguns intermediários recalcitrante. Após 120 minutos de eletrólise, até $20 \mathrm{mg} \mathrm{L}^{-1}$ de $\mathrm{SO}_{4}{ }^{2-}$ foi recuperado da solução. Pode-se então concluir que o SMX pode ser degradado com eficácia, contudo, o mesmo é parcialmente mineralizado devido à formação de subprodutos de reação.

\subsection{Conclusões parciais}

Análise da eficácia do processo eletroquímico utilizando ADE como eletrodo para a degradação de SMX mostrou que a degradação eletroquímica de SMX é muito rápida, com remoção quase que completa em 30 minutos de eletrólise. Além disso, ocorre uma remoção de COT satisfatório dependendo das condições experimentais utilizadas. $\mathrm{O}$ aumento da densidade de corrente e da concentração de $\mathrm{NaCl}$ têm efeito significativo na degradação e remoção de COT, isso possivelmente em razão do aumento do transporte de carga e maior formação de espécies oxidantes. 
Uma cinética de pseudo-primeira ordem foi observada para o degradação de SMX, o processo foi energeticamente viável para altas concentrações de sal e valores de densidade de corrente.

A temperatura não influência o processo de degradação e remoção de COT, além disso, condições ácidas favorecem a remoção de SMX e COT devido ao maior poder oxidante das espécies de cloro presentes em meio ácido. Uma degradação rápida foi observada nas soluções de menor concentração de SMX, mas, por outro lado, o processo foi lento com o aumento da concentração de subprodutos.

Foi possível identificar os intermediários de degradação de SMX durante processo eletroquímico. Utilizando-se a técnica de LC-MS, 9 intermediários principais foram detectados e identificados. O SMX apresenta diferentes rotas de degradação, sendo que, de um modo geral, ocorre a abertura do anel oxazolídico e do anel benzênico, de acordo com o ataque de radicais hidroxilas e cloro. Os dois anéis foram identificados separadamente por causa de ruptura da ligação N-S, seguida de posteriores oxidações dos grupos aromáticos remanescentes.

Os compostos organoclorados também foram identificados, sendo estes responsáveis pelo possível aumento da toxicidade da solução. O SMX foi parcialmente mineralizado, então foi possível identificar alguns íons inorgânicos, tais como $\mathrm{NO}_{3}{ }^{-}{\mathrm{e} \mathrm{SO}_{4}}^{2-}$.

A tecnologia eletroquímica utilizando ADE é um dos métodos amplamente aplicados no tratamento de águas residuárias, de maneira que esses resultados mostram a eficácia do processo eletroquímico que pode ser aplicado para remediação, por exemplo, de efluentes contendo SMX, como águas residuárias de hospitais. 


\section{Capítulo 4}

\section{Degradação eletroquímica foto assistida de SMX}

Neste capítulo é apresentado o estudo da degradação de SMX pelo processo eletroquímico foto assistido utilizando um ânodo do tipo ADE, o que corresponde uma metodologia alternativa promissora para se realizar o tratamento de efluentes. Foram estudadas diferentes variáveis que podem influenciar o processo, tais como, densidade de corrente $\left(10\right.$ a $\left.60 \mathrm{~mA} \mathrm{~cm}{ }^{-2}\right)$, concentração do $\mathrm{Cl}^{-}\left(0,002\right.$ a $\left.0,1 \mathrm{~mol} \mathrm{~L}^{-1}\right)$ e concentração inicial de $\operatorname{SMX}\left(50\right.$ a $\left.200 \mathrm{mg} \mathrm{L}^{-1}\right)$. Vários intermediários de degradação foram detectados e identificados por LC/MS, o que permitiu o estabelecimento de uma rota de degradação.

\subsection{Caracterizações in situ do ADE na presença e na ausência de radiação UV}

\subsubsection{Voltametria Cíclica}

As Figuras 4.1 e 4.2 mostram os perfis voltamétricos do eletrodo de de trabalho (ADE) em solução de $0,033 \mathrm{~mol} \mathrm{~L}^{-1} \mathrm{Na}_{2} \mathrm{SO}_{4}$ e em solução $0,1 \mathrm{~mol} \mathrm{~L} \mathrm{~L}^{-1} \mathrm{NaCl}$, sendo que em tais soluções a força iônica foi mantida constante. Para se realizar os estudos sob tais condições, também foram consideradas as soluções anteriores na presença e na ausência do SMX, assim como a utilização da radiação UV. Considerando as condições experimentais discutidas, não 
pôde ser observado nenhum pico indicando redução ou oxidação até 1,4 V ERH, para ambos os eletrólitos. No caso do $\mathrm{Na}_{2} \mathrm{SO}_{4}$, não foi observada nenhuma diferença nos voltamogramas (Figura 4.1 (a)) na presença ou na ausência do antibiótico SMX, o que significa que o composto não foi oxidado na presença do $\mathrm{Na}_{2} \mathrm{SO}_{4}$.

Todavia, sabe-se que sobre a superfície do ADE são geradas algumas espécies de menor poder oxidativo, que são muito instáveis, e assim, não são capazes de oxidar o SMX. A Figura 4.1 demonstra que na presença do SMX há diminuição da corrente. No entanto, observa-se que no caso do voltamograma obtida ao se utilizar o $\mathrm{NaCl}$, há uma diferença significativa quando há presença e ausência do SMX (Figura 4.2 (b)), devido provavelmente à reação de oxidação entre SMX e um agente oxidante forte, como o $\mathrm{Cl}_{2}$, resultando na geração de subprodutos de degradação.

Pode-se observar, com base nas Figuras 4.2 (a) e (b), que há um pequeno aumento na eficiência quando há presença da luz UV. Tal efeito sinérgico ocorre devido ao fato de que o processo eletroquímico está associado ao fotoquímico. Os superóxidos $\left(\mathrm{O}_{2} \bullet^{-}\right)$formados durante o processo fotoquímico podem gerar quantidades adicionais de radicais hidroxila. Desse modo, o processo fotoquímico pode aumentar os rendimentos em termos dos radicais formados durante a produção eletroquímica do $\mathrm{O}_{2}$ (PELEGRINI et al., 1999).

Quando a radiação UV é incidida, há um aumento pequeno na área voltamétrica, além de ocorrer um deslocamento no início da reação de desprendimento de oxigênio para valores de potenciais menos positivos. Isto não implica, necessariamente, que não haja efeito catalítico, como no caso da produção de espécies oxidadas na superfície do eletrodo, podendo evitar a recombinação do e- promovido à banda de condução com o h+ gerado na banda de valência.

Após a adição do composto SMX à solução, esta espécie pode ser oxidada pelos radicais que são gerados nos processos eletroquímico e eletroquímico foto assistido. Não foram observados aumentos significativos de corrente na presença de SMX, considerando-se as Figuras 4.1 (b) e 4.2 (b). Tal constatação pode ser justificada, provavelmente, em razão da fraca interação entre este composto e a superfície do óxido.

\subsection{Degradação eletroquímica foto assistida do SMX}

\subsubsection{Efeito da densidade de corrente}

O efeito da densidade de corrente na taxa de degradação e remoção de COT do SMX, através do processo eletroquímico foto assistido, foi estudado com base na variação da 


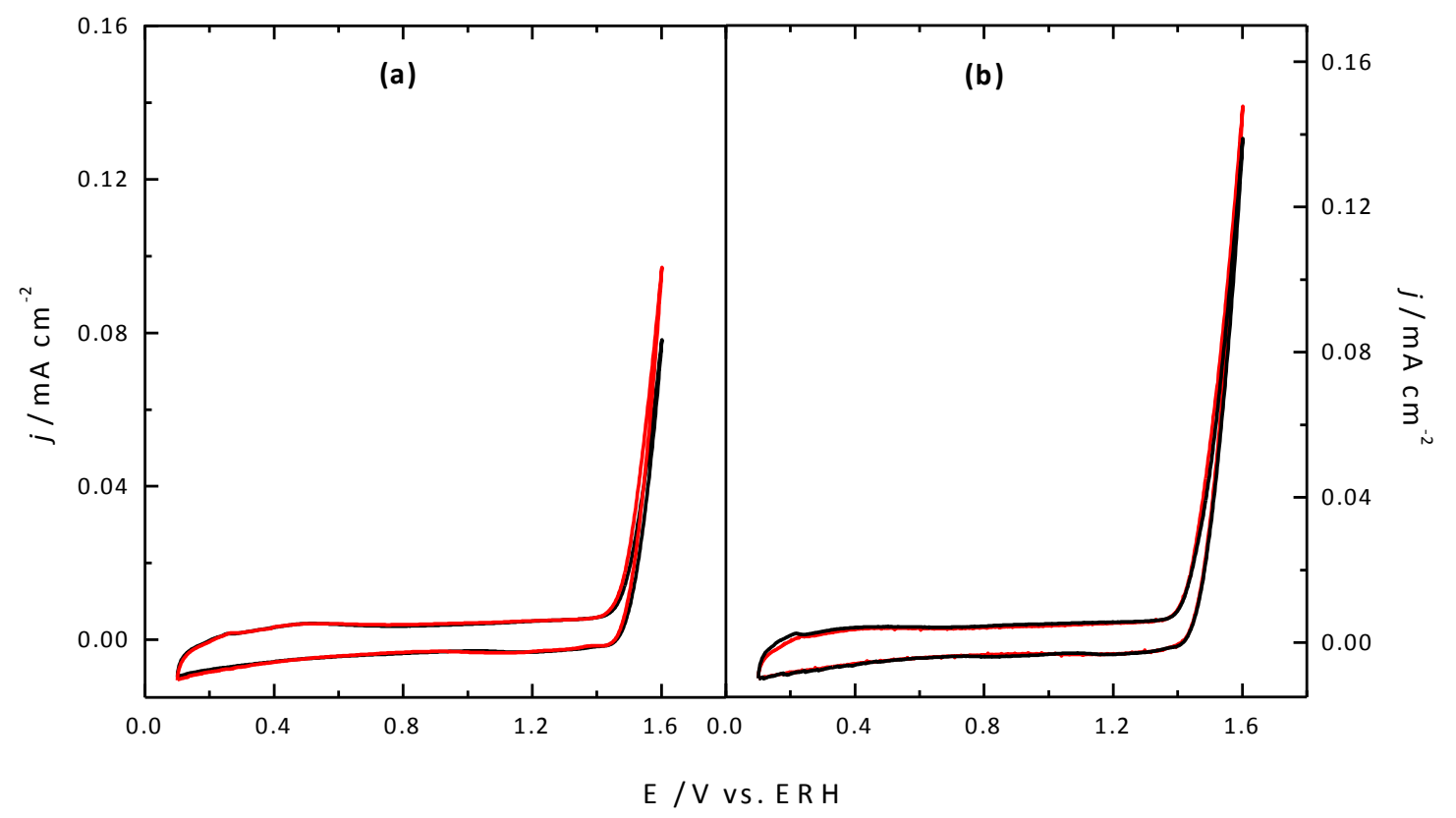

Figura 4.1 - Curvas voltametricas ( $5^{\circ}$ ciclo) do eletrodo de ADE, utilizando-se solução de $\mathrm{Na}_{2} \mathrm{SO}_{4}$ com concentração igual a $0,033 \mathrm{~mol} \mathrm{~L}^{-1}$, na presença (-) e na ausência (-) de SMX: (a) sem aplicação de radiação UV e (b) com radiação UV, empregando-se uma lâmpada de mercúrio de $250 \mathrm{~W}$. Condições: $v=50 \mathrm{mV} \mathrm{s}^{-1}$ a $25^{\circ} \mathrm{C}$.

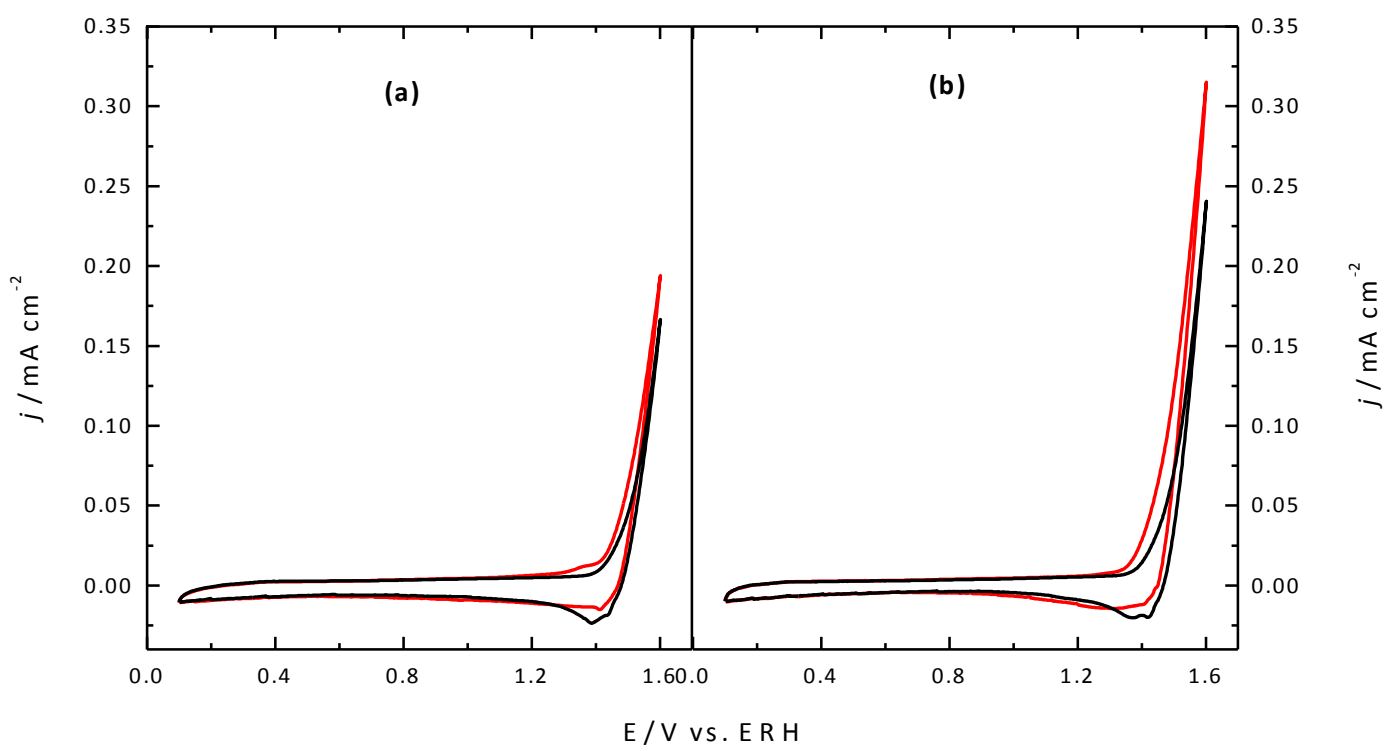

Figura 4.2 - Curvas voltamétricas ( $5^{\circ}$ ciclo) do eletrodo de ADE utilizando $0.1 \mathrm{~mol} \mathrm{~L}^{-1}$ de $\mathrm{NaCl}$, na presença (-) e na ausência (-) de SMX: (a) sem aplicação de radiação UV e (b) com radiação UV usando uma lâmpada de mercúrio de $250 \mathrm{~W}$. Condições: $v=50 \mathrm{mV} \mathrm{s}^{-1}$ a $25^{\circ} \mathrm{C}$. 
densidade de corrente de 10 a $60 \mathrm{~mA} \mathrm{~cm}$. $^{-2}$ A Figura 4.3 mostra os perfis de degradação e remoção de COT ao longo do tempo de fotoeletrólise. O aumento na densidade de corrente significa que há um acréscimo na quantidade de energia elétrica que passa pelo sistema. Como resultado, as taxas de degradação e de remoção de COT aumentam proporcionalmente. Pode ser claramente observado que a degradação do SMX é aumentada para os valores de densidade de corrente mais elevados, devido a um aumento na formação de espécies eletroativas na superfície do eletrodo, permitindo uma melhoraria quanto à geração de lacunas e quanto à separação elétron/lacuna.

A degradação completa do SMX foi obtida por meio da utilização de densidades de corrente com valores de 20, 40 e $60 \mathrm{~mA} \mathrm{~cm}^{-2}$ para os intervalos de tempo de 30, 10 e 6 min, respectivamente. No entanto, para o valor de densidade de corrente de $10 \mathrm{~mA} \mathrm{~cm}{ }^{-2}$, houve degradação de apenas $70 \%$, sendo esta alcançada após 30 min de tratamento.

A Figura 4.3 (b) indica que ocorreu uma redução de COT quando houve aumento na densidade de corrente, assim, o COT foi removido de $32 \%, 33 \%, 48 \%$ e $50 \%$ após 2 h de fotoeletrólise, para valores de densidade de corrente iguais a 10, 20, 40 e $60 \mathrm{~mA} \mathrm{~cm}{ }^{-2}$, respectivamente. Os dados da remoção de COT indicam que não ocorre a mineralização completa do SMX, mesmo com a combinação do sistema eletroquímico com radiação UV, devido à formação de intermediários recalcitrantes.

A Figura 4.4 apresenta o perfil da curva logarítmica de concentração em função do tempo, demostrando que a reação sob as condições investigadas, obedece a uma cinética de pseudo-primeira ordem. Com esses dados, foi possível calcular a constante de velocidade, dispostas tais informações na Tabela. 4.1.

Foi possível observar que a constante de velocidade para uma densidade de corrente igual a $10 \mathrm{~mA} \mathrm{~cm}{ }^{-2}$ é igual a $0,04924 \mathrm{~min}^{-1}$, tendo aumentado para um valor igual a 0,50327 $\min ^{-1}$, para um valor de densidade de corrente igual a $60 \mathrm{~mA} \mathrm{~cm}{ }^{-2}$.

Como o processo de degradação ocorre muito rápido para os valores maiores de densidade da corrente, verifica-se, por sua vez, que os valores de meia-vida $\left(t_{1 / 2}\right)$ são muito pequenos, sendo que para densidade de corrente de a $10 \mathrm{~mA} \mathrm{~cm}{ }^{-2}$, o valor da meia-vida aumentou para 14,073 min. Os valores de energia por ordem são muito maiores para os valores de densidade de corrente iguais a 10 e $60 \mathrm{~mA} \mathrm{~cm}^{-2}$. Para os valores maiores de densidade de corrente, há um aumento no potencial, o que resulta num aumento do consumo de energia. 


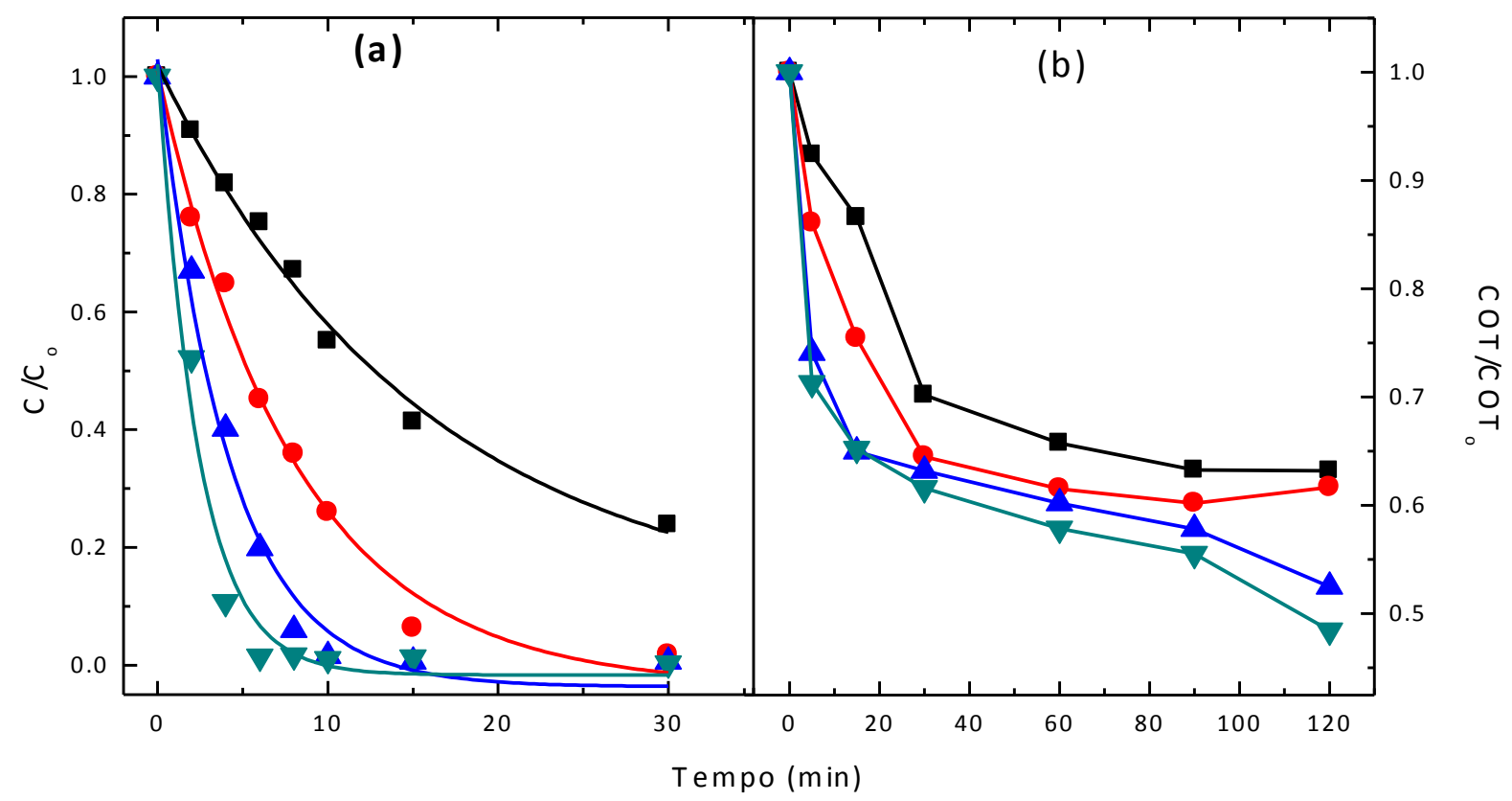

Figura 4.3 - Efeito da densidade de corrente: (口) $10 \mathrm{~mA} \mathrm{~cm}^{-2}$, (O) $20 \mathrm{~mA} \mathrm{~cm}{ }^{-2},(\boldsymbol{\Delta}) 40 \mathrm{~mA} \mathrm{~cm}$ ${ }^{2},(\nabla) 60 \mathrm{~mA} \mathrm{~cm}{ }^{-2}$ na (a) degradação e (b) remoção de $\mathrm{COT}$ (Condições: $\mathrm{pH}_{\mathrm{i}}=3, \mathrm{~T}=25^{\circ} \mathrm{C}, \mathrm{C}_{\mathrm{smx}}=$ $200 \mathrm{mg} \mathrm{L}^{-1} \mathrm{e} \mathrm{C}_{\mathrm{NaCl}}=0,1 \mathrm{~mol} \mathrm{~L}^{-1}$ ).

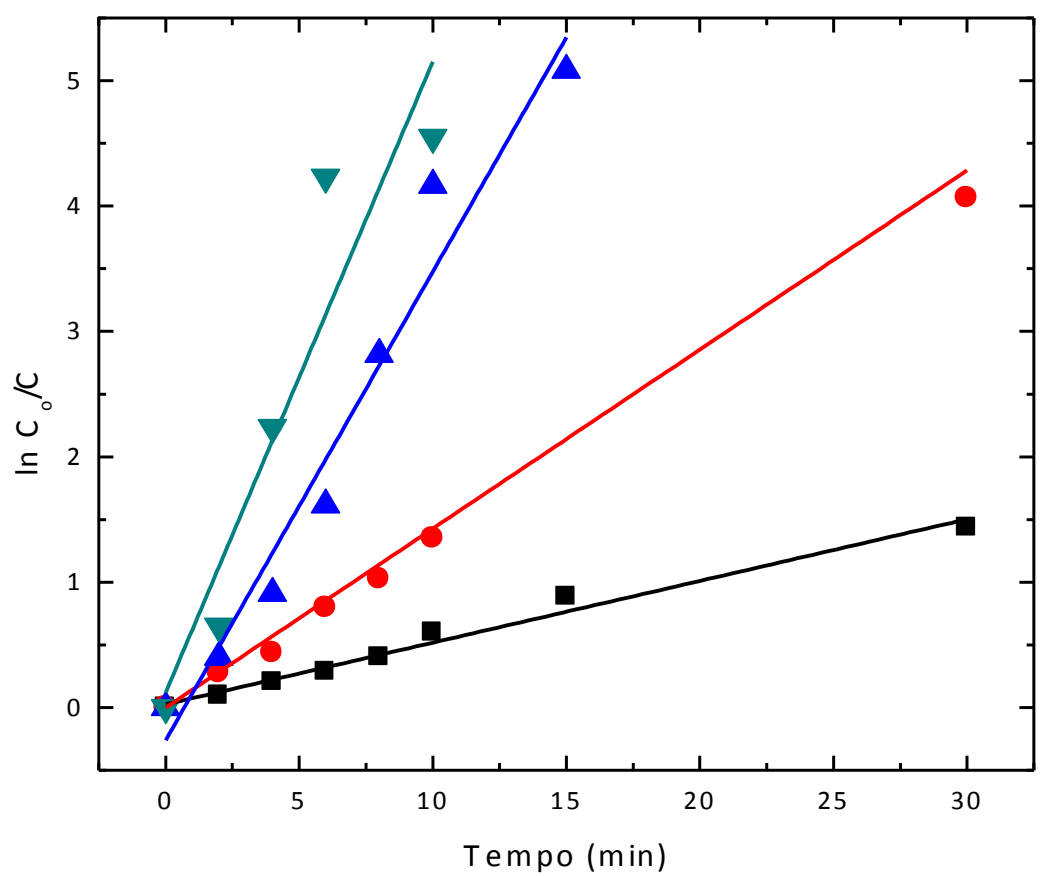

Figura 4.4 - Variação do $\ln \left(\mathrm{C}_{\mathrm{o}} / \mathrm{C}\right)$ em função do tempo de degradação para valores diferentes de

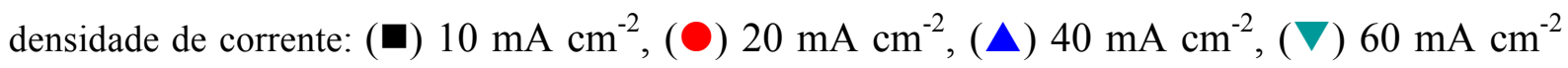
(Condições: $\mathrm{pH}_{\mathrm{i}}=3, \mathrm{~T}=25^{\circ} \mathrm{C}, \mathrm{C}_{\mathrm{smx}}=200 \mathrm{mg} \mathrm{L}^{-1} \mathrm{e} \mathrm{C}_{\mathrm{NaCl}}=0,1 \mathrm{~mol} \mathrm{~L}^{-1}$ ). 
Tabela 4.1 - Parâmetros cinéticos relacionado à degradação foto eletroquímica do SMX

\begin{tabular}{cccc}
\hline \hline Parâmetros & $\mathbf{k}\left(\mathbf{m i n}^{-1}\right)$ & $\mathbf{t}_{\mathbf{1} / \mathbf{2}}(\mathbf{m i n})$ & $\mathbf{R}^{\mathbf{2}}$ \\
\hline \hline $\boldsymbol{i}\left(\mathbf{m A ~ \mathbf { ~ m } ^ { - 2 } )}\right.$ & & & \\
10 & 0,0492 & 14,073 & 0,978 \\
20 & 0,1428 & 4,850 & 0,959 \\
40 & 0,3737 & 1,854 & 0,954 \\
60 & 0,5032 & 1,376 & 0,856 \\
{$[\mathbf{N a C l}]\left(\mathbf{m o l} \mathbf{L}^{-\mathbf{1}}\right)$} & & & \\
0,02 & 0,0284 & 24,367 & 0,956 \\
0,04 & 0,0970 & 7,139 & 0,958 \\
0,08 & 0,2945 & 2,352 & 0,992 \\
0,10 & 0,3737 & 1,854 & 0,956 \\
\hline \hline
\end{tabular}

Malpass et al. (2009) também observaram que há um aumento na remoção do pesticida carbaril com a densidade de corrente, assim como para a degradação eletroquímica fotoassistida em eletrodo de $\mathrm{Ti} / \mathrm{Ru}_{0.3} \mathrm{Ti}_{0.7} \mathrm{O}_{2}$. Os autores sugeriram que o pesticida poderia ser diretamente oxidado na superfície do eletrodo, por meio da formação de espécies sorvidas MO (carbaril).

Em outro estudo Zanoni et al. (2003) investigaram a degradação e a remoção de COT do corante alaranjado remazol 3R, por meio do processo foto-eletrocatalítico, além de terem mostrado que a eficiência do processo aumenta com a elevação do potencial aplicado no sistema. Os resultados sugerem que para maior potencial, a sorção dos corantes é melhor e/ou há uma aceleração na geração/separação dos pares elétron/lacuna. Assim, para valores maiores de potencial, há geração de mais radicais oxidantes ativos, o que promove uma decomposição mais rápida do corante. 


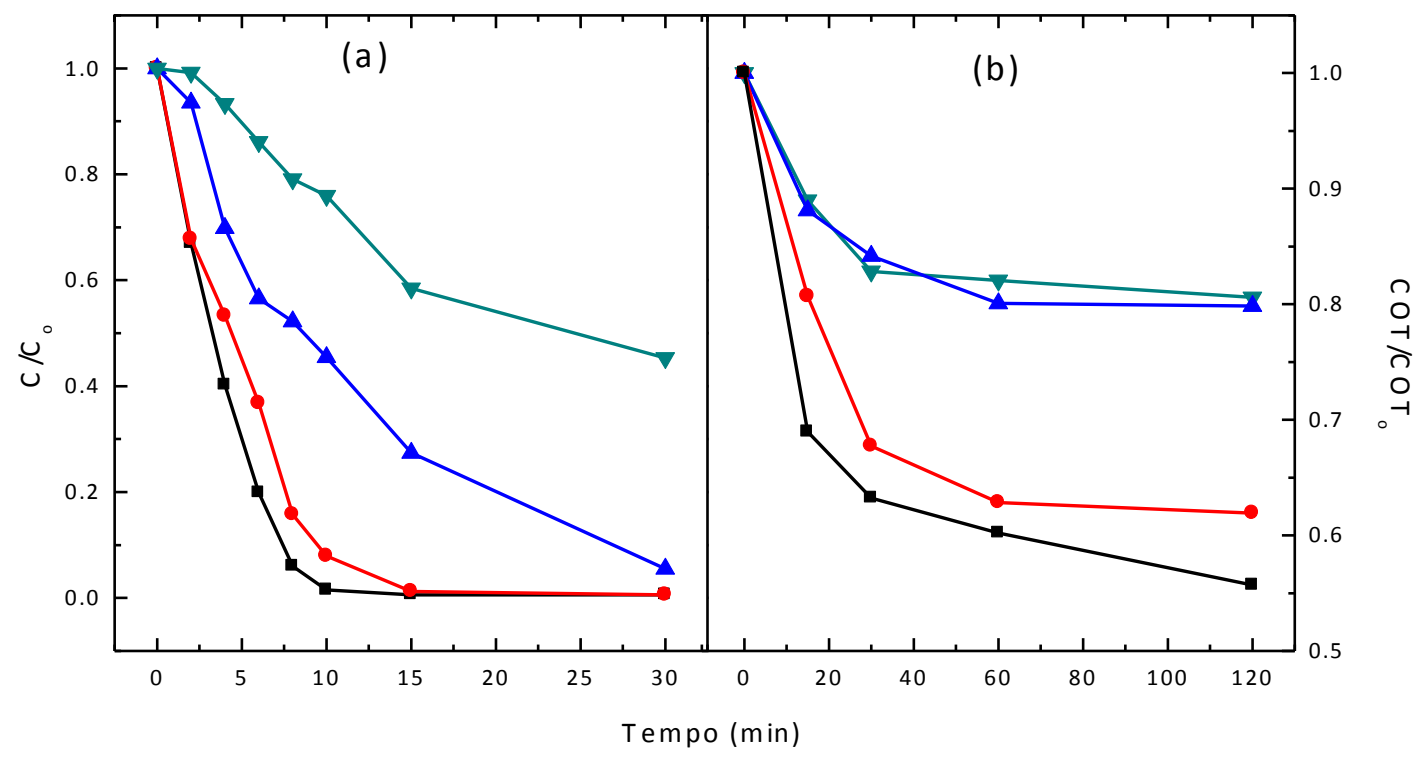

Figura 4.5 - Efeito da concentração do $\mathrm{NaCl}$ na (ם) $0,1 \mathrm{~mol} \mathrm{~L}^{-1},(\mathbf{O}) 0,02 \mathrm{~mol} \mathrm{~L}^{-1},(\boldsymbol{\Delta}) 0,04 \mathrm{~mol}$ $\mathrm{L}^{-1},(\boldsymbol{\nabla}) 0,8 \mathrm{~mol} \mathrm{~L}^{-1}$ na (a) degradação e (b) remoção de $\mathrm{COT}\left(\right.$ Condições: $\mathrm{pH}_{\mathrm{i}}=3, \mathrm{~T}=25^{\circ} \mathrm{C}, \mathrm{C}_{\mathrm{smx}}$ $=200 \mathrm{mg} \mathrm{L}^{-1} \mathrm{e} i=40 \mathrm{~mA} \mathrm{~cm}^{-2}$ ).

\subsubsection{Efeito da concentração do $\mathrm{NaCl}$}

A Figura 4.5 ((a) e (b)) mostra que ocorrem diminuições relativas na concentração e na remoção de COT e do SMX em função do tempo, para valores diferentes de concentração do $\mathrm{NaCl}$. Torna-se evidente através da figura que, com o aumento na concentração do $\mathrm{NaCl}$, a degradação e a remoção de COT melhoraram significativamente.

Para os valores de concentração de $\mathrm{NaCl}$ na faixa de 0,1 a $0,08 \mathrm{~mol} \mathrm{~L}^{-1}$, o SMX foi degradado completamente em 10 e 15 min, respectivamente. Enquanto que para os valores de concentração do $\mathrm{NaCl}$ de 0,04 e $0,02 \mathrm{~mol} \mathrm{~L}^{-1}$, a degradação foi de 50 e $90 \%$, respectivamente, após $30 \mathrm{~min}$ de tratamento.

A Figura 4.5 (b) indica claramente que, com o aumento da concentração do $\mathrm{NaCl}$ de 0,002 a $0,1 \mathrm{~mol} \mathrm{~L}^{-1}$, ocorre uma melhoria na remoção de COT de 20 a 45\%, devido à grande quantidade de espécies oxidantes geradas $\left(\mathrm{Cl}_{2}\right.$ e $\left.\mathrm{HClO}\right)$ na superfície do eletrodo. Essas espécies são geradas eletricamente, podendo ser transformadas em outras espécies que são fortes oxidantes, como mostrado pela equação (4.1) (FENG et al., 2007).

$\mathrm{HOCl}+h v \rightarrow \bullet \mathrm{OH}+\mathrm{Cl} \bullet$ 
Estes radicais reagem com o SMX no seio da solução, acelerando o processo de degradação e de mineralização. Além disso, a absorção da radiação UV também pode resultar na fotólise direta do SMX. Um resultado semelhante foi observado por Zanoni et al. (2003), onde as taxas de degradação e remoção de COT do corante alaranjado de remazol 3R foram melhoradas quando houve o aumento na concentração do $\mathrm{NaCl}$.

Com a utilização de cloreto de sódio na eletro-oxidação de compostos orgânicos, corre-se um risco maior com a possibilidade de serem formados compostos organoclorados, os quais podem ser mais prejudiciais do que o composto principal. Aquino Neto; De Andrade (2009) mostraram que durante o processo de eletro-oxidação do herbicida glifosato, ao utilizar um eletrodo ADE, há aumento da concentração de compostos organoclorados com o incremento na concentração do $\mathrm{NaCl}$.

No entanto, pesquisas vêm demonstrando que os composto organoclorados é rapidamente destruidos antes do final da eletrólise (COMNINELLIS; NERINI, 1995; KARLSSON; OBERG, 2003) observaram que houve uma diminuição na concentração de espécies organocloradas após a irradiação de águas naturais com radiação UV, sem que houvesse a formação de compostos clorados voláteis.

Malpass et al. (2011) relataram diminuição de toxicidade em soluções de atrazina por processo eletroquímico foto assistido, utilizando-se um eletrodo ADE na presença de $\mathrm{NaCl}$ $0,1 \mathrm{~mol} \mathrm{dm}^{-3}$.

A cinética de degradação do SMX foi determinada através da relação $\ln \mathrm{C}_{\mathrm{o}} / \mathrm{C}$ em função do tempo de fotoeletrólise (Figura 4.6), cujo coeficiente linear corresponde a uma constante de pseudo-primeira ordem. A partir da Figura 4.6 foi determinado o valor da constante de velocidade $(\mathrm{k})$ para a degradação eletroquímica foto assistida de SMX, apresentado na Tabela 4.1, confirmando assim que o processo é mais eficiente nas concentrações elevadas de $\mathrm{NaCl}$.

Catanho et al. (2006a) observaram uma degradação máxima da corantes têxteis em concentrações elevada de $\mathrm{NaCl}$ por processos eletroquímico e eletroquímico foto assistido, sugerindo que os processos seguem a cinética de primeira ordem.

\subsubsection{Efeito da concentração inicial do SMX}

Em qualquer processo de tratamento, a concentração inicial de compostos-alvo é um parâmetro importante que influencia significativamente o processo de degradação. A influência da concentração inicial do SMX em sua oxidação foto-eletrocatalítica foi 


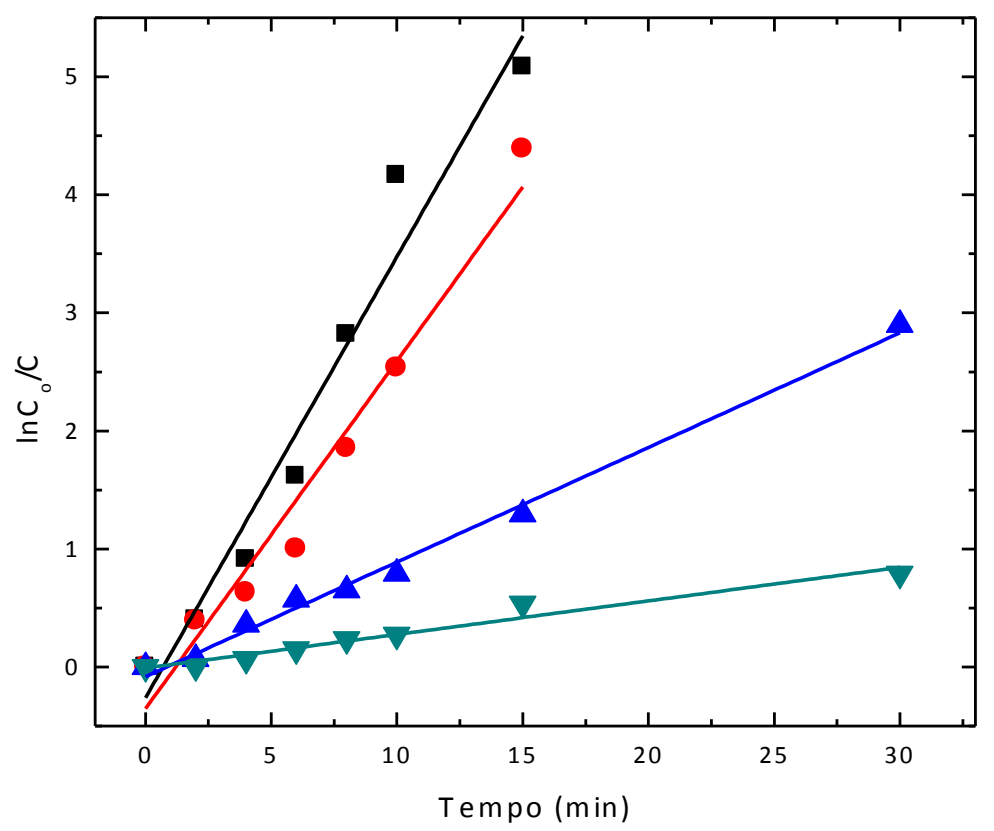

Figura 4.6 - Variação do $\ln \left(\mathrm{C}_{\mathrm{o}} / \mathrm{C}\right)$ em função do tempo para valores diferentes de concentração do

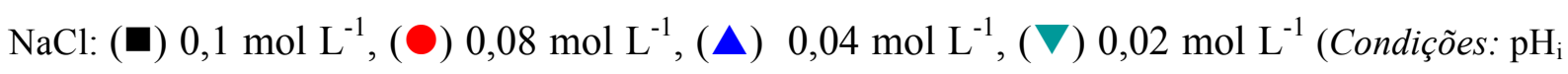
$=3, \mathrm{~T}=25^{\circ} \mathrm{C}, \mathrm{C}_{\mathrm{smx}}=200 \mathrm{mg} \mathrm{L}^{-1} \mathrm{e} i=40 \mathrm{~mA} \mathrm{~cm}^{-2}$ ).

investigada ao se manterem constantes todos os parâmetros anteriores, otimizados como 0,1 mol $\mathrm{L}^{-1}$ de $\mathrm{NaCl}$ e $40 \mathrm{~mA} \mathrm{~cm}^{-2}$ de densidade de corrente, a fim de se obter o melhor desempenho do foto-eletrodo.

Os experimentos foram conduzidos ao se variar a concentração inicial do SMX de 50 a $200 \mathrm{mg} \mathrm{L}^{-1}$. As Figuras 4.7 (a) e (b) demonstram o efeito da concentração inicial do SMX na degradação e remoção de COT. A degradação eletroquímica foto assistido foi muito rápida para as faixas de concentrações iniciais de 50 e $100 \mathrm{mg} \mathrm{L}^{-1}$, sendo que após 5 min de tratamento, o composto foi completamente eliminado. No entanto, a degradação foi relativamente lenta no caso das faixas de concentrações iniciais de 150 a $200 \mathrm{mg} \mathrm{L}^{-1}$, em que o composto foi destruído completamente em 10 e 30 min.

Pode-se observar que o método é capaz de proporcionar uma remoção quase completa para todas as soluções de SMX, independentemente da concentração inicial. O processo eletroquímico foto assistido é capaz de gerar uma quantidade maior de espécies oxidantes, como: $\mathrm{Cl}^{\circ}, \mathrm{Cl}_{2}, \mathrm{HClO}$ e ${ }^{\circ} \mathrm{OH}$. Além disso, para os valores menores de concentração do SMX, com base na proporção de espécies oxidantes que são geradas, existe uma probabilidade maior de que as moléculas SMX sejam atacadas por uma grande quantidade de espécies oxidantes, o que resulta numa degradação mais rápida do composto. 


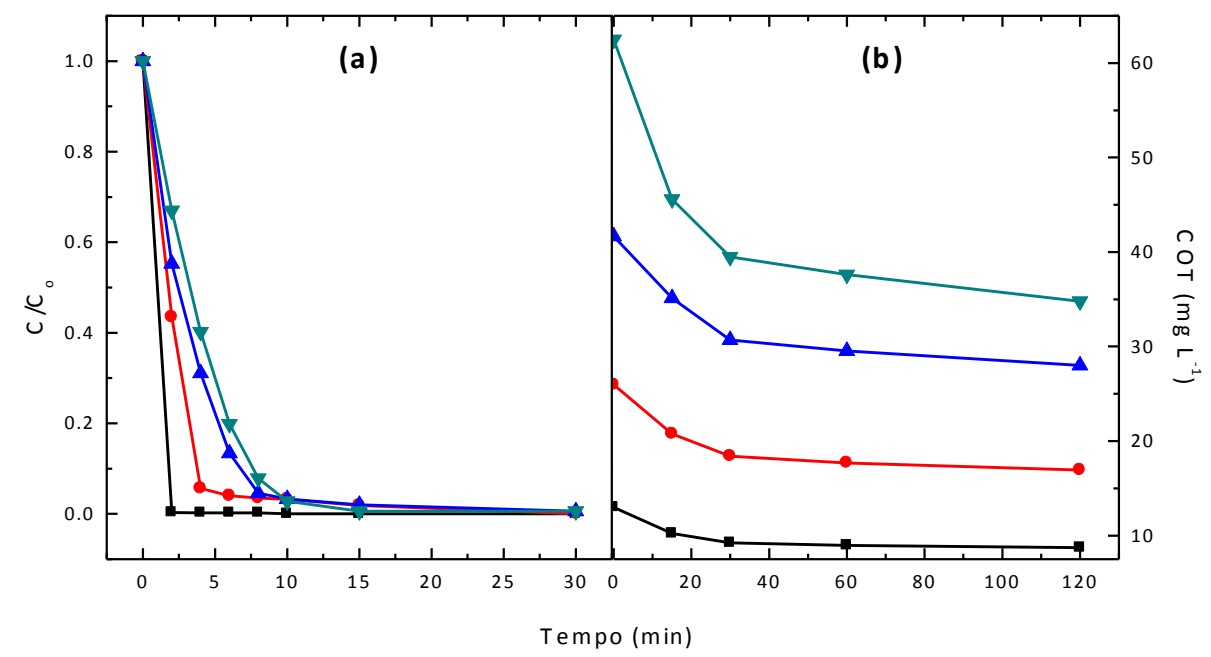

Figura 4.7 - Efeito da concentração inicial do SMX : (ם)50 $\mathrm{mg} \mathrm{L}^{-1},(\mathbf{O}) 100 \mathrm{mg} \mathrm{L}^{-1},(\boldsymbol{\Delta}) 150 \mathrm{mg}$ $\mathrm{L}^{-1},(\boldsymbol{\nabla}) 200 \mathrm{mg} \mathrm{L}^{-1}$ na (a) degradação e (b) remoção de COT (Condições: $\mathrm{T}=25^{\circ} \mathrm{C}, \mathrm{pH}_{\mathrm{i}}=3, \mathrm{C}_{\mathrm{NaCl}}$ $=0,1 \mathrm{~mol} \mathrm{~L}^{-1} \mathrm{e} i=40 \mathrm{~mA} \mathrm{~cm}^{-2}$ ).

A Figura 4.7(b) apresenta as curvas da remoção de COT para diferente valores de concentração inicial do SMX. Pode ser observado que quanto maior a concentração inicial, maior é o percentual de COT removido.

Uma comportamento semelhante foi observado por Zanoni et al. (2003), no caso da degradação foto-eletrocatalítica do corante remazol brilhante $3 \mathrm{R}$, ressaltando que a velocidade de degradação foi acelerada quando a concentração inicial do corante diminuiu de $8,0 \times 10^{-5}$ até $1,5 \times 10^{-5} \mathrm{~mol} \mathrm{~L}^{-1}$, para as condições em que a concentração do $\mathrm{NaCl}$ foi igual a $0,5 \mathrm{~mol} \mathrm{~L}^{-1}, \mathrm{pH} 6,0$ e potencial de eletrodo $\mathrm{E}=+1 \mathrm{~V}$.

Malpass et al. (2010) investigando a degradação eletroquímica foto assistida da atrazina comercial, que é um herbicida. Observaram que a atrazina é removida rapidamente quando a concentração inicial é menor. Todavia, quando a concentração inicial do composto aumenta, o tempo necessário para se realizar o processo de redução também aumenta, notando-se ainda que a porcentagem de DQO diminuiu com o aumento da concentração inicial.

\subsubsection{Consumo energético de degradação eletroquímica foto assistido}

A degradação do SMX, segue uma cinética de pseudo-primeira ordem, e, portanto, a figura de mérito $\mathrm{E}_{\mathrm{EO}}$ (energia eléctrica por ordem) mostrou-se adequada para estimar a eficiência da energia eléctrica. A Figura 4.8 (a) evidencia que a densidade de corrente 


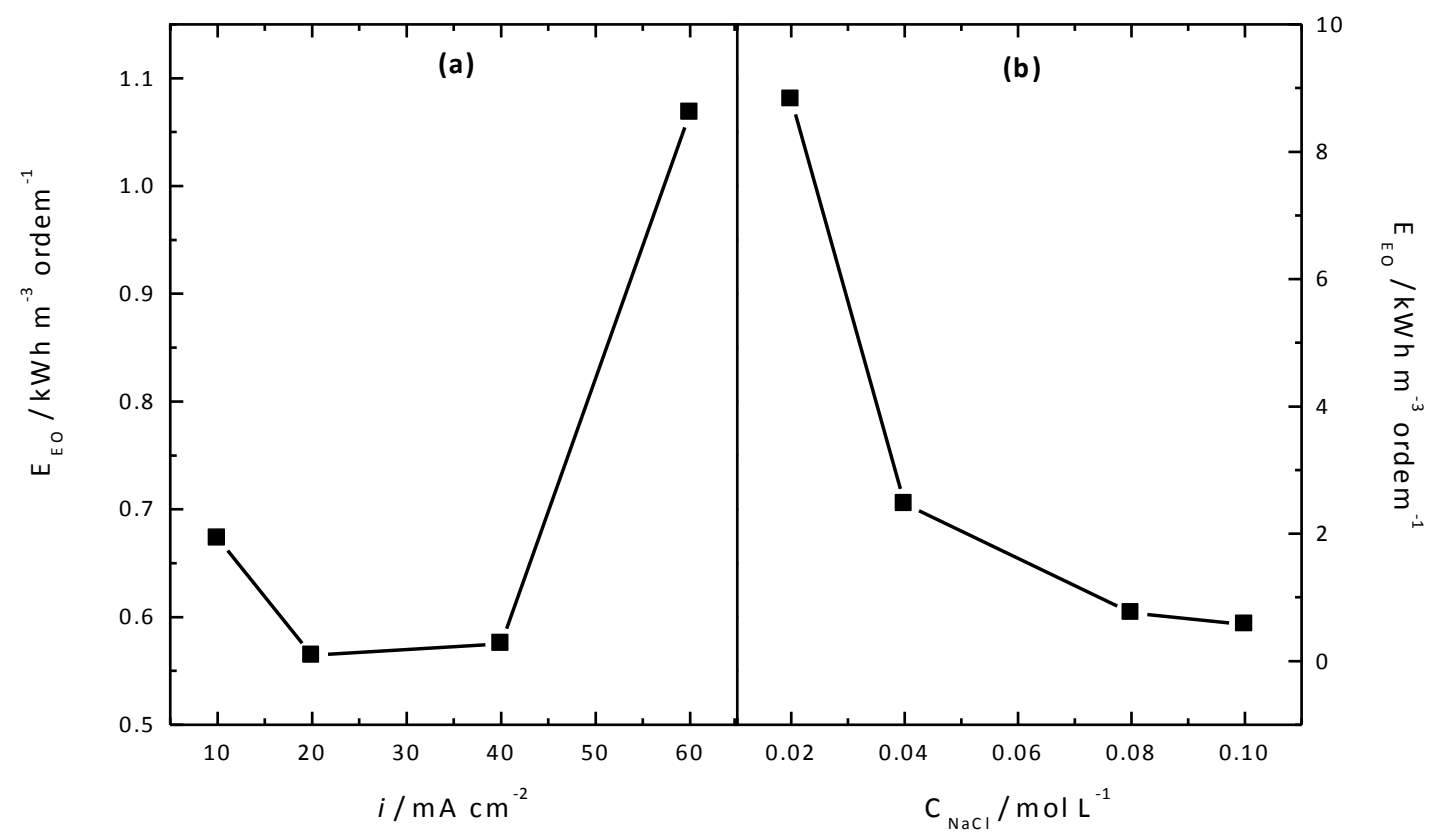

Figura 4.8 - Variação de energia por ordem em função (a) densidade de corrente (Condições: $\mathrm{pH}_{\mathrm{i}}=3$, $\mathrm{T}=25^{\circ} \mathrm{C}, \mathrm{C}_{\mathrm{smx}}=200 \mathrm{mg} \mathrm{L}^{-1}$ e $\left.\mathrm{C}_{\mathrm{NaCl}}=0,1 \mathrm{~mol} \mathrm{~L}^{-1}\right)$, (b) concentração de $\mathrm{NaCl}\left(\right.$ Condições: $\mathrm{pH}_{\mathrm{i}}=3, \mathrm{~T}$ $=25^{\circ} \mathrm{C}, \mathrm{C}_{\mathrm{smx}}=200 \mathrm{mg} \mathrm{L}^{-1} \mathrm{e} i=40 \mathrm{~mA} \mathrm{~cm}^{-2}$ ).

influencia significativamente, em que, neste caso, os valores de densidade de corrente 20 a 40 $\mathrm{mA} \mathrm{cm}{ }^{-2}$ são mais eficientes (menor valor de $\mathrm{E}_{\mathrm{EO}}$ ) para a degradação eletroquímica foto assistida de SMX, enquanto que o valor de energia maior $\left(60 \mathrm{~mA} \mathrm{~cm} \mathrm{~cm}^{-2}\right)$, torna o processo menos eficiente.

O consumo energético é menor do que relatados na literatura para a degradação de carbaril no anodo dimensionalmente estável por Malpass et al. (2009), o que indica a viabilidade do tratamento.

Os valores de $\mathrm{E}_{\mathrm{EO}}$ para as várias concentrações de $\mathrm{NaCl}$ estão indicados na Figura 4.8 (b). Pôde-se observar que o consumo energético foi menor para as maiores concentrações de $\mathrm{NaCl}$, devido, principalmente, ao potencial operacional menor. Entretanto, ao se aplicar o processo eletroquímico foto assistido, o potencial da célula sofre uma diminuição significativa, indicando que há um gasto energético menor no processo eletroquímico foto assistido. O decréscimo de energia por ordem, com o aumento de concentração de cloreto de sódio está de acordo com a literatura (MALPASS et al., 2007). O menor valor de $\mathrm{E}_{\mathrm{EO}}(0,5754$ $\mathrm{kWh} \mathrm{m}^{-3}$ ordem $^{-1}$ ) mostra que o processo é energeticamente mais eficiente para o valor de concentração de $\mathrm{NaCl}$ igual a $0,1 \mathrm{~mol} \mathrm{~L}^{-1}$, no entanto, se o consumo da lâmpada UV for considerado, os valores aumentam para $1.058 \mathrm{kWh} \mathrm{m}^{-3}$ ordem $^{-1}$, o consumo pode diminuir utilizando uma lâmpada de menor potência. 

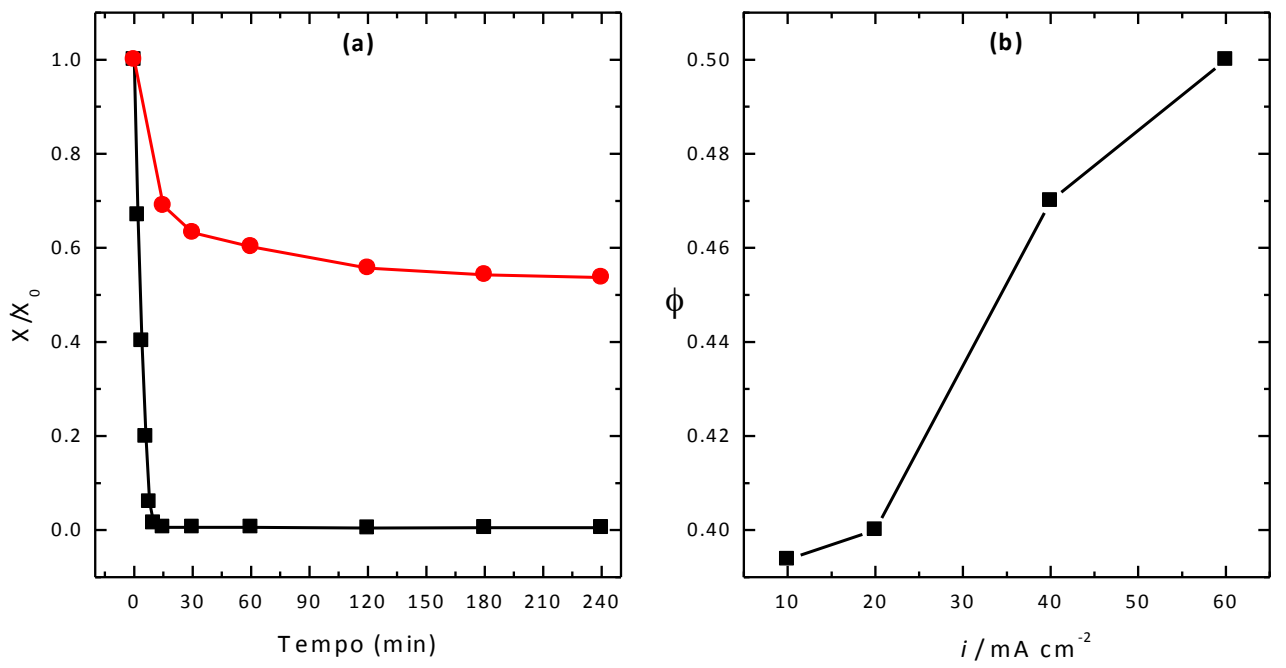

Figura 4.9- (a) Curva do decréscimo relativo da concentração do COT $(\mathcal{O})$ e da concentração do SMX (ロ) em função do tempo de fotoeletrólise (Condições: $i=40 \mathrm{~mA} \mathrm{~cm}{ }^{-2}, \mathrm{pH}=3$, concentração da solução de $\mathrm{NaCl}=0,1 \mathrm{~mol} \mathrm{~L}^{-1}$ e $\mathrm{C}_{\mathrm{smx}}=200 \mathrm{mg} \mathrm{L}^{-1}$ ); (b) Variação do $\phi$ em função de densidade de corrente (Condições: $\mathrm{pH}_{\mathrm{i}}=3, \mathrm{~T}=25^{\circ} \mathrm{C}, \mathrm{C}_{\mathrm{smx}}=200 \mathrm{mg} \mathrm{L}^{-1} \mathrm{e} \mathrm{C}_{\mathrm{NaCl}}=0,1 \mathrm{~mol} \mathrm{~L}^{-}$ $\left.{ }^{1}\right)$.

\subsubsection{Condições otimizadas}

Após a otimização dos parâmetros básicos para os processos eletroquímico foto assistido, foi realizada a fotoeletrólise por um longo período de tempo de $240 \mathrm{~min}$. O processo foi realizado sob condições que resultaram em maiores taxas de degradação e de remoção de COT. As condições consideradas foram: temperatura de $25^{\circ} \mathrm{C}, \mathrm{pH}=3$, concentração do $\mathrm{NaCl}$ igual $0,1 \mathrm{~mol} \mathrm{~L}^{-1}$ e densidade de corrente de $40 \mathrm{~mA} \mathrm{~cm}^{-2}$.

De acordo com a Figura 4.9, pode-se observar que após de 10 min de tratamento, aproximadamente $98 \%$ do SMX havia sido degradado, enquanto que 48\% de COT foi removido. No início do experimento, a remoção de COT foi muito rápida, sendo que nas fases finais, a remoção de COT foi mais lenta, provavelmente pela geração de intermediários recalcitrantes que permanecem em solução.

Foi possível também se obter uma grandeza adimensional $(\phi)$, que indica o grau de combustão total/remoção (MALPASS et al., 2009). Quando $\phi$ tende a 1, tem-se que quase todas as moléculas do SMX foram removidas e mineralizadas posteriormente á $\mathrm{CO}_{2}$. Pode ser observado na Figura 4.9 (b) que os valores de $\phi$ se elevam com o aumento da densidade de corrente, alcançando os valores de 0,50 e 0,48 para os valores de densidade de corrente iguais 
a 60 e $40 \mathrm{~mA} \mathrm{~cm}{ }^{-2}$, respectivamente, o que indica que o COT de SMX foi removido em quase $50 \%$ para as condições estudadas.

\subsection{Detecção dos intermediários e proposição de rota de degradação}

Nas condições otimizadas para o processo eletroquímico foto assistido $\left(40 \mathrm{~mA} \mathrm{~cm}{ }^{-2}\right.$, $0,1 \mathrm{~mol} \mathrm{~L}^{-1}$ ), vários experimentos foram conduzidos para investigar os intermediários durante a fotoeletrólise de SMX. Durante os experimentos, alíquotas foram retiradas e extraídas em intervalos pré-determinados, sendo em seguida analisadas.

No cromatograma obtido após a foto eletrólise de SMX, observou-se a presença de sete principais intermediários. Esses intermediários apresentaram íons moleculares protonados $[\mathrm{M}+\mathrm{H}]+$ de relação massa/carga $(\mathrm{m} / \mathrm{z})$ 288, 273, 321, 110, 193, 377 e 324, referentes aos compostos de baixo peso molecular e compostos de maior peso molecular.

O fragmento $\mathrm{m} / \mathrm{z}=288$ (Figura 4.10) foi identificado no espectro de massas e atribuído à inserção de um cloro radical ao anel aromático do composto padrão, como se verifica no esquema descrito abaixo.<smiles>Cc1cc(NS(=O)(=O)c2ccc(S(=O)(=O)Nc3cc(C)on3)cc2)no1</smiles>

O fragmento $\mathrm{m} / \mathrm{z}=272$ (Figura 4.11) detectado é atribuído ao composto formado pela hidroxilação do anel aromático do composto original, em um ataque direto do radical hidroxila ao anel.<smiles>Cc1cc(NS(=O)(=O)c2ccc(N)cc2)no1</smiles><smiles>Cc1cc(NS(=O)(=O)c2ccc(N)c(O)c2)no1</smiles>
$\mathbf{m} / \mathbf{z}=271[+\mathrm{H}]$ detectado 272 


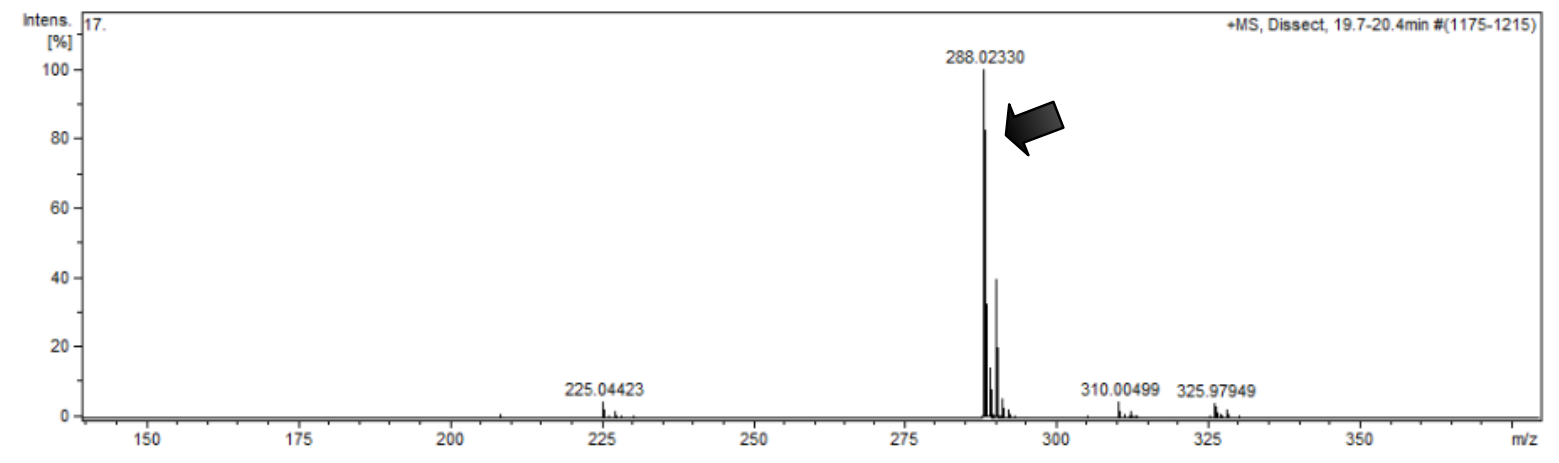

Figura 4.10 - Espectros de massas dos intermediários, referente à m/z=288.

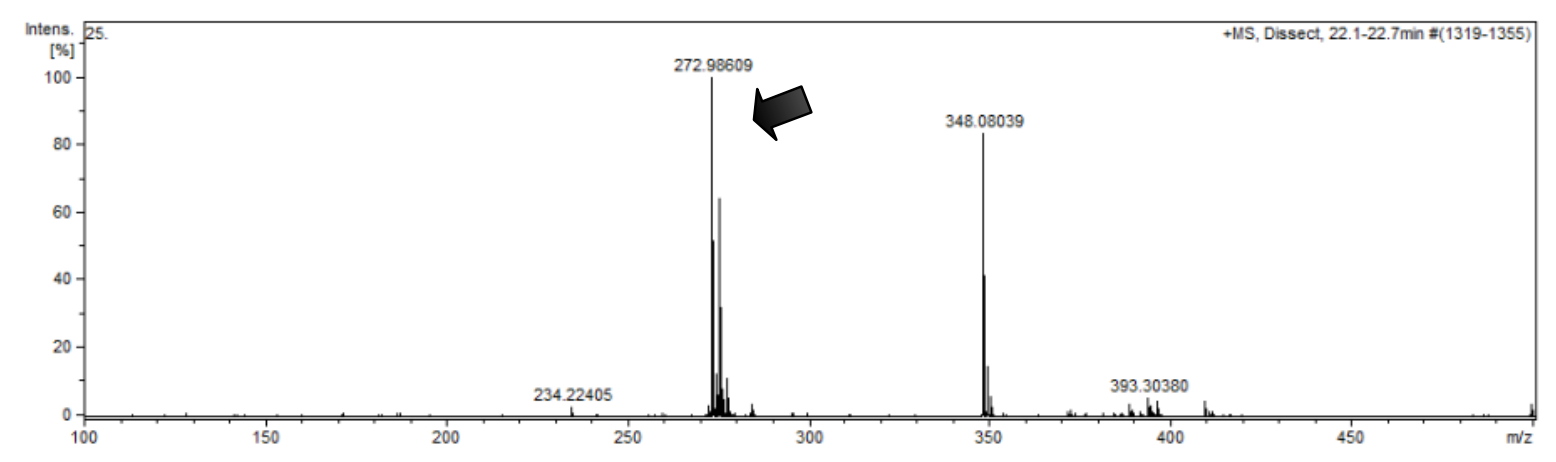

Figura 4.11 - Espectros de massas referentes aos intermediários, condizente à m/z $=272$.

Já o fragmento $\mathrm{m} / \mathrm{z}=321$ indicado na Figura 4.12 corresponde à inserção de 2 radicais de cloro ao anel aromático do fármaco sulfametoxazol, como descrito no esquema abaixo<smiles>Cc1cc(NS(=O)(=O)c2ccc(N)cc2)no1</smiles>

Foram detectados os fragmentos $\mathrm{m} / \mathrm{z}=193$ e 110 representado na Figura 4.13, após um ataque de radical hidroxila nesses fragmentos, quebra-se o anel benzênico, formando assim os compostos alifáticos e os compostos inorgânicos, os quais se mostram descritos de acordo com o mecanismo organizado pela Figura 4.14. 


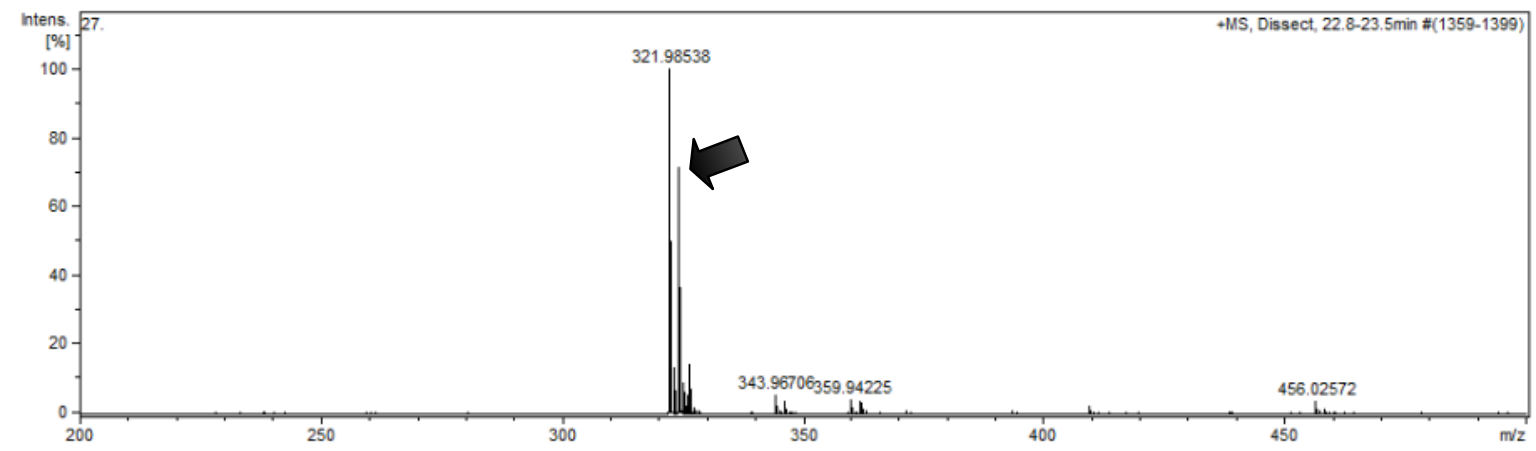

Figura 4.12 - Espectros de massas dos intermediários, referente à $\mathrm{m} / \mathrm{z}=321$.

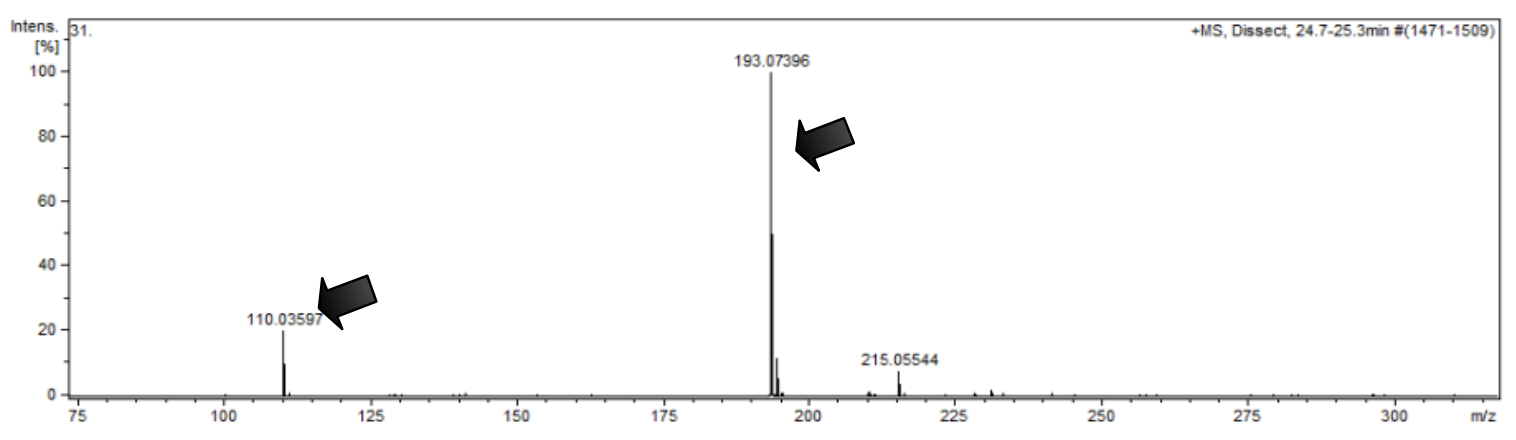

Figura 4.13 - Espectros de massas referentes aos intermediários, correspondente à m/z $(110,193)$.

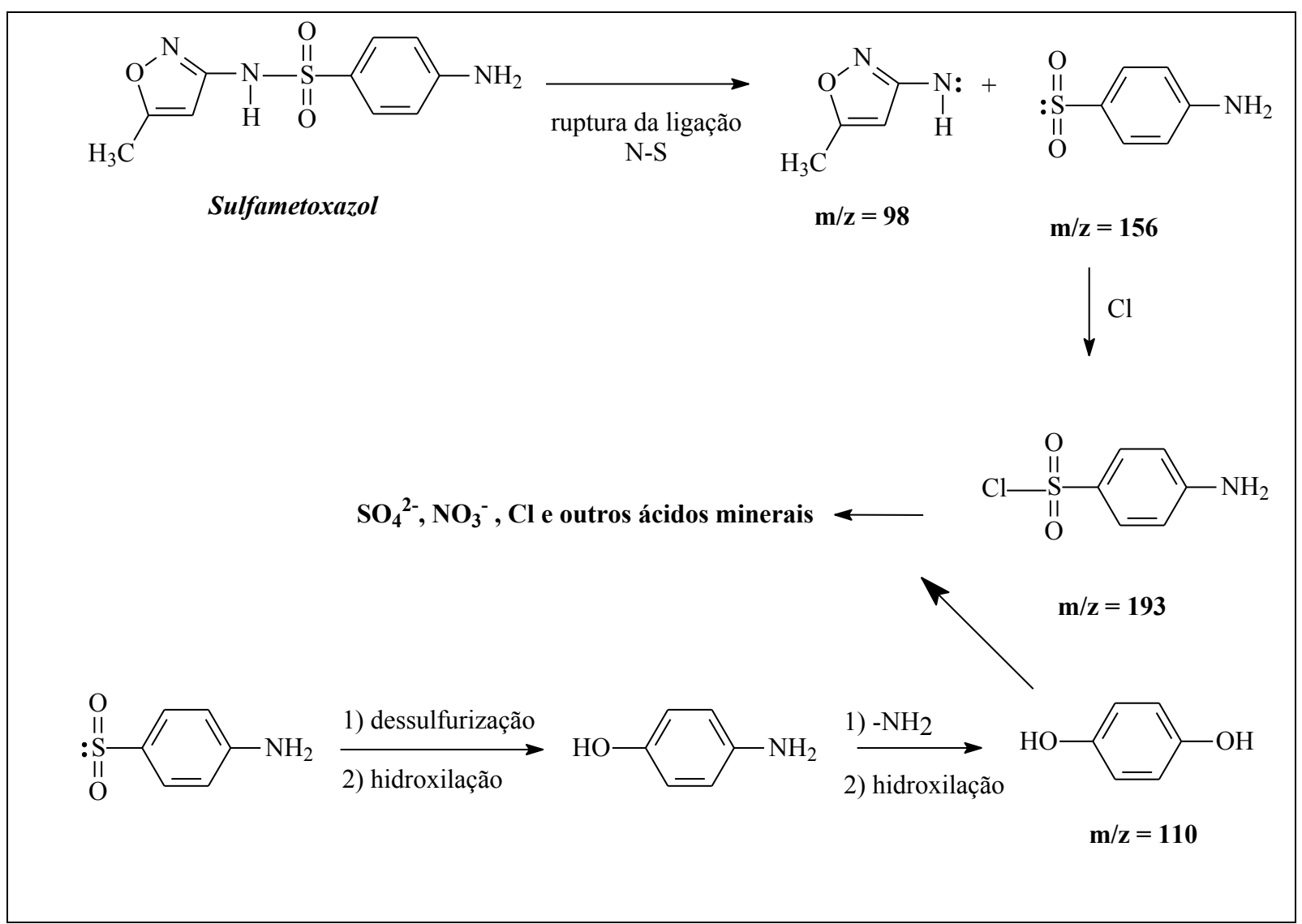

Figura 4.14 - Possível rota de degradação de SMX por processo eletroquímico foto assistido. 


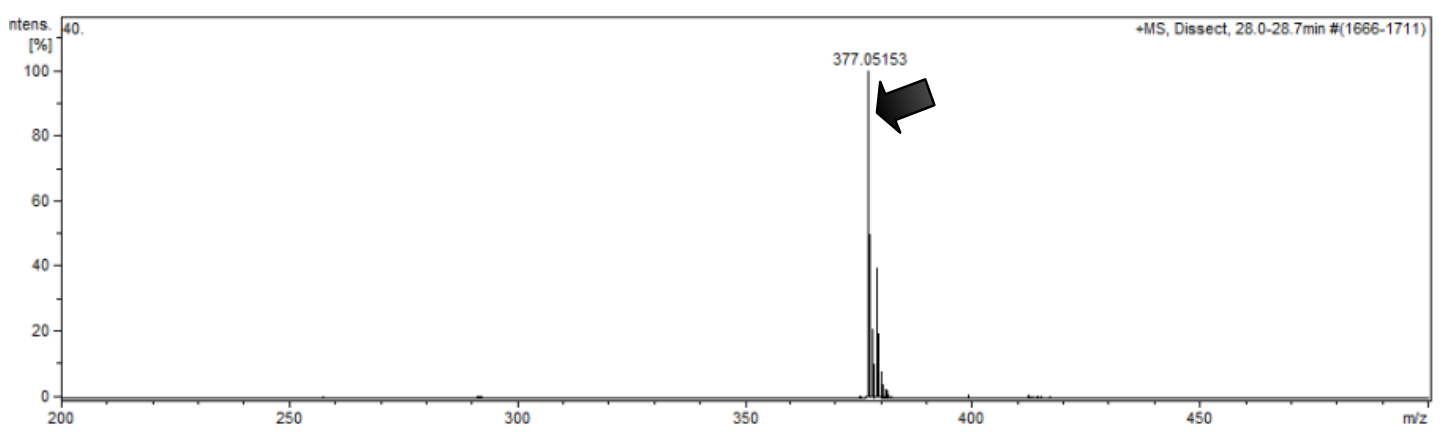

Figura 4.15 - Espectros de massas referentes aos intermediários, relacionado à m/z $=377$.

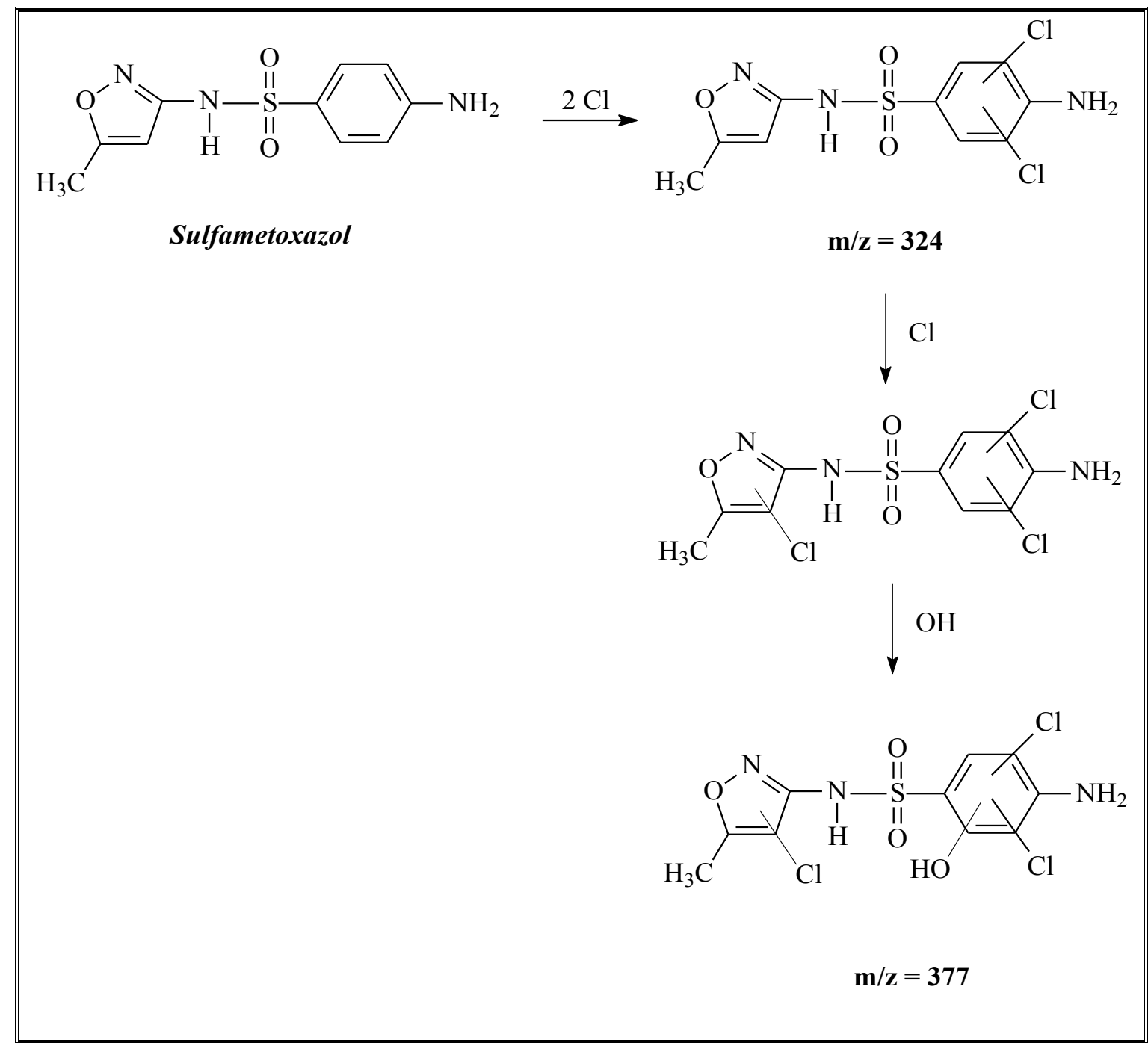

Figura 4.16 - Rota de degradação e conversão de SMX para os compostos referentes à m/z = 377, 324.

Outra possibilidade de reação é a dupla inserção de radicais de cloro ao anel aromático da fração piridínica do composto, gerando-se o fragmento $\mathrm{m} / \mathrm{z}=324$, seguido pela cloração e hidroxilação, resultando, por fim, no intermediário $\mathrm{m} / \mathrm{z}=377$ (Figura 4.15). Os mecanismos de formação desses produtos estão apresentados na Figura 4.16. 


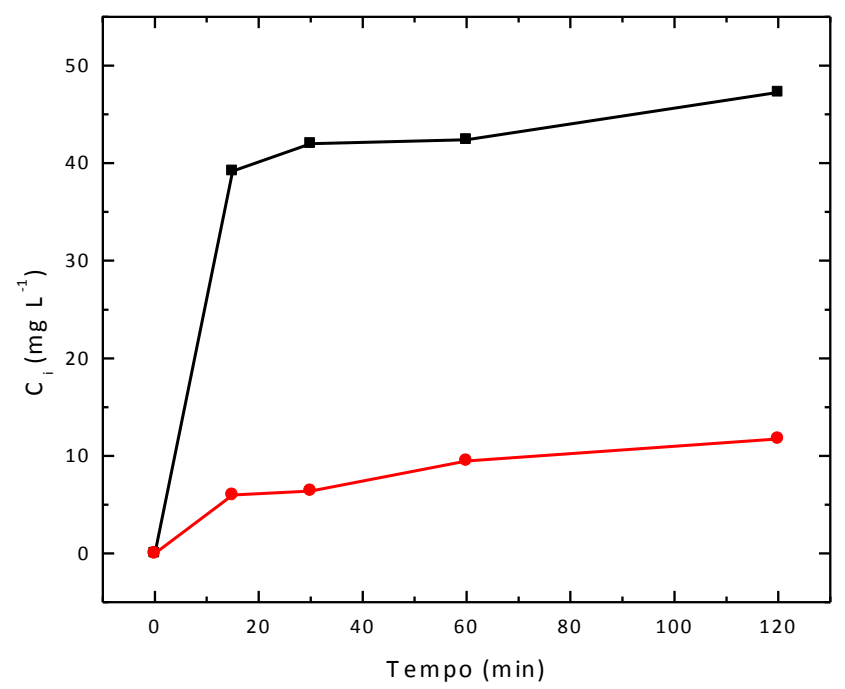

Figura 4.17 - Variação da concentração de intermediários inorgânicos como as espécies $(O) \mathrm{NO}_{3}{ }^{-} \mathrm{e}$ (ם) $\mathrm{SO}_{4}{ }^{2-}$, em função do tempo de eletrólise (Condições: $i=40 \mathrm{~mA} \mathrm{~cm}{ }^{-2}, \mathrm{pH}_{\mathrm{i}}=3, \mathrm{~T}=25^{\circ} \mathrm{C}_{1} \mathrm{C}_{\mathrm{NaCl}}=$ $0,1 \mathrm{~mol} \mathrm{~L}^{-1}$ e $\left._{\mathrm{smx}}=200 \mathrm{mg} \mathrm{L}^{-1}\right)$.

\subsubsection{Intermediários inorgânicos do SMX no processo eletroquímico foto assistido}

Um composto orgânico simples é convertido em $\mathrm{CO}_{2}$ e $\mathrm{H}_{2} \mathrm{O}$ após a ocorrência de sua completa mineralização. No caso de um composto orgânico heteroatômico, este pode ser transformado em seus respectivos fragmentos. Da mesma forma, o SMX é fragmentado em: $\mathrm{SO}_{4}{ }^{2-}, \mathrm{NO}_{2}{ }^{-}, \mathrm{NO}_{3}{ }^{-}$e $\mathrm{NH}_{4}{ }^{+}$após a mineralização.

A análise do COT revelou que aproximadamente 50\% de carbono orgânico foram removidos durante o processo eletroquímico foto assistido, sendo então convertidos em espécies inorgânicas. Deve-se notar que o $\mathrm{NH}_{4}^{+}$não foi determinado pelo método instrumental empregado.

A Figura 4.17 representa a variação da quantidade dos ânions $\left(\mathrm{SO}_{4}{ }^{2-}, \mathrm{NO}_{3}{ }^{-}\right)$que foram gerados durante o processo eletroquímico foto assistido. Observa-se que a concentração de ambos os íons aumentou com o tempo de eletrólise, o que significa que o SMX foi destruído continuamente, e que esses íons foram liberados na solução.

A liberação desses íons foi muito rápida na primeira fase da fotoeletrólise, tornando-se constante, o que se deve principalmente à geração de alguns intermediários recalcitrantes que são dificilmente mineralizados. A Figura 4.17 também indica que houve liberação de soluções de sulfatos e nitratos com concentrações iguais a 45 e $12 \mathrm{mg} \mathrm{L}^{-1}$, respectivamente, após 120 
min de foto-eletrólise. A liberação desses íons inorgânicos em menor concentração, indica claramente que o SMX foi mineralizado parcialmente.

\subsection{Conclusões parciais}

O método eletroquímico foto assistido resulta em uma degradação rápida e completa do SMX, permitindo que ocorra uma remoção de COT de SMX aproximadamente de 50\% após $2 \mathrm{~h}$ de tratamento, sendo os efeitos de vários parâmetros operacionais estudados. A degradação e remoção de COT é mais eficiente para altos valores de cloreto e a densidade de corrente.

A degradação eletroquímica foto assistida do SMX segue uma cinética de pseudoprimeira ordem, em que a constante da reação $(\mathrm{k})$ aumenta com a densidade de corrente e com o aumento na concentração do $\mathrm{NaCl}$.

Durante o processo eletroquímico foto assistido, o SMX é oxidado por diferentes radicais livres como $\left(\mathrm{Cl}_{2} \bullet, \mathrm{Cl} \bullet\right.$ e $\left.\mathrm{OH} \bullet\right)$ e convertido em vários intermediários, alguns com maior peso molecular, como $\mathrm{m} / \mathrm{z}=377$, já outros com baixo peso molecular, como $\mathrm{m} / \mathrm{z}=110$, foram detectados. Também é observada a presença de alguns compostos orgânicos clorados que talvez tenham aumentado a toxicidade da solução, mas é muito interessante verificar que há menos compostos organoclorados detectados nas amostras de processo eletroquímico foto assistidos do que apenas eletroquímico. Além disso, produtos de degradação inorgânicos foram identificados.

Os resultados obtidos indicam que essa metodologia é mais eficiente do que apenas o processo eletroquímico para se tratar compostos como o antibiótico SMX, e ainda os dados de consumo energético demonstram que o processo figure-se como energética e economicamente viável. 


\section{Capítulo 5}

\section{Degradação de sulfametoxazol por processo}

\section{fotoquímico}

Neste capítulo é testado degradação fotoquímica do sulfametoxazol, em particular com a análise da parâmetros básicos, tais como o efeito do $\mathrm{pH}$ (de 2 a 11), temperatura (15 a 45 $\left.{ }^{\circ} \mathrm{C}\right)$ e concentração inicial de $\operatorname{SMX}\left(50\right.$ a $\left.200 \mathrm{mg} \mathrm{L}^{-1}\right)$. Além disso, foram analisados os principais intermediários formados durante o processo fotoquímico, com o objetivo de propor um mecanismo de fotólise, tendo como base as vias de degradação anteriormente.

\subsection{Degradação fotoquímica de SMX}

A radiação UV é uma alternativa importante para o tratamento de efluentes, pois esta promove reações fotoquímicas que levam à destruição das moléculas orgânicas. Assim, tornase essencial investigar a influência da fotólise separadamente quando são aplicados os processos foto-assistidos, tais como o Fenton e o eletroquímico foto assistidos.

Na Figura 3.13 é mostrado o espectro de absorção na região do ultravioleta obtido para o SMX, o qual fornece informações sobre o comprimento de onda onde ocorre a 
absorção de radiação UV e, consequentemente, podendo ser degradado. O SMX absorve a radiação até um comprimento de onda de $300 \mathrm{~nm}$. Assim, para o presente estudo foi utilizada uma lâmpada que emite radiação de faixa de $254 \mathrm{~nm}$, ou seja, eficiente para a degradação do SMX.

Uma série de experimentos foi realizada para investigar a eficácia da fotólise do SMX. Inicialmente foram analisados vários parâmetros que podem influenciar no processo de degradação. Durante os experimentos, a coloração da solução apresentou alterações contínuas, passando de incolor para azul claro e, após essa fase, para azul escuro, sendo que após 120 min de tratamento, a solução voltou a ser incolor, o que foi interpretado como evidência do progresso da degradação.

\subsubsection{Efeito do pH na degradação fotoquímica}

$\mathrm{O}$ valor de $\mathrm{pKa}$ é muito importante para a elucidação do comportamento fotoquímico de um composto. O SMX apresenta dois estados protonados que podem afetar a sua reatividade. Os valores de pKa são: $\mathrm{pKa} 1=1,6$ e pKa2 $=5,7$, significando que o SMX tem uma forma catiônica a $\mathrm{pH}<1,6$, e uma forma aniônica quando o valor de $\mathrm{pH}>5,7$. Assim, torna-se extremamente interessante estudar a fotólise do SMX sob diferentes valores de $\mathrm{pH}$ iniciais do SMX, motivando então uma série de experimentos, onde os valores de pH inicial foram de 2, 3, 5, 7, 9 e 11, mantendo as demais condições experimentais constantes.

Os resultados obtidos são apresentados na Figura 5.1 (a), onde pode ser observado que a condição ácida favoreceu a degradação; por conseguinte, uma degradação completa foi obtida para valores de $\mathrm{pH}$ no intervalo de 2 a 5, após 90 min de tratamento. Nos meios neutros e básicos não foi observada a degradação completa do SMX, mesmo após 120 min de irradiação.

$\mathrm{O} \mathrm{pH}$ foi monitorado durante todos os experimentos, observando-se que este decresceu durante o processo fotoquímico, no entanto, esta redução é mais acentuada em condições básicas e menos notável sob condições ácidas. Isso pode ocorrer devido ao processo de mineralização, com a consequente liberação dos íons inorgânicos, tais como o $\mathrm{SO}_{3}^{-2}, \mathrm{NH}_{4}^{+}$e $\mathrm{NO}_{3}^{-}$.

Também pode ser observado na Figura 5.1 (b) que a remoção de COT apresenta um padrão semelhante, e o máximo de COT removido ocorreu em meio ácido. No entanto, para pH > 5 a remoção de COT é muito menor, sendo que a remoção de COT foi de 16, 13 e 6\% para valores de $\mathrm{pH}$ iniciais de 3, 2 e 5, respectivamente. 


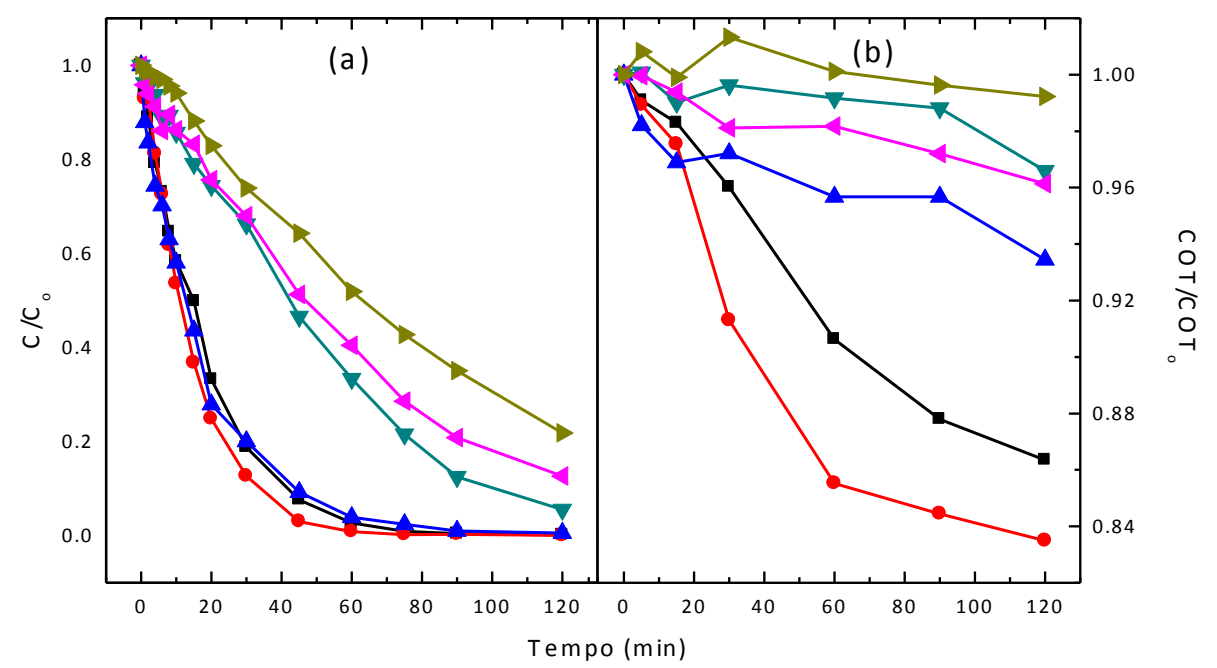

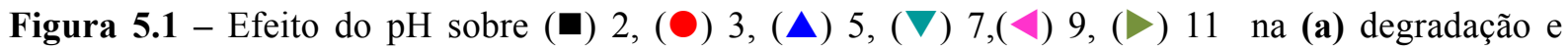
(b) remoção de COT (Condições: $\left.\mathrm{T}=25^{\circ} \mathrm{C} \mathrm{e} \mathrm{C}_{\mathrm{smx}}=200 \mathrm{mg} \mathrm{L}^{-1}\right)$.

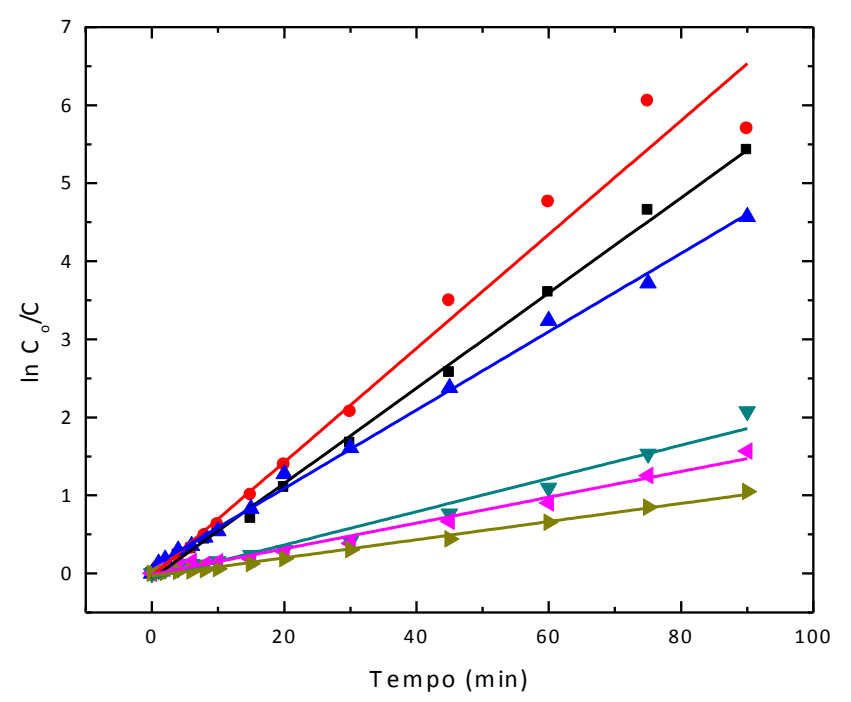

Figura 5.2 - Variação do $\ln \left(\mathrm{C}_{\mathrm{o}} / \mathrm{C}\right)$ em função do tempo de fotólise em diferentes pHs $(\boldsymbol{\square}) 2,(\bullet) 3$, $(\boldsymbol{\Delta}) 5,(\boldsymbol{\nabla}) 7,(<) 9,(\triangleright) 11$ (Condições: $\mathrm{T}=25^{\circ} \mathrm{C} \mathrm{e} \mathrm{C}$ smx $=200 \mathrm{mg} \mathrm{L}^{-1}$ ).

Na Figura 5.2 é apresentada a relação de $\ln \mathrm{C}_{\mathrm{o}} / \mathrm{C}$ em função do tempo, para a qual linhas retas foram obtidas, indicando que a degradação obedece a uma cinética de pseudoprimeira ordem. A Figura 5.2 também mostra que a taxa de degradação é elevada a pH ácido, ou seja, para valores entre 3 e 5 .

Vários estudos mostram que é possível degradar o antibiótico SMX na condição ácida. Mouamfon et al. (2010a) estudaram a degradação de SMX utilizando diferentes processos 
fotoquímicos, e observaram que o antibiótico é eficientemente degradado em $\mathrm{pH}=5$, com o processo de degradação apresentando cinética de pseudo-primeira ordem.

Em outro estudo realizado pelo Mouamfon et al. (2010b), foi verificada a degradação de SMX em efluente de estação de tratamento de esgoto por radiação UV, confirmando que valores de pH de 2, 4 e 5 são melhores para a degradação. Em estudo semelhante, Lester et al. (2008) investigaram que a maior taxa de fotólise de sulfadimethoxine (SMT) em água ocorre a $\mathrm{pH}=2,5$.

No trabalho de Prabhakaran et al. (2009) foi observado que na fotodegradação de dois antibióticos de uso veterinário, fluoroquinolonas difloxacina (DIF) e sarafloxacina (SARA), em sistemas aquosos, a taxa de fotólise diminui acentuadamente em $\mathrm{pH}>7$ para a DIF, enquanto que para a SARA o processo ocorre mais rápido com o aumento de $\mathrm{pH}$.

Na Tabela 5.1 estão apresentados os valores de $\mathrm{k}, \mathrm{t}_{1 / 2}$ e de $\mathrm{E}_{\mathrm{EO}}$ (energia por ordem) para diferentes valores de $\mathrm{pH}$ inicial na degradação de SMX. A Figura 5.7 (a) mostra uma diminuição na constante de velocidade com o aumento de $\mathrm{pH}$, ou seja, os valores de $\mathrm{pH}$ menores (meio ácido) são mais adequados para a degradação fotoquímica de SMX.

\subsubsection{Efeito da concentração inicial SMX na degradação fotoquímica}

Com o objetivo de estudar a influência da concentração inicial do SMX no processo de fotólise, vários experimentos foram realizados com a concentração inicial de SMX variando de 50 a $200 \mathrm{mg} \mathrm{L}^{-1}$. A Figura 5.3(a) mostra que a degradação completa foi obtida em 25, 45, 90 e 120 minutos para as concentrações iniciais de SMX 50, 100, 150 e $200 \mathrm{mg} \mathrm{L}^{-1}$, respectivamente. A degradação foi muito rápida para concentrações de 50 e $100 \mathrm{mg} \mathrm{L}^{-1}$ e mais lenta para 150 e $200 \mathrm{mg} \mathrm{L} \mathrm{L}^{-1}$. A taxa de remoção de COT também mostrou um comportamento similar, como observado na Figura 5.3(b).

A remoção de COT diminuiu com o aumento da concentração de SMX, e a mineralização ocorreu até 10, 16, 18 e 26\% em concentração inicial de SMX 200, 150, 100 e $50 \mathrm{mg} \mathrm{L}{ }^{-1}$. Isso significa que a radiação na faixa do ultravioleta degrada completamente o SMX em todas as quatro concentrações iniciais estudadas, com mineralização em diferentes graus.

Na Figura 5.4 pode ser observada que a degradação fotoquímica de SMX segue uma cinética de pseudo-primeira ordem. Os valores de constante de velocidade para as diferentes 


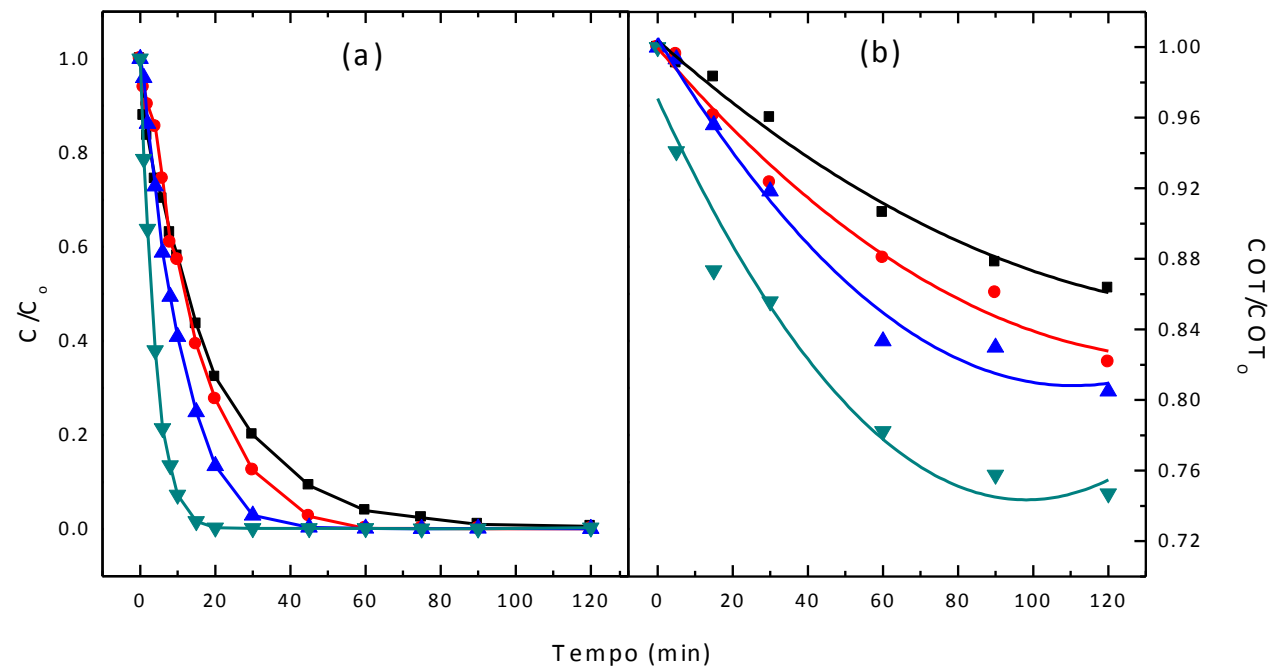

Figura 5.3 -Efeito de concentração inicial do $\operatorname{SMX}(\boldsymbol{\nabla}) 50 \mathrm{mg} \mathrm{L}^{-1}(\mathbf{\Delta}) 100 \mathrm{mg} \mathrm{L}^{-1}(\bullet) 150 \mathrm{mg} \mathrm{L}^{-1}$

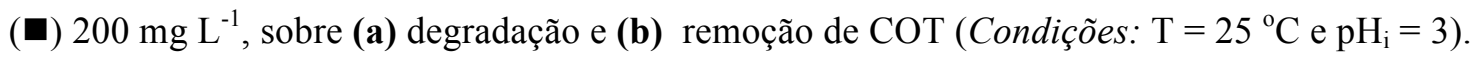

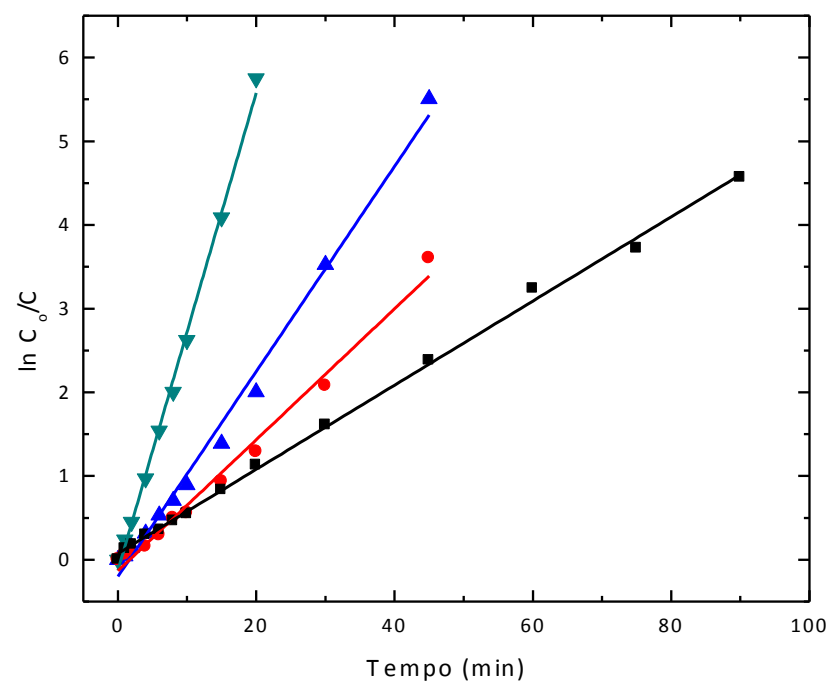

Figura 5.4 - Variação do $\ln \left(\mathrm{C}_{\mathrm{o}} / \mathrm{C}\right)$ em função do tempo de fotólise de SMX em diferentes

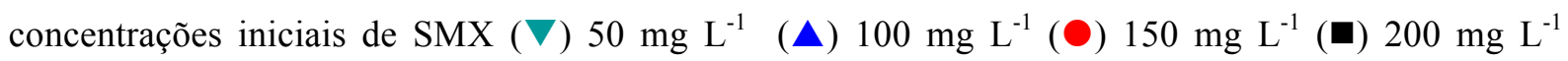
(Condições: $\mathrm{T}=25^{\circ} \mathrm{C} \mathrm{e} \mathrm{pH}_{\mathrm{i}}=3$ ).

concentrações iniciais de SMX são apresentados na Tabela 5.1 e ilustrados na Figura 5.4, indicando uma diminuição da constante de velocidade com o aumento de concentração inicial de SMX. 
Tabela 5.1 - Parâmetros cinéticos e de consumo de energia de degradação fotoquímica.

\begin{tabular}{|c|c|c|c|c|}
\hline Parâmetros & $k\left(\min ^{-1}\right)$ & $\mathbf{t}_{1 / 2}(\min )$ & $\mathbf{R}_{2}$ & 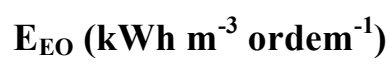 \\
\hline \multicolumn{5}{|l|}{$\operatorname{SMX}\left(\mathrm{mg} \mathrm{L}^{-1}\right)$} \\
\hline 50 & 0,2853 & 2,428 & 0,996 & 0,8971 \\
\hline 100 & 0,1225 & 5,653 & 0,991 & 2,088 \\
\hline 150 & 0,0782 & 8,853 & 0,986 & 3,270 \\
\hline 200 & 0,0502 & 13,782 & 0,998 & 5,091 \\
\hline \multicolumn{5}{|c|}{ Temperatura $\left({ }^{\circ} \mathrm{C}\right)$} \\
\hline 15 & 0,0448 & 15,468 & 0,993 & 5,714 \\
\hline 25 & 0,0487 & 14,227 & 0,995 & 5,255 \\
\hline 35 & 0,0522 & 12,820 & 0,998 & 5,091 \\
\hline 45 & 0,0606 & 11,433 & 0,997 & 4,223 \\
\hline \multicolumn{5}{|l|}{$\mathbf{p H}$} \\
\hline 2 & 0,0610 & 11,358 & 0,995 & 4,196 \\
\hline 3 & 0,0729 & 9,500 & 0,973 & 3,509 \\
\hline 5 & 0,0866 & 8,000 & 0,994 & 2,955 \\
\hline 7 & 0,0213 & 32,53 & 0,996 & 12,018 \\
\hline 9 & 0,0165 & 42,00 & 0,997 & 15,515 \\
\hline 11 & 0,0116 & 56,6 & 0,9979 & 22,031 \\
\hline
\end{tabular}

Em uma maior concentração de SMX, a luz UV se torna limitante, fazendo com que a maior parte da luz seja absorvida por intermediários. No entanto, com uma menor concentração inicial de SMX, a degradação fotoquímica ocorre de forma mais rápida devido ao menor número de moléculas presentes no meio. A Tabela 5.1 também mostra um aumento no tempo de meia-vida $t_{1 / 2}$ e valores de energia por ordem, o que implica no aumento da concentração de SMX. 


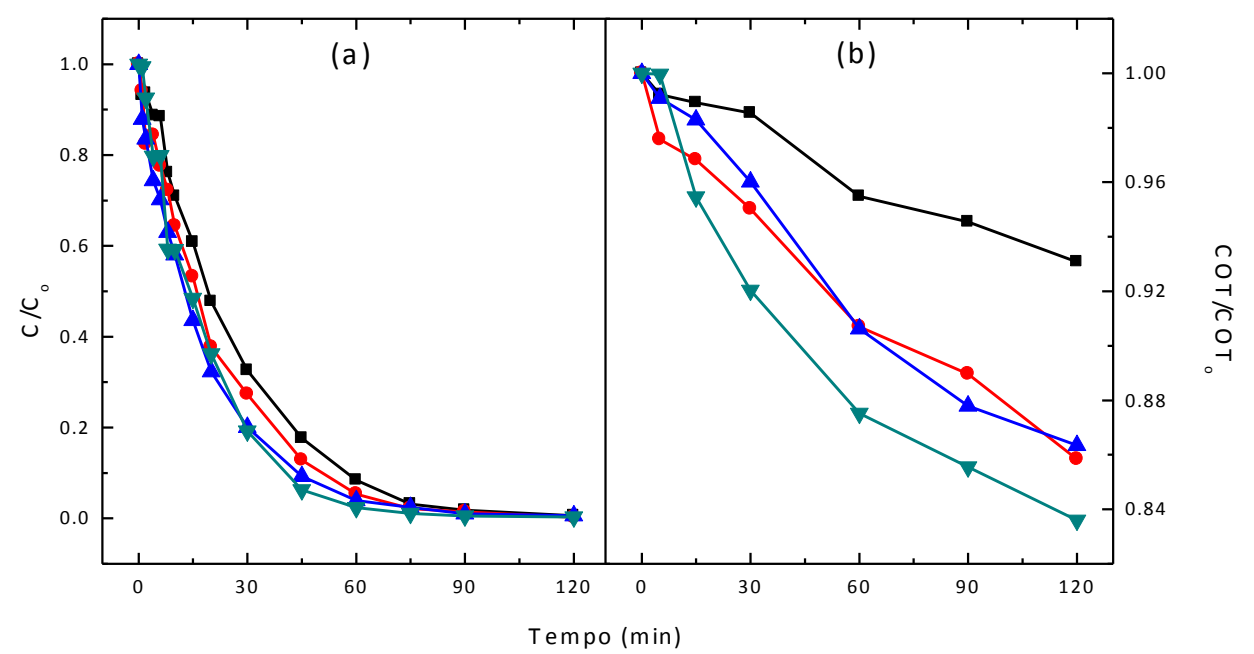

Figura 5.5 - Efeito de temperatura (অ) $15{ }^{\circ} \mathrm{C},(\bullet) 25{ }^{\circ} \mathrm{C},(\boldsymbol{\Delta}) 35^{\circ} \mathrm{C},(\boldsymbol{\nabla}) 45^{\circ} \mathrm{C}$ sobre (a) degradação e (b) remoção de COT (Condições: $\mathrm{C}_{\mathrm{smx}}=200 \mathrm{mg} \mathrm{L}^{-1} \mathrm{e} \mathrm{pH}_{\mathrm{i}}=3$ ).

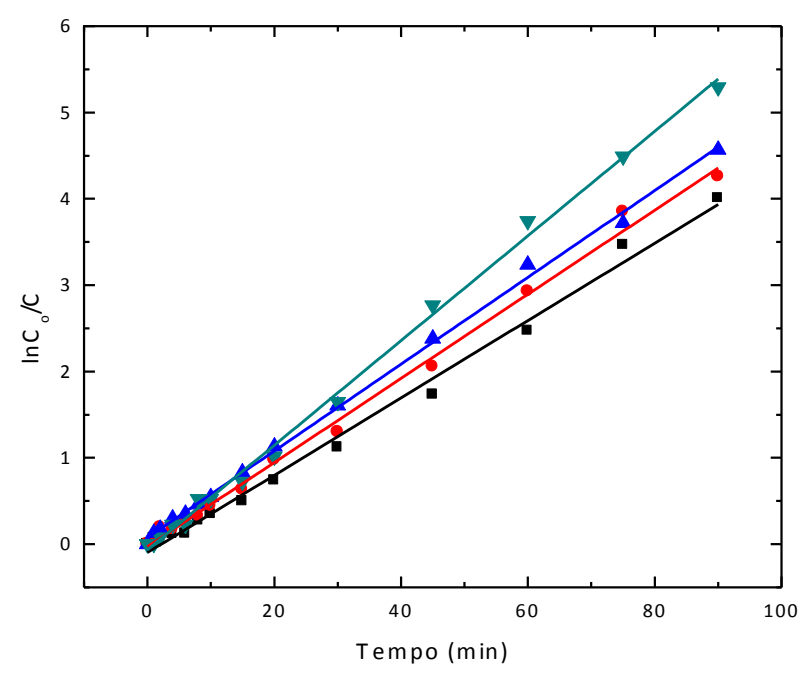

Figura 5.6 - Variação do $\ln \left(\mathrm{C}_{\mathrm{o}} / \mathrm{C}\right)$ em função do tempo de fotólise de SMX em diferentes temperaturas (অ) $15^{\circ} \mathrm{C},(\bullet) 25^{\circ} \mathrm{C},(\boldsymbol{\Delta}) 35^{\circ} \mathrm{C},(\boldsymbol{\nabla}) 45^{\circ} \mathrm{C}$ (Condições: $\mathrm{C}_{\mathrm{smx}}=200 \mathrm{mg} \mathrm{L}^{-1} 1$ e pH $\mathrm{pH}_{\mathrm{i}}=3$ ).

\subsubsection{Efeito da temperatura na degradação fotoquímica}

A temperatura tem uma pequena influência sobre o processo geral de degradação fotoquímica. A temperatura foi variada entre 25 e $45^{\circ} \mathrm{C}$ para a degradação de $\mathrm{SMX}$, e o resultado pode ser verificado nas Figuras 5.5 (a) e (b). Observou-se que a degradação e remoção de COT foram ligeiramente aumentadas com a elevação da temperatura. O aumento na taxa de degradação foi provavelmente devido a um aumento da movimentos e frequência de colisões das moléculas. A Figura 5.6 mostra a relação cinética para as diferentes temperaturas, e as linhas retas implicam que a reação apresenta uma cinética de pseudoprimeira ordem. Os resultados estão de acordo com os vários estudos realizados, tais como o de Luning et al. (2013), que observaram um pequeno aumento da constante de velocidade de 

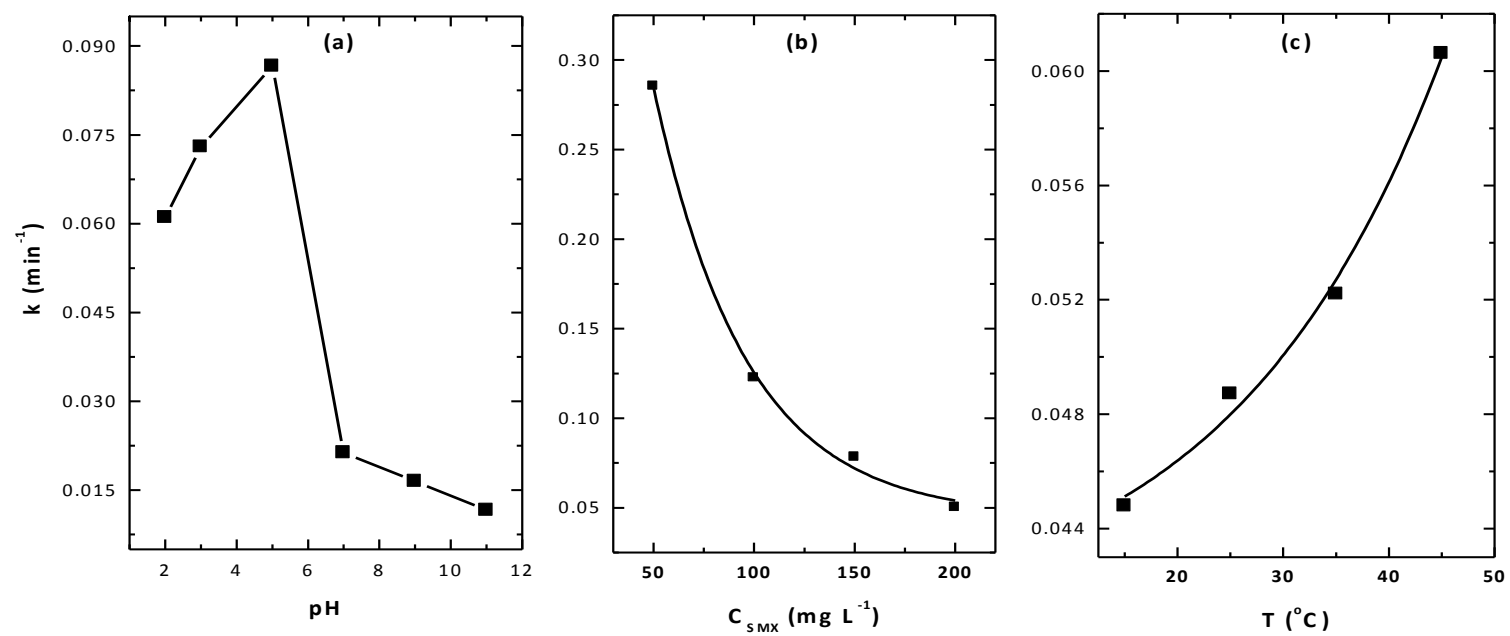

Figura 5.7 - Constante de velocidade (k) em função de (a) $\mathrm{pH}$ (Condições: $\mathrm{T}=25^{\circ} \mathrm{C}$ e $\mathrm{C}_{\mathrm{smx}}=200$ $\mathrm{mg} \mathrm{L} \mathrm{L}^{-1}$ ), (b) concentração inicial de SMX (Condições: $\mathrm{T}=25^{\circ} \mathrm{C}$ e $\mathrm{pH}_{\mathrm{i}}=3$ ), (c) temperatura (Condições: $\mathrm{C}_{\mathrm{smx}}=200 \mathrm{mg} \mathrm{L}^{-1}$ e $\mathrm{pH}_{\mathrm{i}}=3$ ).

fotólise da 2,4-dinitrotolueno e 2,6-dinitrotolueno em água do mar, revelando, por sua vez, que há um aumento no contante de velociadade em temperatura elevada. Similarmente, Lai e Lin (2009) observaram que não há uma degradação significativa dos antibióticos ácido oxolínico e ácido flumequina em água de aquicultura e sedimento com aumento de temperatura. Da mesma forma, Dantas et al. (2008) realizaram estudos de degradação do SMX por processo de ozonização, e observaram que a variação de temperatura não mostra nenhuma alteração na degradação deste antibiótico.

A Tabela 5.1 mostra os valores para a constante de velocidade, meia-vida $t_{1 / 2}$ e a $E_{E O}$ obtido durante o estudo. A constante de velocidade $\mathrm{k}$ foi representada em função da temperatura e apresentado na Figura 5.7 (c), A degradação de SMX foi maior quando a temperatura aumentou. O aumento da temperatura reduz a meia-vida $\left(\mathrm{t}_{1 / 2}\right)$ e a taxa de degradação.

\subsubsection{Consumo energético na degradação fotoquímica de SMX}

Em qualquer processo que se utiliza a energia elétrica, a medida de consumo energético é fundamental. De acordo com as diretrizes da IUPAC, a eficiência de um processo de oxidação que envolve energia elétrica pode ser expressa de acordo com o modelo cinético que corresponde ao sistema que está sobre investigação (BOLTON et al., 2001).

Como neste estudo a degradação do SMX obedece a uma cinética de reação de pseudo-primeira ordem, dispõe-se então da energia por ordem $\left(\mathrm{E}_{\mathrm{EO}}\right)$ e da figura de mérito 

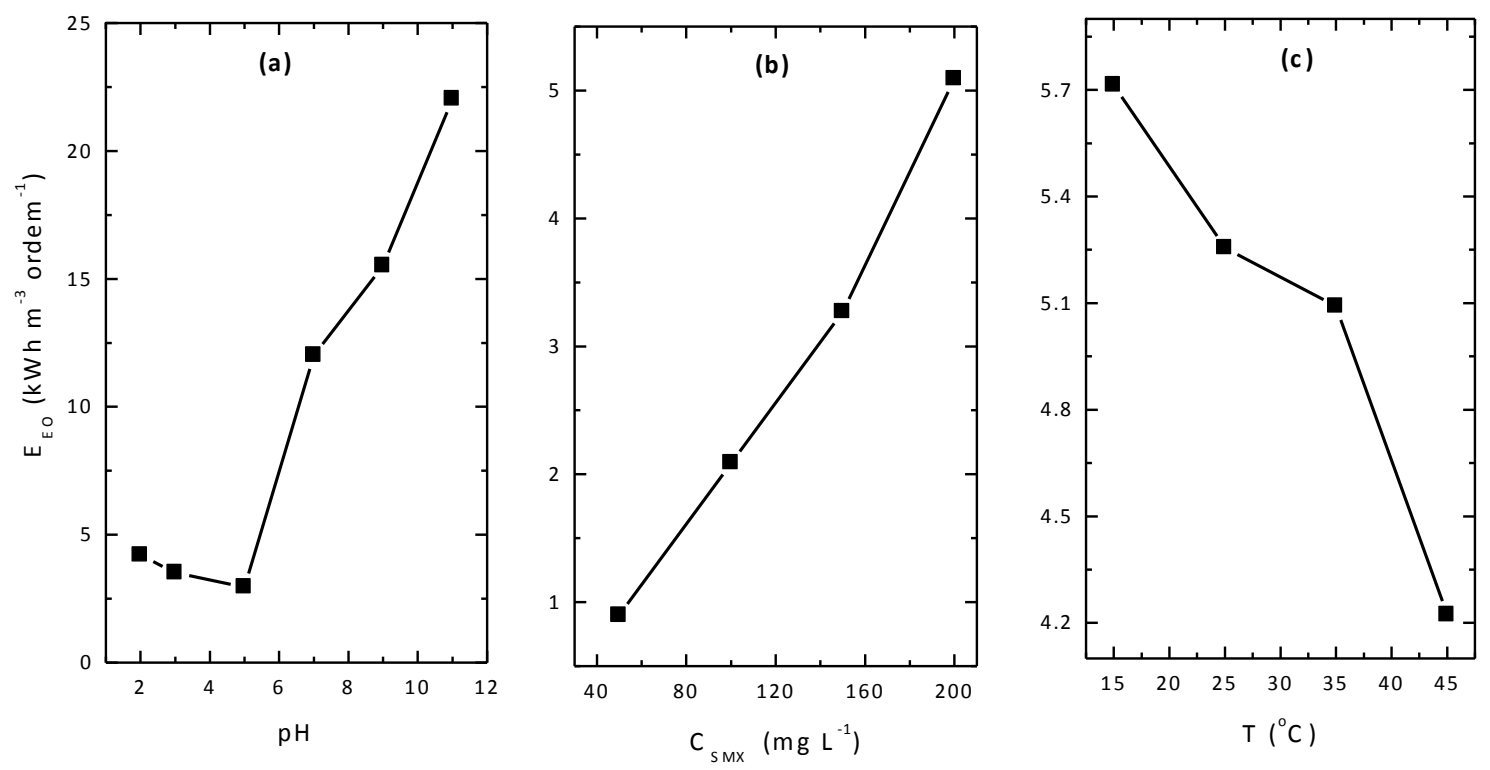

Figura 5.8 - $\mathrm{E}_{\mathrm{EO}}$ energia por ordem $\left(\mathrm{kWh} \mathrm{m}^{-3}\right.$ ordem $\left.^{-1}\right)$ para degradação fotoquímica de SMX em função de (a) $\mathrm{pH}$ (Condições: $\mathrm{T}=25^{\circ} \mathrm{C}$ e $\mathrm{C}_{\mathrm{smx}}=200 \mathrm{mg} \mathrm{L}^{-1}$ ), (b) concentração inicial de SMX (Condições: $\mathrm{T}=25^{\circ} \mathrm{Ce} \mathrm{pH}_{\mathrm{i}}=3$ ), (c) Temperatura (Condições: $\mathrm{C}_{\mathrm{smx}}=200 \mathrm{mg} \mathrm{L}^{-1} 1$ e $\mathrm{pH}_{\mathrm{i}}=3$ ).

apropriada para medir a eficiência do sistema fotoquímico. A $\mathrm{E}_{\mathrm{EO}}$ foi calculada através da equação 2.3 .

$\mathrm{Na}$ Figura 5.8 estão apresentados os valores de energia por ordem, obtidos para a degradação de SMX ao serem utilizados diferentes valores de $\mathrm{pH}$, temperatura e concentrações iniciais de SMX. Pode ser observado pela Figura 5.8 (a) que os valores de $\mathrm{E}_{\mathrm{EO}}$ diminuem no intervalo de $\mathrm{pH}$ de 2 a 5 , mas aumentam em $\mathrm{pH}$ básico.

Em condições básicas, a cor da solução se altera muito rapidamente, tornando-se mais impenetrável à radiação UV, o que causa uma diminuição na constante de velocidade e aumenta o consumo energético. Entretanto, observa-se pela Figura 5.8 (b) que o valor de $\mathrm{E}_{\mathrm{EO}}$ aumenta com aumento da concentração inicial de SMX devido a maior absorção de radiação UV por moléculas de SMX, e também pelo fato da diminuição da constante de velocidade. Por outro lado, a $\mathrm{E}_{\mathrm{EO}}$ decresce com a elevação de temperatura (Figura 5.8(c)), talvez por causa do aumento de movimentos e número de colisões entre moléculas de SMX na solução. Os resultados de $\mathrm{E}_{\mathrm{EO}}$ mostram que o processo fotoquímico para a degradação de SMX é energeticamente viável, e os valores estão de acordo com os estudos realizados por Daneshvar; Aleboyeh, et al. (2005), sendo que os valores obtidos nesse estudo são muito menores do que os observados por Behnajady et al. (2009), o que implica na eficácia do processo fotoquímico para a degradação de SMX. 


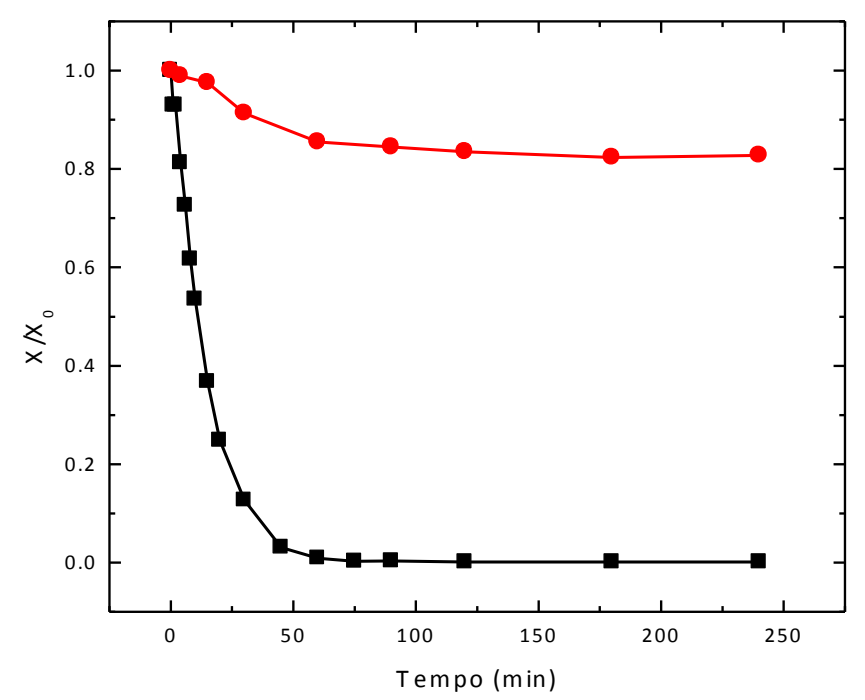

Figure 5.9 - Decréscimo relativo de COT $(\mathcal{O})$ e concentração de SMX (ם) em função do tempo de fotólise (Condições: $\mathrm{pH}=3, \mathrm{~T}=25^{\circ} \mathrm{C} \mathrm{e} \mathrm{C}_{\mathrm{smx}}=200 \mathrm{mg} \mathrm{L}^{-1}$ ).

\subsubsection{Condições otimizadas}

Após a investigação da influência dos parâmetros básicos para a degradação fotoquímica, decidiu-se pela realização de alguns experimentos de $4 \mathrm{~h}$ para obter maior mineralização. Esses experimentos foram realizados em condições otimizadas de: $\mathrm{C}_{\mathrm{smx}}=200$ $m g \mathrm{~L}^{-1} 25^{\circ} \mathrm{C}, \mathrm{pH}=3$ e agitação constante.

É possível observar na Figura 5.9 que, após 75 min de fotólise, quase todo o SMX foi degradado e convertido em outros produtos, mas após $4 \mathrm{~h}$ de tratamento, notou-se apenas cerca de $19 \%$ da mineralização foi obtida. Esta baixa mineralização pode ser atribuída à formação de intermediários mais resistentes à luz UV do que o SMX, e também devido à mudança de cor da solução durante a fotólise que absorve a maior parte da radiação, tornando o processo ineficaz.

\subsection{Detecção dos intermediários de degradação fotoquímica e proposição da possível rota de degradação para o SMX}

Nas condições otimizadas para o processo fotoquímico $\left(\mathrm{pH} 3,200 \mathrm{mg} \mathrm{L}^{-1}\right.$ de SMX e $25^{\circ} \mathrm{C}$ ), alguns experimentos foram realizados para investigar os intermediários de degradação 

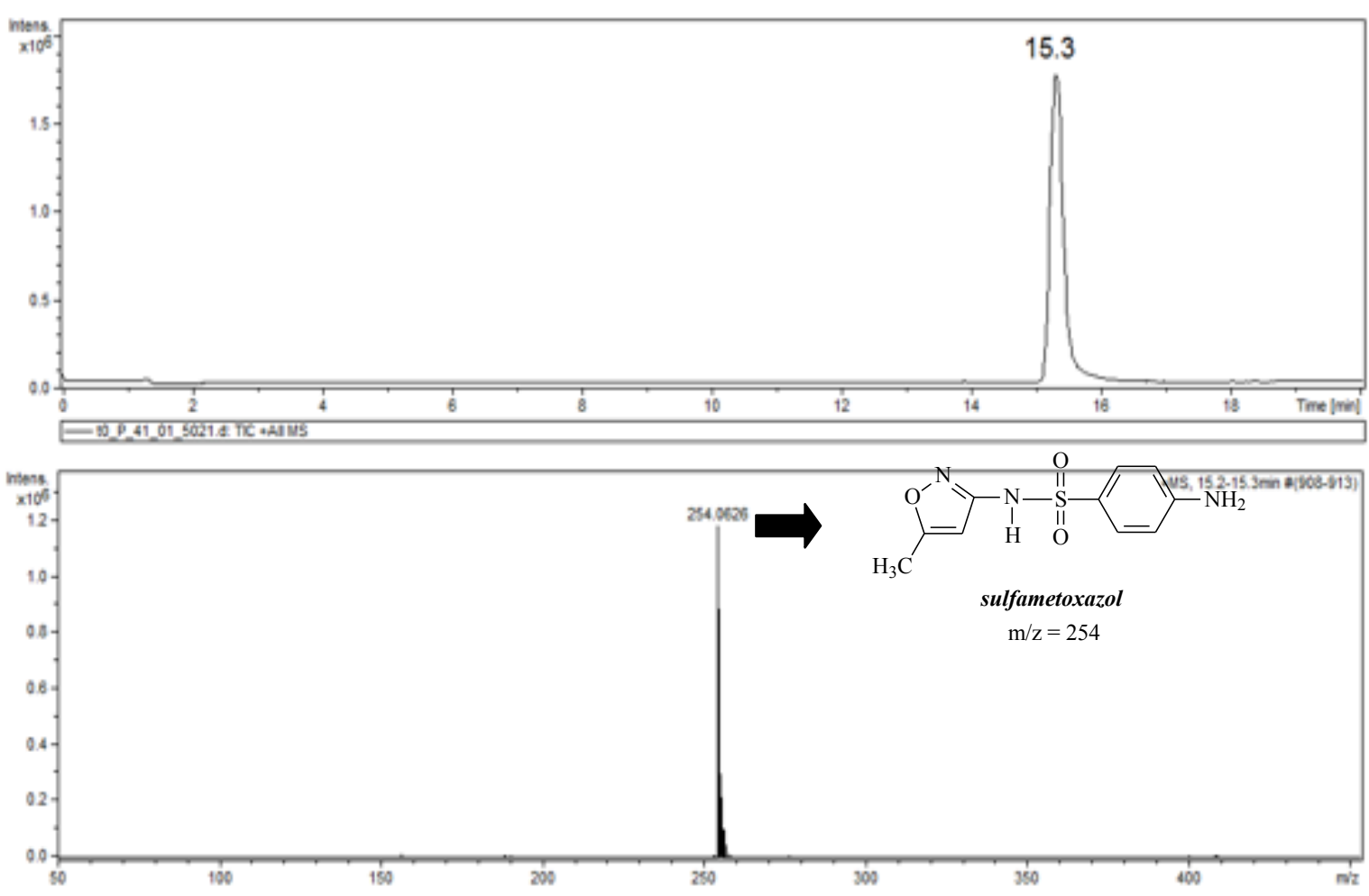

Figura 5.10 - (a) LC-UV cromatograma de padrão de SMX; (b) espectro de massa de SMX m/z = 254 $\left(\mathrm{C}_{10} \mathrm{H}_{11} \mathrm{~N}_{3} \mathrm{SO}_{3}\right)$.

de SMX. Durante os experimentos, alíquotas foram retiradas em intervalos pré-determinados, filtradas com filtro $0,45 \mu \mathrm{m}$, e em seguida analisadas. O espectro LC-MS referente ao composto padrão pode ser observado na Figura 5.10. O composto apresenta massa molar (M) 253 e íon molecular protonado $[\mathrm{M}+\mathrm{H}]^{+}$de relação massa/carga $(\mathrm{m} / \mathrm{z})$ de 254 , localizado em $15,3 \mathrm{~min}$.

No cromatograma obtido na degradação de SMX por radiação UV, pode ser observada a presença de 9 intermediários (Figura 5.11). Alguns dos intermediários foram detectados por Trovó et al. (2009), outros, dentre os identificados, não foram relatados na literatura. Esses intermediários apresentam íons moleculares protonados $[\mathrm{M}+\mathrm{H}]+$ de relação massa/carga $(\mathrm{m} / \mathrm{z})$, e estão apresentados na Tabela 5.2 com as estruturas químicas. 
Tabela 5.2 - Principais intermediários formados durante a degradação de SMX através do processo fotoquímico

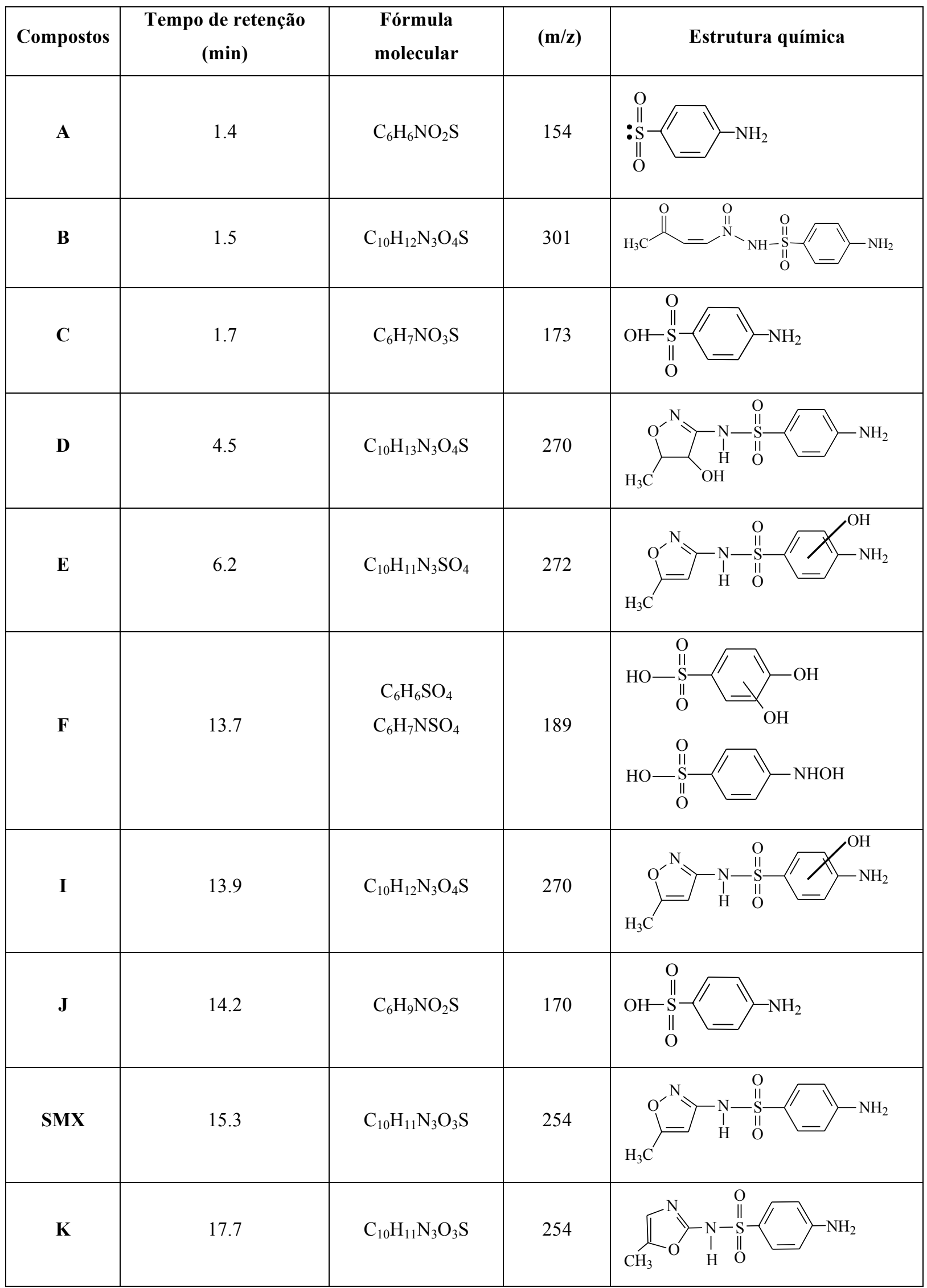




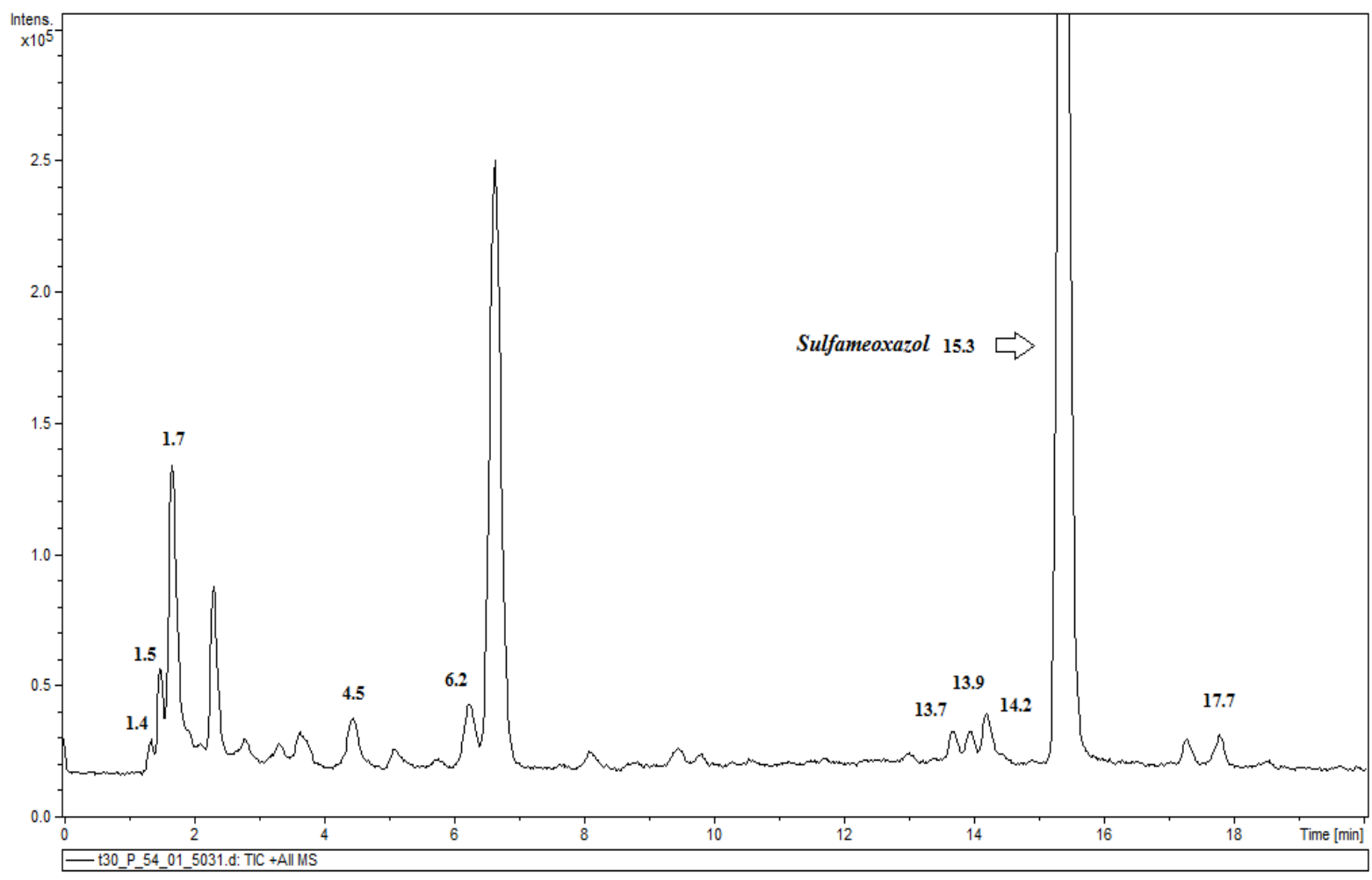

Figura 5.11 - Cromatograma total de LC-MS da amostra retirada após 30 min de fotólise de SMX. (Condições: $\mathrm{pH} 3, \mathrm{C}_{\mathrm{smx}}=200 \mathrm{mg} \mathrm{L}^{-1}$ e temperatura de $25^{\circ} \mathrm{C}$ ).

Na molécula de SMX pode ocorrer a ruptura da ligação N-S, com a consequente liberação de fragmentos correspondentes aos anéis oxazolídico e anilina, pertencentes ao composto. Dessa forma, dois fragmentos com $\mathrm{m} / \mathrm{z}=98 \mathrm{e} \mathrm{m} / \mathrm{z}=158$ foram identificados.<smiles>Cc1cc(NS(=O)(=O)c2ccc(N)cc2)no1</smiles>

sulfonamida ruptura da ligação

$\mathrm{N}-\mathrm{S}$<smiles></smiles>

$\mathbf{m} / \mathbf{z}=97$ $\mathbf{m} / \mathbf{z}=156$

Um dos intermediários reativos formados e identificados é o fragmento $\mathrm{m} / \mathrm{z}=272$, proveniente da adição do radical hidroxila ao anel aromático correspondente e, possivelmente, à fração anilina do composto, ou então ao anel oxazolídico, $\mathrm{O}$ espectro de massas para destes fragmentos estão apresentada na Figura 5.12. 


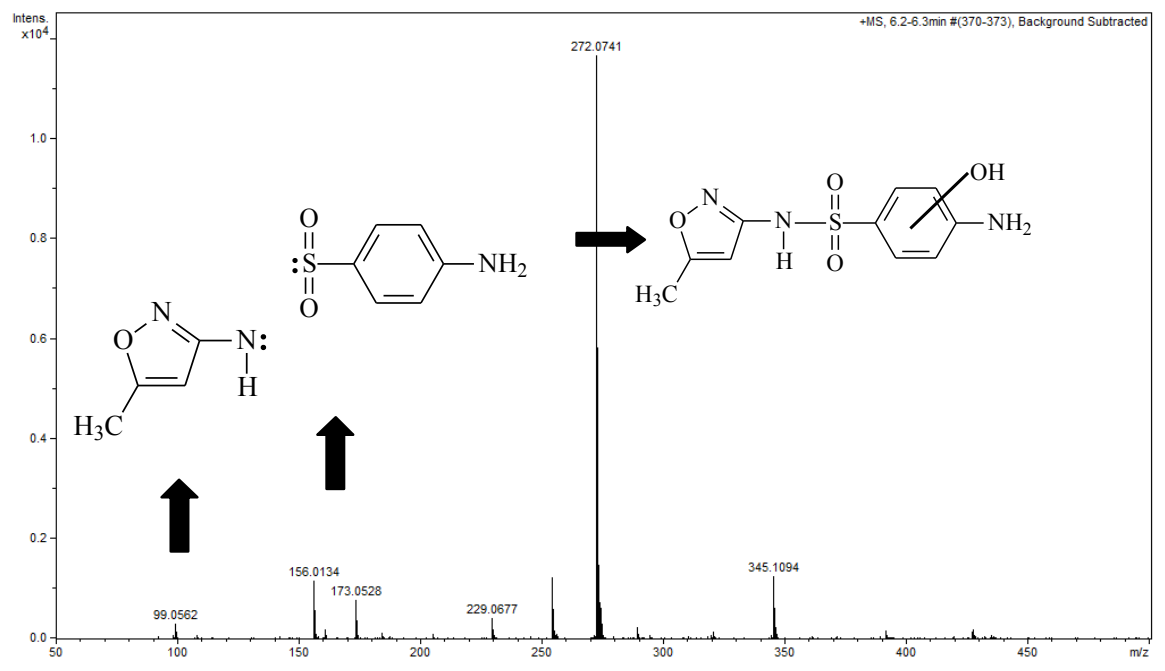

Figura 5.12 - Espectros de massas relacionados aos intermediários, referente à m/z $(99,156,272)$.<smiles>Cc1cc(NS(=O)(=O)c2ccc(N)cc2)no1</smiles>

sulfonamida<smiles>Cc1cc(NS(=O)(=O)c2ccc(N)c(O)c2)no1</smiles>

ou<smiles>Cc1cc(NS(=O)(=O)c2ccc(N)cc2)no1</smiles>
sulfonamida<smiles>CC1ON=C(NS(=O)(=O)c2ccc(N)cc2)C1O</smiles>

Após a ruptura da ligação N-S do composto SMX, pode ocorrer a inserção do radical hidroxila ao grupamento sulfônico, verificando-se então a formação do intermediário $\mathrm{com} \mathrm{m} / \mathrm{z}$ $=173$ característico (Figura 5.13).<smiles>Nc1ccc(S(=O)(=O)O)cc1</smiles> 


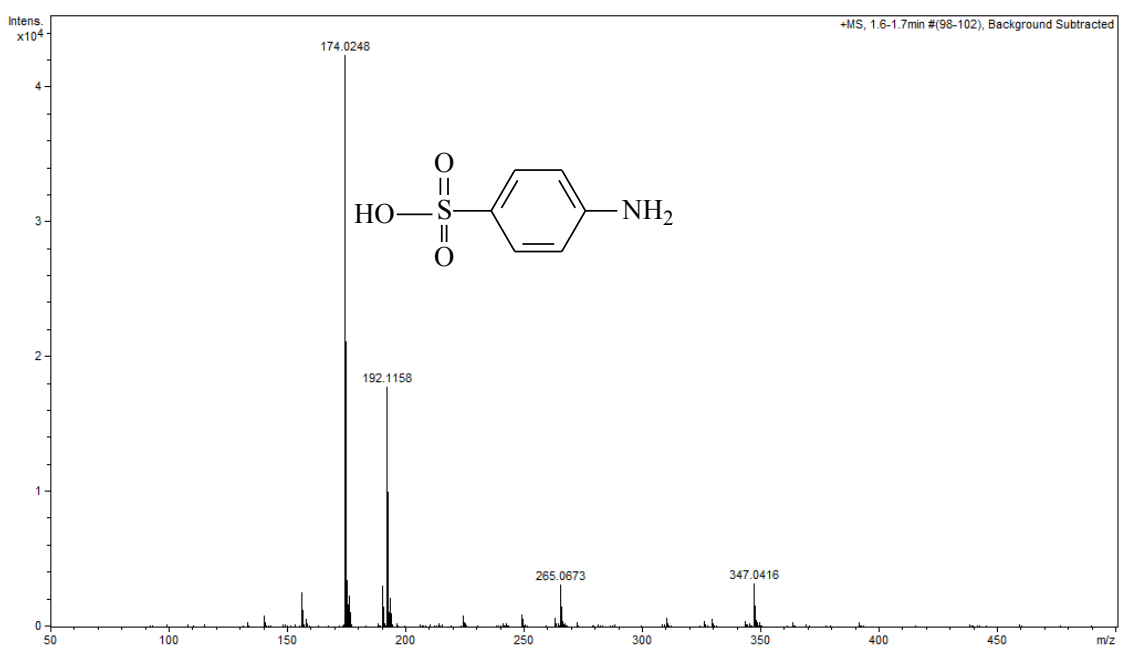

Figura 5.13 - Espectros de massas relativos aos intermediários, referente à m/z 174 .

O fragmento 188 pode ser atribuído ao intermediário formado pela substituição de um hidrogênio pela inserção de um grupamento $\mathrm{OH}$, proveniente do radical hidroxila. $\mathrm{O}$ espectro de massa relacionado com m/z 188 pode ser observado na Figura 5.14.

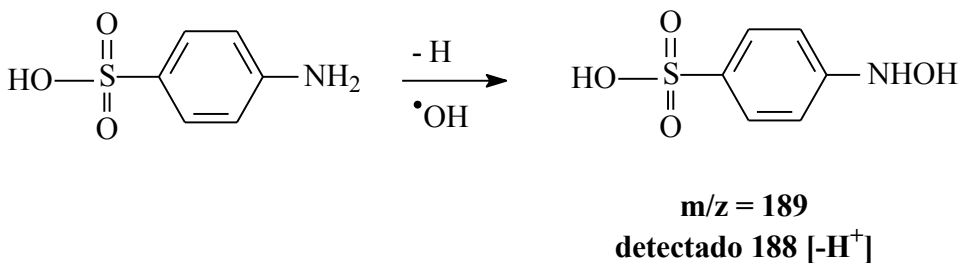

Pode ocorrer a substituição do grupamento $\mathrm{NH}_{2}$ por um $\mathrm{OH}$, e em seguida, ao anel aromático, ou mesmo a inserção do radical hidroxila, sendo então $\mathrm{m} / \mathrm{z}=173$ detectado.<smiles>NNC(=O)O</smiles><smiles>O=S(=O)(O)c1ccc(O)c(O)c1</smiles> 


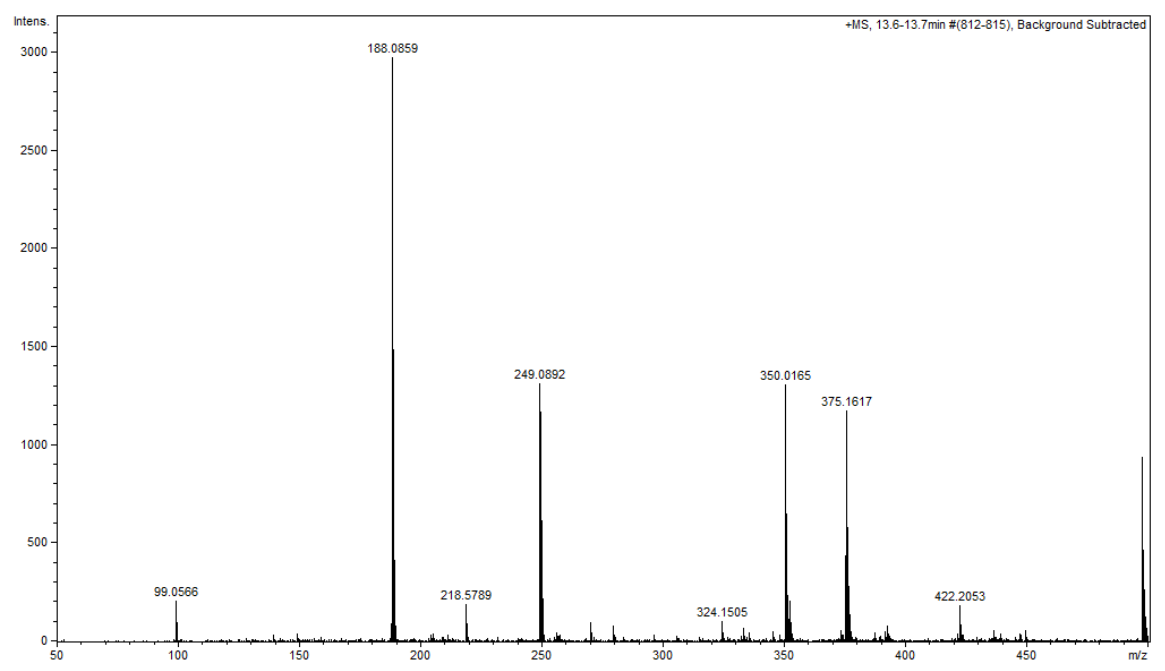

Figura 5.14 - Espectros de massas referentes aos intermediários, condizente à m/z 188 .

A Figura 5.15 apresenta os fragmentos com $\mathrm{m} / \mathrm{z}=301,322$ e 338 podem ser atribuídos à ruptura do anel oxazolídico do composto original, seguida por um processo de hidroxilação que resulta na formação do fragmento $\mathrm{m} / \mathrm{z}=301$. Sendo assim, à dupla ligação, ocorre a inserção de duas hidroxilas, e o fragmento $\mathrm{m} / \mathrm{z}=338$ é identificado. Em seguida, pode ocorrer a eliminação do grupo $\mathrm{NH}_{2}$ da parte anilínica, seguida por um processo de hidroxilação, resultando no fragmento $\mathrm{m} / \mathrm{z}=322$, como descrito no mecanismo proposto.

\subsubsection{Detecção dos intermediários inorgânicos de SMX durante o processo fotoquímico}

A liberação dos íons $\mathrm{NO}_{3}{ }^{-}, \mathrm{NH}_{4}{ }^{+}$e $\mathrm{SO}_{4}{ }^{2-}$ é esperada na degradação de compostos contendo grupos funcionais com átomos de enxofre e nitrogênio (HAMMAMI et al., 2008; STYLIDI et al., 2004).

Os dados de COT obtidos mostraram que o SMX foi pouco mineralizado durante o processo fotoquímico, e também evidenciou a liberação de menor quantidade dos íons inorgânicos, tais como $\mathrm{NO}_{3}{ }^{-}, \mathrm{NH}_{4}{ }^{+}$e $\mathrm{SO}_{4}{ }^{2-}$. A Figura 5.16 apresenta uma liberação gradual desses íons com o aumento do tempo de fotólise. Após $120 \mathrm{~min}, 15 \mathrm{mg} \mathrm{L}^{-1} \mathrm{de} \mathrm{SO}_{4}{ }^{2-}$ foram acumulados na solução, no entanto, a quantidade de íons $\mathrm{SO}_{4}{ }^{2-}$ é maior quando comparada com $\mathrm{NO}_{3}{ }^{-}$e $\mathrm{NH}_{4}{ }^{+}$. A evolução dos íons $\mathrm{NO}_{3}{ }^{-}$e $\mathrm{NH}_{4}{ }^{+}$detectada durante os 120 min dos experimentos fotoquímicos é demonstrada na Figura 5.16, que dispõe a evolução de nitrogênio como íons dos $\mathrm{NO}_{3}{ }^{-} \mathrm{e} \mathrm{NH}_{4}{ }^{+}$no final da fotólise. A maior proporção de nitrogênio foi liberada na forma de $\mathrm{NH}_{4}^{+}$. 


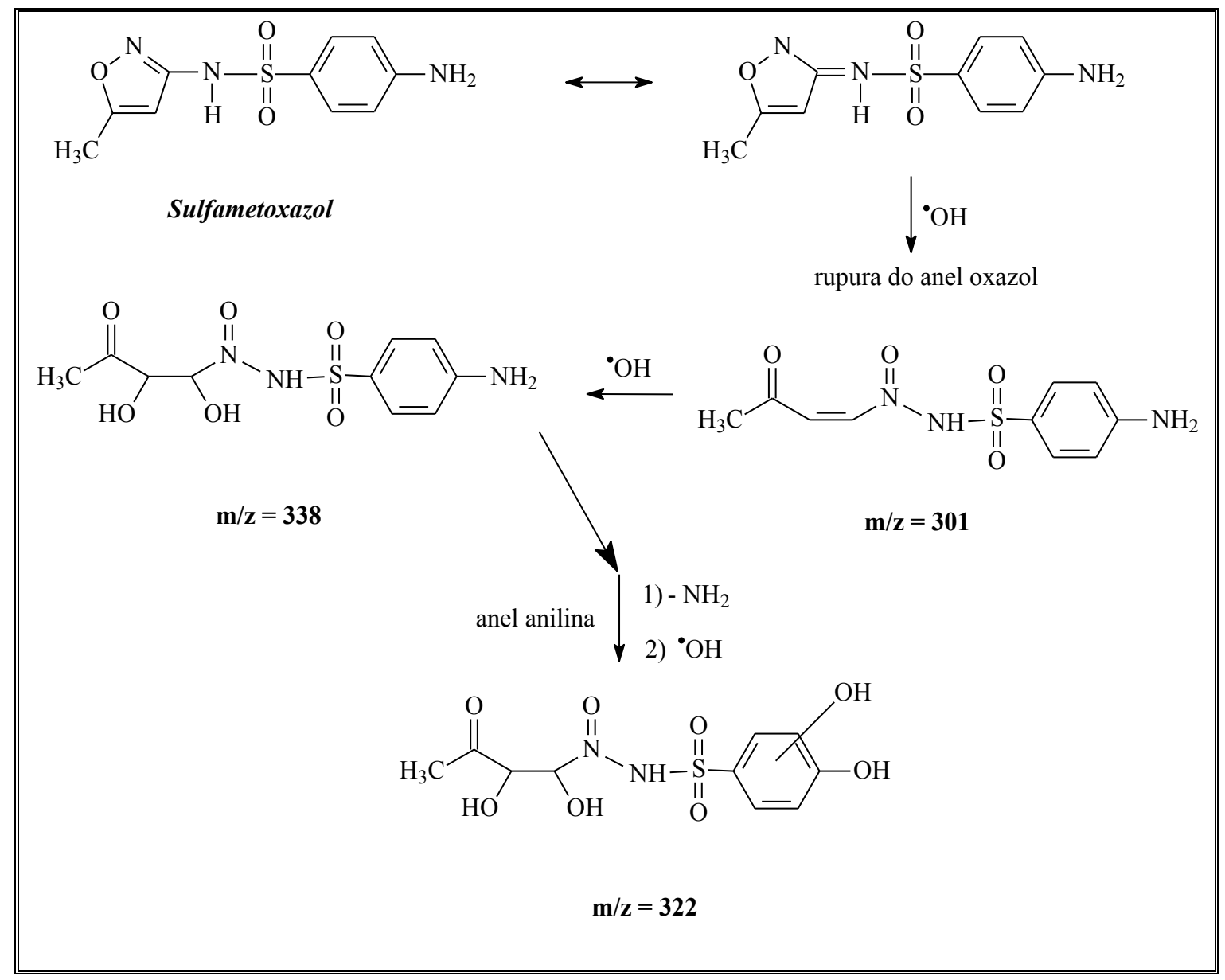

Figura 5.15 - Rota de degradação e conversão de SMX por radiação UV para os compostos referentes a $\mathrm{m} / \mathrm{z}=301,338$ e 322 .

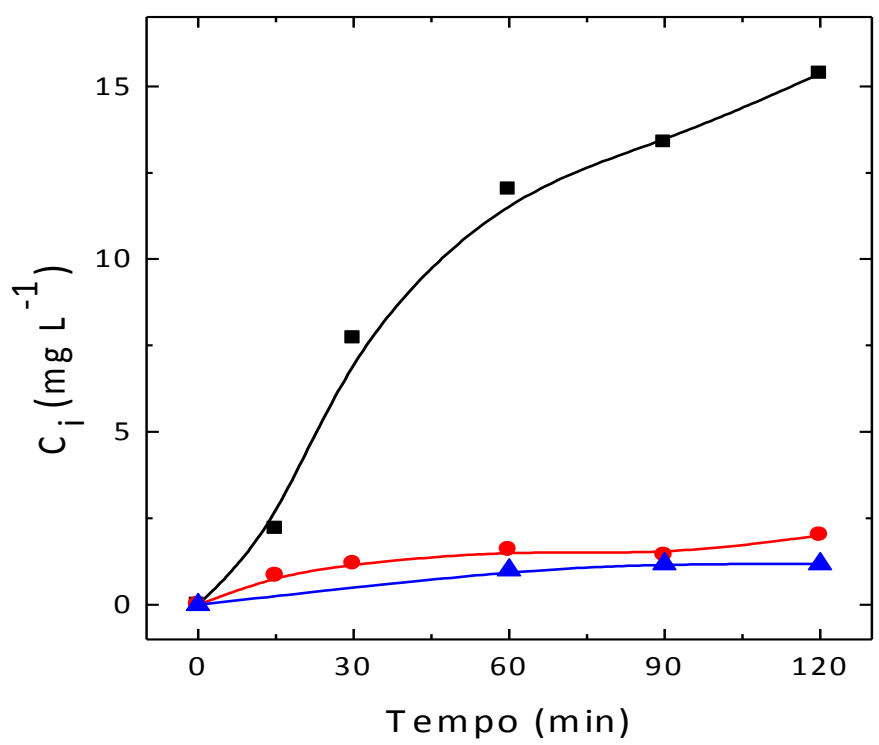

Figura 5.16 - Variação de concentração dos intermediários inorgânicos como (ם) $\mathrm{SO}_{4}{ }^{2-}(\mathbf{O}) \mathrm{NH}_{4}{ }^{+} \mathrm{e}$ (A) $\mathrm{NO}_{3}{ }^{-}$em função do tempo de fotólise (Condições: $\mathrm{pH}=3, \mathrm{~T}=25^{\circ} \mathrm{Ce} \mathrm{C}_{\mathrm{smx}}=200 \mathrm{mg} \mathrm{L}^{-1}$ ). 
Esse íon foi ligeiramente acumulado com o aumento do tempo de fotólise, e recuperado até $2 \mathrm{mg} \mathrm{L}^{-1}$. Da mesma forma, $\mathrm{o} \mathrm{NO}_{3}{ }^{-}$foi recuperado em uma quantidade menor, e a Figura 5.14 mostra que apenas $1,5 \mathrm{mg} \mathrm{L}^{-1}$ foi liberado após 120 minutos de radiação UV. As baixo evolução desses íons indicam menor mineralização de SMX durante o processo fotoquímico.

\subsection{Conclusões parciais}

O processo fotoquímico apresenta-se como uma alternativa para a degradação de SMX em solução aquosa. Os resultados revelam que a temperatura exerce um pequeno efeito sobre a remoção do SMX, já o pH e a concentração inicial de SMX influenciaram fortemente o processo de degradação. O SMX também pode ser degradado eficientemente em $\mathrm{pH} \leq 5$.

O processo de degradação seguiu uma cinética de pseudo-primeira ordem. A figura de mérito (energia elétrica por ordem $\left(\mathrm{E}_{\mathrm{EO}}\right)$ ), é diretamente proporcional à concentração de SMX, e inversamente proporcional à temperatura, ocorrendo, por fim, um consumo menor de energia em pH ácido.

Os intermediários de degradação foram detectados pela técnica de CLAE-EM-TOF, sendo possível observar alguns produtos que não foram relatados na literatura. Diferentes rotas de possível degradação de SMX foram apresentadas.

As espécies mineralizadas $\left(\mathrm{NO}_{3}{ }^{-}, \mathrm{NH}_{4}{ }^{+} \mathrm{e} \mathrm{SO}_{4}{ }^{2-}\right)$ também foram detectadas em pequena quantidade na solução. A remoção de COT foi muito baixa, portanto, concluiu-se que o processo fotoquímico é eficaz para a degradação do SMX, mas é menos eficaz para a sua mineralização total. No entanto, com a combinação desse processo com outro processo oxidativo avançado, como o Fenton e eletroquímico, a eficiência para a mineralização do SMX pode vir a ser melhorada. 


\section{Capítulo 6}

\section{Degradação do SMX por processo Fenton}

Neste capítulo são apresentados resultados da aplicação do processo Fenton para a degradação de sulfametoxazol e a influencia seguintes parâmetros: concentração do $\mathrm{Fe}^{2+}$, concentração do $\mathrm{H}_{2} \mathrm{O}_{2}$, o pH (2-11), temperatura $\left(15-45^{\circ} \mathrm{C}\right)$ e concentração inicial do SMX $\left(50-200 \mathrm{mg} \mathrm{L}^{-1}\right)$. Além disso, são analisados os principais intermediários formados durante o processo Fenton, com o objetivo de se elucidar o mecanismo de reação.

\subsection{Avaliação da degradação de SMX}

$\mathrm{O}$ processo Fenton envolve uma mistura dos íons $\mathrm{Fe}^{2+}$ e $\mathrm{H}_{2} \mathrm{O}_{2}$, gerando radicais hidroxilas $\left({ }^{\circ} \mathrm{OH}\right)$ à temperatura ambiente. $\mathrm{O}$ radical hidroxila possui um valor de potencial de oxidação igual a $+2,8 \mathrm{~V}$, sendo capaz de oxidar e de mineralizar uma grande variedade de compostos orgânicos em geral.

Quando o $\mathrm{H}_{2} \mathrm{O}_{2}$ foi adicionado a uma solução aquosa contendo o sal ferroso e o sulfametoxazol, a cor da solução mudou de incolor para marrom, em 30 segundos. Após 60 min, a cor mudou para o amarelo claro, o que indica o progresso da reação. Vários parâmetros experimentais, tais como $\mathrm{pH}$, temperatura, concentrações de $\mathrm{H}_{2} \mathrm{O}_{2}$ e de $\mathrm{Fe}^{2+}$, têm sido estudados para se realizar a otimização do processo Fenton. 


\subsubsection{Influência da concentração do $\mathrm{Fe}^{2+}$}

Uma série de experimentos foi realizada para elucidar o papel do $\mathrm{Fe}^{2+}$ na degradação de sulfametoxazol, variando-se a concentração de $\mathrm{Fe}^{2+}$ entre 2,5 e $15 \mathrm{mg} \mathrm{L}^{-1}$, mantendo a concentração de $\mathrm{H}_{2} \mathrm{O}_{2}$, constante de $150 \mathrm{mg} \mathrm{L}^{-1}$, para $\mathrm{pH}=3,0$ e temperatura de $25^{\circ} \mathrm{C}$.

Quando a concentração do $\mathrm{Fe}^{2+}$ era baixa $\left(2,5 \mathrm{mg} \mathrm{L}^{-1}\right)$, a eficiência da degradação foi inferior a $70 \%$. A eficiência aumentou progressivamente com o aumento da concentração dos íons $\mathrm{Fe}^{2+}$, devido às maiores quantidades de radicais ${ }^{\circ} \mathrm{OH}$ gerados. A eficiência máxima da degradação do sulfametoxazol foi de $98 \%$ e de $99 \%$, para as concentrações de $\mathrm{Fe}^{2+}$ de a 10 e $15 \mathrm{mg} \mathrm{L}^{-1}$, respectivamente.

A Figura 6.1 (b) demonstra que a degradação para as concentrações mais elevadas do $\mathrm{Fe}^{2+}$ é muito rápida, sendo que se necessita de 6 a 8 min para se degradar de $90 \%$ a $95 \%$ do SMX, respectivamente, entretanto para baixas concentrações de $\mathrm{Fe}^{2+}$ a degradação é lenta, tendo sido consumidos somente 70 e $75 \%$ do SMX, em 30 e 40 min, respectivamente. após 45 min, o processo de degradação se tornou constante para os valores de concentração de $\mathrm{Fe}^{2+}$ iguais a: 5, 10 e $15 \mathrm{mg} \mathrm{L}^{-1}$. Os resultados na Figura 6.1 (a) indicam que a concentração ótima do $\mathrm{Fe}^{2+}$ se encontrava na faixa entre $10 \mathrm{mg} \mathrm{L}^{-1}$ e $15 \mathrm{mg} \mathrm{L}^{-1}$, para se degradar uma solução de SMX igual a $200 \mathrm{mg} \mathrm{L}^{-1}$.

As análises do COT também foram monitoradas em tais condições experimentais. Deve-se notar com base na Figura 6.1 (b), que a remoção total do COT não foi conseguida até que fossem empregadas as concentrações elevadas do $\mathrm{Fe}^{2+}$. As reduções na concentração do COT que foram obtidas ao final da reação, eram iguais a 20, 25, 35 e 40\%, quando as concentrações do $\mathrm{Fe}^{2+}$ apresentavam os valores iguais a: 2,5; $5 ; 10$ e $15 \mathrm{mg} \mathrm{L}^{-1}$.

É possível observar na Figura 6.1 (b) que a maioria do COT foi removida no início da reação, permanecendo constante a sua concentração, em seguida, devido a um decréscimo nas quantidades dos radicais $\bullet \mathrm{OH}$ disponíveis para se realizar a oxidação do SMX, e também por causa das reatividades dos radicais hidroxila, uma vez que estas espécies reagem rapidamente, podendo degradar o composto orgânico.

Um comportamento semelhante também foi observado na literatura com (SHEMER et al., 2006), no estudo da degradação do metronidazole pelo processo Fenton, tendo sido observado que um aumento na dosagem dos íons $\mathrm{Fe}^{2+}$ intensificou significativamente a degradação. Normalmente, realiza-se o estudo desses parâmetros com o objetivo de se obter uma eficiência máxima nos processos degradativos. 


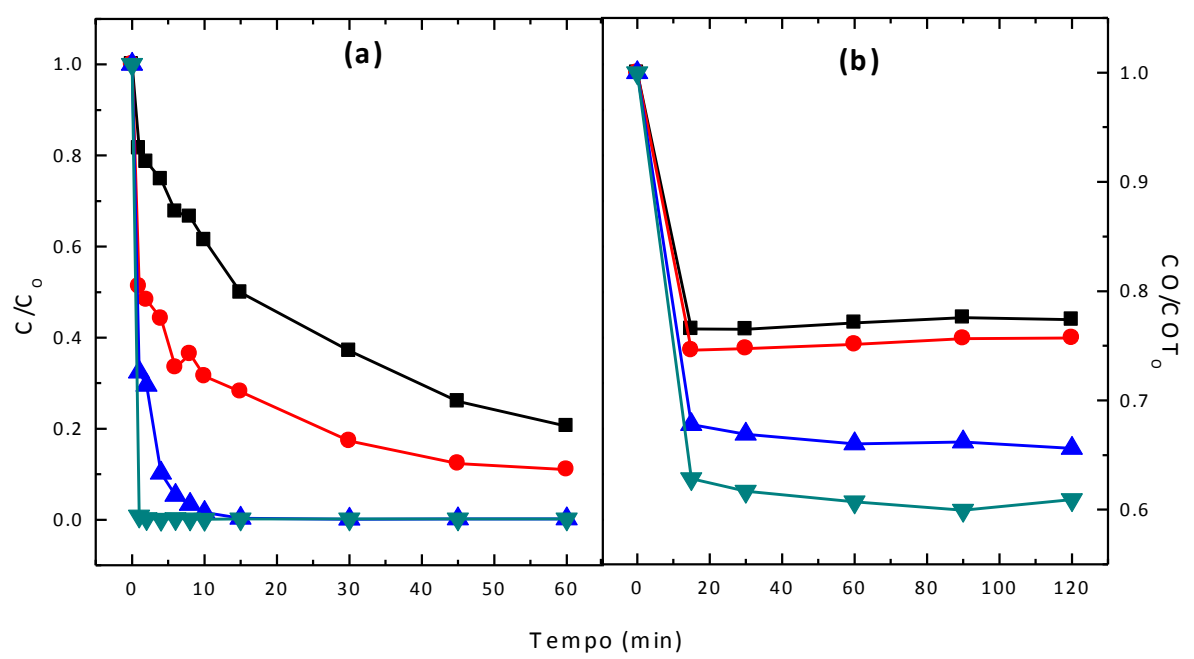

Figura 6.1 - Influência da concentração de $\mathrm{Fe}^{2+}(\boldsymbol{\square}) 2,5 \mathrm{mg} \mathrm{L}^{-1},(\bullet) 5 \mathrm{mg} \mathrm{L}^{-1},(\boldsymbol{\Delta}) 10 \mathrm{mg} \mathrm{L}^{-1},(\boldsymbol{\nabla}) 15$ $\mathrm{mg} \mathrm{L}^{-1}$ na (a) degradação e (b) remoção do COT (Condições: $\mathrm{C}_{\mathrm{SMX}}=200 \mathrm{mg} \mathrm{L}^{-1}, \mathrm{C}_{\mathrm{H} 2 \mathrm{O} 2}=150 \mathrm{mg} \mathrm{L}^{-1}$, $\mathrm{pH}_{\mathrm{i}} 3$ e $\left.\mathrm{T}=25^{\circ} \mathrm{C}\right)$.

Kavitha; Palanivelu (2004) estudaram a influência da concentração do íon $\mathrm{Fe}^{2+}$ e do $\mathrm{H}_{2} \mathrm{O}_{2}$ na eficiência da degradação do fenol $\left(\mathrm{C}=200 \mathrm{mg} \mathrm{L}^{-1}\right)$ por meio do processo Fenton. Os pesquisadores testaram as concentrações do íon na faixa de $2-60 \mathrm{mmol} \mathrm{L}^{-1}$, tendo observado que o percentual máximo de degradação ( $82 \%)$ foi obtido ao utilizar uma concentração igual a $30 \mathrm{mmol} \mathrm{L}^{-1}$. Ao avaliar a demanda química do oxigênio, foi constatado que houve $60 \%$ de remoção do fenol.

\subsubsection{Influência da concentração de $\mathrm{H}_{2} \mathrm{O}_{2}$}

$\mathrm{O} \mathrm{H}_{2} \mathrm{O}_{2}$ atua como agente oxidante no processo Fenton. $\mathrm{O}$ efeito da concentração do $\mathrm{H}_{2} \mathrm{O}_{2}$ na degradação do SMX foi estudado para o intervalo de concentrações entre 25-150 mg $\mathrm{L}^{-1}$, mantendo-se a concentração da espécie $\mathrm{Fe}^{2+}$ igual a $10 \mathrm{mg} \mathrm{L}^{-1}$. A Figura 6.2 (a) mostra que a eficiência da degradação aumentou com o aumento da concentração do $\mathrm{H}_{2} \mathrm{O}_{2}$, devido a um incremento na quantidade do ${ }^{\circ} \mathrm{OH}$ produzido pela reação.

A eficiência máxima de degradação foi igual a $98 \%$, para uma valor de concentração do $\mathrm{H}_{2} \mathrm{O}_{2}$ igual a $150 \mathrm{mg} \mathrm{L} \mathrm{L}^{-1}$. Contudo, quando se adicionou mais $\mathrm{H}_{2} \mathrm{O}_{2}$, não houve uma melhora na eficiência da degradação, o que pode ser justificado devido à decomposição do $\mathrm{H}_{2} \mathrm{O}_{2}$ (reação de desproporcionamento). 
Além disso, o $\mathrm{H}_{2} \mathrm{O}_{2}$ reage com o excesso do íon férrico $\left(\mathrm{Fe}^{3+}\right)$, formando o radical peridroxila $\left(\mathrm{HO}_{2}{ }^{\circ}\right)$, que não é tão ativo como o radical hidroxila, em termos da degradação do SMX. A remoção do COT também foi avaliada para concentrações diferentes do $\mathrm{H}_{2} \mathrm{O}_{2}$. A Figura 6.2 (b) evidencia que um aumento na concentração do $\mathrm{H}_{2} \mathrm{O}_{2}$ entre 25 e $150 \mathrm{mg} \mathrm{L} \mathrm{L}^{-1}$, resulta em um aumento da remoção do COT de $27 \%$ a $38 \%$, respectivamente. A redução máxima do COT só foi possível quando se utilizou uma concentração do $\mathrm{H}_{2} \mathrm{O}_{2}$ igual a $150 \mathrm{mg}$ $\mathrm{L}^{-1}$.

Emami et al. (2010) avaliaram a cinética de degradação do corante (reativo azul 19) e puderam constatar que porcentagem de degradação aumentou quando houve um incremento na dose do peróxido de hidrogênio. Assim, quando foram adicionadas as soluções de $\mathrm{H}_{2} \mathrm{O}_{2}$ com concentrações de 1,5 a $6 \mathrm{mmol} \mathrm{L}^{-1}$, ocorreu um aumento na descoloração de 60 a 97\%, em $40 \mathrm{~min}$. Todavia, para as soluções de concentrações maiores do que $6 \mathrm{mmol} \mathrm{L}^{-1}$, não houve melhoria significativa na cinética de descoloração.

A concentração inicial do $\mathrm{H}_{2} \mathrm{O}_{2}$ desempenha um papel importante com relação à eficiência da descoloração do corante, por meio do processo Fenton. É importante destacar que deve ser feita a otimização da concentração do $\mathrm{H}_{2} \mathrm{O}_{2}$, pois o maior custo do método está relacionado a essa substância química. Elevadas dosagens do $\mathrm{H}_{2} \mathrm{O}_{2}$ resultam numa diminuição da descoloração, ocorrendo assim a decomposição de radicais hidroxila. Tais reações resultam numa redução da probabilidade de que ocorram ataques de moléculas de corante pelos radicais hidroxila, ocasionando uma diminuição da degradação.

\subsubsection{Influência da pH}

$\mathrm{O}$ pH do sistema afeta significativamente a degradação de poluentes quando estes são tratados pelo processo Fenton. Apesar da grande diversidade de substâncias testadas, o pH considerado ótimo na maioria dos estudos realizados se encontra na faixa de $\mathrm{pH}$ entre 2 e 4 . Valores acima de 3,0 fazem com que $\mathrm{Fe}^{3+}$ precipite na forma de hidróxido insolúvel, enquanto que para valores de $\mathrm{pH}$ abaixo, de 2,5, elevadas concentrações do hidrogênio podem sequestrar os radicais hidroxilas.

Uma série de experimentos foi realizada para se estudar a influência do pH da solução na degradação do SMX. Os valores iniciais do $\mathrm{pH}$ foram: 2, 3, 4, 5, 7 e 9, enquanto que a concentração inicial do SMX foi igual a $200 \mathrm{mg} \mathrm{L}^{-1}$. No começo da reação entre o $\mathrm{H}_{2} \mathrm{O}_{2}$ e o $\mathrm{Fe}^{2+}$, o pH da solução reduziu-se rapidamente para um valor aproximadamente de 2,8, considerando-se que os valores inicias de $\mathrm{pH}$ se encontravam na faixa entre $3,0-7,0$, sendo 


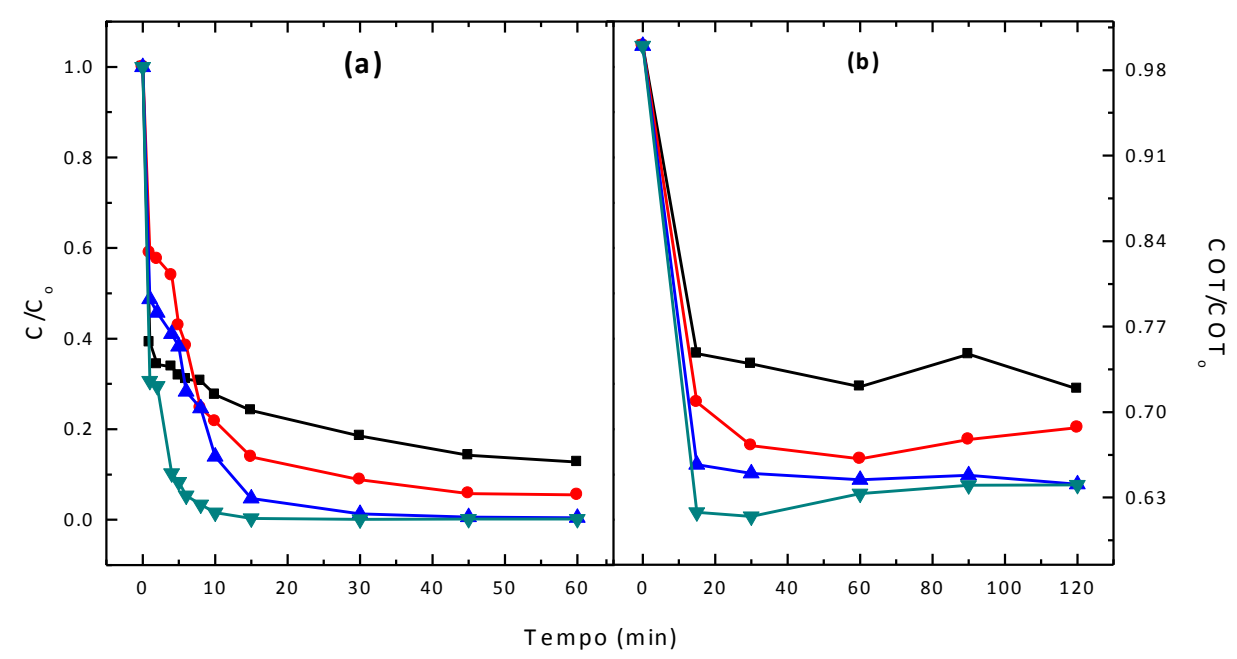

Figura 6.2 - Influência da concentração do $\mathrm{H}_{2} \mathrm{O}_{2}(\boldsymbol{\square}) 25 \mathrm{mg} \mathrm{L}^{-1},(\bullet) 50 \mathrm{mg} \mathrm{L}^{-1},(\boldsymbol{\Delta}) 100 \mathrm{mg} \mathrm{L}^{-1},(\boldsymbol{\nabla})$ $150 \mathrm{mg} \mathrm{L}^{-1}$ na (a) degradação e (b) na remoção do COT (Condições: $\mathrm{C}_{\mathrm{smx}}=200 \mathrm{mg} \mathrm{L}^{-1}, \mathrm{C}_{\mathrm{Fe} 2+}=10$ $\mathrm{mg} \mathrm{L}^{-1}, \mathrm{pH}_{\mathrm{i}}=3$ e $\mathrm{T}=25^{\circ} \mathrm{C}$ ).

que, em seguida, o pH se manteve estável ao longo do tempo de tratamento. As alterações quanto aos valores de $\mathrm{pH}$ podem ser justificadas por duas razões:

i) a hidrólise do sulfato ferroso resultou numa queda do $\mathrm{pH}$,

ii) podem ter sido formados ácidos orgânicos e inorgânicos com a decomposição do SMX. Os resultados relacionados com tais justificativas se encontram na Figura 6.3 .

A partir da Figura 6.3, pode-se observar que a condição básica foi desfavorável para a degradação do SMX, enquanto que para os valores de $\mathrm{pH}$ abaixo de 7, a mesma se apresentou favorável.

A remoção do COT também foi maior quando o $\mathrm{pH}$ da solução diminuiu até o valor igual a 2,8. Na Figura 6.3 (b) podemos observar que houve remoções de 25 e $23 \%$ do COT para os valores de $\mathrm{pH}$ iguais a 3 e 4 , respectivamente, devendo ser salientado que esses resultados estão de acordo com aqueles relatados na literatura.

A taxa de degradação aumentou rapidamente quando o valor do $\mathrm{pH}$ inicial aumentou de 2 para 4, sendo que se manteve constante quando o $\mathrm{pH}$ inicial foi igual a 5. Em outro momento, a degradação foi reduzida drasticamente quando o $\mathrm{pH}$ foi maior do que 7, considerando os casos em que os pHs eram iguais a 7 e 9. 


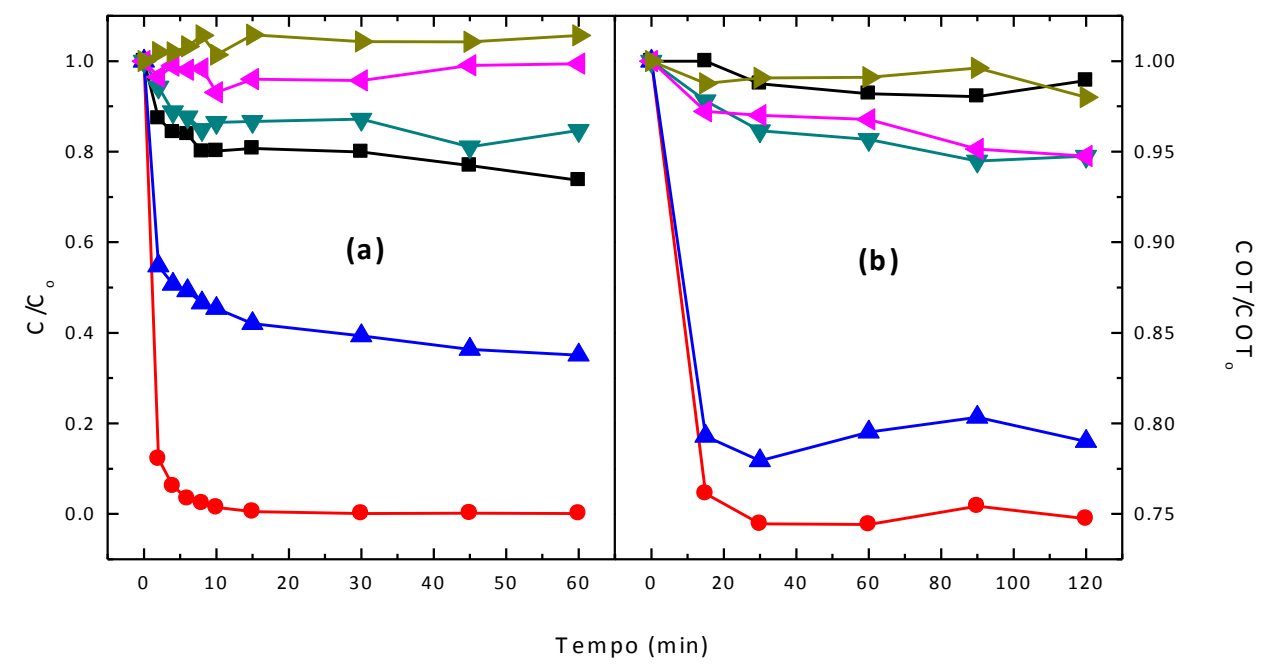

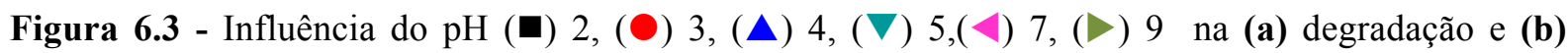
remoção de COT (Condições: $\mathrm{C}_{\mathrm{SMX}}=200 \mathrm{mg} \mathrm{L}^{-1}, \mathrm{C}_{\mathrm{Fe} 2+}=10 \mathrm{mg} \mathrm{L}^{-1}, \mathrm{C}_{\mathrm{H} 2 \mathrm{O} 2}=150 \mathrm{mg} \mathrm{L}^{-1}$, e $\mathrm{T}=25^{\circ} \mathrm{C}$ ).

Os resultados obtidos na discussão anterior estão indicados na Figura 6.3 (a), sendo que tais observações podem, em geral, serem atribuídas à precipitação do $\mathrm{Fe}(\mathrm{OH})_{3}$ e do complexo $\left[\mathrm{Fe}(\mathrm{II})\left(\mathrm{H}_{2} \mathrm{O}\right)_{6}\right]^{+2}$, sendo que este reage mais lentamente com o $\mathrm{H}_{2} \mathrm{O}_{2}$ do que o $[\mathrm{Fe}(\mathrm{II})(\mathrm{OH})]$, resultando numa menor quantidade de radicais hidroxila em meio básico (NOGUEIRA et al., 2007).

Contudo, para valores de $\mathrm{pH}$ muito baixos, como no caso do $\mathrm{pH}$ igual a 2 , também foi observado que houve diminuição da degradação do SMX (Figura 6.3 (a)) e, além disso, o efeito sequestrante dos íons hidrogênio se tornou importante em meio muito ácido, de forma que a reação do $\mathrm{Fe}^{+2}$ com o $\mathrm{H}_{2} \mathrm{O}_{2}$ foi inibida.

Consequentemente, a faixa de valores de $\mathrm{pH}$ entre 2,8 e 4 favorece mais a degradação de SMX, o que está de acordo com a literatura (LUCAS; PERES, 2006; ZHONG et al., 2009; BURBANO et al., 2005), como sendo a faixa de $\mathrm{pH}$ inicial ideal para realizar a oxidação Fenton de muitos compostos orgânicos.

Elmolla; Chaudhuri (2009) otimizaram as condições para se realizar as degradações dos antibióticos amoxicilina, ampicilina e cloxacilina (AMX, AMP e CLX), e relataram o efeito do pH sobre a degradação com relação à Demanda Biológica de Oxigênio / Demanda Química de Oxigênio (DBO/DQO) e a velocidade de degradação do carbono orgânico dissolvido (COD). Os resultados concluíram que o valor de $\mathrm{pH} 3$ é considerado o ideal para se realizar os tratamentos de águas residuárias contendo os antibióticos AMX, AMP e CLX. 


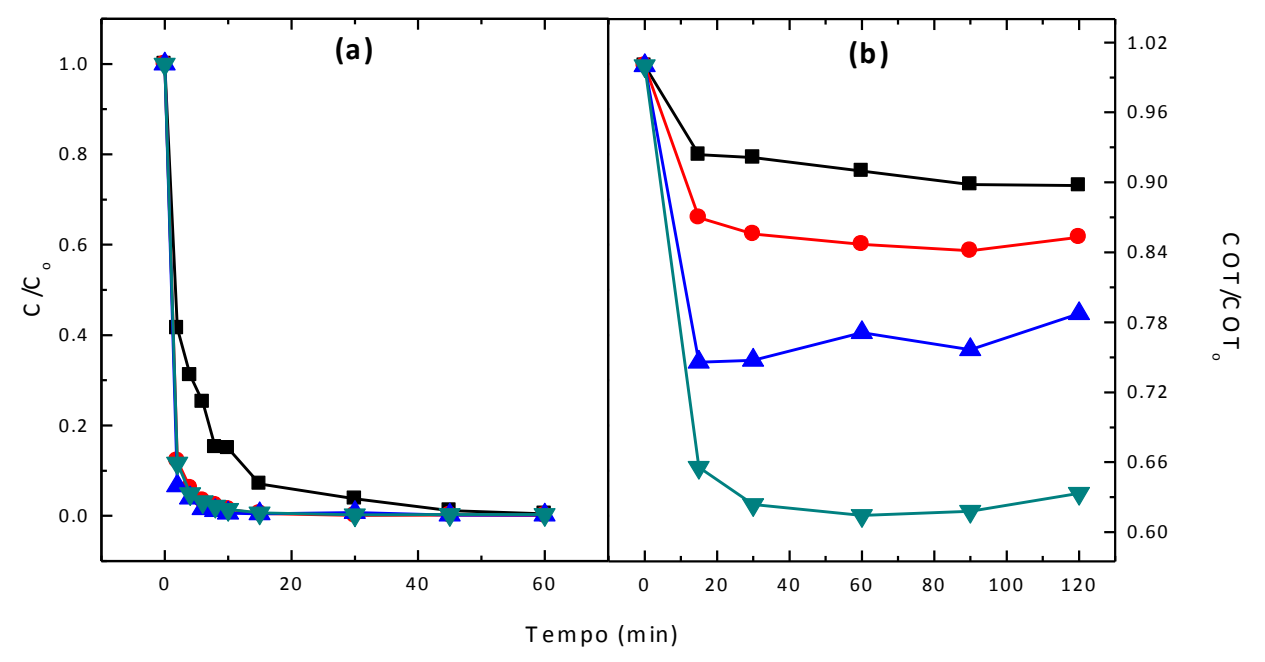

Figura 6.4 - Influência da temperatura $(\square) 15{ }^{\circ} \mathrm{C},(\mathbf{O}) 25^{\circ} \mathrm{C},(\boldsymbol{\Delta}) 35^{\circ} \mathrm{C},(\boldsymbol{\nabla}) 45^{\circ} \mathrm{C}$ na (a) degradação e (b) remoção do COT (Condições: $\mathrm{C}_{\mathrm{SMX}}=200 \mathrm{mg} \mathrm{L}^{-1}, \mathrm{C}_{\mathrm{Fe} 2+}=10 \mathrm{mg} \mathrm{L}^{-1}, \mathrm{C}_{\mathrm{H} 2 \mathrm{O} 2}=150 \mathrm{mg} \mathrm{L}^{-1}$ e $\mathrm{pH}_{\mathrm{i}}=$ $3)$.

\subsubsection{Influência da temperatura}

A temperatura é um fator importante no processo Fenton. Com base nessa constatação, foram realizados experimentos para se determinar o efeito da temperatura na degradação do SMX. Os valores de concentração inicial para o $\mathrm{H}_{2} \mathrm{O}_{2}$ e o Fe $\mathrm{Fe}^{2+}$ foram iguais a 150 e $10 \mathrm{mg} \mathrm{L}^{-1}$, respectivamente. $\mathrm{O}$ valor do $\mathrm{pH}$ inicial foi fixado em 3,0 , enquanto que os experimentos foram realizados nos seguintes valores de temperatura: $15,25,35$ e $45^{\circ} \mathrm{C}$.

A Figura 6.4 (a) indica que a degradação de SMX aumenta com a elevação de temperatura de $15^{\circ} \mathrm{C}$ para $25{ }^{\circ} \mathrm{C}$. Entretanto, esse aumento de degradação foi muito pouco entre 25 e $45{ }^{\circ} \mathrm{C}$. A eficiência de remoção de COT aumentou de $12 \%$ para $38 \%$ quando a temperatura aumentou de 15 para $45{ }^{\circ} \mathrm{C}$ (Figura 6.4 (b)), devido ao fato de que ocorreu um aumento na velocidade de formação, e ainda relacionada ao movimento dos radicais, o que resulta num incremento da velocidade de mineralização do SMX.

\subsubsection{Influência da concentração inicial do SMX}

Verificou-se na Figura 6.5 (a) que a taxa de oxidação foi reduzida quando houve um aumento na concentração inicial do SMX. Uma possível explicação para essa observação é que em uma menor concentração do SMX pode resultar num aumento da capacidade do SMX em competir com o $\mathrm{Fe}^{2+}$ na reação com o $\mathrm{H}_{2} \mathrm{O}_{2}$. 


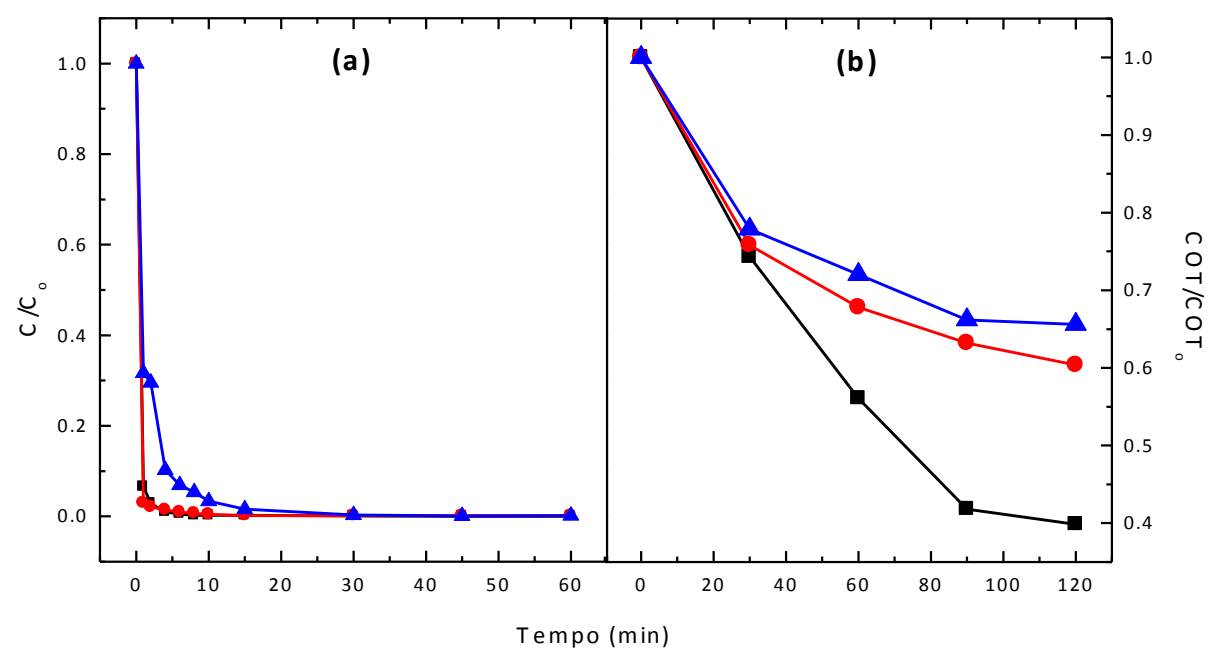

Figura 6.5 - Influência da concentração inicial do SMX (অ) $100 \mathrm{mg} \mathrm{L}^{-1},(\bullet) 150 \mathrm{mg} \mathrm{L}^{-1},(\mathbf{\Delta}) 200 \mathrm{mg}$ $\mathrm{L}^{-1}$, na (a) degradação e (b) remoção do COT (Condições: $\mathrm{C}_{\mathrm{Fe} 2+}=10 \mathrm{mg} \mathrm{L}^{-1}, \mathrm{C}_{\mathrm{H} 2 \mathrm{O} 2}=150 \mathrm{mg} \mathrm{L}^{-1}$, e $\mathrm{pH}_{\mathrm{i}}=3$ e $\left.\mathrm{T}=25^{\circ} \mathrm{C}\right)$.

No entanto, a degradação quando condicionada a um baixo valor de concentração do SMX, como para os valores de 100 e $150 \mathrm{mg} \mathrm{L}^{-1}$, ocorre de maneira muito rápida, de forma que o SMX seja completamente removido em apenas 5 e $8 \mathrm{~min}$, respectivamente, sendo que a degradação foi lenta e o SMX foi removido completamente para o valor de concentração de $200 \mathrm{mg} \mathrm{L}^{-1}$, em 20 min de tratamento.

Uma tendência semelhante foi observada para a remoção do COT, de modo que ocorreram processos de mineralização de 60, 38 e 33\% para as concentrações de 100, 150 e $200 \mathrm{mg} \mathrm{L}^{-1}$, respectivamente. Isso se justifica pelo fato de que mais moléculas do SMX estejam presentes na solução, para uma quantidade relativamente constante do radical $\bullet \mathrm{OH}$ que foi gerado para doses idênticas do $\mathrm{H}_{2} \mathrm{O}_{2}$ e do $\mathrm{Fe}^{+2}$, o que reduziu a eficiência para as concentrações maiores do SMX.

Uma observação semelhante foi constatada por Ma et al. (2010). Esses pesquisadores observaram que a degradação do carbofurano diminuiu de $81 \%$ para $15 \%$, quando a concentração inicial do carbofurano aumentou de $10 \mathrm{mg} \mathrm{L}^{-1}$ para $200 \mathrm{mg} \mathrm{L}^{-1}$. Além disso, $59 \%$ do carbofurano foram degradados em apenas $1 \mathrm{~min}$, quando a concentração inicial do carbofurano foi de $10 \mathrm{mg} \mathrm{L}^{-1}$. 


\subsection{Identificação dos intermediários e possível rota de degradação}

Após a investigação dos parâmetros básicos, vários experimentos foram realizados em condições otimizadas, tais como: $\mathrm{C}_{\mathrm{SMX}}=200 \mathrm{mg} \mathrm{L}^{-1}, \mathrm{C}_{\mathrm{Fe}}{ }^{2+}=10 \mathrm{mg} \mathrm{L}^{-1}, \mathrm{C}_{\mathrm{CH}_{2} \mathrm{O}_{2}}=150 \mathrm{mg} \mathrm{L}^{-1} \mathrm{e}$ $\mathrm{pH}=3$, sendo que as amostras foram analisadas por meio da técnica de CLAE-EM. Baseandose nos resultados dos espectros de massas e nos cromatogramas de degradação do SMX, pelo processo Fenton, foram propostas rotas de degradação para o SMX (Figura 6.6).

Observaram-se na Figura 6.6 que o fragmento $\mathrm{m} / \mathrm{z}=156$ corresponde ao composto formado devido à ruptura da ligação N-S no sulfametoxazol, de tal forma que ocorre a liberação de fragmentos correspondentes aos anéis oxazolídico e à anilina, pertencentes ao fármaco. Em seguida, ocorre a dessulfurização de tal fragmento, seguida por um processo de hidroxilação no qual se observa um fragmento para $\mathrm{m} / \mathrm{z}=108$, de acordo com as Figuras 6.6 e 6.7. A partir do fragmento 156, pode ocorrer a inserção de um radical hidroxila ao grupo sulfônico, o que foi corroborado pela identificação de um fragmento para m/z $=173$ (Figura $6.7)$.

Considerando-se a molécula do fármaco sulfametoxazol, é possível ocorrer nesta a eliminação do grupamento $\mathrm{NH}_{2}$ na forma de $\mathrm{NH}_{3(\mathrm{~g})}$, seguida por uma hidroxilação, de tal forma que o intermediário $\mathrm{m} / \mathrm{z}=242$ pode ser detectado. Um dos intermediários reativos formados e identificados é o fragmento $\mathrm{m} / \mathrm{z}=288$ e seu espectro de massas será apresentado na Figura 6.8, o qual foi confirmado pela detecção do fragmento $\mathrm{m} / \mathrm{z}=270$ (Figura 6.9), de maneira que ambos são formados graças à adição do radical hidroxila ao anel aromático do composto.

De fato, sob as condições experimentais empregadas neste trabalho, foi constatado que ocorreu a mineralização incompleta do antibiótico sulfametoxazol por meio do processo Fenton (Figura 6.6). Provavelmente esse comportamento pode ser o resultado da formação de compostos recalcitrantes, sendo que foram obtidos compostos com baixa massa molecular, podendo ser convertidos em compostos alifáticos, e serem finalmente mineralizados. 


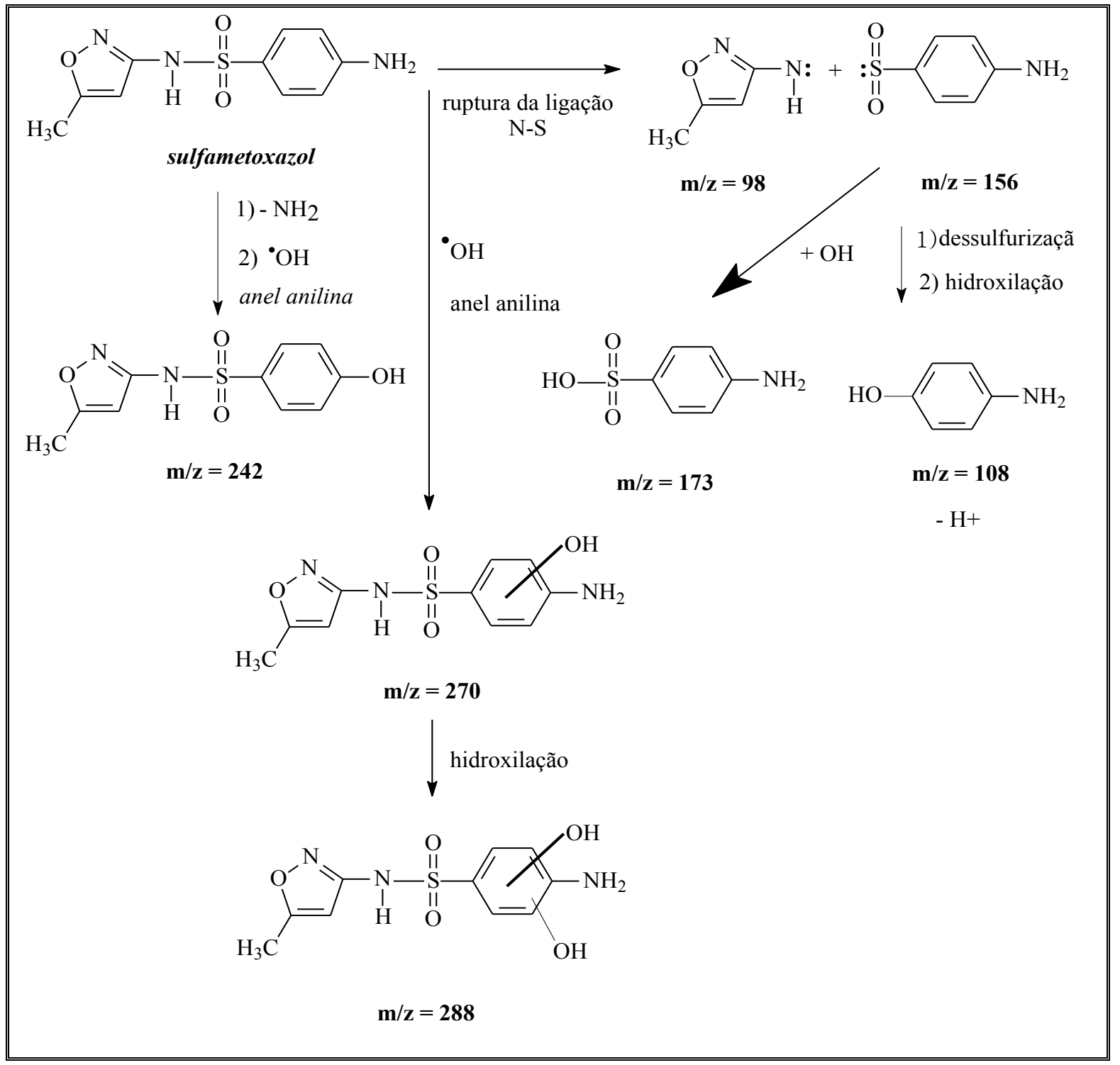

Figura 6.6 - Possível rota de degradação do SMX por meio do processo Fenton.

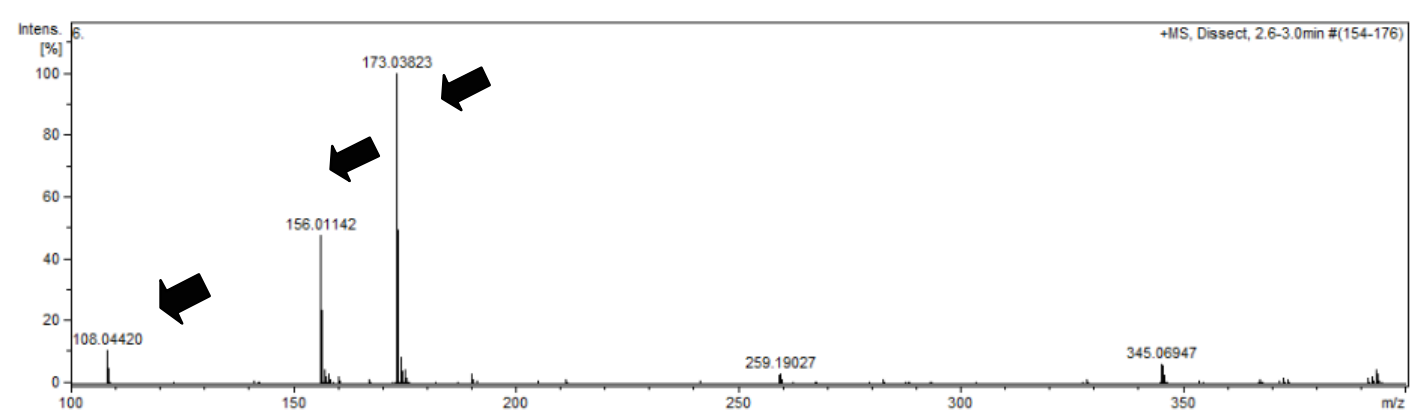

Figura 6.7 - Espectro de massa referente aos intermediários, para valores de m/z =108, 156, 173. 


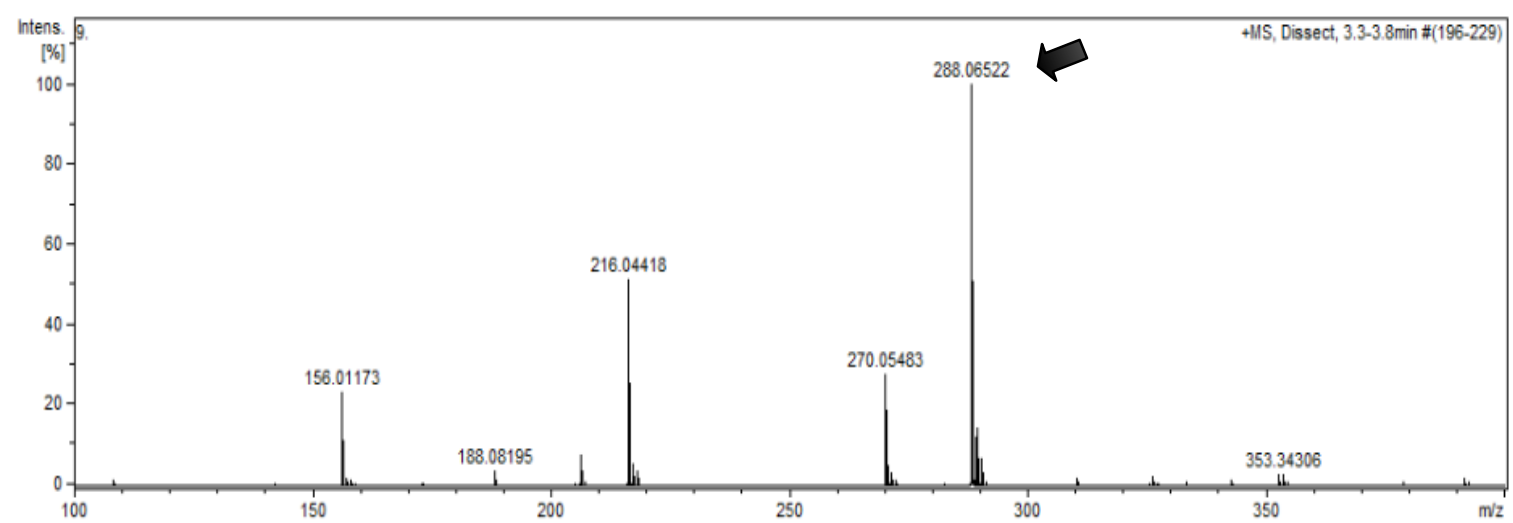

Figura 6.8 - Espectro de massa referente aos intermediários para $\mathrm{m} / \mathrm{z}=288$.

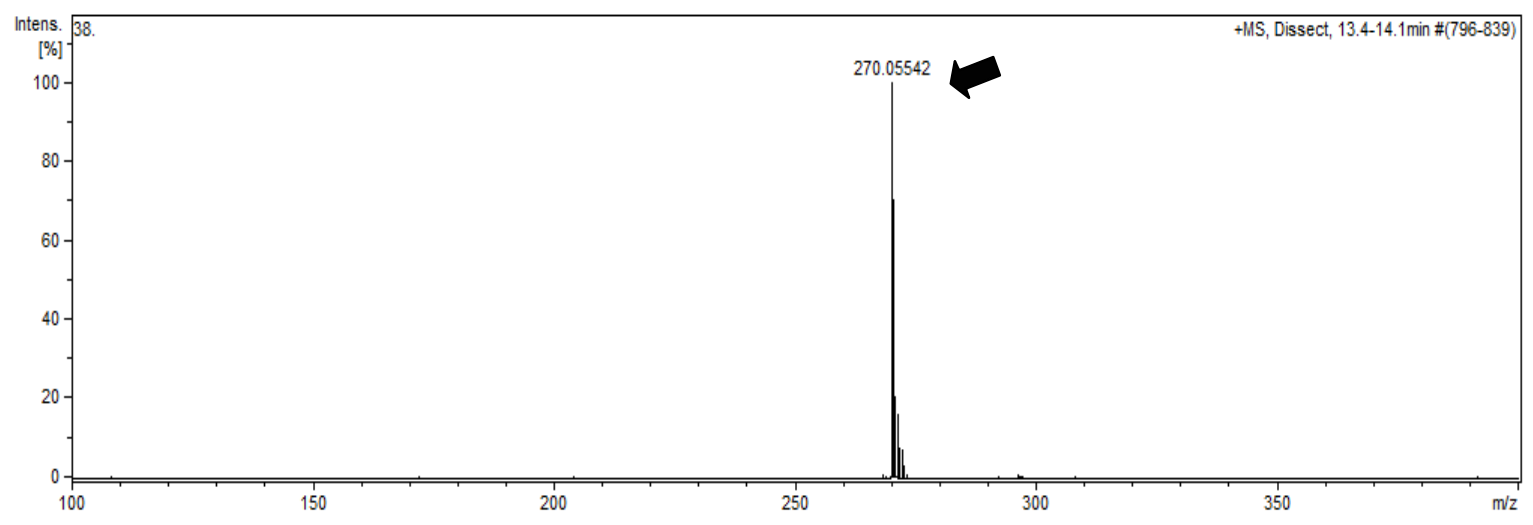

Figura 6.9 - Espectro de massa referente aos intermediários para $\mathrm{m} / \mathrm{z}=270$.

\subsubsection{Identificação dos intermediários inorgânicos do SMX}

Durante a degradação do SMX por meio processo Fenton, íons inorgânicos, tais como o $\mathrm{NO}_{3}{ }^{-}$e o $\mathrm{NH}_{4}{ }^{+}$, têm sido identificados através da técnica de cromatografia iônica, enquanto que o íon sulfato não foi investigado, em razão do emprego do sulfito de sódio como agente inibidor, a fim de se interromper a reação Fenton. A concentração de ambos os íons foi aumentada em solução com o decorrer do tempo, provavelmente devido à destruição do SMX.

A Figura 6.10 expõe que a liberação desses íons é maior na fase inicial do tratamento, sendo que após 40-45 min, tal liberação se tornou quase constante. Já a Figura 6.10 destaca que após 120 min de reação Fenton, foram quantificadas as soluções de concentração 1,2 e 1,6 $\mathrm{mg} \mathrm{L}^{-1}$, aproximadamente, quanto aos íons $\mathrm{NO}_{3}{ }^{-}$e $\mathrm{NH}_{4}{ }^{+}$, respectivamente, o que indica que houve uma pequena velocidade de mineralização. 


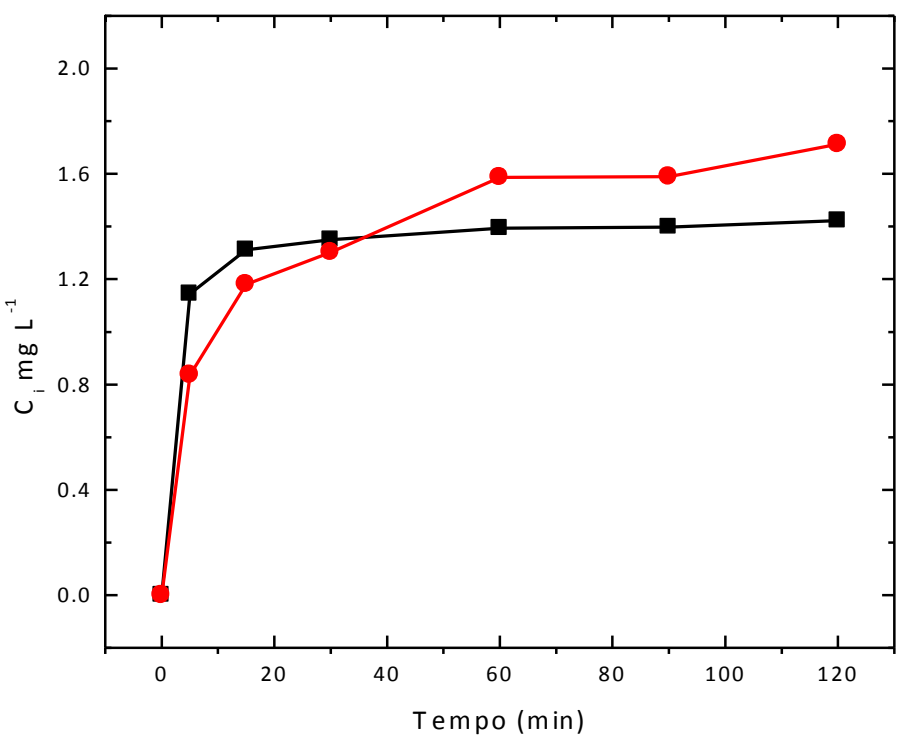

Figura 6.10 - Variações nas concentrações dos íons inorgânicos $(\boldsymbol{\square}) \mathrm{NO}_{3}{ }^{-} \mathrm{e}(\boldsymbol{O}) \mathrm{NH}_{4}{ }^{+}$em função do tempo do tratamento (Condições: $\mathrm{C}_{\mathrm{SMX}}=200 \mathrm{mg} \mathrm{L}^{-1}, \mathrm{C}_{\mathrm{Fe}}{ }^{2+}=10 \mathrm{mg} \mathrm{L}^{-1}, \mathrm{C}_{\mathrm{H} 2 \mathrm{O} 2}=150 \mathrm{mg} \mathrm{L}^{-1}, \mathrm{pH}_{\mathrm{i}}=3 \mathrm{e}$ $\left.\mathrm{T}=25^{\circ} \mathrm{C}\right)$.

\subsection{Conclusões parciais}

A eficiência do processo Fenton para a degradação do SMX em meio aquoso foi avaliada dentre os vários parâmetros importantes que foram analisados, destacaram-se as concentrações das espécies $\mathrm{H}_{2} \mathrm{O}_{2}$, e $\mathrm{Fe}^{2+}$, uma vez que estes reagentes influenciaram significativamente no tratamento. O SMX foi degradado completamente em apenas $12 \mathrm{~min}$ de tratamento no caso das condições otimizadas, tais como as seguintes: $\mathrm{C}_{\mathrm{Fe}^{2+}}=10 \mathrm{mg} \mathrm{L} \mathrm{L}^{-1}, \mathrm{C}_{\mathrm{H}_{2} \mathrm{O}_{2}}$ $=150 \mathrm{mg} \mathrm{L}^{-1}, \mathrm{pH}=3$, tendo ocorrido a remoção de até $28 \%$ do COT.

Os resultados indicam que a condição básica é desfavorável em termos da degradação do SMX, enquanto que para os valores de $\mathrm{pH} \leq 7$, tal degradação é favorável. Similarmente, a temperatura também aumenta a eficiência da degradação e da remoção do COT. Os dados de CLAE-EM e de cromatografia iônica mostraram que sob as condições experimentais realizadas neste trabalho, há a ocorrência de mineralização incompleta do antibiótico sulfametoxazol. No entanto, foram identificados pequenos fragmentos para $\mathrm{m} / \mathrm{z}=98,108$, 156, os quais podem ser transformados em $\mathrm{CO}_{2}$ e $\mathrm{H}_{2} \mathrm{O}$.

O processo Fenton é eficiente para degradação de SMX, entretanto a remoção da matéria orgânica é pequena, de modo que há necessidade de se aumentar a eficiência do processo através do acoplamento com por exemplo a radiação ultravioleta. 


\section{Capítulo 7}

\section{Degradação de sulfametoxazol por processo foto-}

\section{Fenton}

Este capítulo apresenta um estudo voltado para o acoplamento entre o processo de Fenton e a radiação UV para a degradação de sulfametoxazol, a fim de melhorar a eficiência do processo Fenton, verificando a influência dos parâmetros, tais como os efeitos de $\mathrm{Fe}^{2+}$, $\mathrm{H}_{2} \mathrm{O}_{2}$, pH (de 2-11), temperatura (de $15-45^{\circ} \mathrm{C}$ ) e concentração inicial de SMX (de 50 - 200 $\left.\mathrm{mg} \mathrm{L}^{-1}\right)$. Além disso, foram analisados os principais intermediários formados durante o processo foto-Fenton, com o objetivo final de elucidar o mecanismo de degradação.

\subsection{Estudo de parâmetros importantes para o processo foto-Fenton}

As concentrações de $\mathrm{H}_{2} \mathrm{O}_{2}$ e de $\mathrm{Fe}^{2+}$ são parâmetros importantes no processo de fotoFenton. $\mathrm{O} \mathrm{H}_{2} \mathrm{O}_{2}$, quando decomposto, promove a geração do radical hidroxila, agente responsável pela oxidação dos compostos. A concentração desse reagente é um fator muito importante, pois, quando em excesso, compete com o composto alvo pelo radical hidroxila e, quando em baixas concentrações, diminui a formação deste radical, de forma que, consequentemente, pode prejudicar a eficiência do tratamento. 
O estudo desses parâmetros normalmente é realizado com o objetivo de propiciar a máxima eficiência aos processos de degradação. Visto a influência que as concentrações de $\mathrm{Fe}^{2+}$ e de $\mathrm{H}_{2} \mathrm{O}_{2}$ apresentam nos processos de fotodegradação o estudo desses parâmetros é extremamente necessário para a eficiência do processo.

\subsubsection{Influência da concentração de íons $\mathrm{Fe}^{2+}$}

Para avaliar a influência da concentração de $\mathrm{Fe}^{2+}$ no processo de foto-Fenton para a degradação de sulfametoxazol, foram realizados estudos nas concentrações de 2,5, 5, 10 e 15

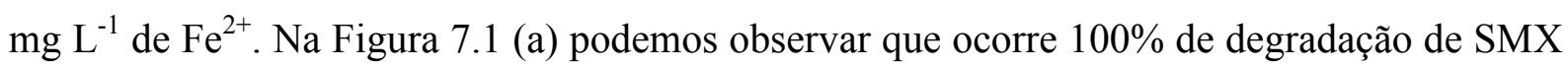
ao final de 4 e 15 min de tratamento, utilizando as concentrações de 15 e $10 \mathrm{mg} \mathrm{L}^{-1}$ respectivamente, o processo de degradação foi lento, obtendo-se $100 \%$ de degradação para as concentrações de 5 e $2,5 \mathrm{mg} \mathrm{L}^{-1}$ de $\mathrm{Fe}^{2+}$ após 30 min de tratamento.

A Figura 7.1 (b) apresenta a remoção de COT, pode-se observar que a mesma aumenta com aumento de concentração de $\mathrm{Fe}^{2+}$, e uma maior remoção, de $43 \%$, foi obtida para 10 e 15 mg L ${ }^{-1}$. Por fim, para as demais concentrações, $40 \%$ da remoção de COT foi atingida. A remoção de COT foi mais rápida no início da reação e, após isso, praticamente ficou constante. Na verdade, uma maior quantidade de radicais hidroxila foi gerada no início da reação, além de ser consumida para a degradação e remoção do COT de SMX.

Sabe-se que a concentração de $\mathrm{Fe}^{2+}$ teve um efeito na decomposição catalítica sobre $\mathrm{H}_{2} \mathrm{O}_{2}$, uma vez que o efeito catalítico também foi maior com o aumento de $\mathrm{Fe}^{2+}$. Geralmente no processo de foto-Fenton, $\mathrm{Fe}^{3+}$ foram gerados na forma de $\mathrm{Fe}(\mathrm{OH})_{2}$ a partir da decomposição de $\mathrm{H}_{2} \mathrm{O}_{2}$ pelos íons $\mathrm{Fe}^{2+}$, em meio ácido. Quando os complexos de $\mathrm{Fe}$ (III) são irradiados, ocorre a promoção de um elétron de um orbital centrado no ligante para um orbital centrado no metal, chamada de transferência de carga ligante-metal, que implica na redução de Fe (III) a Fe (II) e na oxidação do ligante (Equação 7.1), formando o radical hidroxila (MELO et al., 2009).

$\mathrm{Fe}(\mathrm{OH})^{2+}+\mathrm{h} v \rightarrow \mathrm{Fe}^{2+}+{ }^{\cdot} \mathrm{OH}$

$\mathrm{O}$ íon $\mathrm{Fe}^{2+}$ gerado durante a irradiação, quando na presença de peróxido de hidrogênio, reage com este último, dando sequência à reação de Fenton (Equação 7.1). Nesse contexto, a reação é catalítica, sendo então estabelecido um ciclo em que os íons $\mathrm{Fe}^{2+}$ são regenerados, fazendo com que ocorra um aumento na eficiência do processo de degradação, resultando em um aumento na eficiência do processo. Os resultados obtidos estão de acordo 


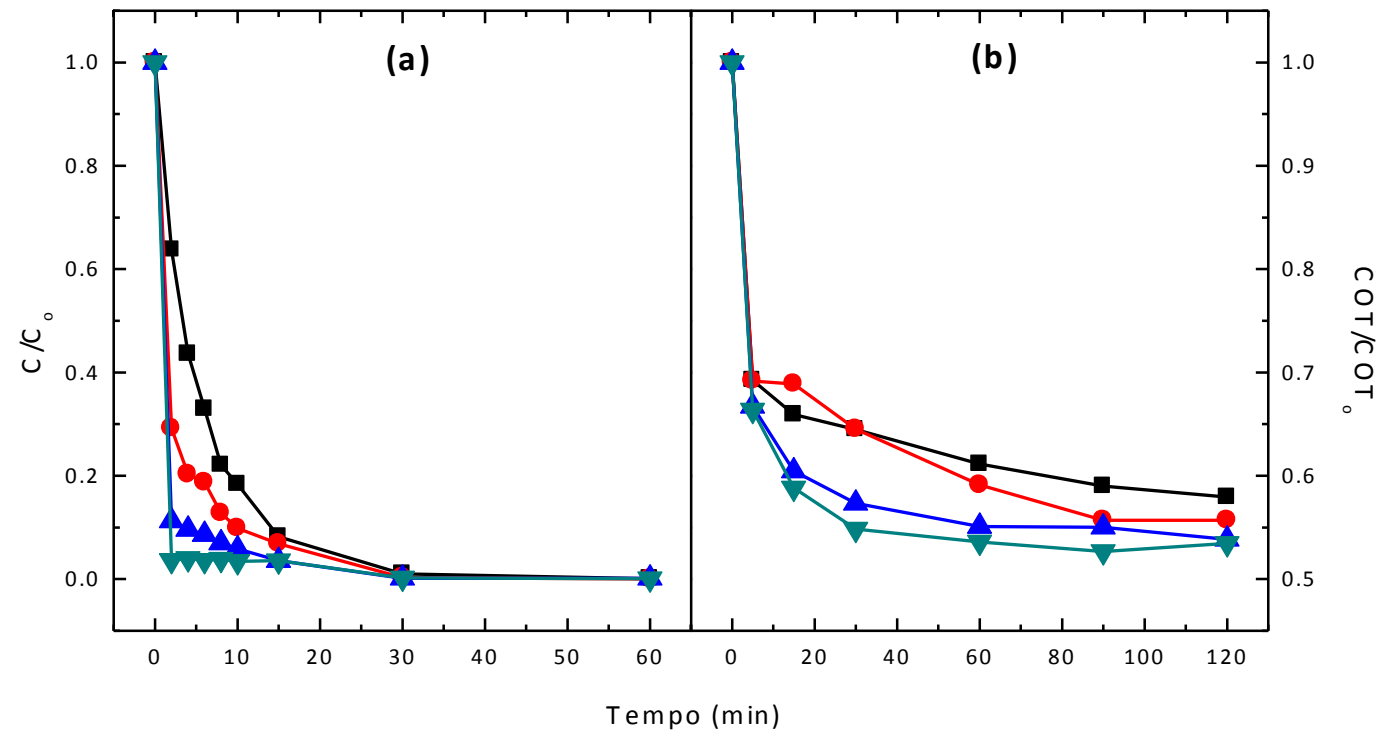

Figura 7.1 - Influência da concentração de $\mathrm{Fe}^{2+}(\boldsymbol{\square}) 2,5 \mathrm{mg} \mathrm{L}^{-1},(\bullet) 5 \mathrm{mg} \mathrm{L}^{-1},(\mathbf{\Delta}) 10 \mathrm{mg} \mathrm{L}^{-1},(\boldsymbol{\nabla}) 15$ $\mathrm{mg} \mathrm{L}^{-1}$ na (a) degradação e (b) remoção do COT, (Condições: $\mathrm{C}_{\mathrm{SMX}}=200 \mathrm{mg} \mathrm{L}^{-1}, \mathrm{C}_{\mathrm{H} 2 \mathrm{O} 2}=150 \mathrm{mg} \mathrm{L}^{-1}$, $\mathrm{pH}_{\mathrm{i}}=3$ e $\left.\mathrm{T}=25^{\circ} \mathrm{C}\right)$.

com os estudos realizados por Trovó et al., (2009), confirmando que a degradação de SMX aumenta mediante maiores concentrações de ferro entre $\left(0,05-0,2 \mathrm{mmol} \mathrm{L}^{-1}\right)$, em processo de Fenton acoplado radiação solar.

\subsubsection{Influência da concentração de $\mathrm{H}_{2} \mathrm{O}_{2}$}

O principal fator que contribui para o custo químico do processo foto-Fenton é o valor pago pelo $\mathrm{H}_{2} \mathrm{O}_{2}$, portanto, é importante minimizar a quantidade de $\mathrm{H}_{2} \mathrm{O}_{2}$ utilizado, especialmente para o tratamento de grandes volumes de águas residuárias contendo poluentes como produtos farmacêuticos. Tendo em vista minimizar os gastos no processo de fotoFenton, a influência da concentração de $\mathrm{H}_{2} \mathrm{O}_{2}$ na degradação de SMX foi investigada.

Nestes experimentos, a concentração inicial do $\mathrm{H}_{2} \mathrm{O}_{2}$ foi alterada de 25 para $150 \mathrm{mg} \mathrm{L}^{-}$ 1 , mas a concentração de $\mathrm{Fe}^{+2}$ foi mantida constante, com concentração de $10 \mathrm{mg} \mathrm{L}^{-1}$. A degradação de SMX sob concentrações diferentes de $\mathrm{H}_{2} \mathrm{O}_{2}$ pode ser verificada na Figura 7.2 (a), e após 30 min de tratamento, aproximadamente 100\% da remoção de SMX foi observada para as três concentrações de 50,100 e $150 \mathrm{mg} \mathrm{L}^{-1}$, já os $90 \%$ de degradação foram observados para $25 \mathrm{mg} \mathrm{L}^{-1}$ de $\mathrm{H}_{2} \mathrm{O}_{2}$. Esses resultados demonstraram que o aumento das concentração de $\mathrm{H}_{2} \mathrm{O}_{2}$ proporciona uma melhor degradação de SMX, devido a um aumento 


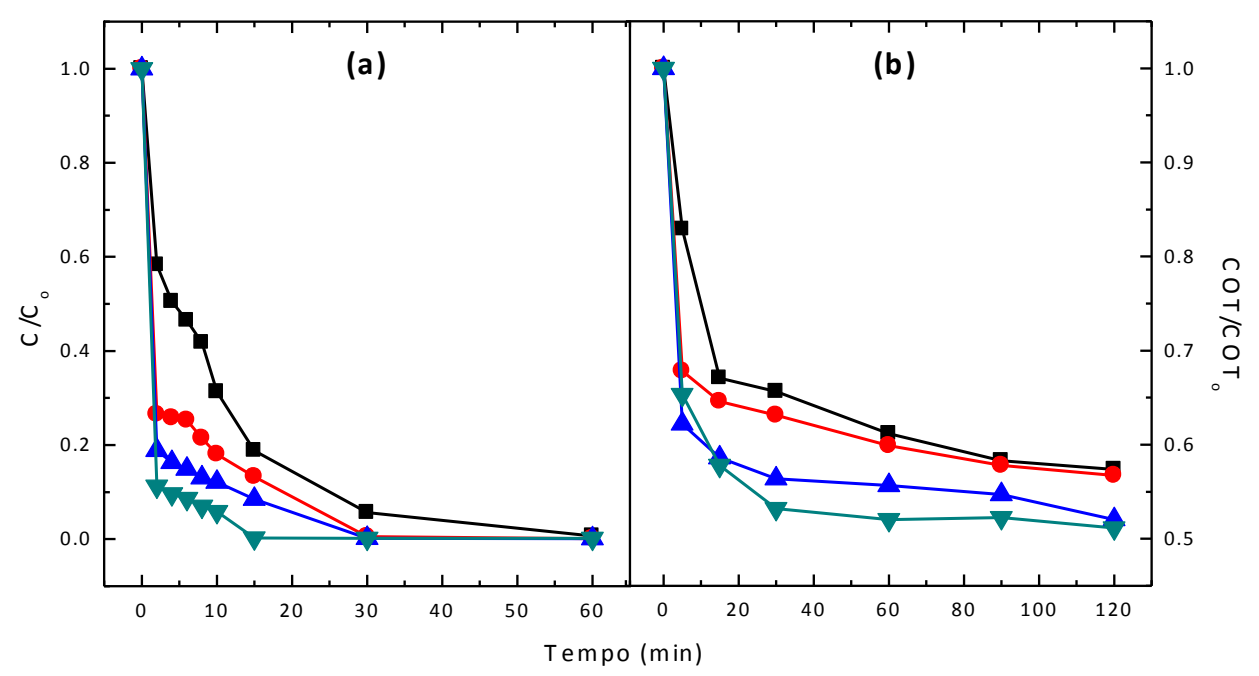

Figura 7.2 - Influência da concentração do $\mathrm{H}_{2} \mathrm{O}_{2}(\boldsymbol{\square}) 25 \mathrm{mg} \mathrm{L}^{-1},(\bullet) 50 \mathrm{mg} \mathrm{L}^{-1},(\boldsymbol{\Delta}) 100 \mathrm{mg} \mathrm{L}^{-1},(\boldsymbol{\nabla})$ $150 \mathrm{mg} \mathrm{L}^{-1}$ na (a) degradação e (b) remoção do COT (Condições: $\mathrm{C}_{\mathrm{smx}}=200 \mathrm{mg} \mathrm{L}^{-1}, \mathrm{C}_{\mathrm{Fe} 2+}=10 \mathrm{mg} \mathrm{L}^{-}$ ${ }^{1}, \mathrm{pH}_{\mathrm{i}}=3$ e $\left.\mathrm{T}=25^{\circ} \mathrm{C}\right)$.

da quantidade de radicais hidroxila na solução, a partir da decomposição de $\mathrm{H}_{2} \mathrm{O}_{2}$. Com relação à remoção de COT, pode-se observar na Figura 7.2 (b) que, com o aumento da concentração de $\mathrm{H}_{2} \mathrm{O}_{2}$ de 25 para $150 \mathrm{mg} \mathrm{L}^{-1}$, ocorreu uma maior remoção de COT de $38 \%$ para $48 \%$ após $120 \mathrm{~min}$ de tratamento significando tal fato que o SMX foi mineralizado parcialmente, formando intermediários que são muito estáveis para degradar.

$\mathrm{Na}$ degradação por processo de foto-Fenton, os radicais hidroxila são os principais agentes para a degradação do SMX. No entanto, um excesso de peróxido de hidrogênio faz com que ocorra uma concorrência nas reações, segundo com (Equação 1.34), $\mathrm{H}_{2} \mathrm{O}_{2}$ pode também atuar como seqüestrador de radical hidroxila, formando o radical hidroperoxila $\left(\mathrm{HO}_{2} \bullet\right)$, o qual apresenta um menor potencial de redução $\left(\mathrm{E}_{\mathrm{o}}=1,42 \mathrm{~V}\right.$ versus $\left.\mathrm{ENH}\right)$ que $\bullet \mathrm{OH}$, prejudicando, portanto, o processo de degradação. Isto ocorre na presença de excesso de $\mathrm{H}_{2} \mathrm{O}_{2}$, pois neste caso, a concentração de $\mathrm{Fe}^{2+}$ no meio é baixa em relação à de $\mathrm{Fe}^{3+}$, uma vez que a reação entre $\mathrm{Fe}^{3+}$ e $\mathrm{H}_{2} \mathrm{O}_{2}$ (Equação 1.25) é muito mais lenta que a decomposição de $\mathrm{H}_{2} \mathrm{O}_{2}$ na presença de $\mathrm{Fe}^{2+}$ (Equação 1.24). $\mathrm{O}$ efeito prejudicial do excesso de $\mathrm{H}_{2} \mathrm{O}_{2}$ na degradação de compostos orgânicos (NOGUEIRA et al., 2007)

$$
\begin{aligned}
& \mathrm{Fe}^{2+}+\mathrm{H}_{2} \mathrm{O}_{2} \rightarrow \mathrm{Fe}^{3+}+\mathrm{OH}^{-}+\bullet \mathrm{OH} \\
& \mathrm{Fe}^{3+}+\mathrm{H}_{2} \mathrm{O}_{2} \rightarrow \mathrm{H}^{+}+\mathrm{Fe}(\mathrm{OOH})^{2+} \\
& \mathrm{HO} \bullet+\mathrm{H}_{2} \mathrm{O}_{2} \rightarrow \mathrm{HO}_{2} \bullet+\mathrm{H}_{2} \mathrm{O}
\end{aligned}
$$


$\mathrm{Na}$ mesma forma Zhao et al. (2004) estudaram a degradação do dimetil ftalato por processo de Fenton de maneira que foi possível demonstrar que as concentrações de $\mathrm{H}_{2} \mathrm{O}_{2}$ aumentam a eficiência em até $5,00 \times 10^{-4} \mathrm{~mol} \mathrm{~L}^{-1}$ e para as concentrações maiores, a taxa de degradação de dimetil ftalato começou a diminuir. Portanto, para o excesso de peróxido de hidrogênio várias reações de concorrência proporcionam um efeito inibidor para a degradação de dimetil ftalato.

\subsubsection{Influência do pH}

$\mathrm{O}$ valor de $\mathrm{pH}$ pode influenciar drasticamente na geração de radicais hidroxila e, consequentemente, na eficiência de degradação de compostos orgânicos. Para determinar o $\mathrm{pH}$ melhor, os experimentos foram conduzidos na faixa de $\mathrm{pH}$ 2-9. A concentração inicial do SMX foi de $200 \mathrm{mg} \mathrm{L}^{-1}$. A Figura 7.3 (a) evidencia o efeito do $\mathrm{pH}$ na degradação de SMX. Pode-se observar nessa Figura que após $30 \mathrm{~min}$ de tratamento, a degradação foi atingida até $100,98,92,75,68$ e $30 \%$ em pH 3, 5, 2, 7, 9 e 11, respectivamente , e a remoção de COT foi verificada em 42, 41, 38, 25, 20 e 5\%, para os seguintes $\mathrm{pH}, 5,2,7,9$ e 11 e 4, respectivamente (Figura $7.3 \mathrm{~b}$ ).

Os resultados demonstraram que o pH influencia significativamente na degradação de SMX, melhorando também a remoção de COT, de maneira que a degradação e mineralização máximas foram alcançadas em condição acido. Isso pode ser explicado pelo efeito do $\mathrm{pH}$ sobre a formação do complexo férrico em solução. Acima de $\mathrm{pH} 2$ até 3, o ferro forma um complexo de $\left[\mathrm{Fe}(\mathrm{OH})\left(\mathrm{H}_{2} \mathrm{O}\right)_{5}\right]^{+2}$ que tem maior coeficiente de absorção da luz UV, além de maior rendimento quântico para a produção de $\bullet \mathrm{OH}$, bem como a regeneração de íons $\mathrm{Fe}^{2+}$.

Em pH 2 ou menor, forma-se um complexo de $\left[\mathrm{Fe}\left(\mathrm{H}_{2} \mathrm{O}\right)_{6}\right]^{3+}$, portanto, a eficácia da absorção de luz, a regeneração de $\mathrm{Fe}^{2+}$ e a degradação orgânica são menores (BENKELBERG; WARNECK, 1995). O pH acima de 4 também não é favorável para a degradação e remoção de $\mathrm{COT}$, devido à formação de $\mathrm{Fe}(\mathrm{OH})_{3}$ precipitado, e também pelo decréscimo do rendimento quântico de formação de radicais hidroxila (CHEN et al. 2007).

No estudo de Elmolla; Chaudhuri (2009) foi verificado que o pH 3 é melhor para a degradação de antibióticos como amoxicilina, ampicilina e cloxacilina (AMX, AMP e CLX).

\subsubsection{Influência da temperatura}

É conhecido que a temperatura atua como um parâmetro importante para o processo de foto-Fenton (PIGNATELLO et al. 2006; ZAPATA et al., 2009; PÉREZ et al., 2002). Por 


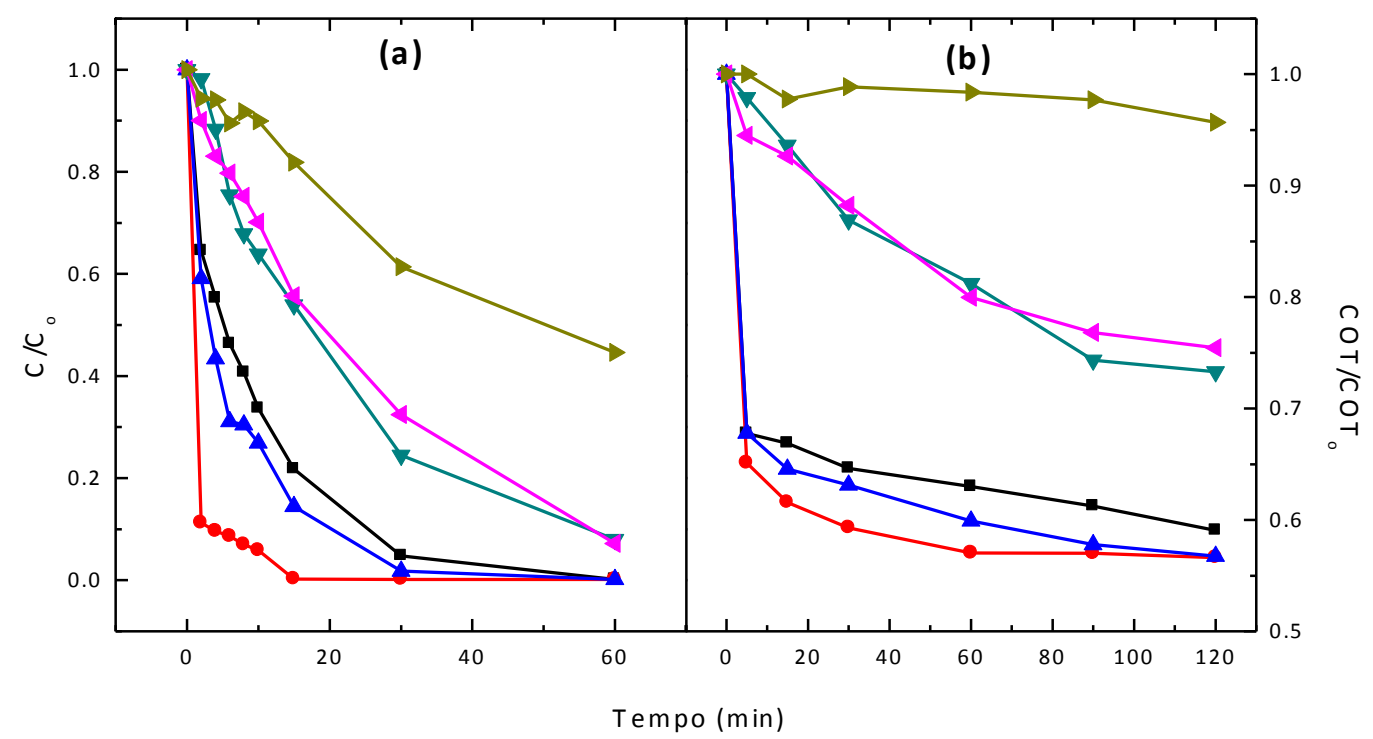

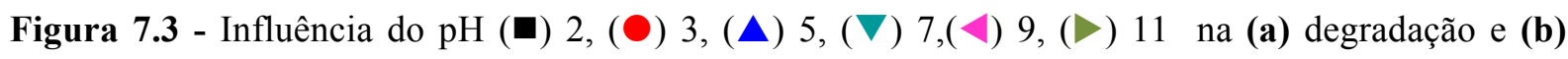
remoção de COT. (Condições: $\mathrm{C}_{\mathrm{SMX}}=200 \mathrm{mg} \mathrm{L}^{-1}, \mathrm{C}_{\mathrm{Fe} 2+}=10 \mathrm{mg} \mathrm{L}^{-1}, \mathrm{C}_{\mathrm{H} 2 \mathrm{O} 2}=150 \mathrm{mg} \mathrm{L}^{-1}$, e $\mathrm{T}=25^{\circ} \mathrm{C}$ ).

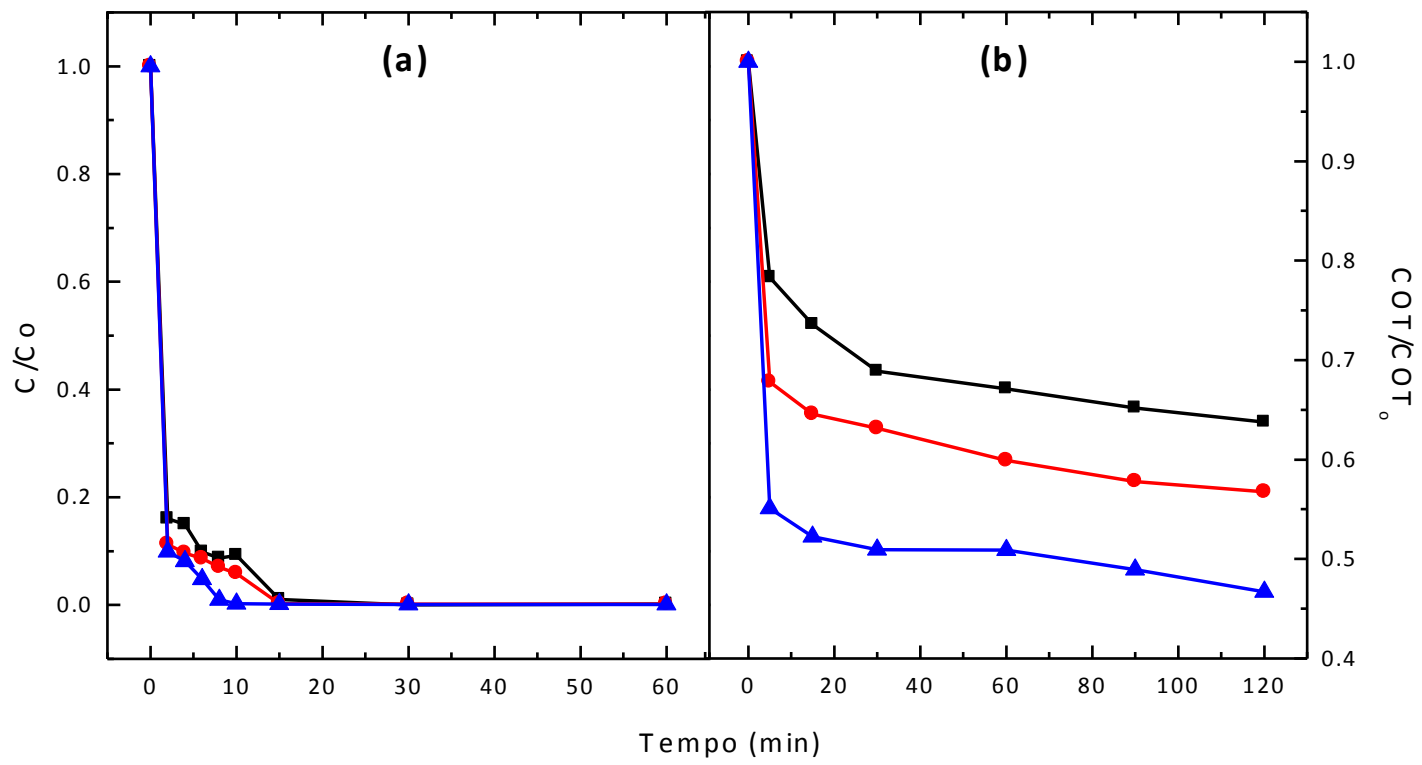

Figura 7.4 - Influência da temperatura (অ) $15{ }^{\circ} \mathrm{C},(\bullet) 25{ }^{\circ} \mathrm{C},(\boldsymbol{\Delta}) 35^{\circ} \mathrm{C}$, na (a) degradação e (b) remoção do COT, (Condições: $\mathrm{C}_{\mathrm{SMX}}=200 \mathrm{mg} \mathrm{L}^{-1}, \mathrm{C}_{\mathrm{Fe} 2+}=10 \mathrm{mg} \mathrm{L}^{-1}, \mathrm{C}_{\mathrm{H} 2 \mathrm{O} 2}=150 \mathrm{mg} \mathrm{L}^{-1}$ e $\mathrm{pH}_{\mathrm{i}}=3$ ).

isso, a sua influência na degradação tem sido estudado. Uma série de experimentos foi realizada em três temperaturas diferentes $\left(15,25,35^{\circ} \mathrm{C}\right)$, a fim de encontrar a condição mais favorável. A Figura 7.4 apresenta a degradação e a mineralização do SMX em três temperaturas testadas.

A eficiência de processo de foto-Fenton aumentou gradualmente com a temperatura, podendo-se observar pela Figura 7.4 (a) que a temperatura influencia pouco a degradação de SMX. Contudo, a Figura 7.4 (b) destaca que o incremento de temperatura tem um efeito 
significativo na taxa de remoção de COT, sendo que 50, 40 e 30\% de remoção de COT foram obtidos para as temperaturas de 15,25 , e $35{ }^{\circ} \mathrm{C}$ respectivamente.

Tal fato pode ser explicado por uma velocidade maior na geração de íon férrico, que é ainda mais rápida quando se aumenta a temperatura, permitindo que mais íons $\mathrm{Fe}^{2+}$ estejam disponíveis para gerar os radicais hidroxila. Uma observação semelhante tem sido observado pelos pesquisadores Pérez et al. (2002) para a remoção de contaminantes orgânicos dos efluentes de indústria de papel e celulose. Utiliza-se para tanto o processo de Fenton e fotoFenton, de modo que os estudos demostraram um aumento de remoção de COT com a elevação de temperatura.

Em outro estudo, Oancea; Meltzer (2013) apresentaram uma dependência da constante de velocidade na temperatura que aumenta com a elevação da temperatura até $50{ }^{\circ} \mathrm{C}$. Acima de $50{ }^{\circ} \mathrm{C}$, a constante de velocidade diminuiu devido à decomposição do peróxido de hidrogênio em água e oxigênio.

Da mesma forma, Zapata et al. (2009) estudaram a degradação de pesticide, indicando que a eficiência aumentou gradualmente com a temperatura em experimentos no intervalo entre $25-42{ }^{\circ} \mathrm{C}$. Isso poderia ser explicado por uma taxa mais rápida de regeneração de ferroso a partir de íon férrico, que é ainda mais rápido nas altos valores de temperatura, permitindo que mais $\mathrm{Fe}^{2+}$ estejam disponíveis para gerar os radicais hidroxila. No entanto, à temperatura de $50{ }^{\circ} \mathrm{C}$ e acima disso, o processo de degradação foi significativamente mais lento, reduzindo a eficiência em razão da precipitação de íons ferro durante o processo.

\subsubsection{Influência da concentração inicial de SMX}

As concentrações de SMX variam muito em água residuais, por isso, faz-se necessário estudar o efeito da concentração inicial de SMX sobre a degradação por processo de fotoFenton. A influência da concentração inicial de SMX é mostrada na Figura 7.5 (a) e (b). É possível observar que a taxa de degradação diminuiu com o aumento da concentração inicial de SMX em 100, 98, 80 e 78\%, onde a degradação foi atingida em apenas 3 min de tratamento para as concentrações de $50,100,150$ e $200 \mathrm{mg} \mathrm{L}^{-1}$.

Contudo, o SMX foi degradado completamente para as quatro concentrações em 15 minutos de tratamento. Um comportamento semelhante pode ser verificado na Figura 7.5 (b), com remoção de COT em 90, 60, 40, e 38\% para as concentrações de 50, 100, 150 e 200 mg $\mathrm{L}^{-1}$ de SMX, respectivamente. $\mathrm{O}$ aumento da concentração inicial de SMX aumenta o número 


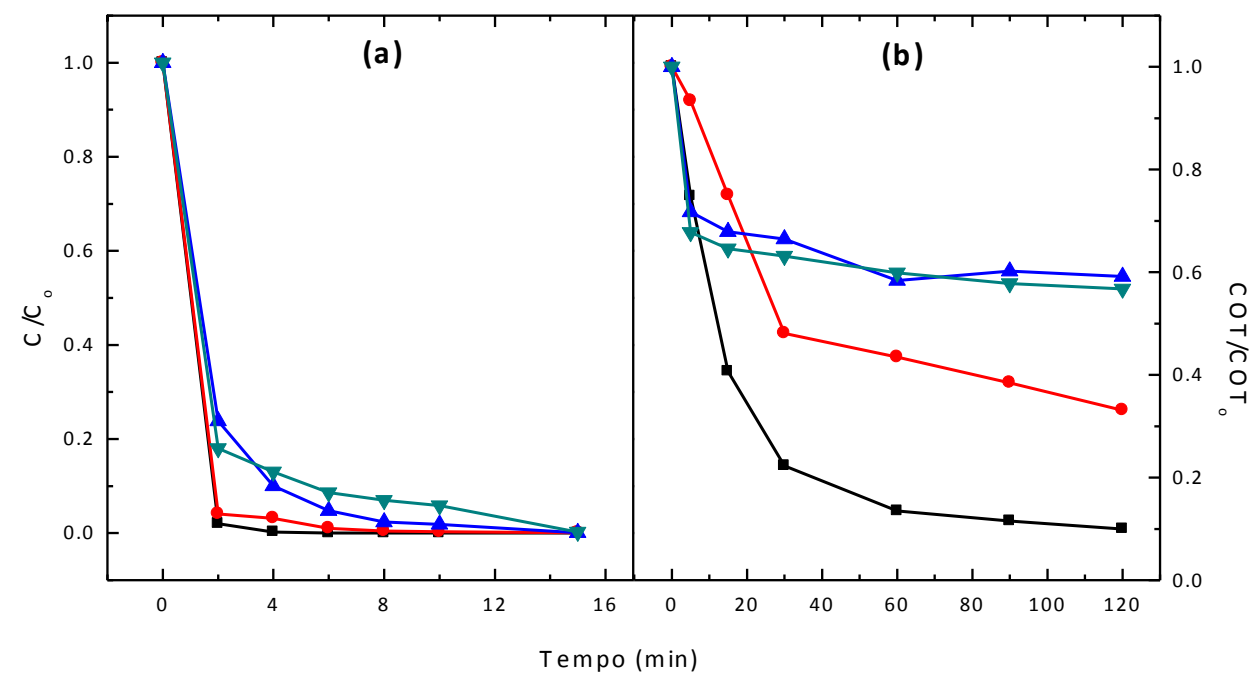

Figura 7.5 - Influência da concentração inicial do SMX (ロ) $50 \mathrm{mg} \mathrm{L}^{-1},(\bullet) 100 \mathrm{mg} \mathrm{L}^{-1},(\boldsymbol{\Delta}) 150 \mathrm{mg}$ $\mathrm{L}^{-1}(\boldsymbol{\nabla}) 200 \mathrm{mg} \mathrm{L}^{-1}$ na (a) degradação e (b) remoção do COT (Condições: $\mathrm{C}_{\mathrm{Fe} 2+}=10 \mathrm{mg} \mathrm{L}^{-1}, \mathrm{C}_{\mathrm{H} 2 \mathrm{O} 2}=$ $150 \mathrm{mg} \mathrm{L}^{-1}$, e $\mathrm{pH}_{\mathrm{i}}=3, \mathrm{~T}=25^{\circ} \mathrm{C}$ ).

de moléculas e a quantidade de ${ }^{\cdot} \mathrm{OH}$ permanece constante, por isso a degradação e a mineralização diminuíram. Outro fator importante é que a penetração dos fótons na solução diminuiu a alta concentração do SMX, diminuindo também a concentração de radical hidroxila. Os resultados obtidos estão de acordo com estudos realizados por Elmolla; Chaudhuri (2009), que verificaram a degradação dos antibióticos como amoxicilina, ampicilina e cloxacilina (AMX, AMP e CLX).

\subsection{Identificação dos intermediários na degradação de SMX pelo processo de foto- Fenton}

Vários experimentos foram conduzidos para avaliar os intermediários de SMX por processo foto-Fenton. Nos processos de Fenton e foto-Fenton, o radical hidroxila é o espécie principal para degradar o SMX, então, no processo de foto-Fenton foram obtidos praticamente os mesmos fragmentos observados no processo Fenton, baseando-se nos resultados dos espectros de massas e nos cromatogramas de degradação de SMX pelo processo de fotoFenton.

Esses intermediários são gerados a partir de uma ruptura da ligação N-S, ou pelo ataque no anel aromático por um radical hidroxila. Os fragmentos correspondentes a $\mathrm{m} / \mathrm{z}=$ $98,156,110,174$ e 288 foram identificados, e os espectros de massas estão apresentada nas Figura 7.6-7.11. 


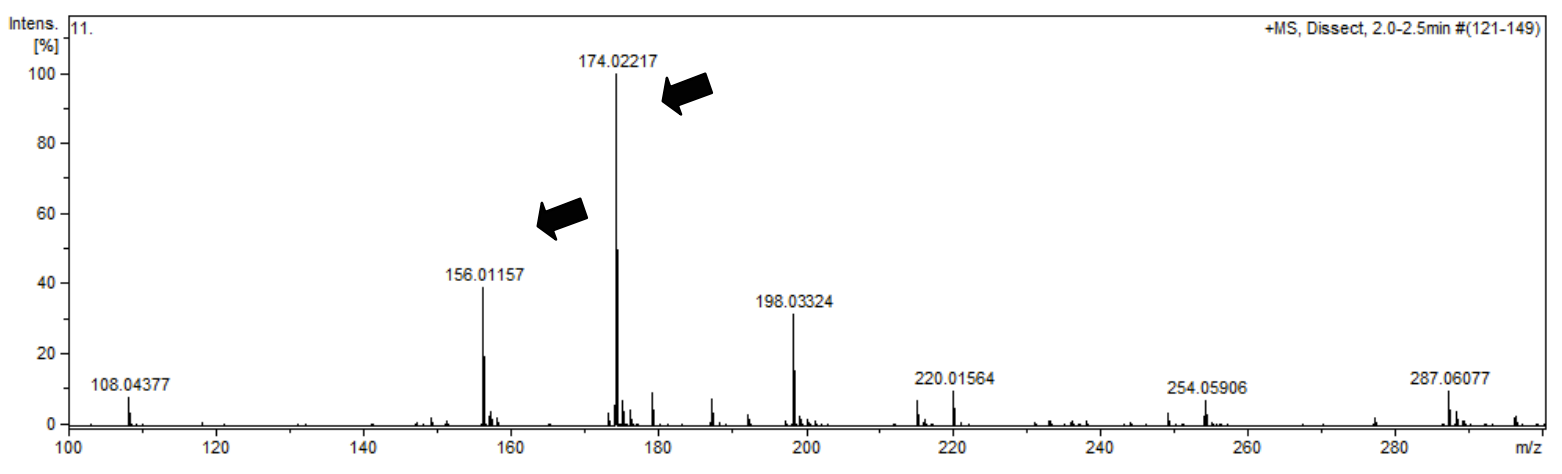

Figura 7.6 - Espectro de massa referente aos intermediários para $\mathrm{m} / \mathrm{z}=174,156$.

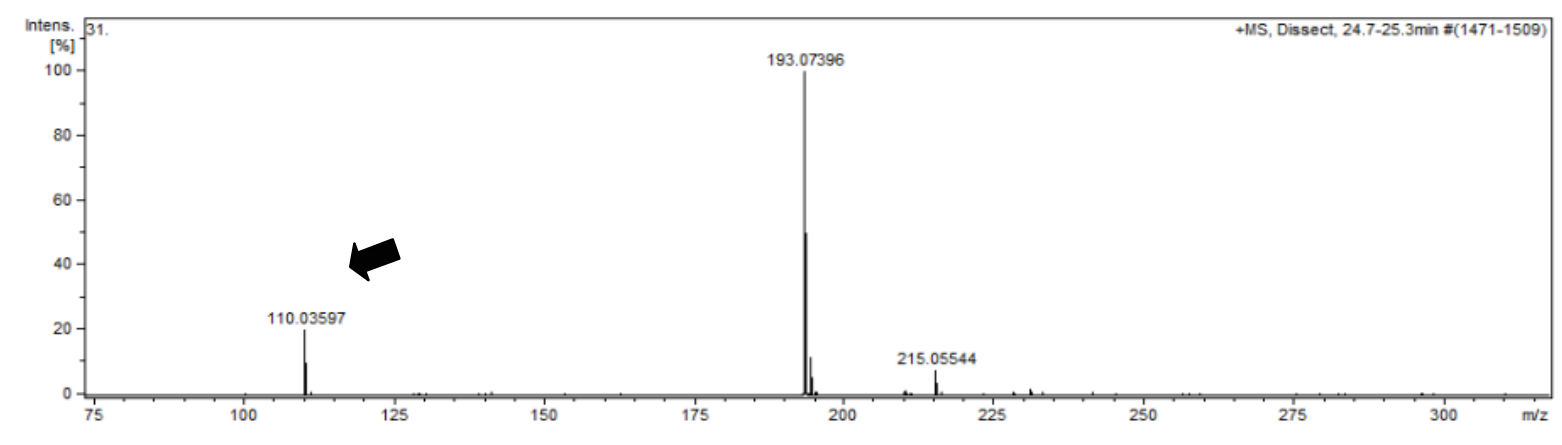

Figura 7.7 - Espectro de massa referente aos intermediários para $\mathrm{m} / \mathrm{z}=110$

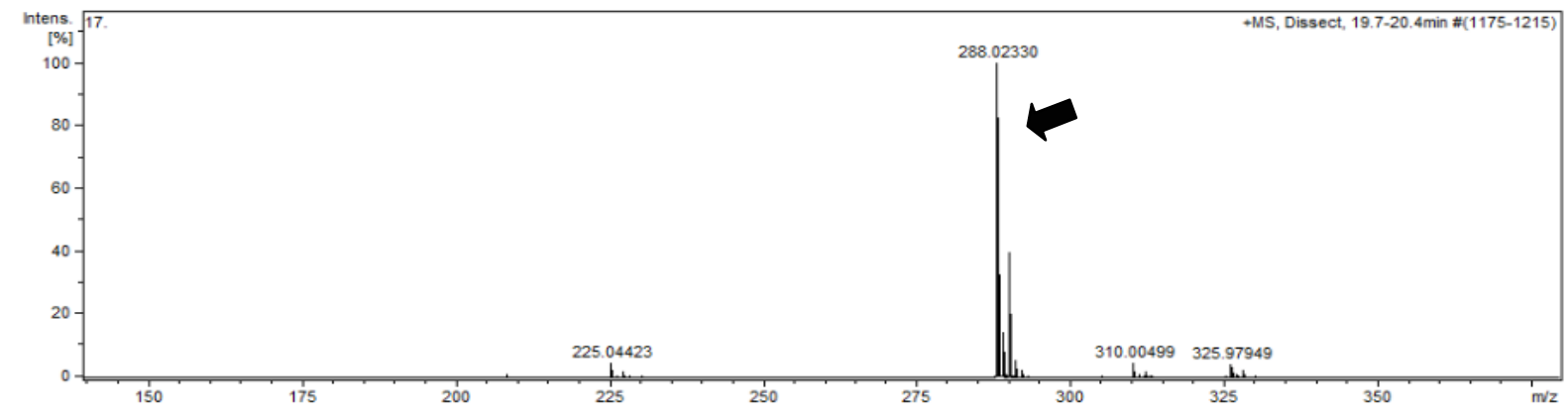

Figura 7.8 - Espectro de massa referente aos intermediários para $\mathrm{m} / \mathrm{z}=288$

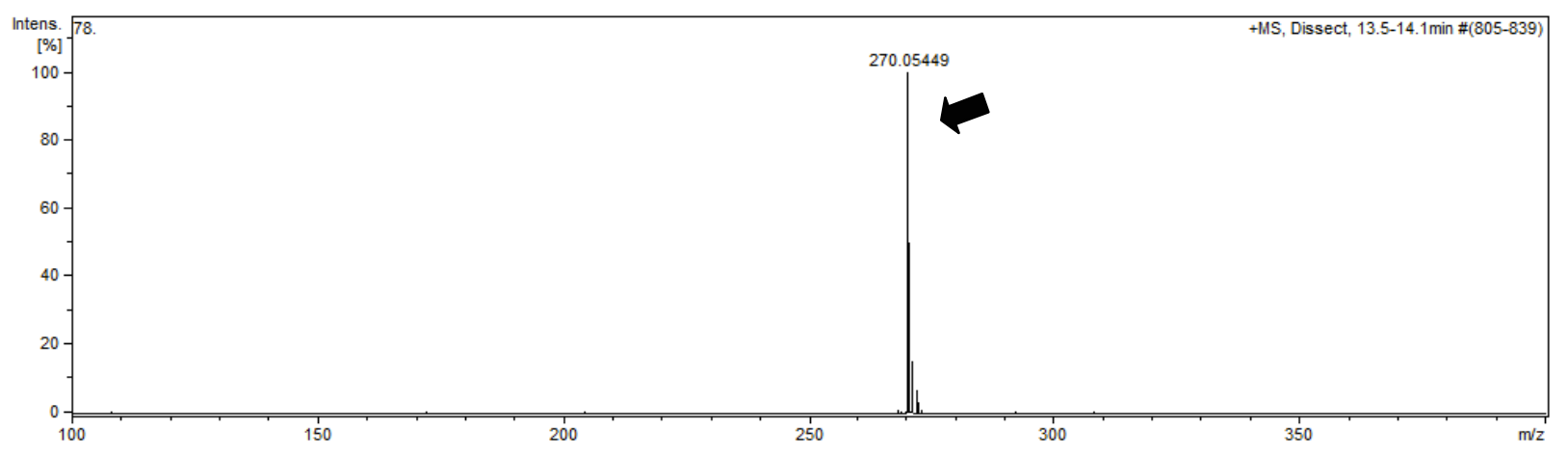

Figura 7.9 - Espectro de massa referente aos intermediários para $\mathrm{m} / \mathrm{z}=270$. 


\subsection{Conclusões parciais}

A degradação de SMX em solução aquosa foi investigada pelo processo foto-Fenton em diferentes condições experimentais, incluindo diferentes dosagens de $\mathrm{H}_{2} \mathrm{O}_{2}$ e $\mathrm{Fe}^{2+}$ e diferente $\mathrm{pH}$ iniciais. O SMX foi quase completamente degradado, e $42 \%$ do COT é removido após 120 minutos de reação para o SMX com concentração inicial de $200 \mathrm{mg} \mathrm{L}^{-1}$ e $\mathrm{H}_{2} \mathrm{O}_{2}$ e $\mathrm{Fe}^{2+}$ em doses de 150 e $10 \mathrm{mg} \mathrm{L}^{-1}$, respectivamente, em $\mathrm{pH}=3$.

A eficiência da degradação foi reforçada por um aumento de $\mathrm{H}_{2} \mathrm{O}_{2}$ e $\mathrm{Fe}^{2+}$, no entanto, o aumento da concentração inicial de SMX proporciona um efeito negativo na degradação. A remoção de COT aumenta significativamente com a redução do $\mathrm{pH}$, sendo que em $\mathrm{pH} 3$ foi observada uma melhora na degradação de SMX. Similarmente, o aumento de temperatura entre 15 e $35^{\circ} \mathrm{C}$ aumenta a eficiência do processo foto-Fenton.

$\mathrm{O}$ ataque de radical hidroxila na molécula de SMX ocorre provavelmente na ligação entre N-S e o anel aromático, formando produtos com a relação massa/carga igual a $\mathrm{m} / \mathrm{z}=98$, 156, 110, 174 e 288. Os resultados mostraram que a remoção de COT melhorou com o acoplamento do radiação de UV com o processo de Fenton. 


\section{Capítulo 8}

\section{Comparação de eficiência e conclusões}

\subsection{Eficiência dos processos}

Vários processos, nomeadamente eletroquímico, eletroquímico foto assistido e fotoquímico, Fenton e foto-Fenton foram aplicados para a degradação e mineralização de SMX em solução aquosa.

Na Figura 8.1 está representada a degradação (\%) e a remoção de COT (\%) de SMX para os diferentes processos. Pode-se observar que praticamente $100 \%$ de remoção de SMX ocorreu após 30 min para a maioria dos processos estudados, exceto o fotoquímico, em que $80 \%$ de remoção foi alcançada após 30 min de tratamento. Também se mostrou evidente que a degradação foi mais eficiente quando utilizado o acoplamento da luz UV com o processo eletroquímico e Fenton.

A eficiência dos processos, em termos de redução de COT após de 120 min de tratamento é ilustrada na Figura 8.1 e pode-se observar que apenas $19 \%$ de mineralização ocorre para processo fotoquímico. Entretanto, durante os processos eletroquímico, Fenton, foto-Fenton e eletroquímico foto assistido, a remoção do COT alcançada até 29, 32, 42 e 48\% 


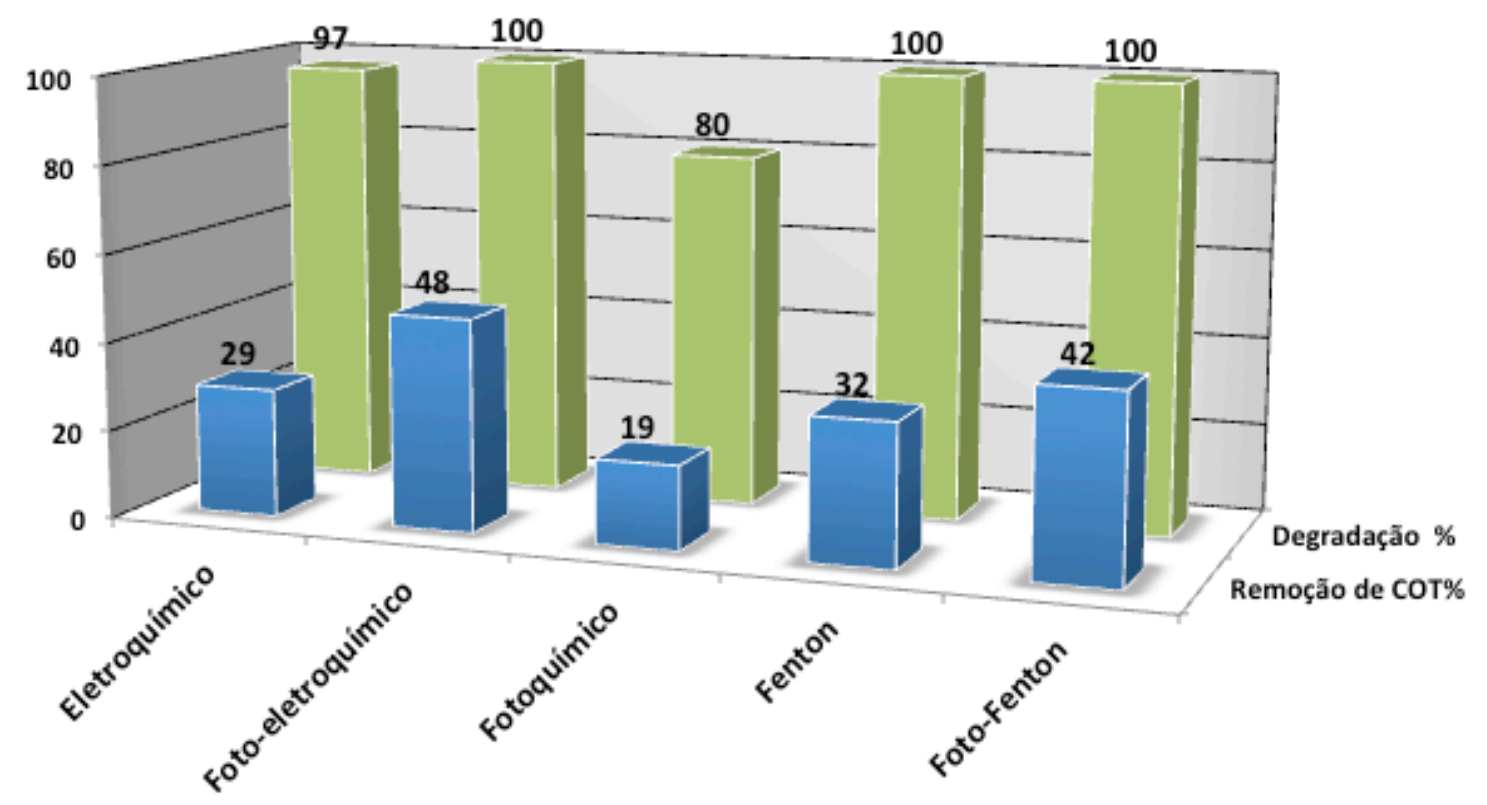

Figura 8.1 - Eficiência de degradação após 30 min e remoção de COT de SMX por vários processos, após 120 min de tratamento.

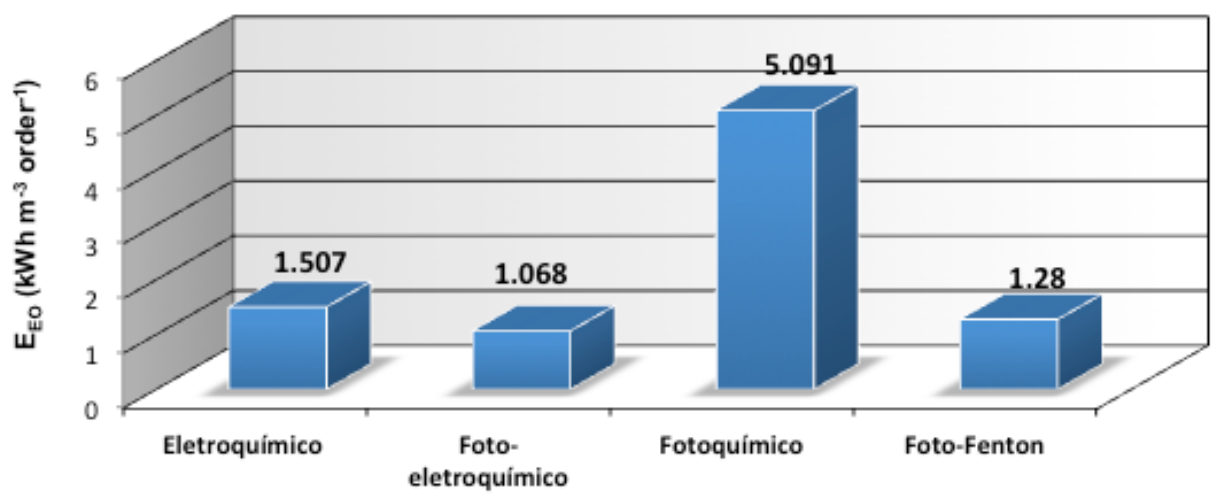

Figura 8.2 - Avaliação de energia por ordem para a degradação de SMX por meio de vários processos.

respectivamente. A redução de COT foi mais eficiente pela combinação de luz com o processo eletroquímico e Fenton. É óbvio que o processo fotoquímico é menos eficiente em termos de redução de COT do que outros.

A Figura 8.2 mostra o consumo de energia para os processos, e está implícito que os processos eletroquímico foto assistido e foto-Fenton foram energeticamente mais eficientes que os processos eletroquímico e fotoquímico, por causa dos elevados valores de constantes de velocidade da reação e potencial da célula e da lâmpada. Durante os processos 
eletroquímico e eletroquímico foto assistido, o $\mathrm{E}_{\mathrm{EO}}$ dependeu dos parâmetros experimentais como densidade de corrente, concentração de $\mathrm{NaCl}$ e $\mathrm{pH}$, que são os agentes responsáveis para aumentar a constante de velocidade e a eficiência dos processos. $\mathrm{O}$ valor de $\mathrm{E}_{\mathrm{EO}}$ para $\mathrm{O}$ processo eletroquímico foto assistido é baseado no potencial aplicado para o sistema, mas quando se agrega ao potencial da lâmpada, então o valor aumenta significativamente.

A avaliação dos intermediários de degradação de SMX revelou que diversos produtos devem ser de reação de SMX por diferentes espécie oxidante em vários processos de degradação. Como no processo eletroquímico, o radical hidroxila e o cloro ativo são responsáveis pela destruição de SMX, similarmente no processo eletroquímico foto assistido, são vários agentes oxidantes gerados como $\mathrm{Cl}_{2} \bullet, \mathrm{Cl} \bullet, \mathrm{OH} \bullet$ e $\mathrm{O}_{2}{ }^{\bullet-}$ que atacam os anéis e a ligação entre anéis, transformando o SMX para os fragmentos respectivos. Os mecanismos de degradação por processos eletroquímico e eletroquímico foto assistido são diferente por causa de diferentes espécies oxidante, mas nas dois processos vários compostos organoclorados também foram identificados, mas é muito interessante verificar que há menos compostos organoclorados detectados nas amostras de processo eletroquímico foto assistidos do que apenas eletroquímico. Nos processos eletroquímicos, alguns hidrocarbonetos de cadeia aberta e de baixo peso molecular foram identificados que indica destruição completa de SMX.

Da mesma forma, os processos Fenton e foto-Fenton produzem radical hidroxila e, dessa forma, podem gerar intermediários semelhantes e segue uma rota quase igual. Sobre os intermediários de degradação de SMX formados durante degradação com Fenton, não foi possível concluir que são exatamente os mesmos compostos formados pelo processo de fotoFenton, porém, sem dúvida, são compostos isômeros com a entrada de uma ou duas hidroxilas na molécula do SMX.

No processo fotoquímico, também foram obtidos alguns compostos diferentes do que os encontrados em outros processos, tais como $\mathrm{m} / \mathrm{z}=301,322$ e 338. Todavia, é mais interessante a formação de 4 intermediários em comum $(\mathrm{m} / \mathrm{z}=288,270,156$ e 98), mas em todos os processos o fragmento $\mathrm{m} / \mathrm{z}=110$ é comum em processos eletroquímicos e Fenton e foto-Fenton, exceto no fotoquímico.

Os processos que utilizam radiação UV dependem fortemente da intensidade e do comprimento de onda da radiação. Esses parâmetros são completamente ignorados quando a avaliação cinética é aplicada, assim, não é possível comparar razoavelmente esses diversos processos apenas com base no tempo. Portanto, as vantagens e as desvantagens de cada processo devem ser consideradas, além da comparação dos parâmetros descritos acima (ANDREOZZI et al., 1999). 
Uma grande vantagem dos processos baseados na oxidação fotolítica é a possibilidade de operarem em condições de temperatura e pressão normais, bem como a de utilizarem eficientemente a luz solar ou até mesmo a luz ultravioleta para a irradiação, o que deve resultar em uma considerável economia, especialmente para as operações em planta piloto. Por outro lado, os métodos fotolíticos podem resultar em maior necessidade energética (SHEMER et al., 2006).

Com relação aos processos Fenton e foto-Fenton, os reagentes são seguros para manusear e não agridem o meio ambiente. Equipamentos complexos não são exigidos, o que pode ajudar na transição de escala de laboratório para uma planta piloto (KAVITHA; PALANIVELU, 2004).

Uma grande desvantagem dos processos Fenton e foto-Fenton é a forte dependência do pH da solução e das concentrações de peróxido de hidrogênio e de ferro. A necessidade de pH ácido (2-4), com o intuito de se obter uma alta eficiência de tratamento, é uma das desvantagens do processo. Os sais de ferro podem ser considerados uma fonte de poluição, e por isso a neutralização é essencial, a fim de precipitar o ferro dissolvido como hidróxido ferroso/férrico. Portanto, a formação de lodo de ferro pode causar problemas de deposição no meio ambiente (MELO et al., 2009).

Os processos eletroquímico e eletroquímico foto assistido apresentaram uma maior eficiência de degradação e remoção de COT e de SMX. A grande vantagem desses processos é que a degradação pode ocorrer via radicais hidroxila, ou por elétrons que são ambientalmente corretos, mas corre-se um grande risco no uso de sal como eletrólito suporte, podendo gerar alguns compostos clorados que talvez sejam mais tóxicos do que o composto principal.

\subsection{Conclusões}

Os resultados apresentados nesta tese mostram que antibiótico SMX, pode ser eliminado por meio de várias métodos, ou seja, eletroquímico, eletroquímico foto assistido, fotoquímico, Fenton e foto-Fenton. Os resultados mostraram que o SMX é quase completamente removido em $30 \mathrm{~min}$ de tratamento por processos eletroquímico, eletroquímico foto assistido, Fenton e foto-Fenton, entretanto o processo fotoquímico é mais lento, e a remoção completa ocorre somente após 120 minutos.

O processo eletroquímico foto assistido foi mais eficiente, sendo $48 \%$ de COT removido, provavelmente devido à geração de vários oxidante fortes, tais como $\mathrm{Cl}_{2} \bullet, \mathrm{Cl} \bullet, \cdot \mathrm{OH}$ 
e lacunas. Essa técnica também apresenta melhor desempenho quando comparada às técnicas fotoquímica e eletroquímica e Fenton, aplicadas estas de forma independentes.

A eficiência dos métodos eletroquímico e eletroquímico foto assistido dependem da densidade de corrente e da concentração de $\mathrm{NaCl}$, o que tornam mais eficiente para a degradação e a remoção de COT, isso possivelmente em razão do aumento do transporte de massa e devido a uma maior formação de espécies oxidantes. A temperatura teve pouca influência sobre a degradação, e o $\mathrm{pH}$ ácido foi mais favorável para a remoção de SMX e COT. Estudos de cinética demonstraram que os processos seguiram uma cinética de pseudoprimeira ordem e a constante de velocidade foi melhor com o aumento da densidade de corrente e concentração de $\mathrm{NaCl}$. Os valores da energia por ordem $\left(\mathrm{E}_{\mathrm{EO}} / \mathrm{kWh} \mathrm{m}^{-3}\right.$ ordem $\left.^{-1}\right)$ para a degradação do SMX foram mais elevados para os processos eletroquímicos do que para o eletroquímico foto assistido, além de diretamente proporcional à densidade de corrente e inversamente proporcional à concentração de $\mathrm{NaCl}$.

Foi possível identificar os intermediários da degradação de SMX durante o processo eletroquímico e eletroquímico foto assistido, sendo que, de um modo geral, ocorreu a abertura do anel oxazolídico e do anel benzênico, de acordo com o ataque de radicais hidroxila e cloro. Os dois anéis foram identificados separadamente por causa da ruptura da ligação N-S, seguida de posteriores oxidações dos grupos aromáticos remanescentes. Os compostos organoclorados também foram identificados, sendo estes responsáveis pelo possível aumento da toxicidade de solução. O SMX foi parcialmente mineralizado, de modo a possibilitar a identificação de alguns íons inorgânicos, tais como $\mathrm{NO}_{3}{ }^{-} \mathrm{e} \mathrm{SO}_{4}{ }^{2-}$.

O processo fotoquímico apresenta-se como uma alternativa eficiente para a degradação de SMX em solução aquosa. Os resultados revelaram que a temperatura tem pequeno efeito sobre a remoção do SMX, já o $\mathrm{pH}$ e a concentração inicial de SMX influenciaram fortemente o processo de degradação. Também o SMX pode ser degradado eficientemente em $\mathrm{pH}$ 2-5. O processo de degradação seguiu uma cinética de pseudo-primeira ordem. A energia elétrica por ordem é diretamente proporcional à concentração de SMX, e inversamente proporcional com a temperatura, havendo um consumo menor de energia em pH ácido. Os intermediários de degradação foram detectados pela técnica de CLAE-EM-TOF, o que tornou possível observar alguns produtos que não foram relatados na literatura. Diferentes rotas da possível degradação de SMX foram apresentadas. As espécies mineralizadas $\left(\mathrm{NO}_{3}{ }^{-}, \mathrm{NH}_{4}^{+}\right.$e $\left.\mathrm{SO}_{4}{ }^{2-}\right)$ também foram detectadas em pequena quantidade na solução. A remoção de COT foi muito baixa, portanto, a combinação desses processos com outro processo oxidativo avançado, como o Fenton, pode melhorar a eficiência para 
mineralização do SMX.

Os processos Fenton e foto-Fenton degradaram eficientemente o SMX em meio aquoso. Vários parâmetros importantes avaliados foram as concentrações das espécies $\mathrm{H}_{2} \mathrm{O}_{2}$,

e $\mathrm{Fe}^{2+}$, pois esses reagentes influenciaram significativamente no tratamento. O SMX praticamente foi degradado e 28 e 42\% do COT removido após 120 minutos de reação em processo Fenton e foto-Fenton respectivamente, para o SMX com concentração inicial de 200

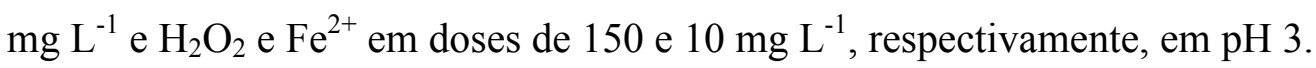

Os resultados indicaram que a condição básica foi desfavorável em termos da degradação do SMX, enquanto que para os valores de $\mathrm{pH}$ menores do que 7 , tal degradação foi favorável. Similarmente, a temperatura também aumenta a eficiência da degradação e da remoção do COT. Os dados de CLAE-EM e de cromatografia iônica mostraram que sob as condições experimentais realizadas neste trabalho, foi observada a ocorrência de uma mineralização incompleta do antibiótico sulfametoxazol. No entanto, foram identificados pequenos fragmentos com $\mathrm{m} / \mathrm{z}=98,108,156$, os quais podem ser transformados em $\mathrm{CO}_{2} \mathrm{e}$ $\mathrm{H}_{2} \mathrm{O}$. Esses resultados oferecem a possibilidade de tratamento dos efluentes hospitalares contendo antibiótico como SMX por meio das técnicas eletroquímico e eletroquímico foto assistido, fotoquímico, Fenton e foto-Fenton.

\subsection{Perspectivas Futuras}

A partir dos resultados do presente trabalho e de suas conclusões, podem ser propostas os seguintes tópicos:

- Avaliar a toxicidade dos produtos de degradação dos antibióticos SMX;

- Estudar a degradação de outros antibióticos que são amplamente utilizados ao redor do mundo por vários métodos, de forma comparativa;

- Estudar a viabilidade e o potencial de aplicação destes processos em diferentes matrizes, tais como, como urina artificial e água potável;

- Adaptar os processos para tratamento de efluentes reais, tais como, dos hospitais e indústrias farmacêuticas;

- Empregar a degradação eletroquímica e eletroquímica foto assistida em combinação com os processos Fenton e foto-Fenton para o efluente real de um hospital (em pequena e grande escala) ou inverter a ordem dos tratamentos. Para isso seria necessário testar previamente as possíveis aplicações;

- Aplicar essas metodologias em meu país de origem (Paquistão) para os efluentes dos hospitais, clínicas veterinárias e indústrias farmacêuticas; 


\section{Referências Bibliográficas}

ABDELMALEK, F.; TORRES, R. A.; COMBET, E.; PETRIER, C.; PULGARIN, C.; ADDOU, A. Gliding Arc Discharge (GAD) assisted catalytic degradation of bisphenol A in solution with ferrous ions. Separation and Purification Technology, v. 63, n. 1, p. 30-37, 2008.

ABELLÁN, M. N.; BAYARRI, B.; GIMÉNEZ, J.; COSTA, J. Photocatalytic degradation of sulfamethoxazole in aqueous suspension of TiO2. Applied Catalysis B: Environmental, v. 74, n. 3-4, p. 233-241, 2007.

AFRICA, A.; DALVIE, M.; LONDON, L. Usage of endocrine disrupting pesticides in South African agriculture. Epidemiology, v. 114, n. 1, p. s331-s311, 2006.

ALONSO-MAGDALENA, P.; MORIMOTO, S.; RIPOLL, C.; FUENTES, E.; NADAL, A. The estrogenic effect of bisphenol A disrupts pancreatic beta-cell function in vivo and induces insulin resistance. Environmental Health Perspectives, v. 114, p. 106-112, 2006.

ALVES, P. A.; MALPASS, G. R. P.; JOHANSEN, H. D.; AZEVEDO, E. B.; GOMES, L. M.; VILELA, W. F. D.; MOTHEO, A. J. Photo-assisted electrochemical degradation of real textile wastewater. Water Science and Technology, v. 61, p. 491-498, 2010.

ANDREOZZI, R.; CAPRIO, V.; INSOLA, A.; MAROTTA, R. Advanced oxidation processes ( AOP ) for water purification and recovery. Catalysis Today, v. 53, p. 51-59, 1999.

AQUINO NETO, S.; DE ANDRADE, A. R. Electrooxidation of glyphosate herbicide at different DSA ${ }^{\circledR}$ compositions: $\mathrm{pH}$, concentration and supporting electrolyte effect.

Electrochimica Acta, v. 54, n. 7, p. 2039-2045, 2009.

ARSLAN-ALATON, I.; DOGRUEL, S. Pre-treatment of penicillin formulation effluent by advanced oxidation processes. Journal of Hazardous Materials, v. 112, n. 1-2, p. 105-13, 2004.

ARSLAN-ALATON, I.; GURSES, F. Photo-Fenton-like and photo-fenton-like oxidation of Procaine Penicillin G formulation effluent. Journal of Photochemistry and Photobiology A: Chemistry, v. 165, n. 1-3, p. 165-175, 2004.

BAIRD, C. Environmental chemistry. 2nd ed. New York: Freeman and Company, 1999.

BARCELÓ, D. Emerging pollutants in water analysis. TrAC Trends in Analytical Chemistry, v. 22, n. 10, p. xiv-xvi, 2003.

BAUTITZ, I. R.; NOGUEIRA, R. F. . Photodegradation of lincomycin and diazepam in sewage treatment plant effluent by photo-Fenton process. Catalysis Today, v. 151, p. 94-99, 2010 . 
BAUTITZ, I. R.; NOGUEIRA, R. F. P. Degradation of tetracycline by photo-Fenton process-Solar irradiation and matrix effects. Journal of Photochemistry and Photobiology A: Chemistry, v. 187, n. 1, p. 33-39, 2007.

BEHNAJADY, M. A.; VAHID, B.; MODIRSHAHLA, N.; SHOKRI, M. Evaluation of electrical energy per order (EEO) with kinetic modeling on the removal of Malachite Green by US/UV/H2O2 process. Desalination, v. 249, n. 1, p. 99-103, 2009.

BENKELBERG, H.-J.; WARNECK, P. Photodecomposition of iron(III) hydroxo and sulfato complexes in aqueous solution: wavelength dependence of $\mathrm{OH}$ and $\mathrm{SO}^{4-}$ Quantum Yields. The Journal of Physical Chemistry, v. 99, n. 14, p. 5214-5221, 1995.

BIGSBY, R.; CHAPIN, R. E.; DASTON, G. P.; DAVIS, B. J.; GORSKI, J.; GRAY, L. E.; HOWDESHELL, K. L.; ZOELLER, R. T.; VOM SAAL, F. S. Evaluating the effects of endocrine disruptors on endocrine function during development. Environmental Health Perspectives, v. 107, n. 4, p. 613-8, 1999.

BILA, D. M.; DEZOTTI, M. Desreguladores endócrinos no meio ambiente: efeitos e conseqüências. Química Nova, v. 30, n. 3, p. 651-666, 2007.

BIRKHØJ, M.; NELLEMANN, C.; JARFELT, K.; JACOBSEN, H.; ANDERSEN, H. R.; DALGAARD, M.; VINGGAARD, A. M. The combined antiandrogenic effects of five commonly used pesticides. Toxicology and Applied Pharmacology, v. 201, n. 1, p. 10-20, 2004.

BOBU, M.; YEDILER, A.; SIMINICEANU, I.; SCHULTE-HOSTEDE, S. Degradation studies of ciprofloxacin on a pillared iron catalyst. Applied Catalysis B: Environmental, v. 83, n. 1-2, p. 15-23, 2008.

BOLTON, J. R.; BIRCHER, K. G.; TUMAS, W.; TOLMAN, C. A. Figures-of-merit for the technical development and application of advanced oxidation technologies for both electricand solar-driven systems (IUPAC Technical Report). Pure and Applied Chemistry, v. 73, n. 4, p. 627-637, 2001.

BONFATTI, F.; DE BATTISTI, A.; FERRO, S.; LODI, G.; OSTI, S. Anodic mineralization of organic substrates in chloride-containing aqueous media. Electrochimica Acta, v. 46, n. 23, p. 305-314, 2000.

BOREEN, A. L.; ARNOLD, W. A; MCNEILL, K. Photochemical fate of sulfa drugs in the aquatic environment: sulfa drugs containing five-membered heterocyclic groups. Environmental Science \& Technology, v. 38, n. 14, p. 3933-40, 2004.

BRAIN, R. A.; HANSON, M. L.; SOLOMON, K. R.; BROOKS, B. W. Aquatic plants exposed to pharmaceuticals: effects and risks. In: WHITACRE D. M. (Ed.); Reviews of environmental contamination and toxicology. New York: Springer, v. 192, p.67-115, 2008.

BRAIN, R. A.; JOHNSON, D. J.; RICHARDS, S. M.; HANSON, M. L.; SANDERSON, H.; LAM, M. W.; YOUNG, C.; MABURY, S. A.; SIBLEY, P. K.; SOLOMON, K. R.; Microcosm evaluation of the effects of an eight pharmaceutical mixture to the aquatic 
macrophytes Lemna gibba and Myriophyllum sibiricum. Aquatic Toxicology, v. 70, n. 1, p. 23-40, 2004.

BRITTO, J. M.; RANGEL, M. DO C. Processos avançados de oxidação de compostos fenólicos em efluentes industriais. Química Nova, v. 31, n. 1, p. 114-122, 2008.

BROWN, K. D.; KULIS, J.; THOMSON, B.; CHAPMAN, T. H.; MAWHINNEY, D. B. Occurrence of antibiotics in hospital, residential, and dairy effluent , municipal wastewater, and the Rio Grande in New Mexico. Science of the Total Environment, v. 366, p. 772-783, 2006.

BURBANO, A. A.; DIONYSIOU, D. D.; SUIDAN, M. T.; RICHARDSON, T. L. Oxidation kinetics and effect of $\mathrm{pH}$ on the degradation of MTBE with Fenton reagent. Water Research, v. 39, n. 1, p. 107-18, 2005.

CARNEIRO, P. A; OSUGI, M. E.; FUGIVARA, C. S.; BORALLE, N.; FURLAN, M.; ZANONI, M. V. B. Evaluation of different electrochemical methods on the oxidation and degradation of Reactive Blue 4 in aqueous solution. Chemosphere, v. 59, n. 3, p. 431-9, 2005.

CARNEIRO, P. A.; OSUGI, M. E.; SENE, J. J.; ANDERSON, M. A.; ZANONI, M. V. B. Evaluation of color removal and degradation of a reactive textile azo dye on nanoporous $\mathrm{TiO} 2$ thin-film electrodes. Electrochimica Acta, v. 49, n. 22-23, p. 3807-3820, 2004.

CATANHO, M.; MALPASS, G. R.P.; MOTHEO, A. J. Avaliação dos tratamentos eletroquímico e fotoeletroquímico na degradação de corantes têxteis. Química Nova, v. 29, n. 5, p. 983-989, 2006a.

CATANHO, M.; MALPASS, G. R. P.; MOTHEO, A. J. Photoelectrochemical treatment of the dye reactive red 198 using DSA ${ }^{\circledR}$ electrodes. Applied Catalysis B: Environmental, v. 62, n. 3-4, p. 193-200, 2006b.

CATER, S. R.; STEFAN, M. I.; BOLTON, J. R.; SAFARZADEH-AMIRI, A. UV/ $/ \mathrm{H}_{2} \mathrm{O}_{2}$ Treatment of Methyl tert-Butyl Ether in contaminated waters. Environmental Science \& Technology, v. 34, p. 659-662, 2000.

CHEN, S.; ZHENG, Y.; WANG, S.; CHEN, X. Ti/RuO2-Sb2O5-SnO2 electrodes for chlorine evolution from seawater. Chemical Engineering Journal, v. 172, n. 1, p. 47-51, 2011.

CHEN, Y.; WU, F.; LIN, Y.; DENG, N.; BAZHIN, N.; GLEBOV, E. Photodegradation of glyphosate in the ferrioxalate system. Journal of Hazardous Materials, v. 148, n. 1-2, p. 360-5, 2007.

CHOI, K. J.; KIM, S. G.; KIM, C. W.; KIM, S. H. Determination of antibiotic compounds in water by on-line SPE-LC/MSD. Chemosphere, v. 66, n. 6, p. 977-984, 2007.

COMNINELLIS, C. Electrocatalysis in the electrochemical conversion/combustion of organic pollutants for waste water treatment. Electrochimica Acta, v. 39, n. 11-12, p. 1857-1862, 1994. 
COMNINELLIS, C.; DEBATTISTI, A. Electrocatalysis in anodic oxidation of organics with simultaneous oxygen evolution. Journal De Chimie Physique Et De Physico-Chimie Biologique, v. 93, p. 673-679, 1996.

COMNINELLIS, C.; NERINI, A. Anodic oxidation of phenol in the presence of $\mathrm{NaCl}$ for wastewater treatment. Journal of Applied Electrochemistry, v. 25, n. 1, p. 23-28, 1995.

DANESHVAR, N.; ALEBOYEH, A.; KHATAEE, A. R. The evaluation of electrical energy per order (EEo) for photooxidative decolorization of four textile dye solutions by the kinetic model. Chemosphere, v. 59, p. 761-767, 2005.

DANTAS, R. F.; CONTRERAS, S.; SANS, C.; ESPLUGAS, S. Sulfamethoxazole abatement by means of ozonation. Journal of Hazardous Materials, v. 150, n. 3, p. 790-4, 2008.

DIAMANTI-KANDARAKIS, E.; BOURGUIGNON, J. ;; GIUDICE, L. ;; HAUSER, R.; PRINS, G.S.; SOTO, A.M.; ZOELLER, R.T.; GORE, A.C. Endocrine-disrupting chemicals: an endocrine society scientific statement. Endocrine Reviews, v. 30, p. 293, 2009.

DICKERSON, S. M.; GORE, A. C. Estrogenic environmental endocrine-disrupting chemical effects on reproductive neuroendocrine function and dysfunction across the life cycle.

Reviews in Endocrine \& Metabolic Disorders, v. 8, p. 143-159, 2007.

DIRANY, A.; SIRÉS, I.; OTURAN, N.; OTURAN, M. A. Electrochemical abatement of the antibiotic sulfamethoxazole from water. Chemosphere, v. 81, n. 5, p. 594-602, 2010.

U.S. DEPARTMENT OF DEFENSE (DoD), Emerging Contaminants. 2006, Disponível em: $<$ http://www.denix.osd.mil/denix/Public/Library/MERIT/merit.html $>$ Acesso em: 31 july 2013.

DODD, M. C.; HUANG, C.-H. Transformation of the antibacterial agent sulfamethoxazole in reactions with chlorine: kinetics, mechanisms, and pathways. Environmental Science \& Technology, v. 38, n. 21, p. 5607-15, 2004.

DOKIANAKIS, S. N.; KORNAROS, M. E.; LYBERATOS, G. On the effect of pharmaceuticals on bacterial nitrite oxidation. Water Science and Technology, v. 50, n. 5, p. 341-346, 2004.

EL-DESOKY, H. S.; GHONEIM, M. M.; EL-SHEIKH, R.; ZIDAN, N. M. Oxidation of Levafix CA reactive azo-dyes in industrial wastewater of textile dyeing by electro-generated Fenton's reagent. Journal of Hazardous Materials, v. 175, p. 858-865, 2010.

ELLIS, J. B. Pharmaceutical and personal care products (PPCPs) in urban receiving waters. Environmental Pollution, v. 144, p. 184-189, 2006.

ELMOLLA, E.; CHAUDHURI, M. Optimization of Fenton process for treatment of amoxicillin, ampicillin and cloxacillin antibiotics in aqueous solution. Journal of Hazardous Materials, v. 170, n. 2-3, p. 666-72, 2009. 
ELMOLLA, E. S.; CHAUDHURI, M. Degradation of the antibiotics amoxicillin, ampicillin and cloxacillin in aqueous solution by the photo-Fenton process. Journal of Hazardous Materials, v. 172, p. 1476-1481, 2009.

EMAMI, F.; TEHRANI-BAGHA, A. R.; GHARANJIG, K.; MENGER, F. M. Kinetic study of the factors controlling Fenton-promoted destruction of a non-biodegradable dye.

Desalination, v. 257, n. 1-3, p. 124-128, 2010.

ESPLUGAS, S.; BILA, D. M.; KRAUSE, L. G. T.; DEZOTTI, M. Ozonation and advanced oxidation technologies to remove endocrine disrupting chemicals (EDCs) and pharmaceuticals and personal care products (PPCPs) in water effluents. Journal of Hazardous Materials, v. 149, n. 3, p. 631-42, 2007.

FENG, Y.; SMITH, D. W.; BOLTON, J. R. Photolysis of aqueous free chlorine species ( $\mathrm{HOCl}$ and $\mathrm{OCl}-$ ) with $254 \mathrm{~nm}$ ultraviolet light. Journal of Environmental Engineering and Science, v. 6, n. 3, p. 277-284, 2007.

FENTON, H. J. H. Oxidation of tartaric acid in presence of iron. Journal of the Chemical Society Transactions, v. 65, p. 899, 1894.

FÓTI, G. Oxidation of organics by intermediates of water discharge on $\mathrm{IrO}[\mathrm{sub} 2]$ and synthetic diamond anodes. Electrochemical and Solid-State Letters, 1999.

FROMME, H.; OTTO, T.; PILZ, K.; NEUGEBAUER, F. Levels of synthetic musks; bromocyclene and PCBs in eel (Anguilla anguilla) and PCBs in sediment samples from some waters of Berlin/Germany. Chemosphere, v. 39, p. 1723-1735, 1999.

GHISELLI, G.; JARDIM, W. F. Interferentes endócrinos no ambiente. Química Nova, v. 30, n. 3, p. 695-706, 2007.

GIOKAS, D. L.; VLESSIDIS, A. Application of a novel chemometric approach to the determination of aqueous photolysis rates of organic compounds in natural waters. Talanta, v. 71, p. 288-295, 2007.

GOBEL, A.; ATHOMSEN, A.; MCARDELL, C. S.; JOSS, A.; GIGER, W. Occurrence and sorption behavior of sulfonamides, macrolides, and trimethoprim in activated sludge treatment. Environmental Science Technology, v. 39, n. 11, p. 3981-3989, 2005.

GOBEL, A.; MCARDELL, C. S.; JOSS, A.; SIEGRIST, H.; GIGER, W. Fate of sulfonamides, macrolides, and trimethoprim in different wastewater treatment technologies. Science of the Total Environment, v. 372, n. 2-3, p. 361-371, 2007.

GOBEL, A.; MCARDELL, C. S.; SUTER, M. J. F.; GIGER, W. Trace determination of macrolide and sulfonamide antimicrobials, a human sulfonamide metabolite, and trimethoprim in wastewater using liquid chromatography coupled to electrospray tandem mass spectrometry. Analytical Chemistry, v. 76, n. 16, p. 4756-4764, 2004.

GOMES, L.; MIWA, DOUGLAS W; MALPASS, G. R. P.; MOTHEO, A. J. Electrochemical Degradation of the Dye Reactive Orange 16 using Electrochemical Flow-Cell. Journal of Brazilian Chemical Society, v. 22, n. 7, 2011. 
GONZÁLEZ, O.; SANS, C.; ESPLUGAS, S. Sulfamethoxazole abatement by photo-Fenton toxicity, inhibition and biodegradability assessment of intermediates. Journal of Hazardous Materials, v. 146, n. 3, p. 459-64, 2007.

GROVER, D. P.; ZHANG, Z. L.; READMAN, J. W.; ZHOU, J. L. A comparison of three analytical techniques for the measurement of steroidal estrogens in environmental water samples. Talanta, v. 78, n. 3, p. 1204-10, 2009.

GUINEA, E.; BRILLAS, E.; CENTELLAS, F.; CAÑIZARES, P.; RODRIGO, MANUEL A.; SÁEZ, C. Oxidation of enrofloxacin with conductive-diamond electrochemical oxidation, ozonation and Fenton oxidation: a comparison. Water Research, v. 43, p. 2131-2138, 2009.

HAARSTAD, K.; BORCH, H. Indications of hormonally active substances in municipal solid waste leachate: mobilization and effect studies from Sweden and Norway. Journal of Environmental Science and Health. Part A, Toxic/Hazardous Substances \& Environmental Engineering, v. 39, p. 901-913, 2004.

HAMMAMI, S.; BELLAKHAL, N.; OTURAN, N.; OTURAN, M. A.; DACHRAOUI, M. Degradation of Acid Orange 7 by electrochemically generated $(*) \mathrm{OH}$ radicals in acidic aqueous medium using a boron-doped diamond or platinum anode: a mechanistic study. Chemosphere, v. 73, p. 678-684, 2008.

HOMEM, V.; SANTOS, L. Degradation and removal methods of antibiotics from aqueous matrices--a review. Journal of Environmental Management, v. 92, n. 10, p. 2304-47, 2011.

IBANEZ, J. G.; RAJESHWAR, K.; SWAIN, G. M. Electrochemistry and the environment. Journal of Applied Electrochemistry, v. 24, p. 1077-1091, 1994.

JELIC, A.; GROS, M.; GINEBREDA, A.; CESPEDES-SÁNCHEZ, R.; VENTURA, F.; PETROVIC, M.; BARCELO, D. Occurrence, partition and removal of pharmaceuticals in sewage water and sludge during wastewater treatment. Water Research, v. 45, p. 1165-1176, 2011.

JIAO, S.; ZHENG, S.; YIN, D.; WANG, L.; CHEN, L. Aqueous oxytetracycline degradation and the toxicity change of degradation compounds in photoirradiation process. Journal of Environmental Sciences, v. 20, n. 7, p. 806-813, 2008.

JIAO, S.; ZHENG, S.; YIN, D.; WANG, L.; CHEN, L. Aqueous photolysis of tetracycline and toxicity of photolytic products to luminescent bacteria. Chemosphere, v. 73 , n. 3, p. 377$82,2008$.

JONES, H. O. A.; VOULVOULIS, N.; LESTER, J. N. Human pharmaceuticals in wastewater preatment Processes. Critical Reviews in Environmental Science and Technology, v. 35, n. 4, p. 401-427, 2005.

KARLSSON, S. A.; OBERG, G. UV-light induced mineralization of organic matter bound chlorine in Lake Bjän, Sweden--a laboratory study. Chemosphere, v. 52, n. 2, p. 463-469, 2003. 
KAVITHA, V.; PALANIVELU, K. The role of ferrous ion in Fenton and photo-Fenton processes for the degradation of phenol. Chemosphere, v. 55, n. 9, p. 1235-43, 2004.

KIM, Y.; CHOI, K.; JUNG, J.; PARK, S.; KIM, PAN-GYI.; PARK, J. Aquatic toxicity of acetaminophen, carbamazepine, cimetidine, diltiazem and six major sulfonamides, and their potential ecological risks in Korea. Environment International, v. 33, n. 3, p. 370-5, 2007.

KONIECKI, D.; WANG, R.; MOODY, R. P.; ZHU, J. Phthalates in cosmetic and personal care products: concentrations and possible dermal exposure. Environmental Research, v. 111, p. 329-336, 2011.

KUMAR, A.; XAGORARAKI, I. Pharmaceuticals, personal care products and endocrinedisrupting chemicals in U.S. surface and finished drinking waters: a proposed ranking system. The Science of the Total Environment, v. 408, p. 5972-5989, 2010.

KÜMMERER, K. Pharmaceuticals in the environment: sources, fate, effects and risks. 3rd ed. Berlin: Springer, 2008. p. 3-17.

KÜMMERER, K.; HENNINGER, A. Promoting resistance by the emission of antibiotics from hospitals and households into effluent. Clinical microbiology and Infection, v. 9, p. 1203-1214, 2003.

LAI, H.-T.; LIN, J.-J. Degradation of oxolinic acid and flumequine in aquaculture pond waters and sediments. Chemosphere, v. 75, n. 4, p. 462-8, 2009.

LAPWORTH, D. J.; BARAN, N.; STUART, M. E.; WARD, R. S. Emerging organic contaminants in groundwater: A review of sources, fate and occurrence. Environmental Pollution, v. 163, p. 287-303, 2012.

LARSSON, D. G. J.; DE PEDRO, C.; PAXEUS, N. Effluent from drug manufactures contains extremely high levels of pharmaceuticals. Journal of Hazardous Materials, v. 148, p. 751-755, 2007.

LESTER, Y.; GOZLAN, I.; AVISAR, D.; MAMANE, H. Photodegradation of sulphadimethoxine in water by medium pressure UV lamp. Water Science and Technology, v. 58, n. 5 , p. $1147-54,2008$.

LEVINE, A. D.; MEYER, M. T.; KISH, G. Evaluation of the persistence of micropollutants through pure-oxygen activated sludge nitrification and denitrification. Water Environment Research, v. 78, n. 11, p. 2276-2285, 2006.

LIN, H.; NIU, J.; XU, J.; LI, Y.; PAN, Y. Electrochemical mineralization of sulfamethoxazole by $\mathrm{Ti} / \mathrm{SnO} 2-\mathrm{Sb} / \mathrm{Ce}-\mathrm{PbO} 2$ anode: Kinetics, reaction pathways, and energy cost evolution. Electrochimica Acta, v. 97, p. 167-174, 2013.

LUCAS, M. S.; PERES, J. A. Decolorization of the azo dye reactive black 5 by Fenton and photo-Fenton oxidation. Dyes and Pigments, v. 71, n. 3, p. 236-244, 2006.

LUNING PRAK, D. J.; MILEWSKI, E. A.; JEDLICKA, E. E.; KERSEY, A. J.;

O'SULLIVAN, D. W. Influence of $\mathrm{pH}$, temperature, salinity, and dissolved organic matter on 
the photolysis of 2,4-dinitrotoluene and 2,6-dinitrotoluene in seawater. Marine Chemistry, v. 157, p. 233-241, 2013.

MA, Y.-S.; SUNG, C.-F.; LIN, J.-G. Degradation of carbofuran in aqueous solution by ultrasound and Fenton processes: Effect of system parameters and kinetic study. Journal of Hazardous Materials, v. 178, p. 320-325, 2010.

MALPASS, G. R. P.; MIWA, D. W.; GOMES, L.; AZEVEDO, E B.; VILELA, W. F. D.; FUKUNAGA, M. T.; GUIMARÃES, J. R.; BERTAZZOLI, R.; MACHADO, S. A. S.; MOTHEO, A. J. Photo-assisted electrochemical degradation of the commercial herbicide atrazine. Water Science and Technology, v. 62, n. 12, p. 2729-36, 2010.

MALPASS, G. R. P.; MIWA, D. W.; MACHADO, S. A S.; OLIVI, P.; MOTHEO, A J. Oxidation of the pesticide atrazine at DSA electrodes. Journal of Hazardous Materials, v. 137, n. 1, p. 565-72, 2006.

MALPASS, G. R. P.; MIWA, D. W.; MACHADO, S. A. S.; MOTHEO, A. J. Decolourisation of real textile waste using electrochemical techniques: effect of electrode composition.

Journal of Hazardous Materials, v. 156, n. 1-3, p. 170-7, 2008.

MALPASS, G. R. P.; MIWA, D. W.; MIWA, A. C. P.; MACHADO, S. A. S.; MOTHEO, A. J. Study of photo-assisted electrochemical degradation of carbaryl at dimensionally stable anodes (DSA). Journal of Hazardous Materials, v. 167, n. 1-3, p. 224-9, 2009.

MALPASS, G. R. P.; MIWA, D. W.; MORTARI, D. A.; MACHADO, S. A. S.; MOTHEO, A. J. Decolorisation of real textile waste using electrochemical techniques: effect of the chloride concentration. Water Research, v. 41, n. 13, p. 2969-77, 2007.

MALPASS, G. R. P.; MIWA, D. W.; SANTOS, R. L.; VIEIRA, E. M.; MOTHEO, A. J. Unexpected toxicity decrease during photoelectrochemical degradation of atrazine with $\mathrm{NaCl}$. Environmental Chemistry Letters, v. 10, n. 2, p. 177-182, 2011.

MARTÍNEZ-HUITLE, C. A.; BRILLAS, E. Electrochemical alternatives for drinking water disinfection. Angewandte Chemie (International ed. in English), v. 47, p. 1998-2005, 2008 .

MASTERS, P. A.; O’BRYAN, T. A.; ZURLO, J.; MILLER, D. Q.; JOSHI, N. Trimethoprimesulfamethoxazole revisited. Archives of Internal Medicine, v. 163, n. 4, p. 402-410, 2003.

MCCLELLAN, K.; HALDEN, R. U. Pharmaceuticals and personal care products in archived U.S. biosolids from the 2001 EPA National Sewage Sludge Survey. Water Research, v. 44, p. $658-668,2010$.

MELO, S. A. S.; TROVÓ, A. G.; BAUTITZ, I. R.; NOGUEIRA, R. F. P. Degradação de fármacos residuais por processos oxidativos avançados. Química Nova, v. 32, n. 1, p. 188 $197,2009$. 
MIÈGE, C.; CHOUBERT, J. M.; RIBEIRO, L.; EUSÈBE, M.; COQUERY, M. Fate of pharmaceuticals and personal care products in wastewater treatment plants--conception of a database and first results. Environmental Pollution, v. 157, n. 5, p. 1721-6, 2009.

MIWA, D. W.; MALPASS, G. R. P.; MACHADO, S. A. S.; MOTHEO, A. J. Electrochemical degradation of carbaryl on oxide electrodes. Water Research, v. 40, p. 3281-3289, 2006.

MOTOYAMA, M.; NAKAGAWA, S.; TANOUE, R.; SATO, Y.; NOMIYAMA, K.; SHINOHARA, RYOTA. Residues of pharmaceutical products in recycled organic manure produced from sewage sludge and solid waste from livestock and relationship to their fermentation level. Chemosphere, v. 84, p. 432-438, 2011.

MOUAMFON, M. V. N.; LI, W.; LU, S.; QIU, Z.; CHEN, N.; LIN, K. Photodegradation of sulphamethoxazole under UV-light irradiation at $254 \mathrm{~nm}$. Environmental Technology, v. 31, p. 489-494, 2010a.

MOUAMFON, M. V. N.; LI, W.; LU, S.; CHEN, N.; QIU, Z.;LIN, K. Photodegradation of Sulfamethoxazole applying UV- and VUV-based processes. Water, Air \& Soil Pollution, v. 218, n. 1-4, p. 265-274, 2010 b.

NOGUEIRA, R. F. P.; SILVA, M. R. A.; TROVÓ, A. G. Influence of the iron source on the solar photo-Fenton degradation of different classes of organic compounds. Solar Energy, v. 79, n. 4, p. 384-392, 2005.

NOGUEIRA, R. F. P.; TROVÓ, A. G.; SILVA, M. R. A. DA; VILLA, R. D.; OLIVEIRA, M. C. DE. Fundamentos e aplicações ambientais dos processos fenton e foto-fenton. Química Nova, v. 30, n. 2, p. 400-408, 2007.

OANCEA, P.; MELTZER, V. Photo-Fenton process for the degradation of Tartrazine (E102) in aqueous medium. Journal of the Taiwan Institute of Chemical Engineers, v. 44, n. 6, p. 990-994, 2013.

PANIZZA, M. Importance of electrode material in the electrochemical treatment of wastewater containing organic pollutants. Electrochemistry for the Environment. p.25, 2010 .

PANIZZA, M.; CERISOLA, G. Direct and mediated anodic oxidation of organic pollutants. Chemical reviews, v. 109, n. 12, p. 6541-69, 2009.

PANIZZA, M.; CERISOLA, G. Electrochemical oxidation of 2-naphthol with in situ electrogenerated active chlorine. Electrochimica Acta, v. 48, p. 1515-1519, 2003.

PELEGRINI, R.; BERTAZZOLI, R. Descoloração e degradação de poluentes orgânicos em soluções aquosas através do processo fotoeletroquímico. Química Nova, v. 25, p. 477, 2002.

PELEGRINI, R.; PERALTA-ZAMORA, P.; DE ANDRADE, A. R.; REYES, J.; DURÁN, N. Electrochemically assisted photocatalytic degradation of reactive dyes. Applied Catalysis B: Environmental, v. 22, n. 2, p. 83-90, 1999. 
PENG, X.; WANG, Z.; KUANG, W.; TAN, J.; LI, K. A preliminary study on the occurrence and behavior of sulfonamides, ofloxacin and chloramphenicol antimicrobials in wastewaters of two sewage treatment plants in Guangzhou, China. Science of the Total Environment, v. 371, n. 1-3, p. 314-322, 2006.

PERALTA-HERNÁNDEZ, J. M.; MEAS-VONG, Y.; RODRÍGUEZ, F. J.; CHAPMAN, T. W.; MALDONADO, M. I.; GODÍNEZ, L. A. In situ electrochemical and photoelectrochemical generation of the fenton reagent: a potentially important new water treatment technology. Water Research, v. 40, p. 1754-1762, 2006.

PÉREZ, M.; TORRADES, F.; DOMÈNECH, X.; PERAL, J. Fenton and photo-Fenton oxidation of textile effluents. Water Research, v. 36, n. 11, p. 2703-10, 2002.

PÉREZ, M.; TORRADES, F.; GARCÍA-HORTAL, J. A.; DOMÈNECH, X.; PERAL, J. Removal of organic contaminants in paper pulp treatment effluents under Fenton and photoFenton conditions. Applied Catalysis B: Environmental, v. 36, n. 1, p. 63-74, 2002.

PÉREZ-MOYA, M.; GRAELLS, M.; CASTELLS, G.; AMIGÓ, J.; ORTEGA, E.; BUHIGAS, G.; PÉREZ, L. M.; MANSILLA, HÉCTOR D. Characterization of the degradation performance of the sulfamethazine antibiotic by photo-Fenton process. Water Research, v. 44, n. 8, p. 2533-40, 2010.

PETROVIC, M.; BARCELÓ, D. Application of liquid chromatography/quadrupole time-offlight mass spectrometry (LC-QqTOF-MS) in the environmental analysis. Journal of Mass Spectrometry, v. 41, p. 1259-1267, 2006.

PHILLIPS, P. J.; SMITH, S. G.; KOLPIN, D. W.; ZAUGG, S. D.; BUXTON, H. T.; FURLONG, E. T.; ESPOSITO, K.; STINSON, B. Pharmaceutical formulation facilities as sources of opioids and other pharmaceuticals to wastewater treatment plant effluents. Environmental Science \& Technology, v. 44, p. 4910-4916, 2010.

PIGNATELLO, J. J.; OLIVEROS, E.; MACKAY, A. Advanced oxidation processes for organic contaminant destruction based on the fenton reaction and related chemistry. Critical Reviews in Environmental Science and Technology, v. 36, n. 1, p. 1-84, 2006.

PRABHAKARAN, D.; SUKUL, P.; LAMSHÖFT, M.; MAHESWARI, M. A.; ZÜHLKE, S.; SPITELLER, M. Photolysis of difloxacin and sarafloxacin in aqueous systems.

Chemosphere, v. 77, n. 6, p. 739-46, 2009.

RADJENOVIC, J.; PETROVIC, M.; BARCELÓ, D. Analysis of pharmaceuticals in wastewater and removal using a membrane bioreactor. Analytical and Bioanalytical Chemistry, v. 387, p. 1365-1377, 2007.

RADJENOVIĆ, J.; PETROVIĆ, M.; BARCELÓ, D. Complementary mass spectrometry and bioassays for evaluating pharmaceutical-transformation products in treatment of drinking water and wastewater. TrAC Trends in Analytical Chemistry, v. 28, n. 5, p. 562-580, 2009. 
RAHMAN, M. F.; YANFUL, E. K.; JASIM, S. Y. Occurrences of endocrine disrupting compounds and pharmaceuticals in the aquatic environment and their removal from drinking water: challenges in the context of the developing world. Desalination, v. 248, n. 578-585, 2009.

RAJESHWAR, K.; IBANEZ, J. G. Environmental electrochemistry: fundamentals and applications in pollution sensors and abatemen. San Diego: Academic press, 1997. p. 398.

RAJKUMAR, D.; KIM, J. G. Oxidation of various reactive dyes with in situ electro-generated active chlorine for textile dyeing industry wastewater treatment. Journal of Hazardous Materials, v. 136, n. 2, p. 203-12, 2006.

RAJKUMAR, D.; SONG, B. J.; KIM, J. G. Electrochemical degradation of Reactive Blue 19 in chloride medium for the treatment of textile dyeing wastewater with identification of intermediate compounds. Dyes and Pigments, v. 72, n. 1, p. 1-7, 2007.

REEMTSMA, T.; JEKEL, M. Organic pollutants in the water cycle: properties, occurrence, analysis and environmental relevance of polar compounds. New York: Wiley, 2006. p. 1-40.

RICHARD, S.; MOSLEMI, S.; SIPAHUTAR, H.; BENACHOUR, N.; SERALINI, G.-E. Differential effects of glyphosate and roundup on human placental cells and aromatase. Environmental Health Perspectives, v. 113, p. 716-720, 2005.

ROBERT, D.; MALATO, S. Solar photocatalysis: a clean process for water detoxification. The Science of the Total Environment, v. 291, p. 85-97, 2002.

SHARMA, V. K.; MISHRA, S. K.; RAY, A. K. Kinetic assessment of the potassium ferrate(VI) oxidation of antibacterial drug sulfamethoxazole. Chemosphere, v. 62, n. 1, p. 128-34, 2006.

SHEMER, H.; KUNUKCU, Y. K.; LINDEN, K. G. Degradation of the pharmaceutical metronidazole via UV, Fenton and photo-Fenton processes. Chemosphere, v. 63, n. 2, p. 269-76, 2006.

SIMOND, O.; SCHALLER, V.; COMNINELLIS, C. Theoretical model for the anodic oxidation of organics on metal oxide electrodes. Electrochimica Acta, v. 42, p. 2009-2012, 1997.

SKOLD, O. Resistance to trimethoprim and sulfonamides. Veterinary Research, v. 32, n. 34, p. 261-273, 2001.

SOCHA, A.; CHRZESCIJANSKA, E.; KUSMIEREK, E. Electrochemical and photoelectrochemical treatment of 1-aminonaphthalene-3,6-disulphonic acid. Dyes and Pigments, v. 67, p. 71-75, 2005.

SOCHA, A.; SOCHOCKA, E.; PODSIADŁY, R.; SOKOŁOWSKA, J. Electrochemical and photoelectrochemical degradation of direct dyes. Coloration Technology, v. 122, n. 4, p. 207-212, 2006. 
SOCHA, A.; SOCHOCKA, E.; PODSIADŁY, R.; SOKOŁOWSKA, J. Electrochemical and photoelectrochemical treatment of C.I. Acid Violet 1. Dyes and Pigments, v. 73, p. 390-393, 2007.

STYLIDI, M.; KONDARIDES, D. I.; VERYKIOS, X. E. Visible light-induced photocatalytic degradation of Acid Orange 7 in aqueous $\mathrm{TiO} 2$ suspensions. Applied Catalysis B:

Environmental, v. 47, n. 3, p. 189-201, 2004.

SUÁREZ, S.; CARBALLA, M.; OMIL, F.; LEMA, J. M. How are pharmaceutical and personal care products (PPCPs) removed from urban wastewaters? Reviews in Environmental Science and Bio/Technology, v. 7, n. 2, p. 125-138, 2008.

TRASATTI, S. Electrocatalysis: understanding the success of DSA®. Electrochimica Acta, v. 45, n. 15-16, p. 2377-2385, 2000.

TRIVEDI, P.; VASUDEVAN, D. Spectroscopic investigation of ciprofloxacin speciation at the goethite-water interface. Environmental Science \& Technology, v. 41, p. 3153-3158, 2007.

TROVÓ, A. G.; MELO, S. A. S.; NOGUEIRA, R. F. P. Photodegradation of the pharmaceuticals amoxicillin, bezafibrate and paracetamol by the photo-Fenton processApplication to sewage treatment plant effluent. Journal of Photochemistry and Photobiology A: Chemistry, v. 198, n. 2-3, p. 215-220, 2008.

TROVÓ, A. G.; NOGUEIRA, R. F. P.; AGÜERA, A.; FERNANDEZ-ALBA, A. R.; SIRTORI, C.; MALATO, S. Degradation of sulfamethoxazole in water by solar photoFenton. Chemical and toxicological evaluation. Water Research, v. 43, n. 16, p. 3922-31, 2009.

TROVÓ, A. G.; NOGUEIRA, R. F. P.; AGÜERA, A.; SIRTORI, C.; FERNÁNDEZ-ALBA, A. R. Photodegradation of sulfamethoxazole in various aqueous media: persistence, toxicity and photoproducts assessment. Chemosphere, v. 77, n. 10, p. 1292-8, 2009.

VIENO, N. M.; HÄRKKI, H.; TUHKANEN, T.; KRONBERG, L. Occurrence of pharmaceuticals in river water and their elimination in a pilot-scale drinking water treatment plant. Environmental Science \& Technology, v. 41, n. 14, p. 5077-84, 2007.

WANG, A.; LI, Y.-Y.; ESTRADA, A. L. Mineralization of antibiotic sulfamethoxazole by photoelectro-Fenton treatment using activated carbon fiber cathode and under UVA irradiation. Applied Catalysis B: Environmental, v. 102, n. 3-4, p. 378-386, 2011.

XIE, Y. B.; LI, X. Z. Interactive oxidation of photoelectrocatalysis and electro-Fenton for azo dye degradation using TiO2-Ti mesh and reticulated vitreous carbon electrodes. Materials Chemistry and Physics, v. 95, n. 1, p. 39-50, 2006.

YANG, S.; CHA, J.; CARLSON, K. Simultaneous extraction and analysis of 11 tetracycline and sulfonamide antibiotics in influent and effluent domestic wastewater by solid-phase extraction and liquid chromatography-electrospray ionization tandemmass spectrometry. Journal of Chromatography A, v. 1097, n. 1-2, p. 40-53, 2005. 
YANG, X.; FLOWERS, R. C.; WEINBERG, H. S.; SINGER, P. C. Occurrence and removal of pharmaceuticals and personal care products (PPCPs) in an advanced wastewater reclamation plant. Water Research, v. 45, p. 5218-5228, 2011.

YOUSEF, M. I.; SALEM, M. H.; IBRAHIM, H. Z.; Helmi, S.; Seehy, M. A.; Bertheussen, K. Toxic effects of carbofuran and glyphosate on semen characteristics in rabbits. Journal of Environmental Science and Health. Part. B, Pesticides, Food Contaminants, and Agricultural Wastes, v. 30, p. 513-534, 1995.

ZAINAL, Z.; LEE, C. Y.; HUSSEIN, M. Z.; KASSIM, A.; YUSOF, N. A. Electrochemicalassisted photodegradation of dye on $\mathrm{TiO} 2$ thin films: investigation on the effect of operational parameters. Journal of Hazardous Materials, v. 118, p. 197-203, 2005.

ZANONI, M. V. B.; SENE, J. J.; ANDERSON, M. A. Photoelectrocatalytic degradation of Remazol Brilliant Orange 3R on titanium dioxide thin-film electrodes. Journal of Photochemistry and Photobiology A: Chemistry, v. 157, n. 1, p. 55-63, 2003.

ZAPATA, A.; OLLER, I.; BIZANI, E.; SÁNCHEZ-PÉREZ, J. A.; MALDONADO, M.I.; MALATO, S. Evaluation of operational parameters involved in solar photo-Fenton degradation of a commercial pesticide mixture. Catalysis Today, v. 144, n. 1-2, p. 94-99, 2009.

ZHAO, X.-K.; YANG, G.-P.; WANG, Y.-J.; GAO, X.-C. Photochemical degradation of dimethyl phthalate by Fenton reagent. Journal of Photochemistry and Photobiology A: Chemistry, v. 161, n. 2-3, p. 215-220, 2004.

ZHONG, Y.; JIN, X.; QIAO, R.; QI, X.; ZHUANG, Y. Destruction of microcystin-RR by Fenton oxidation. Journal of Hazardous Materials, v. 167, p. 1114-1118, 2009. 